\title{
Recoil effect of the ice hockey stick during a slap shot
}

By

Alejandro Villaseñor-Herrera

\begin{abstract}
A Thesis
Submitted to the

Faculty of Graduate Studies and Research

in partial fulfillment of the requirements for the degree of:
\end{abstract}

Master of Science

Department of Kinesiology and Physical Education

McGill University

Montreal, Quebec, Canada

October, 2004

(C) Alejandro Villaseñor-Herrera, 2004 


$\begin{array}{ll}\begin{array}{l}\text { Library and } \\ \text { Archives Canada }\end{array} & \begin{array}{l}\text { Bibliothèque et } \\ \text { Archives Canada }\end{array} \\ \begin{array}{l}\text { Published Heritage } \\ \text { Branch }\end{array} & \begin{array}{l}\text { Direction du } \\ \text { Patrimoine de l'édition }\end{array} \\ \begin{array}{l}\text { 395 Wellington Street } \\ \text { Ottawa ON K1A 0N4 }\end{array} & \begin{array}{l}\text { 395, rue Wellington } \\ \text { Ottawa ON K1A ON4 } \\ \text { Canada }\end{array} \\ \end{array}$

Your file Votre référence

ISBN: 0-494-06466-8

Ourfile Notre référence

ISBN: 0-494-06466-8

NOTICE:

The author has granted a nonexclusive license allowing Library and Archives Canada to reproduce, publish, archive, preserve, conserve, communicate to the public by telecommunication or on the Internet, loan, distribute and sell theses worldwide, for commercial or noncommercial purposes, in microform, paper, electronic and/or any other formats.

The author retains copyright ownership and moral rights in this thesis. Neither the thesis nor substantial extracts from it may be printed or otherwise reproduced without the author's permission.
AVIS:

L'auteur a accordé une licence non exclusive permettant à la Bibliothèque et Archives Canada de reproduire, publier, archiver, sauvegarder, conserver, transmettre au public par télécommunication ou par l'Internet, prêter, distribuer et vendre des thèses partout dans le monde, à des fins commerciales ou autres, sur support microforme, papier, électronique et/ou autres formats.

L'auteur conserve la propriété du droit d'auteur et des droits moraux qui protège cette thèse. $\mathrm{Ni}$ la thèse ni des extraits substantiels de celle-ci ne doivent être imprimés ou autrement reproduits sans son autorisation.
In compliance with the Canadian

Privacy Act some supporting forms may have been removed from this thesis.

While these forms may be included in the document page count, their removal does not represent any loss of content from the thesis.
Conformément à la loi canadienne sur la protection de la vie privée, quelques formulaires secondaires ont été enlevés de cette thèse.

Bien que ces formulaires aient inclus dans la pagination, il n'y aura aucun contenu manquant. 


\section{ACKNOWLEDGMENTS}

I would like to acknowledge all the people who have been involved and made possible the completion of this academic journey with the present master thesis. Firstly, I would like to thank my supervisor Dr. David Pearsall for his encouragement, guidance and patience throughout every single stage of this project and during the whole master degree program. Secondly, I have to thank Dr. René Turcotte for his constant advices, suggestions and feedback in the improvement of this research project. Thirdly I have to thank to my colleagues of the Ice Hockey Research Team: Alex Trumper and TK Woo for their valuable help in the data collection and processing, Scott McGrail for his assistance in the data collection and experimental set up, as well as Karen Lomond, Nicholas Broad and Joel Bergeron. Fourthly, I want to thank Curt Dewan for his constant support as a colleague and as a friend since the very beginning of the master, and for helping me with my English skills. Fifthly, I want to thank my very close friends in México City for their invaluable support; Gerardo Rodriguez for sharing with me his structural dynamics expertise and that unique friendship for more than twenty years, Rocío Ruíz for being the kindest friend ever, Rubén Rodriguez for a strong friendship and for his art with the guitar, and Mónica Ramírez for her unforgettable support on difficult times.

And last but not least, I want to give my deepest gratitude to my parents, Dr. Héctor M. Villaseñor and Juanita Herrera for their unconditional love and support in my academic career and in my entire life. 
TABLE OF CONTENTS

ACKNOWLEDGMENTS

LIST OF TABLES

11

ABSTRACT

15

RÉSUMÉ

16

DEFINITIONS 17

CHAPTER 1

19

INTRODUCTION

1.1 Nature AND SCOPE OF THE PROBlem 20

$\begin{array}{lll}1.2 & \text { RATIONAL } & 22\end{array}$

1.3 ObJeCtIVES OF THE StUdY 23

1.4 HYPOTHESES $\quad 24$

1.5 LIMITATIONS $\quad 24$

1.6 DELIMITATIONS $\quad 25$

1.7 INDEPENDENT (IV) AND DEPENDENT (DV) VARIABLES

CHAPTER 2 : REVIEW OF LITERATURE

2.1 ICE HOCKEY BASICS

2.2 ICE HOCKEY SLAP SHOTS $\quad 27$

2.3 KINEMATIC ANALYSIS METHODS

2.4 ACCElERAtion MEAsuring TeChNIQUeS

2.5 BASIC ENERGY CONCEPTS

$\begin{array}{ll}2.6 \text { STRUCTURAL DYNAMICS } & 45\end{array}$ 
3.1 ICE HOCKEY STICK AND PUCK

$\begin{array}{ll}3.2 \text { SUBJECTS } & 55\end{array}$

3.3 TESTING APPARATUS

3. 3.1. High Speed Video System 56

$\begin{array}{ll}\text { 3.3.2. Accelerometer } & 57\end{array}$

3.4 TESTING PROTOCOL

3. 5 DATA ANALYSIS

3.5.1 Stick kinematics $\quad 61$

3.5.2 Acceleration Data Processing 66

3.5.3 Stick and Puck Energies $\quad 67$

$\begin{array}{ll}\text { 3.5.4 Statistical Analysis } & 73\end{array}$

\begin{tabular}{ll} 
CHAPTER 4 : RESULTS & 77 \\
\hline
\end{tabular}

4. 1 ANOVA OF ACCELEROMETER MEASURES

4.1.1 ANOVA of Puck Accelerations $\quad 77$

4.1.2 ANOVA of Puck Velocities $\quad 77$

$\begin{array}{ll}\text { 4.1.3 ANOVA of Times } & 78\end{array}$

4.2 ANOVA OF STICK KINEMATICS MEASURES. HSC.

4.2.1 ANOVA of Stick Joint Angle Displacements

4.2.2 ANOVA of Stick Joint Angular Velocity 92

4.2.3 ANOVA of Maximum deflection distance of the Stick : d 93

4.3 ANOVA OF STICK AND PUCK ENERgY MEASURES.

4.4. REgRESSIONS AND CORRELATION STATISTICS. 98

4.5 REgRESSIONS AND CORRELATION STATISTICS OF PUCK VELOCITY VERSUS AVERAGE ACCELERATION AND CONTACT TIMES.

4.6 REgRESSIONS AND CORRELATION STATISTICS OF PUCK VELOCITY VERSUS MAXIMUM JOINT ANGLE WITHIN $T_{A}$.

4.7 REGRESSIONS AND CORRELATION STATISTICS OF PUCK VELOCITY VERSUS TIMES OF MAXIMUM AND MINIMUM JOINT ANGLES WITHIN $T_{A}$.

4.8 REGRESSIONS AND CORRELATION STATISTICS OF PUCK VELOCITY VERSUS TIMES OF MAXIMUM AND MINIMUM JOINT ANGULAR VELOCITIES WITHIN $T_{A}$. 
4.9 REgRESSIONS AND CORRELATION STATISTICS OF PUCK VELOCITY VERSUS MAXIMUM AND MINIMUM JOINT ANGULAR VELOCITIES WITHIN $T_{A}$.

4.10 REgRESSIONS AND CORRELATION STATISTICS OF PUCK VELOCITY VERSUS TIME TO MINIMUM SEGMENT JOINT ANGLE WITHIN $T_{\text {A. }}$.

4.11 REGRESSIONS AND CORRELATION STATISTICS OF PUCK VELOCITY VERSUS MAXIMUM AND MINIMUM SEGMENT JOINT ANGLE IN TOTAL EVENT.

4.12 REgRESSIONS AND CORRELATION STATISTICS OF PUCK VELOCITY VERSUS TIME TO MINIMUM SEGMENT JOINT ANGLE IN TOTAL EVENT.

4.13 REgRESSIONS AND CORRELATION STATISTICS OF PUCK VELOCITY VERSUS RECOIL ANGLE AND TIME TO MAXIMUM TOTAL DEFLECTION IN TOTAL EVENT.

4.14 REGRESSIONS AND CORRELATION STATISTICS OF PUCK VELOCITY VERSUS MAXIMUM AND MINIMUM ANGLE DEFLECTIONS IN TOTAL EVENT, AND MAXIMUM DEFLECTION DISTANCE.

4.15 REgRESSIONS AND CORRELATION STATISTICS OF PUCK VELOCITY VERSUS TIMES TO MAXIMUM AND MINIMUM TOTAL DEFLECTIONS IN TOTAL EVENT.

4.16 REGRESSIONS AND CORRELATION STATISTICS OF PUCK VELOCITY VERSUS STICK AND PUCK KINETIC ENERGIES.

CHAPTER 5

DISCUSSION

5.1 GENERAL- HYPOTHESES

5.2 PUCK VELOCITY

$\begin{array}{ll}\text { 5.3 TEMPORAL EVENTS WITHIN T } & 117\end{array}$

$\begin{array}{ll}\text { 5.4 TEMPORAL EVENTS OUTSIDE T } & 120\end{array}$

5.5 STICK ANGLE DISPLACEMENTS AND STICK DEFLECTION DISTANCE 121

5.6 MECHANICAL ENERGY AND IMPULSE

$\begin{array}{ll}\text { 5.7 FUTURE DIRECTIONS AND RELEVANCE } & 128\end{array}$

$\begin{array}{ll}\text { CONCLUSION } & 133\end{array}$

APPENDIX A : ETHICS APPROVAL 134 
B.1 ACCELEROMETER 136

B.1.1 PUCK ACCELERATIONS 136

B.1.2 PUCK VELOCITIES

B.1.3 TIMES 136

B.2 STICK KINEMATICS. HSC.

B.2.1 STICK JOINT ANGLE DISPLACEMENTS 139

B.2.2 MAXIMUM DEFLECTION DISTANCE ON THE STICK : D 142

B.2.3 STICK JOINT ANGULAR VELOCITY

B.2.4 STICK AND PUCK ENERGY 143

REFERENCES $\quad 144$ 


\section{LIST OF FIGURES}

Figure 2.1.1 Fundamental HOCKEy SKILLS (PEARSALL ET AL., 2000)

FIgURE 2.3.1 PERSPECTIVES OF BIOMECHANICAL ANALYSIS (ADAPTED FROM HAMILL \& KNUTZEN, 2003)

FIGURE 2.4.1 PIEZOELECTRIC ACCELEROMETER

( ADAPTED FROM BRÜEL \&KJAER, MEASURING VIBRATION, 1982)

FIGURE 2.4.2 COMMON CONFIGURATIONS IN PIEZOELECTRIC ACCELEROMETERS (ADAPTED FROM BRÜEL \&KJ/ER, MEASURING VIBRATION, 1982)

FIGURE 2.5.1 FORCE F ACTING DURING A SMALL DISPLACEMENT $\Delta$, (ADAPTED FROM OHANIAN 1985)

FIGURE 2.5.2 AN IDEAL STRAIN-STRESS CURVE, SHOWING ELASTIC AND PLASTIC REGIONS, AS WELL AS THE ELASTIC MODULUS.

(ADAPTED FROM DHANJOO, 1982; HAMILL \& KNUTZEN, K.M.,2003)

FIGURE 2.6.1 BEAM ELEMENT UNDER FLEXURAL STRESS

(ADAPTED FROM RODRIGUEZ ET AL.,1996)

FIGURE 2.6.2 BEAM REPRESENTATION OF A SYSTEM MASS-ROD DURING IMPACT $\quad 47$

FIGURE 2.6.3 DYNAMIC RESPONSE OF THE SYSTEM MASS-BOX DURING IMPACT

FIGURE 3.3.1 PIEZOELECTRIC TRIAXIAL ACCELEROMETER USED IN THE STUDY.

(HTTP://WWW.KISTLER.COM)

FIGURE 3.3.2 COMPUTER AND CABLE SYSTEMS FOR HSC (A) AND ACCELEROMETER INSIDE THE PUCK (B). ALSO, MARKERS ON THE STICK (C) AND ON THE TOP OF THE PUCK (B) ARE SHOWN

FIGURE 3.3.3 SET UP OF THE EXPERIMENT. STICK ANGLE DEFLECTIONS ( $\odot 5-6, \Theta 6-7, \Theta 7-8$, OTOTAL ), ACCELEROMETER'S AXIS AND COMPLETE COMPUTER SYSTEMS

FIGURE 3.5.1 SYNCHRONIZATION OF STICK KINEMATICS AND PUCK ACCELERATION (G'S) THROUGH THE PUCK CIRCUIT CONTACT

FIGURE 3.5.2 INITIAL (T1) AND FINAL (T6) PUCK CONTACT OF THE SLAP SHOT. IT IS SHOWN IN THE TOP LEFT CORNER THAT THE PUCK/BLADE CIRCUIT WAS “ON".

FIGURE 3.5.3 MAXIMUM BEND (T2) AND MAXIMUM RECOIL (T4) OF THE SLAP SHOT 65

FIGURE 3.5.4 MAXIMUM $\omega$ (T3) AND MINIMUM $\omega$ (T5) OF THE SLAP SHOT 65 
FIGURE 3.5.5 GRAPHIC EXAMPLE OF THE ACCELERATION DATA INTEGRATION (I.E. PUCK VELOCITY)

FIGURE 3.5.6 DECONSTRUCTION OF THE SWING SLAP SHOT IN TERMS OF KINETIC ENERGY AND VELOCITIES, I.E. TRANSLATIONAL VELOCITY $\left(v_{t}\right)$, ANGULAR VELOCITY $\left(\omega_{s}\right)$ AND TOTAL LENGTH OF THE STICK SHAFT (R)

FIGURE 3.5.7 STICK SHAFT DIMENSIONS, SHOWING MAJOR AND MINOR AXIS (ADAPTED FROM PEARSALL ET AL, 1999)

FIGURE 3.5.8 DEFLECTION DISTANCE OF STICK SHAFT 71

FIGURE 4.1.1 PUCK-BLADE CONTACT TIMES $T_{A}$ AND $T_{B}$

FIGURE 4.1.2 TIME POINTS FOR STICK BEND PHASE WITHIN T A $_{\mathrm{A}} 80$

FIGURE 4.1.3 TIME POINTS FOR STICK RECOIL PHASE WITHIN T A $_{4}$

FIGURE 4.1.4 STICK JOINT ANGULAR VELOCITY $(\omega)$ OBSERVED AT STICK BEND PHASE WITHIN $T_{A}$

FIGURE 4.1.5 STICK JOINT ANGULAR VELOCITY $(\omega)$ OBSERVED AT STICK RECOIL PHASE WITHIN $T_{A}$

FIGURE 4.1.6 TIME POINTS FOR MAXIMUM $\left(T_{\text {MAX } \theta}\right)$ AND MINIMUM $\left(T_{\text {MIN } \theta}\right)$ TOTAL DEFLECTION $\Theta$ IN TOTAL EVENT

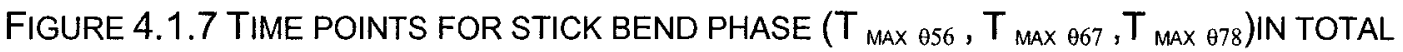
EVENT

FIGURE 4.1.8 TIME POINTS FOR STICK RECOIL PHASE $\left(T_{\text {MIN 956, }} T_{\text {MIN 967, }} T_{\text {MIN } 978}\right.$ ) IN TOTAL EVENT

FIGURE 4.2.1 MAXIMUM STICK SEGMENT JOINT ANGLE DISPLACEMENTS (BEND PHASE) WHITHIN $T_{A}$

FIGURE 4.2.2 MINIMUM STICK SEGMENT JOINT ANGLE DISPLACEMENTS (RECOIL PHASE) WHITHIN $T_{A}$

FIGURE 4.2.3 MAXIMUM STICK SEGMENT JOINT ANGLES IN TOTAL EVENT

FIGURE 4.2.4 MINIMUM STICK SEGMENT JOINT ANGLES IN TOTAL EVENT

FIGURE 4.2.5 RECOIL ANGLE IN TOTAL EVENT

FIGURE 4.2.6 T-TEST FOR DIFFERENCES IN MAXIMUM STICK BENDING BETWEEN SEGMENT 4 $\left(\operatorname{MAX} \theta_{56}\right)$ VS SEGMENT5 (MAX $\left.\theta_{67}\right)$ AND $6\left(\operatorname{MAX} \theta_{78}\right)$ 
FIGURE 4.2.7 T-TEST FOR DIFFERENCES IN MAXIMUM STICK BENDING BETWEEN SEGMENT 5 $\left(\operatorname{MAX} \theta_{67}\right)$ VS SEGMENT $4\left(\operatorname{MAX} \theta_{56}\right)$ AND $6\left(\operatorname{MAX} \theta_{78}\right)$

FIGURE 4.2.8 T-TEST FOR DIFFERENCES IN MINIMUM STICK DEFLECTION BETWEEN SEGMENT 4(MAX $\left.\theta_{56}\right)$ VS SEGMENT $5\left(\operatorname{MAX} \theta_{67}\right)$ AND $6\left(\operatorname{MAX} \theta_{78}\right) \quad 90$

FIGURE 4.2.9-TEST FOR DIFFERENCES IN MINIMUM STICK DEFLECTION BETWEEN SEGMENT 5 $\left(\operatorname{MAX} \theta_{67}\right)$ VS SEGMENT 4(MAX $\left.\theta_{56}\right)$ AND $6\left(\operatorname{MAX} \theta_{78}\right) \quad 90$

FIGURE 4.2.10 MAXIMUM AND MINIMUM $\Theta$ DEFLECTION IN TOTAL EVENT 91

FIGURE 4.2.11 STICK JOINT ANGULAR VELOCITIES OBSERVED AT STICK BEND PHASE WITHIN $\mathrm{T}_{\mathrm{A}}$

FIGURE 4.2.12 STICK JOINT ANGULAR VELOCITIES OBSERVED AT STICK RECOIL PHASE WITHIN $\mathrm{T}_{\mathrm{A}}$

FIGURE 4.2.13 MAXIMUM STICK DISTANCE DEFLECTION

FIGURE 4.2.14 AVERAGE STICK KINETIC ENERGY (ROTATIONAL, TRANSLATIONAL AND TOTAL) IN THE SLAP SHOT SWING

FIGURE 4.2.15 MAXIMUM STICK KINETIC ENERGY (ROTATIONAL, TRANSLATIONAL AND TOTAL) IN THE SLAP SHOT SWING

FIGURE 4.2.16 MEANS OF STICK ELASTIC POTENTIAL (BEND) ENERGY 97

FIGURE 4.2.17 MEANS OF PUCK KINETIC ENERGY 97

FIGURE 4.4.1 LINEAR REGRESSION FOR TOTAL PUCK CONTACT(T $\left.{ }_{B}\right)$ VS FINAL PUCK VELOCITY(VEL_MS)

FIGURE 4.7.1 LINEAR REGRESSION FOR TIME TO MINIMUM $\omega$ WITHIN T A $_{\text {(TIME 5): }} T_{\text {MIN } \omega 67}$ VS

FINAL PUCK VELOCITY (VEL_MS)

FIGURE 4.11.1 LINEAR REGRESSION FOR TIME TO MINIMUM $\Theta$ IN TOTAL EVENT: $T_{\text {MIN } 956, \text { VS }}$ FINALPUCKVELOCITY(VEL_MS)

FIGURE 4.13.1 LINEAR REGRESSION FOR MAXIMUM ANGLE DEFLECTION IN TOTAL EVENT: MAX $\theta V S$ FINAL PUCK VELOCITY (VEL_MS)

FIGURE 4.13.2 LINEAR REGRESSION FOR MAXIMUM DISTANCE DEFLECTION OF THE STICK: D VS FINAL PUCK VELOCITY (VEL_MS)

FIGURE 4.15.12 LINEAR REGRESSION FOR STICK ROTATIONAL (MAXIMUM)ENERGY:

$E_{\text {MAX_ROT }}$ VS FINAL PUCK VELOCITY (VEL_MS)

FIGURE 4.15.2 LINEAR REGRESSION FOR STICK TRANSLATIONAL (MAXIMUM) ENERGY:

$E_{\text {MAX_tR }}$ VS FINAL PUCK VELOCITY (VEL_MS) 
FIGURE 4.15.3 LINEAR REGRESSION FOR STICK TOTAL (MAXIMUM) ENERGY: E $_{\text {MAX_tOT }}$ VS FINAL PUCK VELOCITY (VEL_MS)

FIGURE 4.15.4 LINEAR REGRESSION FOR STICK ELASTIC POTENTIAL (BEND) ENERGY: $E_{D}$ VS FINAL PUCK VELOCITY (VEL_MS)

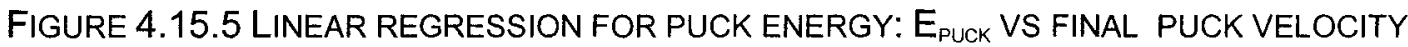
(VEL_MS)

FIGURE 5.1 PERCENTAGE BEND-RECOIL DURING PUCK-BLADE CONTACT TIME IN THE SLAP SHOT

FIGURE 5.2 AVERAGE MAXIMUM AND MINIMUM JOINT ANGLE DISPLACEMENTS WITHIN TA 122

FIGURE 5.3 SUMMARY OF ENERGY EVENTS FOR THE STICK-PUCK SYSTEM DURING THE SLAP SHOT, WHERE SWING KINETIC ENERGY ( $\left.E_{\text {MAX_TOT }}\right)$, STICK ELASTIC (BEND) ENERGY ( $\left.E_{D}\right)$ AND PUCK KINETIC ENERGY ( $E_{\text {PUCK }}$ ) ARE SHOWN. ÄLSO, LOSS OF KINETIC ENERGY OF THE SYSTEM ( $\triangle$ KE) AND THE 'IMPULSE' $(\vec{J})$ IMPARTED TO THE PUCK ARE INDICATED

FIGURE 5.7.1 CANTILEVER BEAM CONFIGURATION

FIGURE 5.7.2 MAIN EXTERNAL CONTACT FORCES INVOLVED IN A SLAP SHOT THAT MUST BE CONSIDERED FOR FUTURE FULL STICK DYNAMICS STUDIES 


\section{LIST OF TABLES}

TABLE 2.2.1 SUMMARY OF PUCK VELOCITIES (KM/H) DURING A SLAP SHOT REPORTED BY VARIOUS STUDIES (PEARSALL ET AL. 2000).

TABLE 2.4.1 MAIN ChARACTERISTICS Of PIEZOELECTRIC ACCELEROMETERS. (NIGg \& HERZOG 2002)

TABLE 3.3.1 MAIN CHARACTERISTICS OF THE TRIAXIAL ACCELEROMETER, MODEL 8792A500 (HTTP://WWW.KISTLER.COM)

TABLE 3.5.1 SUMMARY OF VARIABLES INVESTIGATED 74

TABle 4.1.1. Puck AVerage accelerations (G'S) . 77

TABLE 4.1.2 FINAL PUCK VELOCITIES. 78

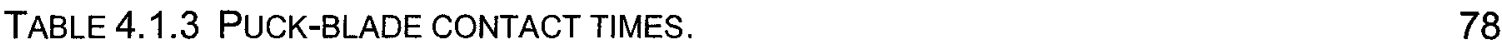

TABLE 4.1.4 PERCENTAGE PUCK-BLADE CONTACT TIMES.

TABLE 4.1.5 TIME POINTS FOR STICK BEND PHASE WITHIN $T_{A}$.

TABLE 4.1.6 TIME POINTS FOR STICK RECOIL PHASE WITHIN T A. $_{9}$

TABLE 4.1.7 STICK JOINT ANGULAR VELOCITY $(\omega)$ OBSERVED AT STICK BEND PHASE WITHIN $T_{A}$.

TABLE 4.1.8 STICK JOINT ANGULAR VELOCITY $(\omega)$ OBSERVED AT STICK RECOIL PHASE WITHIN $\mathrm{T}_{\mathrm{A}}$.

TABLE 4.1.9 TIME POINTS FOR MAXIMUM ( $\left.T_{\text {MAX } \theta}\right)$ AND MINIMUM $\left(T_{\text {MIN } \theta}\right)$ TOTAL DEFLECTION $\Theta$ IN TOTAL EVENT.

TABLE 4.1.10 TIME POINTS FOR STICK BEND PHASE IN TOTAL EVENT. 83

TABLE 4.1.11 TIME POINTS FOR STICK RECOIL PHASE IN TOTAL EVENT. 83

TABLE 4.2.1 MAXIMUM STICK SEGMENT JOINT ANGLE DISPLACEMENTS (BEND PHASE)WHITHIN $T_{\text {A. }}$

TABLE 4.2.2 MINIMUM STICK SEGMENT JOINT ANGLE DISPLACEMENTS (RECOIL PHASE) WHITHIN $T_{A \text {. }}$

TABLE 4.2.3 MAXIMUM STICK SEgMENT JOINT ANGLES IN TOTAL EVENT. 
TABLE 4.2.5 RECOIL ANGLE IN TOTAL EVENT.

TABLE 4.2.6 MAXIMUM AND MiNIMUM $\Theta$ DEFLECTION IN TOTAL EVENT.

TABLE 4.2.7 STICK JOINT ANGULAR VELOCITIES OBSERVED AT STICK BEND PHASE WITHIN $\mathrm{T}_{\mathrm{A}}$.

TABLE 4.2.8 STICK JOINT ANGULAR VELOCITIES OBSERVED AT STICK RECOIL PHASE WITHIN $T_{A}$.

TABLE 4.2.9 MAXIMUM STICK DISTANCE DEFLECTION.

TABLE 4.3.1 AVERAGE STICK KINETIC ENERGY (ROTATIONAL, TRANSLATIONAL AND TOTAL) IN THE SLAP SHOT SWING.

TABLE 4.3.2 MAXIMUM STICK KINETIC ENERGY (ROTATIONAL, TRANSLATIONAL AND TOTAL) IN THE SLAP SHOT SWING.

TABLE 4.3.3 STICK ELASTIC POTENTIAL AND PUCK ENERGIES.

TABLE 4.6.1 CORRELATION MATRIX OF DV: PUCK VELOCITY AND MAXIMUM SEGMENT JOINT ANGLE.

TABLE 4.7.1 CORRELATION MATRIX OF DV: PUCK VELOCITY, TIMES TO MAXIMUM AND MINIMUM $\Theta$ WITHIN $T_{\text {A. }}$

TABLE 4.8.1 CORRELATION MATRIX OF DV: PUCK VELOCITY, TIMES TO MAXIMUM AND MINIMUM $\omega$ WITHIN T $T_{A}$.

102

TABLE 4.9.1 CORRELATION MATRIX OF DV: PUCK VELOCITY, MAXIMUM AND MINIMUM SEGMENT JOINT $\omega$ WITHIN $T_{A}$.

TABLE 4.10.1 CORRELATION MATRIX OF DV: PUCK VELOCITY AND TIME TO MIN $\Theta$ (RECOIL) WITHIN $T_{A}$.

TABLE 4.11.1 CORRELATION MATRIX OF DV: PUCK VELOCITY, MAXIMUM AND MINIMUM ANGLE IN TOTAL EVENT.

TABLE 4.12.1 CORRELATION MATRIX OF DV: PUCK VELOCITY AND TIME TO MIN $\Theta$ IN TOTAL EVENT.

TABLE 4.13.1 CORRELATION MATRIX OF DV: PUCK VELOCITY, RECOIL ANGLE IN TOTAL EVENT AND TIME TO MAX TOTAL DEFLECTION $\theta$ IN TOTAL EVENT .

TABLE 4.14.1 CORRELATION MATRIX OF DV: PUCK VELOCITY, MAXIMUM AND MINIMUM ANGLE DEFLECTION IN TOTAL EVENT, AND MAXIMUM STICK DISTANCE DEFLECTION.

TABLE 4.15.1 CORRELATION MATRIX OF DV: PUCK VELOCITY, TIME TO MAXIMUM AND MINIMUM TOTAL DEFLECTION $\Theta$ IN TOTAL EVENT. 
TABLE 4.16.1 CORRELATION MATRIX OF DV: PUCK VELOCITY, STICK KINETIC ENERGY (TRANSLATIONAL AND ROTATIONAL), TOTAL STICK KINETIC ENERGY, STICK ELASTIC POTENTIAL ENERGY AND PUCK KINETIC ENERGY.

TABLE B.1.1 ANALYSIS OF VARIANCE OF AVERAGE PUCK ACCELERATION. 136

TABLE B.1.2 ANALYSIS OF VARIANCE OF FINAL PUCK VELOCITY. 136

TABLE B.1.3 ANALYSIS OF VARIANCE OF CONTACT TIMES T A AND T.

TABLE B.1.4 ANALYSIS OF VARIANCE OF PERCENTAGE $T_{B} . T_{A}$.

TABLE B.1.5 ANALYSIS OF VARIANCE OF MAXIMUM AND MINIMUM ANGLE DEFLECTION WITHIN $T_{A}$.

TABLE B.1.6 ANALYSIS OF VARIANCE OF MAXIMUM AND MINIMUM STICK ANGULAR VELOCITIES WITHINT $_{A}$

TABLE B.1.7 ANALYSIS OF VARIANCE OF TIMES TO MAXIMUM AND MINIMUM TOTAL DEFLECTION IN TOTAL EVENT.

TABLE B.1.8 ANALYSIS OF VARIANCE OF TIMES TO MAXIMUM AND MINIMUM DEFLECTION IN TOTAL EVENT.

TABLE B.2.1 ANALYSIS OF VARIANCE OF MAXIMUM AND MINIMUM SEGMENT JOINT ANGLES WITHIN $\mathrm{T}_{\mathrm{A}}$.

TABLE B.2.2 ANALYSIS OF VARIANCE OF MAXIMUM AND MINIMUM SEGMENT JOINT ANGLES IN TOTAL EVENT.

TABLE B.2.3 ANALYSIS OF VARIANCE OF RECOIL ANGLE IN TOTAL EVENT.

TABLE B.2.4 POST HOC ANALYSIS BETWEEN MAX. SEGMENT JOINT ANGLES 5-6 vs 6-7,7-8.

TABLE B.2.5 POST HOC ANALYSIS BETWEEN MAX. SEGMENT JOINT ANGLES 6-7 VS 7-8, 5-6.

TABLE B.2.6 POST HOC ANALYSIS BETWEEN MIN. SEGMENT JOINT ANGLES 5-6 VS 6-7, 7-8.

TABLE B.2.6 POST HOC ANALYSIS BETWEEN MIN. SEGMENT JOINT ANGLES 6-7 VS 5-6, 7-8.

TABLE B.2.7 ANALYSIS OF VARIANCE OF MAXIMUM AND MINIMUM ANGLE DEFLECTION. 141

TABLE B.2.8 ANALYSIS OF VARIANCE OF MAXIMUM DISTANCE DEFLECTION.

TABLE B.2.9 ANALYSIS OF VARIANCE OF MAX. AND MIN. SEGMENT JOINT ANGULAR VELOCITIES WITHIN $T_{A}$. 
TABLE B.2.10 ANALYSIS OF VARIANCE OF STICK AND PUCK ENERGIES. 


\begin{abstract}
This thesis examined the 'recoil' effect of the ice hockey stick shaft during a stationary slap shot. Nine subjects were tested. Four were classified as 'elite' and the remaining five as the 'recreational' group. Their performances were evaluated by simultaneously recording stick movement and bending from high-speed video capture $(1000 \mathrm{~Hz})$ and puck acceleration from a triaxial accelerometer positioned inside the puck. Data were analyzed with a one-way ANOVA for several dependant variables including final puck velocity, stick shaft bending, blade-puck contact time and stick kinetic energy. The results indicated that: 1) the puck velocity was influenced by skill level, blade-puck contact time and stick bending energy but not puck acceleration. Further studies are needed to address the influence of events before and after blade-puck contact as well as the strength of the player on the mechanical energy and impulse given to the puck.
\end{abstract}




\section{RÉSUMÉ}

Cette thèse devait examiner le effet du recourbement de l'axe de bâton d'hockey sur glace pendant un lancer frappé. Neuf sujets ont été examinés. Quatre ont été classifiés comme 'élite' et cinq comme 'récréationnel'. Leurs exécutions ont été évalués en enregistrant simultanément le mouvement du bâton et le recourbement avec capture cinématographique à haute vitesse (1000 hertz) et l'accélération de la rondelle avec un accéléromètre à trois axes placé à l'intérieur du rondelle. Les données ont été analysés avec un ANOVA à sens unique pour plusieurs variables dépendantes comprenant vitesse de rondelle, recourbement d'axe de bâton, le temps de contact de lame-rondelle et l'énergie cinétique final du bâton. Les résultats ont indiqué que : 1) la vitesse de rondelle a été influencée par le niveau de compétence, temps de contact de lame-rondelle et l'énergie de recourbement de bâton mais pas l'accélération de la rondelle. D'autres études sont nécessaires pour adresser l'influence des événements avant et après le contact de la lame-rondelle, soit la force des joueurs sus l'énergie mécanique et l'impulsion donnée à la rondelle. 


\section{DEFINITIONS}

Backswing: The stick is raised backward from behind the puck to the highest point over the shoulders.

Bending angle: Stick shaft deformation in the minor axis due to initial impact (ground and puck) during the slap shot.

Bending Energy: Stick elastic (potential) energy due to impact (based on maximum stick distance deflection).

Bend-Phase: Period of stick shaft deformation in the minor axis due to initial impact (ground and puck) during the slap shot.

Deflection Distance: The distance of stick shaft deformation in the minor axis due to impact.

Downswing: The stick is swung forward from the highest point over the shoulders to the impact with the ground.

Follow through: The phase when the stick is off the ground and continuously decelerates forward until the end of swing movement.

Loading: The maximum bending and torsion occur on the shaft of the stick during the impact between the stick and the puck.

Pre-loading: The initial impact between the stick and the ground.

Puck Energy: Kinetic energy (i.e. energy of motion) of the puck as a result from the impact during the slap shot.

Puck Impulse: Impulse transmitted to the puck during the impact (i.e. bladepuck) in the slap shot.

Recoil Angle: Stick shaft deformation in the minor axis that follows the bending angle during the slap shot (i.e. unbending)

Recoil-Phase: Period of Stick shaft deformation in the minor axis that follows the bend-phase during the slap shot (i.e. unbending period)

Release: The moment when the puck is propelled by the stick.

Segment Joint Angle: Angle observed within stick shaft due to its deformation in the minor axis during the slap shot. 
Slap shot: A type of shooting technique that is able to produce the maximum puck velocity in ice hockey.

Stick Energy: Stick kinetic energy observed in the downswing (i.e. previous to impact) during a slap shot.

Time window A $\left(\mathrm{T}_{\mathrm{A}}\right)$ : Initial to final blade-puck contact times during the slap shot.

Total puck contact $\left(\mathbf{T}_{\mathbf{B}}\right)$ : Total effective contact time between blade and puck during the slap shot. 


\section{CHAPTER 1}

\section{INTRODUCTION}

The hockey stick is a basic and fundamental tool in the game of ice hockey. It is used as an extension of the arms in order to control puck movement as well as to project the puck in passing and shooting.

In general the stick has not changed substantially in form; (with the noted exception of blade curvature) however, the materials used to construct the stick have evolved.

In the beginning, hockey sticks were made completely of wood. By the 1950's, shaft and blade were constructed separately and then joined to form the complete stick. Later on in the 1960's, the stick was modified with a curvature applied to the blade that allowed improvement in the maneuverability during forehand stick handling as well as in the shooting velocity (Dowbiggin, B., 2001; Pearsall et al.,1999). By the 1970's the wood used and weight were reduced by enveloping the wood core and the blade with fiberglass and plastics. Lately in the 1980's and 1990's alternative construction materials for the stick include carbon plastics, aluminum alloys and fiberglass in various combinations.

The hockey stick is used for controlling puck position and shooting into the opponent team's net. Shooting skills are determined by several mechanical factors (Pearsall et al. 2000), particularly the trajectory of the puck is determined mainly by: impulse of the puck, acceleration of the puck, mass of the puck, contact time with the puck, initial velocity of the puck, initial/final velocity of the 
stick, mass of the stick, forces exerted by the player, stiffness of the stick and stick bending.

\subsection{Nature and Scope of the Problem}

The ability of shooting the puck with an optimal precision and velocity is a decisive factor in the overall performance of a player (Pearsall et al., 2000). For this reason the impulse given to the puck, which is directly proportional to its velocity, is a determinant mechanical factor in a hockey game. Hence the puck velocity measures have been used as one of the primary parameters of shot performance. Depending on the level of the player, it is expected that puck velocities for the standing slap shot fall within 80 to $115 \mathrm{~km} / \mathrm{h}$. However, it is possible to record higher velocities due to improvements in the material construction of ice hockey sticks as well as training programs of players.

Different approaches and methods have been used to calculate puck velocities in a slap shot, such as: impact velocity by Alexander et al. (1964) with a ballistic method, instantaneous velocity by Chau et al. (1973) using cinematography and maximal velocity by Rothsching (1997) with a radar gun among others. However, nowadays alternative technologies can be considered for measuring impact puck responses in a slap shot, such as the piezoelectric accelerometers and various opto-electric tracking devices (e.g. vicon, optotrack) that permit high sampling rates (i.e. greater than $1000 \mathrm{~Hz}$ ).

On the other hand, stick bending (Pearsall et al. 2000) and puck contact time (Doré \& Roy, 1976; Hoerner, 1989; Marino 1998) have been identified as 
important mechanical factors related to shooting, and consequently related to puck velocity. However, the link between contemporary stick mechanical properties and shot performance is not easily identified. For instance, Pearsall et al. (1999) conducted a biomechanical study of slap shots performed by six elite players using different sticks, and surprisingly the elastic stiffness characteristics of the stick (varying between $13 \mathrm{KN} / \mathrm{m}$ and $19 \mathrm{KN} / \mathrm{m}$ bending stiffness) were found to have a minimal effect in determining shot velocity.

Nonetheless, there is reason to believe that material properties may influence projectile speed. Therefore, in other sports in which ball impacts are involved, impact contact time is also considered a shooting factor. For example in golf, it is believed that impact duration is a factor in the performance of the shot (Roberts et al. 2001). Thus, generally golfers perceive that the ball is "absorbed" by traditional wooden clubs increasing the contact time between ball and clubface and decreasing the speed at which the ball leaves the club face. On the other hand, with modern titanium clubs they believe the face to be "harder" and perceive the ball to come off the club face quickly with increased velocity and a reduced contact time.

It is possible to divide the ice hockey stick research into twelve main areas with different categories and interest (Murphy, S., 2001):

1) Type of shots (e.g. slap shot, wrist shot, snap shot, stick handling),

2) Type of stick (e.g. wood, glass-wood, composite),

3) Geometric parameters (e.g. shaft length, mass, curve/pattern),

4) Static parameters (e.g. materials, shaft stiffness, blade strength), 
5) Kinematics (e.g. 2D, 3D, puck velocity, stick trajectory),

6) Dynamics (e.g. typical loads, puck reaction forces, blade dynamics),

7) Puck parameters (e.g. mass, diameter, thickness),

8) Participant interaction (e.g. anthropometrics, coordination, specific training),

9) Game situations (e.g. shooting while moving at max velocity, stationary shooting.),

10)Playing surfaces (e.g. new ice, polyethylene, snow covered ice),

11)Manufacturing technology (e.g. wood, aluminum, laminates),

12) Modeling (e.g. type of shot, shaft \& blade, puck deformations).

Particularly, direct relationships between the areas of kinematics and dynamics in shooting performance still need to be addressed.

\subsection{Rationale}

In Canada, the sport industry and recreational activity products related to ice hockey are an important example of manufacturing processes and engineering innovations in equipment designs, materials and constructions. Such industry helps Canada to remain economically competitive both in domestic and international markets. Particularly, most major manufacturers of ice hockey equipment currently are based in Canada (e.g. Toronto, Montreal, and Calgary). Moreover, ice hockey has a substantial social and economic value in Canada. It is estimated that over 4.5 million Canadians are involved in hockey as players, coaches, officials or direct volunteers (Hockey Canada, annual report, 2003). 
Consequently, applied ice hockey research is relevant for sport industry in order to design and manufacture better products.

Regarding ice hockey stick research, several studies have been conducted (e.g. Marino, G.W. 1998, Pearsall et al. 1999, Murphy S., 2001, Wu et al. 2003) with respect to the performance of shooting skills. The stick parameters examined have included bending and torsion stiffness with a variety of construction materials. From these studies, the authors suggested that movement patterns of elite players were predominant factors in determining critical outcomes such as puck velocity despite the variation of stick stiffness. However, the effect of the different mechanical factors (e.g. stick bend, puck velocity, puck contact time) on shooting performance are not completely understood; for instance, how do these parameters affect the catapult or recoil effect of the stick during a shot. Hence, the purpose of this study was to investigate the relationship between puck velocity and stick bending during a stationary slap shot.

\subsection{Objectives of the Study}

The purpose of this study was to examine the recoil ('catapult') effect of the ice hockey stick shaft during a stationary slap shot as observed for elite and recreational players. Puck velocity, stick bending (angle and distance deflection), and puck contact time were the main parameters of interest. In addition, estimates of stick kinetic energy during the swing, shaft elastic energy storage and recoil, as well as energy transfer to the puck will be determined. 


\subsection{Hypotheses}

The following research hypotheses are stated:

1) There will be significant differences between elite and recreational players in puck velocities and stick bending energy;

2) A high correlation between puck velocity and stick bending energy will be found; and

3) A high correlation between puck contact (acceleration and time) and puck velocity will be found.

\subsection{Limitations}

1) The experiment was conducted in room temperature $\left(22^{\circ}\right.$ to $\left.24^{\circ} \mathrm{C}\right)$ instead of ice rink temperature;

2) The subjects performed the tasks on a polyethylene sheet (i.e. artificial ice surface) instead of the actual ice surface;

3) All the slap shots were performed with players remaining stationary;

4) The subjects did not wear the full gear (i.e. no skates, shoulder paths, elbow pads, hockey pants, shin guards, jock strap, neck guard and helmet) but did use gloves;

5) The experiment was not performed under a real game situation;

6) The target was only 3 m away;

7) Stick kinematics were focused on the lower part of the shaft (i.e. 3 last distal segments); 
8) Stick and human kinetics were not measured;

9) Only nine male subjects were recruited; and

10) Only 2D stick kinematics was performed.

\subsection{Delimitations}

1) Only the slap shot was measured;

2) Only one type of hockey stick was used (i.e. wood brand Bauer Supreme $3030)$;

\subsection{Independent (IV) and Dependent (DV) Variables}

IV: Skill (2 factors, i.e. elite and recreational).

DV:

- Puck: acceleration, velocity and energy.

- Stick:

- angle deflection (i.e. bend and recoil),

- angular velocity,

- distance deflection, and its respective

- times of occurrence, as well as

o the bending energy.

- Stick/Puck: Contact Times 


\section{CHAPTER 2}

\section{REVIEW OF LITERATURE}

\subsection{Ice Hockey Basics}

The origins of ice hockey in Canada date back to the 1880's, when it was a recreational winter activity (Pearsall et al., 2000; Dowbiggin, B., 2001). The natural environment of the cold winter provided the ice. Due to the special conditions that are needed in the game of ice hockey (e.g. low friction surface) a unique set of skills is involved. Such skills include the general movement patterns of skating, stick handling, and checking. These movements patterns are characterized by a series of voluntary movements in time and space. The following diagram (Figure 2.1.1) summarizes the fundamental hierarchy of hockey skills.

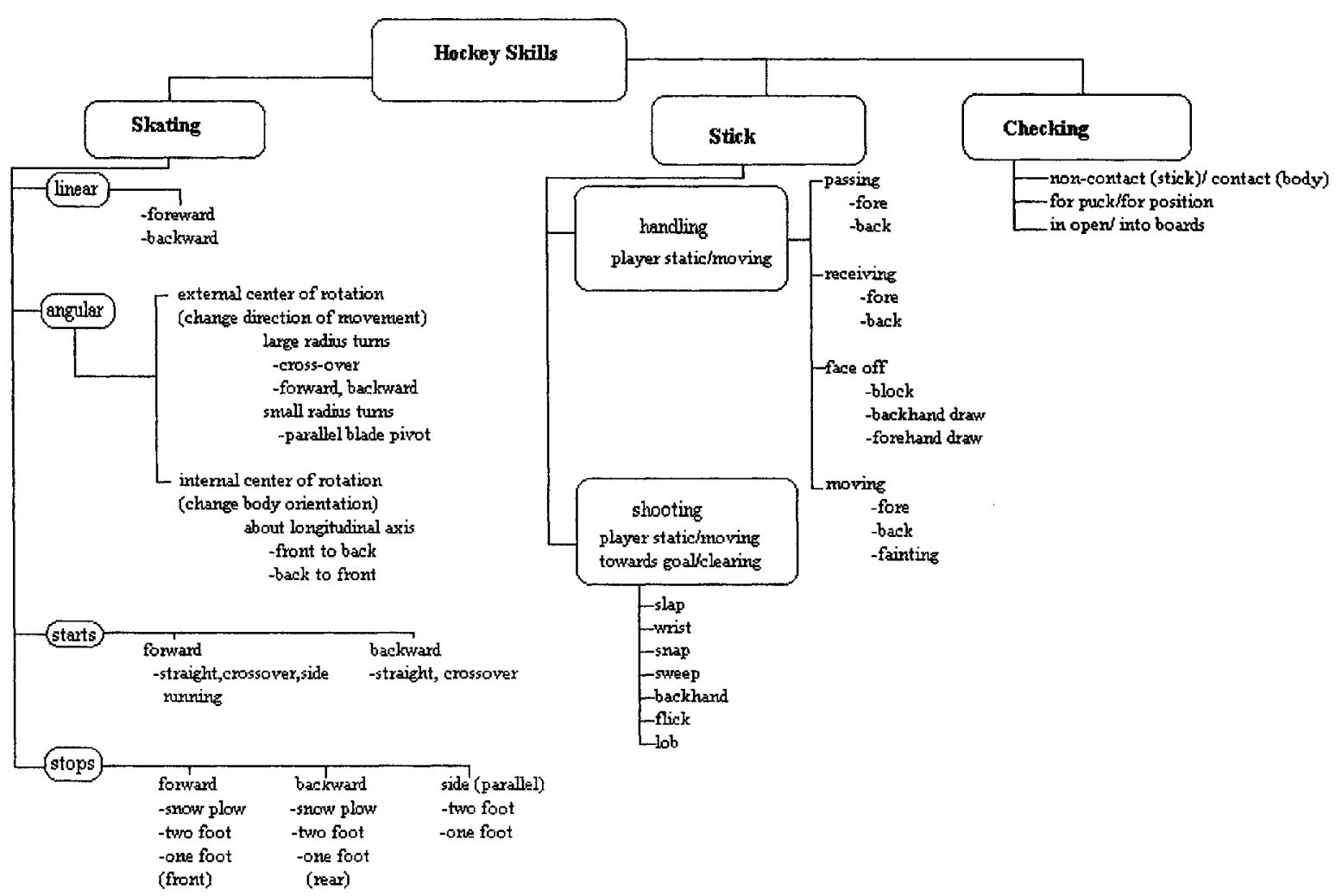

Figure 2.1.1 Fundamental Hockey Skills (Pearsall et al., 2000) 


\subsection{Ice Hockey Slap Shots}

There are two main shooting techniques: the wrist shot and the slap shot. The slap shot is executed by grasping the stick with both hands approximately 40 to $60 \mathrm{~cm}$ apart. The skill involves six different phases: backswing, downswing, preloading, loading, release and follow-through (Pearsall et al., 1999; Wu et al 2003)

During the preloading phase, the blade of the stick makes contact with the ice surface prior (6 to 12 inches) to impact with the puck (creating the "slap" sound) and stick bending is initiated. Subsequently, the puck is impacted by the blade (loading phase) and then propelled (released phase) towards the goal or net.

On the other hand, a wrist shot involves less swing than the slap shot, with the hands holding the stick 0.15 to $0.30 \mathrm{~m}$ apart; and it is used for higher accuracy (Hoerner, 1989).

Through the years, puck velocities have been used as a guideline for measuring the performance in slap shots as well as in wrist shots. Some of the different approaches and techniques for calculating puck velocities in a slap shot are summarized in Table 2.2.1.

In early research, qualitative approaches were done for describing the mechanics of slap shots. For example, Hayes in 1965 suggested than a heavier stick would increase the striking mass but decrease the velocity at contact. Wells and Luttgens (1976) concluded that different parts of the body have different contributions in the performance of the slap shot (e.g. $25 \%$ trunk, 40 to $45 \%$ shoulders, and 30 to $35 \%$ elbow and wrist movements). 
Table 2.2.1 Summary of puck velocities $(\mathrm{km} / \mathrm{h})$ during a slap shot reported by various studies (Pearsall et al. 2000).

\begin{tabular}{|c|c|c|c|c|c|}
\hline \multirow[b]{2}{*}{ Studies } & \multirow[b]{2}{*}{ Method } & \multirow[b]{2}{*}{ Velocity } & \multirow[b]{2}{*}{ Age } & \multicolumn{2}{|c|}{ Slap Shot [km/h] } \\
\hline & & & & Skate & Stand \\
\hline Alexander et al. 1963 & Ballistic & Impact & Adult & 127 & 111 \\
\hline $\begin{array}{l}\text { Alexander et al. } 1964 \\
\text { Cotton }\end{array}$ & Ballistic & Impact & Varsity & 121 & \\
\hline 1966 & Stop & & Adult & 100 & 90 \\
\hline Furlong 1968 & Watch & Average & Pro's & 175 & \\
\hline Chau et al. 1973 & Cine & Instant & Adult & 132 & 110 \\
\hline Roy et al. 1974 & Cine & Average & Junior B & 89 & 92 \\
\hline \multirow[t]{2}{*}{ Roy and Dore 1976} & Sound & Average & Pee wee & & 69 \\
\hline & & & Adult & & 96 \\
\hline Dore and Roy 1976 & Sound & Average & $\begin{array}{l}\text { Adult } \\
\text { High }\end{array}$ & 104 & 97 \\
\hline \multirow[t]{2}{*}{ Simm and Chau 1978} & Cine & $\operatorname{Max}$ & School & 150 & \\
\hline & & & Adult & 200 & \\
\hline Rothsching 1997 & Radar & Max & Varsity & & 108 \\
\hline
\end{tabular}

Later , Emmert (1984) found different muscle activation patterns for the slap shot phases, such as pectoralis major, deltoid and biceps brachi during the back swing phase; pectoralis major, anterior deltoid, external/internal obliques in the downswing phase and finally teres major, latissimus dorsi, obliques, triceps and anterior deltoid.

As can be noticed in Table 2.2.1, Alexander et al. (1963) conducted one of the first quantitative studies regarding speed and accuracy in slap shots as well as wrist shots. By comparing both type of shots, it was found that slap shots were faster $(30.8$ to $35.3 \mathrm{~m} / \mathrm{s})$ than wrist shots $(26.6$ to $32.6 \mathrm{~m} / \mathrm{s})$. Cotton (1966) found higher velocities of the wrist and slap shots while skating (90 and $100 \mathrm{~km} / \mathrm{h}$ respectively).

Chau and colleagues (1973) used high speed cinematography to recorded the kinematics of several hockey activities (two adult players and one juvenile), such as skating speeds, stick kinematics, puck velocities and puck impact forces among others. Shooting speeds were recorded with two cameras, at frames of 
$400 \mathrm{~Hz}$ and 750 to $1000 \mathrm{~Hz}$ respectively. A maximum skating slap shot puck velocity of $132 \mathrm{~km} / \mathrm{h}$ was found.

Later, Roy and colleagues (1974) by using high-speed filming (200 to $500 \mathrm{~Hz}$ ) recorded puck velocities (Junior B players) finding the maximum value for a slap shot of $89 \mathrm{~km} / \mathrm{h}$. Also, they recorded stick kinematics included the impulse duration during puck-blade contact, maximal deflection, maximal angular velocity and percentage of puck velocity among others. In such study the authors suggested that stick deformation was mainly due to friction blade/ice rather than blade/puck.

In a study made by Roy and Doré (1976) average puck velocities were determined with a digital time counter triggered by a magnetic cell embedded in the ice and stopped by the impact sound recorded by a microphone. Slap shot velocities of $69 \mathrm{~km} / \mathrm{h}$ were found for the pee wee group, the adult group had average velocities of $97 \mathrm{~km} / \mathrm{h}$.

On the other hand, stick stiffness is considered another relevant factor in shooting. For instance, Roy and Doré (1976) investigated the effect of the stick with two different stiffnesses on the velocity and accuracy of slap and sweep shots of pee wee level players (11 years old). Two different sticks were used, a senior stiff stick $(24.1 \mathrm{lb} / \mathrm{in})$ and a senior flexible stick $(17.1 \mathrm{lb} / \mathrm{in})$. The authors suggested that the flexible stick produced a $4 \%$ increase in velocity (from 54.4 $\mathrm{km} / \mathrm{h}$ to $56.8 \mathrm{~km} / \mathrm{h}$ ) and in accuracy.

Also Roy and Doré $(1973,1974,1975,1976)$ performed the first kinetic studies of the slap shot, as well as wrist shots, sweep shots and backhand shots. Stick 
dynamics response was obtained by using high-speed film (200 frames/s) cinematography and strain gauges located on the shaft and blade. Regarding the kinematics, they calculated: puck velocity, impulse phase, deflection of the shaft during the impulse phase and velocity of the blade during impulse phase. For the kinetics, the authors suggested again that flexible sticks required lower forces to achieve the same puck velocity recorded with stiffer sticks.

An experiment conducted by Lessard et al. (1994) in the Department of Mechanical Engineering at McGill University, analyzed shaft stiffness dynamic responses of three different materials: aluminum, carbon fiber and wood. By performing linear and torsional static deformation analysis, the authors found stiffer properties for carbon fiber and aluminum sticks than wooden sticks.

Marino (1998) also analyzed the performance characteristics of different hockey sticks (e.g. wood, composite and aluminum), by testing weight, center of mass, flex strength, torsional resistance and break force. Aluminum sticks were found the strongest whereas composite sticks were found the lightest.

A study conducted by Pearsall and colleagues (1999) examined the influence of stick stiffness on the performance of ice hockey slap shots. Six elite players participated on the study, performing six slap shots with sticks of four different shaft stiffness $(13 \mathrm{KN} / \mathrm{m}, 16 \mathrm{KN} / \mathrm{m}, 17 \mathrm{KN} / \mathrm{m}$ and $19 \mathrm{KN} / \mathrm{m})$. The dynamics of the slap shots were evaluated by recording initial ground reaction forces and the stick deformation from the high speed filming system. Also puck velocities were obtained by using a radar gun. The highest maximum puck velocity was found for the stick with a stiffness of $13 \mathrm{KN} / \mathrm{m}(108.2 \mathrm{~km} / \mathrm{h})$, whereas the lowest was 
recorded for the stick with stiffness of $17 \mathrm{KN} / \mathrm{m}(105.9 \mathrm{~km} / \mathrm{h})$. On the other hand, for the ground reaction forces measured by a force plate, the highest peak vertical force was found on the stick with the stiffness of $17 \mathrm{KN} / \mathrm{m}$ and the lowest peak vertical force on the stick with the stiffness of $13 \mathrm{KN} / \mathrm{m}$. In terms of stick kinematics, the highest peak deflection and greatest time for reaching this value was found on the stick with the lowest stiffness $(13 \mathrm{KN} / \mathrm{m})$. However, the authors suggested that the results indicate that the subjects are probably more important in determining shot velocities than the stick characteristics.

More recently Wu et al. (2003) examined the performances of slap and wrist shots using sticks with different stiffness (carbon fiber composite and wood laminate). Forty subjects (male and female) of different skills levels participated in the study. The mechanics of the shots were measured by using simultaneously a force plate, a high speed camera (1000 frames/s) and a radar gun. The results showed that slap shots produced greater puck velocities than wrist shots. For instance, male skill players produced puck velocities of $108 \mathrm{~km} / \mathrm{h}(30 \mathrm{~m} / \mathrm{s})$ for the slap shot and $70.92 \mathrm{~km} / \mathrm{h}(19.7 \mathrm{~m} / \mathrm{s})$ for the wrist shot. Furthermore they found that shot velocity was directly related to the skill level and upper body strength of the person taking the shot.

\subsection{Kinematic Analysis Methods}

A biomechanical analysis can be conducted by either of two perspectives: kinematics and kinetics (Levangie, 2001; Hamill \& Knutzen, 2003). Kinematics is concerned with motion characteristics and analyzes motion from a spatial and 
temporal perspective without regard for the forces producing the motion; whereas kinetics examines the forces acting on the system. The following Figure 2.3.1 illustrates such perspectives.

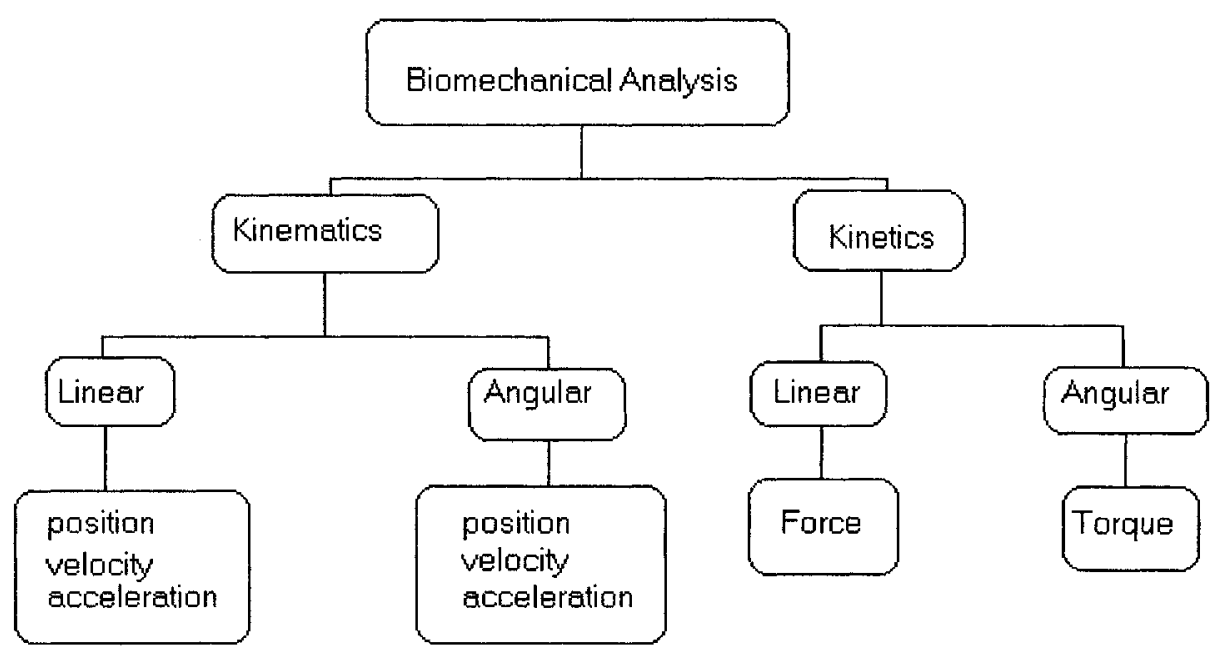

Figure 2.3.1 Perspectives of Biomechanical Analysis (adapted from Hamill \& Knutzen, 2003).

Since the origin of human locomotion research, optical measurement techniques have made a substantial impact in the understanding of motion analysis. Etienne Jules Marey (1830-1904) was a prolific pioneer of such optical instrumentation (Novacheck 1997; Nigg \& Herzog, 2002 ); he was among the first to achieve photographic documentation of movement with the photographic rifle. Marey (1882) published the first chronophotographic pictures of a marching human and a horse jumping an obstacle.

Eadweard Muybridge, a contemporary of Marey, used a series of cameras to take multiple pictures in rapid succession of animals and humans in movement, publishing the 11 volume photographic work, Animal Locomotion(1887), considered one of the treasures of early photography studies in human and 
animal movement (Inman et al.1981; Nigg \& Herzog 2002; Andriacci \& Alexander 2000).

Today, camera and marker systems are the most frequently used tool in biomechanical kinematic analysis (Nigg \& Herzog, 2002). Such systems include conventional high-speed film cameras, high speed video cameras and cameras that sense electromagnetic wave signals. Markers, which are used for representing points on the system of interest such as prominent bony landmarks, may be passive (e.g. reflective tape) or active (e.g. electronic transmitters).

In such systems, passive markers are tracked when they reflect the light back of the camera source light. The video signal is digitally converted and fed into a computer that examines the video data looking for objects above a threshold of light. This process (i.e. digitization) involves viewing each frame of the video tape and identifying and storing the coordinates (i.e. $x, y, z$ ) for each of the markers, in each of the frames of the film. However, a camera provides a $2 D$ image of a $3 D$ situation on a "film" (or video) medium. The determination of three-dimensional spatial coordinates from several (at least two cameras) two-dimensional sets of data is performed by using the DLT (direct linear transformation) method (AbdelAziz and Karara, 1971). That is, for " $m$ " markers, the DLT method provides a linear relationship between the two-dimensional coordinates of a marker, on the film and its three dimensional location in the space (Nigg \& Herzog 2002, Pourcelot et al., 2000). The accuracy of the 3D reconstruction positions of the markers depends mainly upon the quality of the DLT reconstruction, the quality of 
the lenses used, the accuracy of the calibration frame and the deformation of the film.

\subsection{Acceleration Measuring Techniques}

The use of accelerometers in biomechanics is relatively new, due to the fact that the piezoelectric effect was discovered by the Curie brothers in 1880 , which was later used to quantify forces and accelerations. The piezoelectric effect was put to practical use in the 1920's and 1930's. The KISTLER Company constructed the first commercially available piezoelectric force plate for gait analysis for the biomechanics laboratory of the ETH Zürich in 1969. Thus, acceleration measuring techniques have been developed parallel to force measuring methods ( Nigg \& Herzog ,2002).

Accelerometers have been widely used in biomechanical research, for instance, Prokop (1972) used accelerometers mounted in the shoe sole of spike shoes on several track surfaces. Later, Morris (1973) used five accelerometers to quantify the three-dimensional movement of the shank. Afterwards, accelerometers mounted on head, hip and shank were used during alpine skiing (Nigg,1973) and, walking and running (Unold,1974). In subsequent years, the use of accelerometers in biomechanical analysis has been extended in several ways, such as: for measuring vibration in soft tissue (Saha,1977), for the quantification of joint kinematics $($ Chao,1978), for measuring skeletal accelerations at the tibia (Light,1980), and for determining the bone to bone impact forces in the ankle and knee joint with an effective mass model (Denoth, 1980) among others. 
Today, accelerometers are frequently used for biomechanical evaluations of protective equipment for sports (e.g. helmets), helping mainly in the development of safety standards of sport helmets (Bishop, 1993, Pearsall et al. 1998). For instance, prior to the introduction of an ice hockey helmet standard in Canada several players died from blows to the head even though they were wearing head protection (Fekete, 1968).

Measuring principles used in accelerometers include strain gauge, piezoresistive, piezoelectric and inductive transducers. Piezoelectric accelerometers in general are transducers universally used for vibration measurements. Its acceleration proportional output can be integrated to give velocity and displacement proportional signals. The heart of a piezoelectric accelerometer is the slice of piezoelectric material, usually an artificially polarized ferroelectric ceramic, which has the unique piezoelectric effect. When it is mechanically stressed, either in tension, compression or shear, it generates an electrical charge across its pole faces which is proportional to the applied force. The piezoelectric element is arranged so that when the assembly is vibrated the mass applies force to the piezoelectric element which is proportional to the vibration acceleration (i.e. $2^{\text {nd }}$. Newton Law, $F=m a)$. For frequencies below the resonant frequency of the springmass system, the acceleration of the mass will be the same as the acceleration of the base, and as a result the output signal magnitude will proportional to the acceleration to which the system is subjected.

The following Figure 2.4.1 illustrates the construction of a piezoelectric accelerometer. 


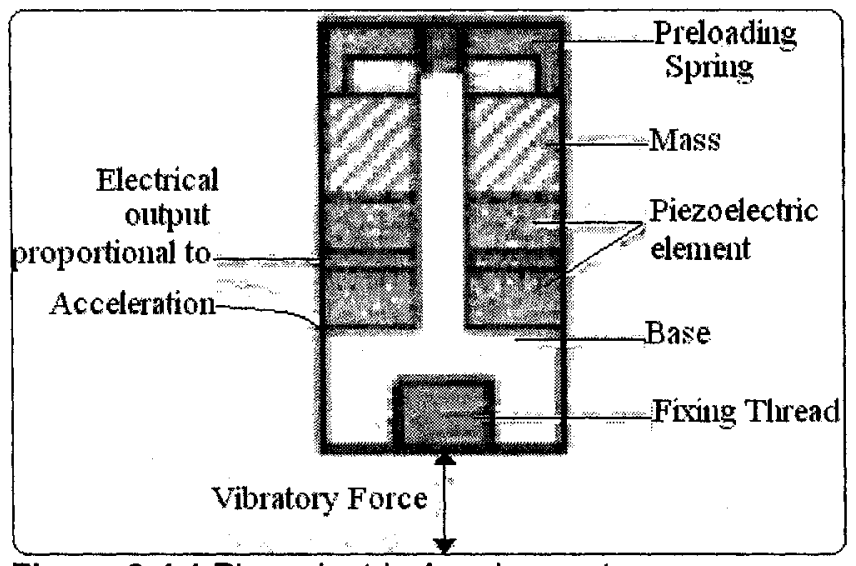

Figure 2.4.1 Piezoelectric Accelerometer

( adapted from Brüel \&Kjær, Measuring Vibration, 1982)

There are two common configurations for piezoelectric accelerometers: The Compression Type, where the mass exerts a compressive force on the piezoelectric element, and The Shear Type where the mass exerts a shear force on the piezoelectric element. The following Figure 2.4.2 illustrates these two types of configurations.
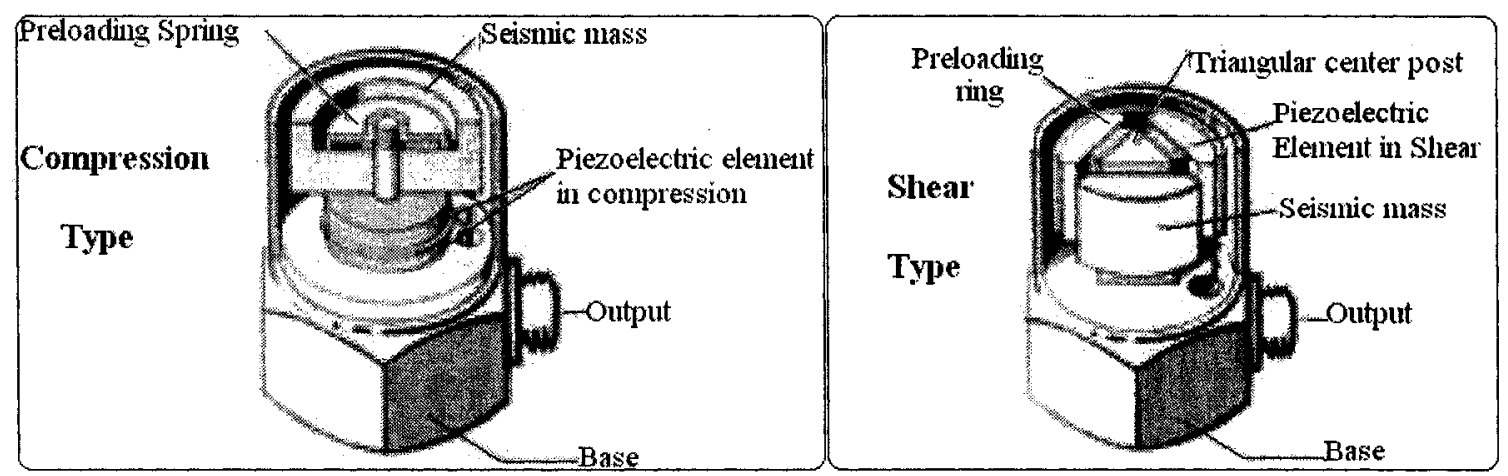

Figure 2.4.2 Common configurations in piezoelectric accelerometers (adapted from Brüel \&Kjær, Measuring Vibration, 1982)

As a general rule vibration parameters are usually measured in metric units in accordance with the ISO requirements (Brüel \&Kjær, Measuring Vibration, 1982), however the gravitational constant " $g$ " is still widely used for acceleration levels, where a factor of almost $10(9.81)$ relates the two units, so that conversion within $2 \%$ is a simple matter. 
Three main characteristics are considered in the construction of accelerometers: sensitivity, mass and dynamic range. It is ideal to have a high output level, but here the weight of the accelerometer could be compromised due to the fact that high sensitivity normally implies a relatively big piezoelectric assembly. However in normal circumstances the sensitivity is not a critical problem as modern preamplifiers are designed to accept low level signals.

The mass of accelerometers becomes important when measures on light test objects are needed, because additional mass could significantly alter the vibration levels and frequencies at the measuring point. As a general rule, the accelerometer mass should not be greater than one tenth of the dynamic mass of the vibration part onto which is mounted. The following table 2.4.1 summarizes the main characteristics of piezoelectric accelerometers typically used in biomechanical experiments.

Table 2.4.1 Main Characteristics of piezoelectric accelerometers. (Nigg \& Herzog 2002)

\begin{tabular}{llllll}
\hline Transducer & MASS & $\begin{array}{l}\text { NATURAL } \\
\text { FREQUENCY }\end{array}$ & $\begin{array}{l}\text { FREQUENCY } \\
\text { RESPONSE }\end{array}$ & $\begin{array}{l}\text { SHOCK } \\
\text { RATING }\end{array}$ & RANGE \\
\hline Piezoelectric low & $20,000 \mathrm{to}$ & 0 to $5000 \mathrm{~Hz}$ & $\begin{array}{l}\text { Several } \\
\text { magnitudes }\end{array}$ & $0.01 \mathrm{to}$ \\
& $1-2 \mathrm{~g}$ & $30,000 \mathrm{~Hz}$ & & $\begin{array}{l}\text { higher than } \\
\text { upper limit }\end{array}$ \\
& & & $\begin{array}{l}\text { of range } \\
\text { of }\end{array}$ &
\end{tabular}

As we can see, most accelerometers used in biomechanical analysis are extremely light and weigh only a few grams. The natural frequency is typically high and the frequency response is sufficiently for the frequencies relevant for biomechanical measurements. Piezoelectric accelerometers have the advantage 
on the higher range respect to other types (e.g. strain gauges, piezoresistive, inductive).

\subsection{Basic Energy Concepts}

Since this research project involves estimates of energy, it is relevant to review basic kinetic concepts (e.g. work, mechanical energy).

Considering a particle moving in one dimension, if a constant force $F x$, along the $x$ axis, acts on the particle, then the work done by the force on the particle as it moves some given distance is defined as the product of the force and the displacement: $\quad W=F_{x} \Delta_{x}$

In the case of three-dimensional motion where the different directions of the force and displacement are considered: $W=F_{x} \Delta_{x}+F_{y} \Delta_{y}+F_{z} \Delta_{z}$

$$
\text { Or more general : } W=\vec{F} \cdot \Delta \vec{r}
$$

Such dot product is equal to: $W=F \Delta_{r} \operatorname{Cos} 6$

where $F$ is the constant force acting on the particle while undergoing a displacement with an angle 6 between the force and the displacement.

When the Force $F$ is not constant, the definition of work in the case of a threedimensional force, involves an integral. Figure 2.5.1 shows how a particle moves along some given path from point $P_{1}$ to point $P_{2}$. By dividing the path into short segments, each of length $\Delta r$, the force and direction of motion within each segment are approximately constant and the work done on the particle is given by equation (2.5.4). 


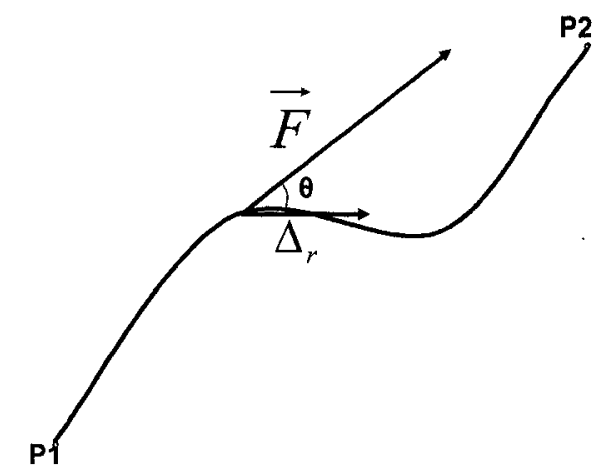

Figure 2.5.1 Force $\mathbf{F}$ acting during a small displacement $\Delta_{r}$ (adapted from Ohanian 1985).

Then, the total work is approximately the sum of all such amount of work. In the limit when $\Delta_{r} \rightarrow 0$, this sum becomes the integral:

$W=\int_{P_{1}}^{P_{2}} F \operatorname{Cos} \theta d r$

where $\mathrm{dr}$, is the element of length along the path followed by the particle, more compactly

$$
W=\int_{P_{1}}^{P 2} F \bullet d r
$$

This expression helps to derive an important identity between the work done on a particle and the change of speed of the particle.

Thus, from equation 2.5.6 :

$$
W=\int_{P 1}^{P_{2}}\left(F_{x} d x+F_{y} d y+F_{z} d z\right)
$$

Considering the first term of the integrand $\quad F_{x}=m \frac{d V_{x}}{d t}$

The integrand of the first term is $\int_{P_{1}}^{P_{2}} F_{x} d x=\int_{P_{1}}^{P_{2}} m \frac{d V_{x}}{d t} d x \quad$ Eq. (2.5.9) 
where the velocity $V_{x}$ is function of time.

However for the purpose of the integration in equation 2.5.9, it is better to express the velocity as a function of position.

Then $\quad \frac{d V_{x}}{d t}=\frac{d V_{x}}{d t} \cdot \frac{d x}{d x}$

Or $\quad \frac{d V_{x}}{d t}=\frac{d V_{x}}{d x} \cdot \frac{d x}{d t} \Rightarrow \frac{d V_{x}}{d t}=\frac{d V_{x}}{d x} \cdot V_{x}$

Consequently, by substituting in equation 2.5 .4

$$
\int_{P 1}^{P 2} F_{x} d x=\int_{P 1}^{P 2} m \cdot V_{x} \frac{d V_{x}}{d x} d x=\int_{V_{1 x}}^{V_{2 x}} m \cdot V_{x} d V_{x}
$$

And by the theorem of calculus we obtain

$$
\int_{V_{1 x}}^{V_{2 x}} m \cdot V_{x} d V_{x}=m \cdot\left[\frac{1}{2} V_{x}^{2}\right]_{V_{1 x}}^{V_{2 x}}=m\left[\frac{1}{2} V_{2 x}^{2}-\frac{1}{2} V_{1 x}^{2}\right]
$$

$W=\frac{1}{2} m V_{2 x}^{2}-\frac{1}{2} m V_{1 x}^{2}$

Where $V_{1 x}$ is the $x$ velocity at $P_{1}$ and $V_{2 x}$ is the $x$ velocity at $P_{2}$. For the components $F_{y}$ and $F_{z}$, following the same process the final result for equation (2.5.7) will be:

$$
W=\int_{P 1}^{P 2}\left(F_{x} d x+F_{y} d y+F_{z} d z\right)=\frac{1}{2} m V_{2 x}^{2}-\frac{1}{2} m V_{1 x}^{2}+\frac{1}{2} m V_{2 y}^{2}-\frac{1}{2} m V_{1 y}^{2}+\frac{1}{2} m V_{2 z}^{2}-\frac{1}{2} m V_{1 z}^{2}
$$

Or $\quad W=\frac{1}{2} m V_{2}^{2}-\frac{1}{2} m V_{1}^{2}$ 
Where, $\quad V^{2}=V_{x}^{2}+V_{y}^{2}+V_{z}^{2}$

Equation (2.5.13) is showing that the work done by the net force between $P_{1}$ and $P_{2}$ is proportional to the change in the square of the velocity.

The quantity $K=\frac{1}{2} m V^{2}$

is called the kinetic energy of the particle.

Hence, equation (2.5.5) says that the work done on the particle by the net force equals the change in the kinetic energy.

$$
W=K_{2}-K_{1}
$$

Or

$$
W=\Delta K
$$

Result called the work energy-theorem.

Therefore, kinetic energy (i.e. energy of motion) is a measure of the degree to which a system has the ability to do work on some other system (Lerner, 1996; Ohanian, 1985; Hamill \& Knutzen, 2003). The generation of a sufficient level of kinetic energy is especially important when projecting an object (e.g. batting, ice hockey slap shot). For example, kinetic energy is developed in baseball over the collision phase with the bat and will project the ball at velocities of more than 100 mph. A kinetic energy in the range of $320 \mathrm{~J}$ and $115 \mathrm{~J}$ for the bat and the ball respectively, before the collision, has been found. After the contact, the kinetic energy of the bat was reported to be reduced to $156 \mathrm{~J}$ and the ball's kinetic energy increased to $157 \mathrm{~J}$ (Fallon et al., 2000). 
On the other hand, mechanical energy also can be measured as the capacity of a particle to do work by virtue of its position in the space. Considering the case of gravitational potential energy for a particle of mass $m$ moving under the influence of the constant gravitational force (i.e. $F_{x}=0, F_{y}=0, F_{z}=-\mathrm{mg}$ ) from point $P_{1}$ to point $P_{2}$, and from the definition of work (Equation 2.5.15):

$$
\begin{gathered}
\left.W=\int_{Z 1}^{Z 2}(-m g) d z=-m g\right]_{Z 1}^{Z 2}=-m g\left(Z_{2}-Z_{1}\right) \\
\Rightarrow \quad W=-m g\left(Z_{2}-Z_{1}\right)=-m g Z_{2}+m g Z_{1} \\
\text { Or } \quad W=-U\left(Z_{2}\right)+U\left(Z_{1}\right)
\end{gathered}
$$

Where the function $U(Z)=m g z$ is called the gravitational potential energy.

If the only force acting on a particle is gravity then by combining equation (2.5.16) and equation (2.5.15) the relation between potential energy and kinetic energy is obtained:

$$
\begin{aligned}
& -U\left(Z_{2}\right)+U\left(Z_{1}\right)=K_{2}-K_{1} \quad \text { Eq. (2.5.17) } \\
& \Rightarrow \quad K_{1}+U\left(Z_{1}\right)=K_{2}+U\left(Z_{2}\right)
\end{aligned}
$$

This equality indicates that that quantity $K+U(Z)$, is a constant of the motion

$$
K+U(Z)=[\text { cons } \tan t] \quad \text { Eq. (2.5.18) }
$$

The sum of kinetic and potential energies is called the mechanical energy of the particle, and is designed with an $E$

$$
E=K+U(Z) \quad \text { Eq. (2.5.19) }
$$

If the only force acting on the particle is gravity, then the mechanical energy remains constant: $\quad E=[$ cons $\tan t]$ 
This is the law of conservation of mechanical energy.

Since the sum of the potential and kinetic energies must remain constant during the motion, an increase in one must be compensated by a decrease in the other; this means that during the motion, kinetic energy is converted into potential energy and vice versa.

An object that is deformed may also store potential energy. This type of energy has to do with elastic forces. When an object is deformed, the resistance to the deformation increases as the object is stretched. Thus the force that deforms the object is stored and may be released as elastic energy.

The force applied to deform a structure and the resulting deformation are referred to as stress and strain (Hamill \& Knutzen, 2003; Nigg \& Herzog 2002), respectively. A typical engineering material when subjected to a uniaxial or tension test will demonstrate a stress-strain (Dhanjoo, 1982; Hamill \& Knutzen, K.M.,2003). curve as figure 2.5 .2 shows:

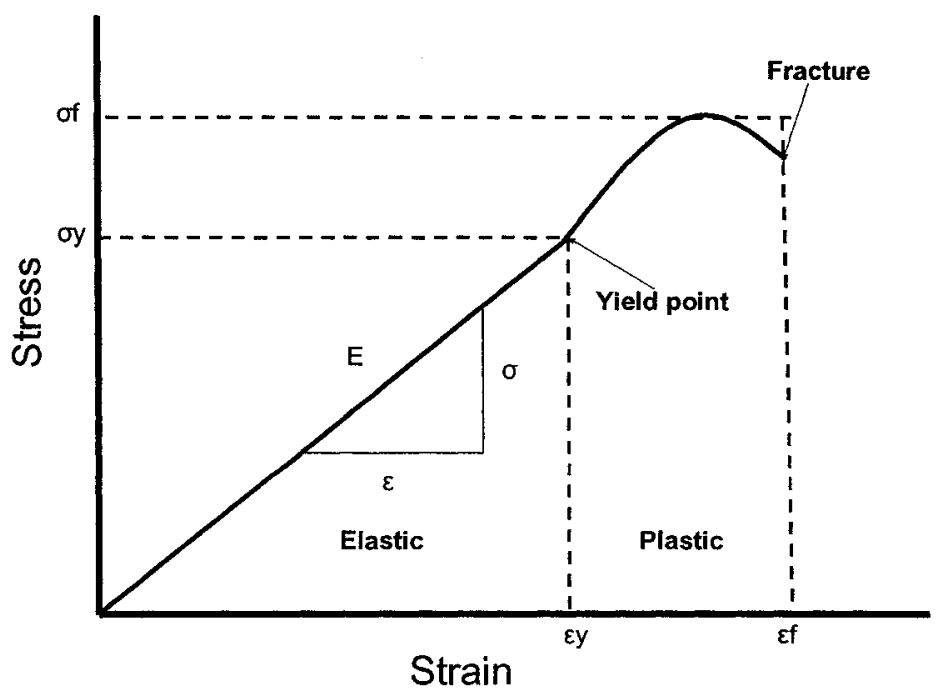

Figure 2.5.2 An ideal Strain-Stress Curve, Showing elastic and plastic regions, as well as the elastic modulus. (adapted from Dhanjoo, 1982; Hamill \& Knutzen, K.M.,2003) 
In this curve, the slope of the linear portion of the curve is the elastic modulus, or stiffness of the material. Stiffness is thus calculated as:

$k=\frac{\text { stress }}{\text { strain }}=\frac{\sigma}{\varepsilon}$

where $\quad \sigma$ is the force per unit area $\sigma=\frac{F}{A}$, and

$\varepsilon$ is the relative change of length $\varepsilon=\frac{\Delta L}{L}$.

For very small extensions or strain, up to the order of $0.1 \%$ (Dhanjoo, 1982) the material behaves in a linear and elastic manner. In other terms, when the load is removed the material responds like a spring (i.e. mass-spring system) and returns to its original position. When loading is applied at stresses above the elastic limit (yield point), then permanent or plastic deformation (fracture) occurs. The material can normally sustain much higher elongation, of the order of $35 \%$ of its original length, before fracture of the material occurs (Dhanjoo, 1982).

Following a similar procedure as the one described for obtaining the kinetic energy (Lerner,1996; Ohanan,1985), and considering Hook's Law ( $F=-K x)$, it is possible to obtain the potential elastic energy( i.e. strain energy) as :

$$
S E=\frac{1}{2} k x^{2}
$$

where $x$ is the distance over the object is deformed, and $k$ (i.e. stiffness) is the proportionality constant, which depends on the material deformed and represents the object's ability to store energy.

Widely discussed in biomechanics literature (Hamill \& Knutzen, 2003) is how muscles and tendons, and certain devices such as spring boards for diving, store this strain energy and release it to aid in human movement. 
In athletics performance several pieces of equipment (e.g. trampolines, poles in pole vaulting, ice hockey sticks in shooting) achieve such and end.

One example of the use of energy storage is the design of the tuned running track at Harvard University, where McMahon and Greene (1979) analyzed the mechanics of running and the energy interactions between the runner and the track in order to develop and optimum design for the track and surface. In this study an average speed advantage of nearly $3 \%$ was observed, during the first season on the new track.

\subsection{Structural Dynamics}

Due to the limitations in modelling and in mathematical solutions for static and dynamics responses of several mechanical systems, engineers and mathematicians have proposed different approaches for modelling the elements that constitute a system. Thus, several numerical techniques with different degrees of complexity have been developed, in order to solve the analytical model (i.e. differential equation) that describes a specific problem.

In general, for modelling a system under several external actions, simplifications and assumptions are made with respect in the physical properties of the system or in its actual behaviour, in order to find the most relevant effects and responses of the system. Following these simplifications and through the mathematical model, it has been possible to propose a representation of the system and the actions on it. It is possible to then obtain a solution describing the effects on an element or specific mechanical system. 
Particularly, for modelling the elements of a system under bending forces, elements designated as "beams" have been used. These "beam" elements are structures that carry loads which are mainly transverse to the longitudinal direction, thus producing flexural stresses and lateral displacements (i.e. deflection curves) (Paz, 1991; Rodriguez et al. 1996; Chopra, 1995). Figure 2.6.1 illustrates a basic beam element and its deflection due to an external force.

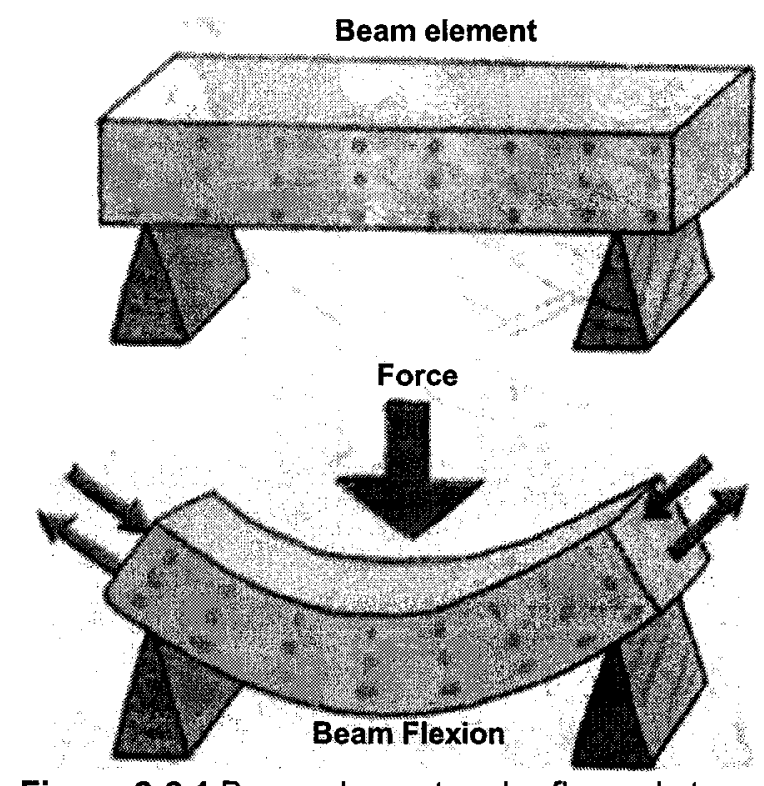

Figure 2.6.1 Beam element under flexural stress (adapted from Rodriguez et al., 1996).

In general, a beam element flexion depends basically on two aspects:

a) support conditions (i.e. boundary conditions)

b) actions on the element (i.e. external forces)

The support conditions will determine the degrees of freedom of the element, that is, the displacement restrictions of the element. The actions on the element will lead to consideration of the specific response to study, whether static or dynamic in nature. 
In the study of a beam element response it could be of interest to know:

- the maximum deflection caused by external forces, or

- the deflection occurring at specific points of the element (e.g. closer to the support point), or

- specific points under impact conditions (i.e. collisions) with other bodies.

The following basic example could illustrate this concept and give the base for studying more complex problems (e.g. stick-puck impact).

Considering the example illustrated on Figure 2.6.2, a box with a mass of 1000 $\mathrm{kg}$ that is release from $1 \mathrm{~m}$ height over the center of a rod, whose physical dimensions and properties are given by:

Longitudinal length $(L)=10 \mathrm{~m}$

Transverse section $=0.20 \mathrm{~m} \times 0.50 \mathrm{~m}$

Modulus of elasticity $(E)=25,000 \mathrm{MPa}$

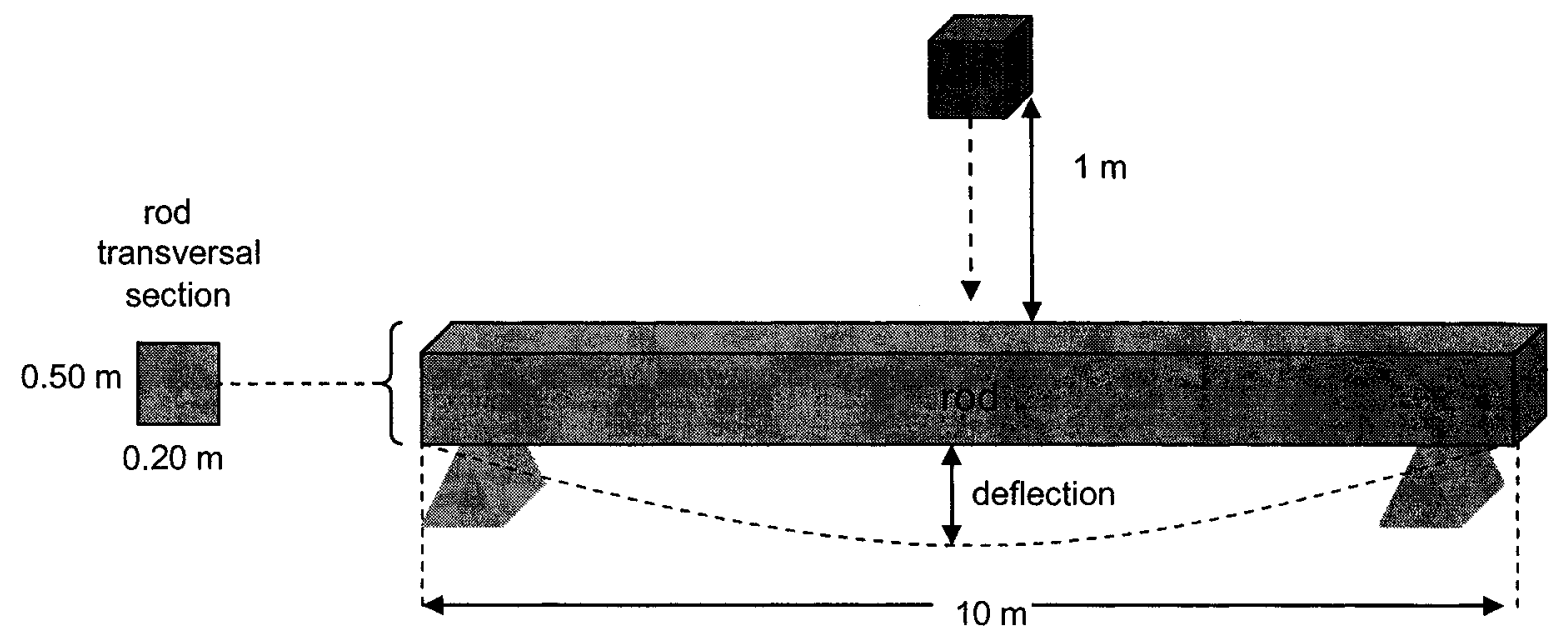

Figure 2.6.2 Beam representation of a system mass-rod during impact.

Under the assumption, that the box remains adhered to the rod at the time of the

initial impact, the main objectives for studying the system mass-rod would be: 
- Describe the oscillatory movement generated on the rod,

- Estimate the maximum vertical deflection of the rod,

- Estimate maximum forces acting on the rod

The first step for finding the solution to this problem is to formulate the model of the system with one degree of freedom, in order to describe the oscillation movement generated on the rod. When the impact takes place the rod will tend to bend and vibrate due to the impact. In this way, a dynamic system is created, where the mass is initially given by the box and the "stiffness" is given by the rod, which can be modelling as a "beam" element.

This system can be represented by the following differential equation (Elishakoff at al. 1987, Chopra, 1995, Rodriguez et al., 1996; Irvine,1999; Paz,1991;) :

$$
m \ddot{x}+k x=0
$$

Where

$$
\begin{array}{ll}
m & \mathrm{~m}=\text { box mass } \\
k & \mathrm{k}=\text { stiffness of the beam element } \\
\ddot{x} & =\text { acceleration of the system } \\
x & =\text { displacement of the system }
\end{array}
$$

Before solving this differential equation of $2^{\text {nd }}$ degree, it is necessary to find ' $m$ ' and ' $k$ '. Since the box mass is known, it is only necessary to determine the stiffness (i.e. $\mathrm{k}$ ), which is function of the parameters:

$L=$ Length of beam element, $E=$ Modulus of elasticity of the beam model, $\mathrm{I}=$ Moment of inertia of the element, 
And a Factor ' $S$ ' which is function of the beam element; in the case of the current example:

$S=48$, then the stiffness of the beam element is given by

$$
K=\frac{48 E I}{L^{3}}
$$

Where

$L=10 \mathrm{~m}$,

$E=25000 \mathrm{MPa}$,

And

$I=\frac{0.5^{3} \times 0.2}{12}=0.002083 \mathrm{~m}^{4}$

Then, by substituting in Equation 2.6.2 the stiffness is obtained

$K=\frac{48 \times 25000 \times 0.002083}{10^{3}}=2.5 \mathrm{MPa}^{*} \mathrm{~m}=2.5^{*} 10^{6} \mathrm{~N} / \mathrm{m}$

Given that the mass is $1000 \mathrm{~kg}$, the frequency of the system (beam+box) in rad/s will be given by

$\omega=\sqrt{\frac{k}{m}}=50 \mathrm{rad} / \mathrm{s}$

or

$f=\frac{\omega}{2 \pi}=7.96 \mathrm{~Hz}$

with a period $T=1 / f=1 / 7.96=0.126 \mathrm{~s}$

Eq.(2.6.5)

Based on the above analysis, and considering the static deflection of the beam element given by 


$$
\delta e=\frac{W}{k}=\frac{m g}{k}
$$

It is possible to obtain the differential equation in equilibrium for the system.

Thus, by substituting ' $\mathrm{k}$ ' in terms of frequency (Equation 2.6.3) in Equation 2.6.1 and then dividing by ' $m$ ' the resultant expression is given by:

$$
\ddot{x}+\omega^{2} x=0
$$

Where

$\ddot{x}=$ acceleration

$\omega=$ angular frequency of the system

$x=$ displacement

And whose solution is given by

$$
x(t)=\left(\frac{v_{0}}{\omega}\right) \sin (\omega t)+\cos (\omega t)
$$

where ' $x$ ' is the deflection of the beam element.

At the instant of the impact box-rod, that is at $t=0$, the displacement of the mass is zero, then $\quad x_{o}=0$.

To obtain the velocity of the mass at the moment of the impact, it is necessary to obtain the velocity of the box after falling $1 \mathrm{~m}$. The kinetic energy (i.e. $\mathrm{mv}^{2} / 2$ ) of the box in the instant of the impact must be the same as the potential energy before it is released (i.e. wh).

That is

$$
\frac{1}{2} m v^{2}=w h
$$


where $m=\frac{w}{g}$

By isolating the velocity, it is obtained

$$
v^{2}=2 g h
$$

$\Rightarrow \quad v^{2}=2 g h=2 * 9.81 * 1=19.6 \mathrm{~m}^{2} / \mathrm{s}^{2}$

Then, the resultant velocity of the box at the moment of the impact is given by

$$
v=4.43 \mathrm{~m} / \mathrm{s}
$$

That is, $v_{o}$ is $4.43 \mathrm{~m} / \mathrm{s}$.

Thus, it is possible to obtain the deflection in the centre of the rod at any instant 't', after the impact.

Then, by substituting in Equation 2.6.8, it is obtained the maximum dynamic deflection of the rod:

$$
\begin{aligned}
& x(t)=\left(v_{0} / \omega\right) \sin (\omega t)+x_{0} \cos (\omega t)=(4.43 / 50) \sin (50 t)+0 \cos (50 t) \\
& \Rightarrow x(t)=0.0886 \sin (50 t)
\end{aligned}
$$

This can be seen graphically as the following Figure 2.6 .3 shows. 


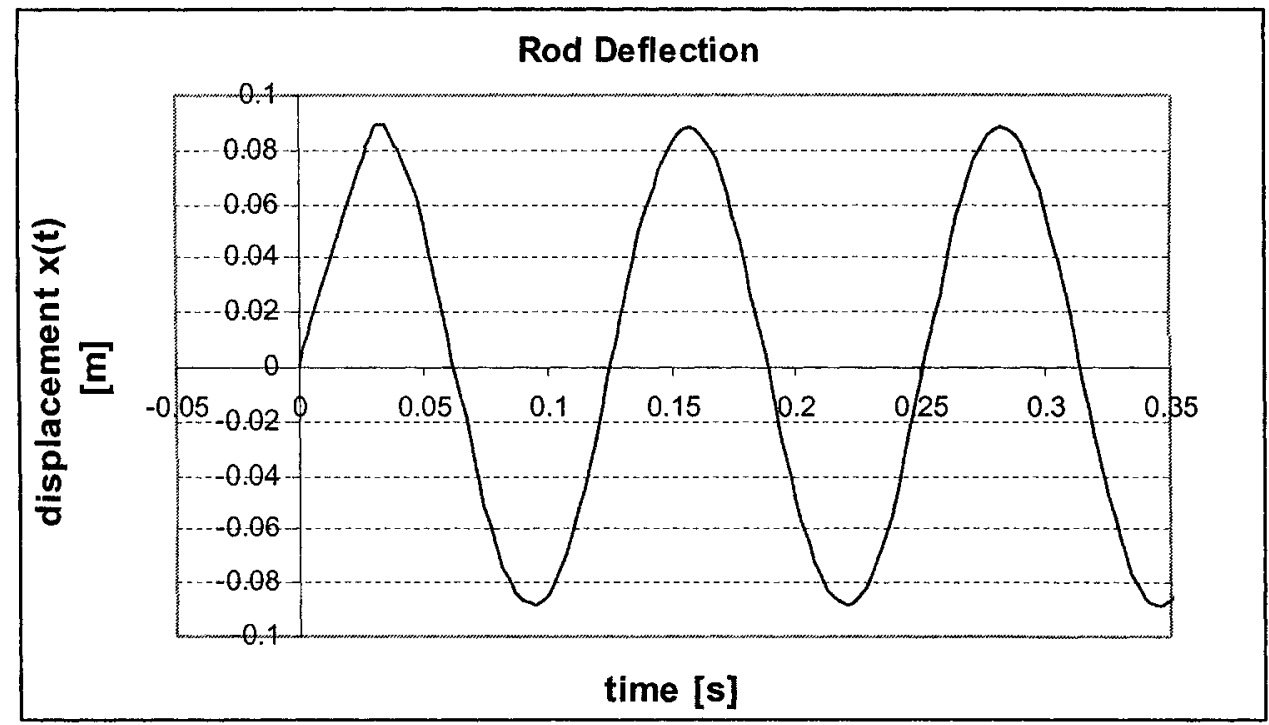

Figure 2.6.3 Dynamic response of the system mass-box during impact.

The maximum dynamic deflection produced on the centre of the bar is taking place at the instant

$50 \mathrm{t}=\pi / 2$

that is, when $t=\pi / 100=0.0314 \mathrm{~s}$ and this deflection is $0.0886 \mathrm{~m}$, that is:

$$
0.0886 \mathrm{k}=0.0886^{*} 2.5^{\star} 10^{6}=221500 \mathrm{~N}
$$

This force can be obtained through the calculation of the maximum acceleration and then by multiplying by the mass. The expression for the acceleration is obtained by deriving twice respect to the time the equation of the displacement previously obtained, that is

By taking , $x(t)=0.0886 \sin (50 t)$

And then deriving, the velocity is obtained

$\dot{x}(t)=0.0886 \omega \cos (\omega t)$

Eq. (2.6.12) 
And deriving again, the expression for the acceleration is given by

$$
\ddot{x}(t)=-0.0886 \omega^{2} \sin (\omega t)=-221.5 \sin (\omega t)
$$

The maximum acceleration is taking place at $\mathrm{t}=0.0314 \mathrm{~s}$, that is when the maximum displacement is occurring, and whose value is $-221.5 \mathrm{~m} / \mathrm{s}^{2}$. Thus, the maximum force is

$$
\begin{aligned}
& F=m a=(1000) \times(-221.5 \sin (50(0.0314))) \\
& F=221500 \mathrm{~N}
\end{aligned}
$$

Which is the same value as the one previously obtained.

It should be notice that a different value would be obtained if the box is placed directly on the rod (i.e. no distance falling), in such case the load on the rod would be

$1000 \mathrm{~kg} * 9.81 \mathrm{~m} / \mathrm{s}^{2}=9800 \mathrm{~N}$

and the maximum deflection produced on the rod

$$
\delta e=W / k=9800 / 2.5 * 10^{6}=0.004 \mathrm{~m}
$$

It can be seen from the previous basic example, the similarities between the system analyzed rod-box and the event of impact stick-puck during a slap shot, where the box could be the puck, and the stick could substitute by the rod. However, given the simultaneous non-constant forces existing during the event of the slap shot, predicting stick shaft deformation is not and easy task, which might be one of the reasons of the almost non existent research in impact bladepuck during slap shot. 
However, static studies have been done, based on a "beam" model, for instance Lessard et al. ( 1994) studied the linear deformation (i.e. static bending stiffness) and torsional deformation (i.e. torsional stiffness) based on the 'beam' cantilever configuration. 


\section{CHAPTER 3}

\section{MATERIALS AND METHODS}

\subsection{Ice Hockey Stick and Puck}

Hockey sticks of wood laminate shaft construction (Bauer Supreme 3030) with left and right handed blades were used in the experiment. The stick shaft dimensions were: length $1.35 \mathrm{~m}$, major axis length $0.02 \mathrm{~m}$, mass $0.6 \mathrm{~kg}$.

The puck physical parameters were: mass (accelerometer + puck) $0.260 \mathrm{~kg}$, diameter $7.62 \mathrm{~cm}$ ( 3 inches), thickness $2.54 \mathrm{~cm}$ ( 1 inch).

\subsection{Subjects}

Nine male subjects volunteered for this study and signed the consent forms. This research was approved by the Ethics Board of the Faculty of Education at McGill University (see attached ethics approval, Appendix A). Based on a review of each subject's background with regards to experience ice hockey and preliminary shot velocity tests (threshold $=100 \mathrm{~km} / \mathrm{h}$ ), four were classified as the elite group (mean mass: $181.4 \pm 8.7 \mathrm{~cm}$, mean weight: $85.2 \pm 7.5 \mathrm{~kg}$, mean age $31 \pm 13.3$ years) and the remaining five as the recreational group (mean height: $171.9 \pm 8$ $\mathrm{cm}$, mean mass: $74.5 \pm 9.5 \mathrm{~kg}$, mean age: $28.8 \pm 7.6$ years). Only two subjects from the elite group were right handed shooters, and the rest, including the recreational group, were left handed shooters.

\subsection{Testing Apparatus}

Data collection consisted of the simultaneous use of a high speed video recording (HSC Motion Scope RedLake Imaging, Model PCl 1000), and a 
piezoelectric triaxial accelerometer (Kistler Inst. Co., model 8792A500) linked to a coupler (Charge Amplifier Type 5134, Kistler Instrumentation Corp., Amherst, NY,USA) then to a data acquisition card (AT-MIO-16X PC DAQ board, National Instruments). Puck/stick contact time were recorded using the same DAQ by means of wrapping the blade of the hockey stick and the puck with a metal foil (Figure 3.3.2), thereby creating a $\pm 5 \vee$ contact circuit which allowed the synchronization of both systems (i.e. HSC and accelerometer).

\section{3.1. High Speed Video System}

A high-speed video system $(1000 \mathrm{~Hz})$ was used to record the stick movements. The camera was positioned $4 \mathrm{~m}$ laterally to the puck and $1.10 \mathrm{~m}$ vertically above the puck. The camera was oriented horizontally and perpendicular of the stick's main plane (sagittal) of motion. Eight adhesive reflective markers were placed along the shaft of the stick at $0.10 \mathrm{~m}$ intervals above $0.20 \mathrm{~m}$ from the heel blade. The blade of the stick was wrapped with a metal foil (Figure 3.3.2), in order to create a contact circuit similar to the method used by Roberts et al. (2001) . The markers locations were digitized using the Ariel Performance Analysis System TM (Ariel Dynamics, San Diego CA) and could be located to within 3mm per pixel (picture element) from the video recording of an $1.5 \mathrm{~m}$ by $1.5 \mathrm{~m}$ filed of view. Angle deflections, velocities and respective times of occurrence from the four distal segments $4,5,6$ and 7 (Figures $3.3 .3,3.5 .1$ ) were the three dependant variables obtained from this analysis. The total angle of deflection ( $\left.\theta_{\text {total }}\right)$ of simple bending observed in the camera's plane of view was calculated as the 
intercept angle between projection lines from segment $4\left(\theta_{5-6}\right)$ and segment 6 $(\theta 7-8)$ of the stick (Figure 3.3.3). The four segments were located below the bottom hand of the stick.

\subsubsection{Accelerometer}

A piezoelectric triaxial accelerometer (Model 8792A500, Kistler Instrum..Corp, Amherst, NY, USA) was used for obtaining puck accelerations for each trial. The main technical characteristics and dimensions are showed in the following table 3.3.1 and figure 3.3.1.

Table 3.3.1 Main characteristics of the triaxial accelerometer, Model 8792A500 (http://www:kistler.com)

\begin{tabular}{|c|c|c|c|c|}
\hline $\begin{array}{l}\text { Acceleration } \\
\text { range } \\
\text { [g] }\end{array}$ & $\begin{array}{l}\text { Acceleration } \\
\text { limit } \\
\text { [gpk] }\end{array}$ & $\begin{array}{l}\text { Thresold } \\
\text { [grms] }\end{array}$ & $\begin{array}{l}\text { Sensitivit] } \\
{[\mathrm{mV} / \mathrm{g}]}\end{array}$ & $\begin{array}{l}\text { Resonant } \\
\text { frequency } \\
{[\mathrm{kHz}]}\end{array}$ \\
\hline & \pm 1000 & 0.0 & 1 & 54 \\
\hline
\end{tabular}

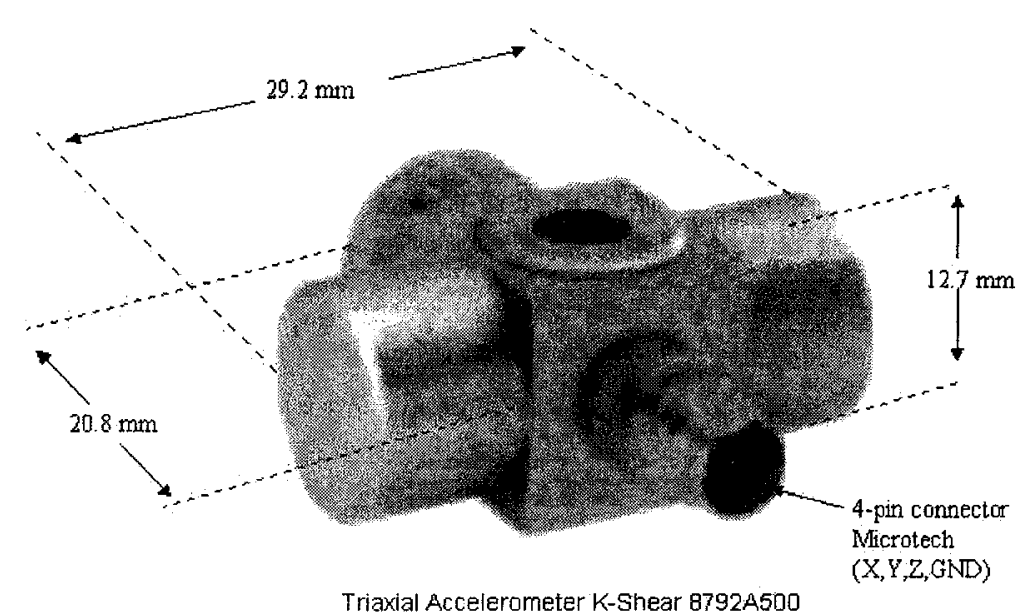

Figure 3.3.1 Piezoelectric triaxial accelerometer used in the study. (http://www.kistler.com)

As was mentioned before the signal output from the accelerometer is typically small voltage or charge and is proportional to the applied stimulus. 
Accelerometer sensitivity is the constant which defines the relationship between the input and output signal and is commonly provided in terms of $\mathrm{mV} / \mathrm{g}$ or $\mathrm{pC} / \mathrm{g}$. Low impedance sensors are typically chosen for maximum sensitivity within the expected input acceleration range. Thus, a calibration certificate with the exact value was provided by the manufacturer. Since the available full scale voltage is \pm 5 volts, the sensitivity can be determined by dividing the expected acceleration range into the full scale voltage. For example, a $\pm 50 \mathrm{~g}$ range indicates a sensitivity of $100 \mathrm{mV} / \mathrm{g}$. Regarding our model of accelerometer (Kistler Model $8792 \mathrm{~A} 500$ ), the sensitivity was $10 \mathrm{mV} / \mathrm{g}$.

An accelerometer's sensitivity is calibrated at a specific frequency (commonly $100 \mathrm{~Hz}$ ) and its deviation from this reference sensitivity is presented typically by stating its $5 \%$ or $10 \%$ deviations limits in terms of frequency.

The accelerometer was embedded in the center of a modified puck (i.e. core drilled out). This puck was further wrapped with metal adhesive foil to create the contact circuit linked by a $10 \mathrm{~m}$ cable (i.e. through the $\pm 5 \mathrm{v}$ signal given by the HSC data-output) to a similar metal foil on the blade (Figure 3.3.2). In addition, the accelerometer was attached to a cable leading to an amplifier (Charge Amplifier Type 5134, Kistler Instrum. Corp., Amherst, NY, USA) and to a PC DAQ board (AT-MIO-16X,National Instruments) and the signals were recorded at $10 \mathrm{KHz}$ using LabView 6.1 software in a PC Pentium III(IBM,128 MB Ram, Windows 98, Second Edition). In summary the experimental set up is shown in Figure 3.3.3. 

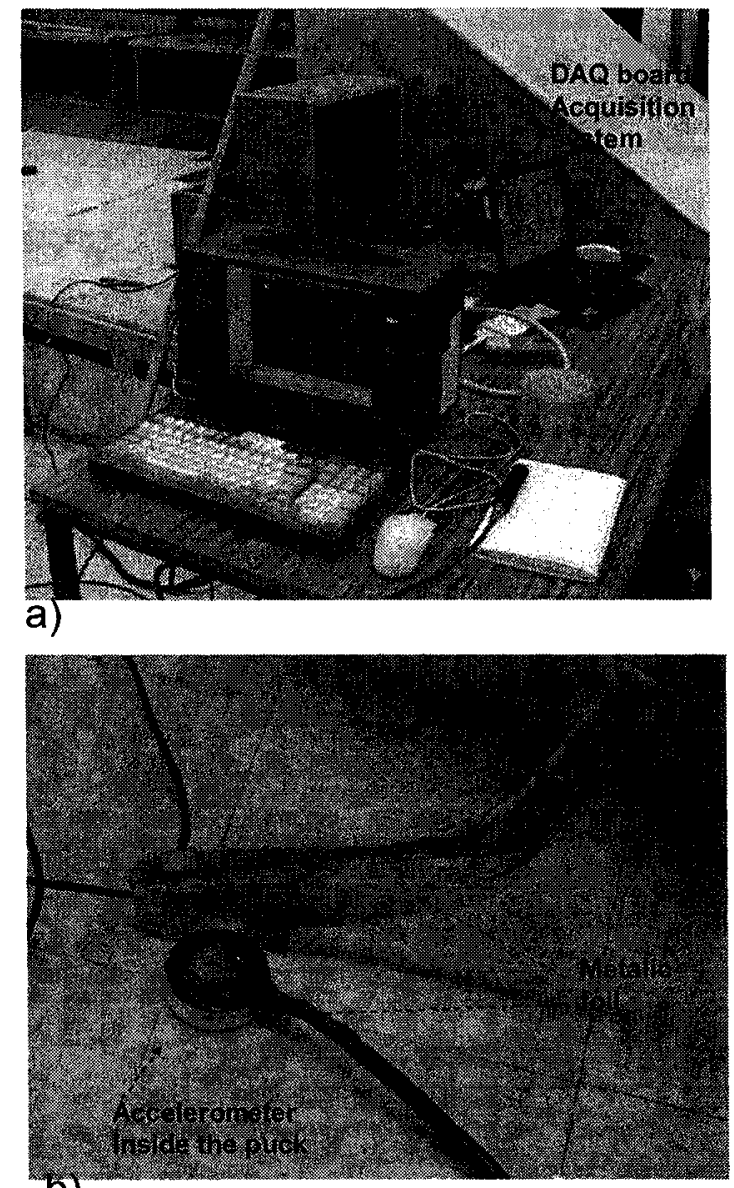

b)

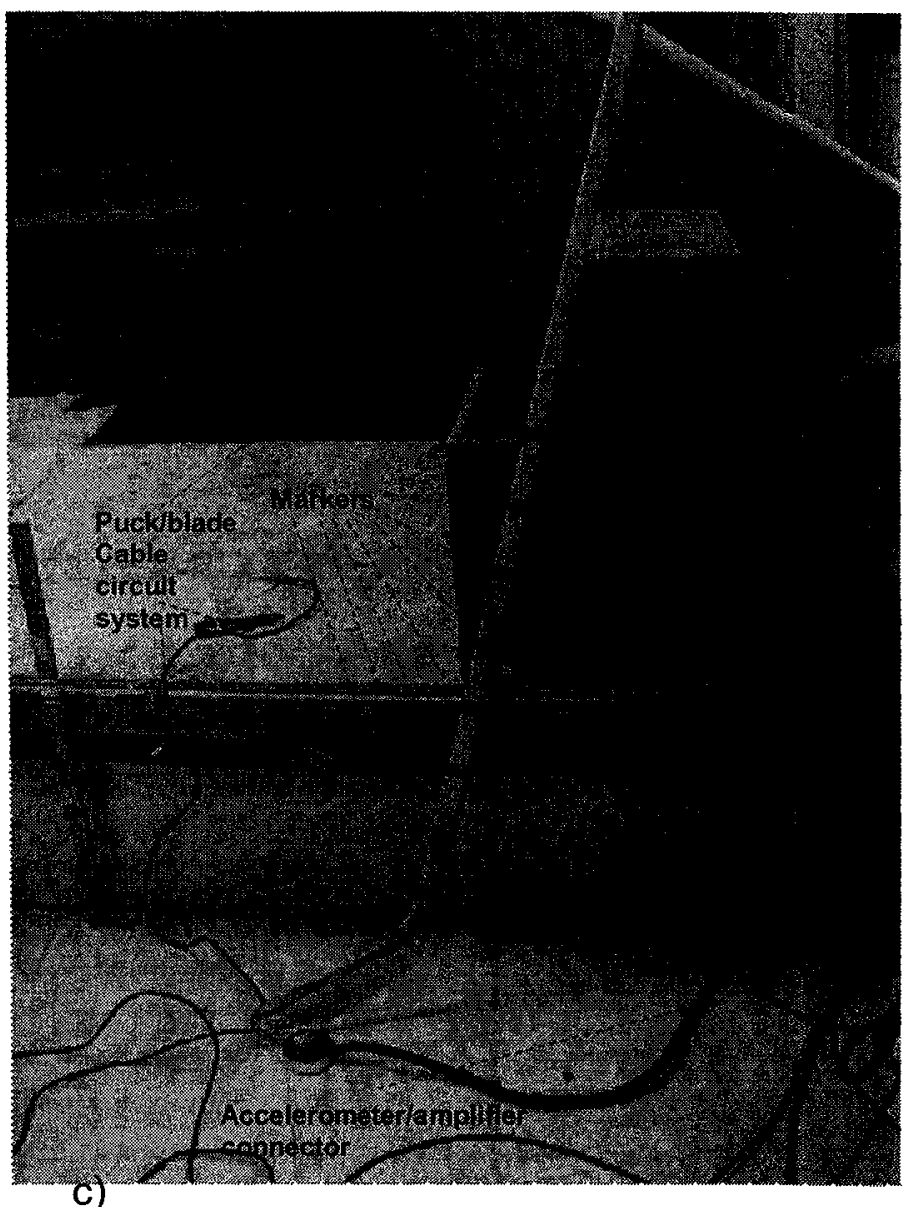

Figure 3.3.2 Computer and cable systems for HSC (a) and accelerometer inside the puck (b). Also, markers on the stick (c) and on the top of the puck (b) are shown. 


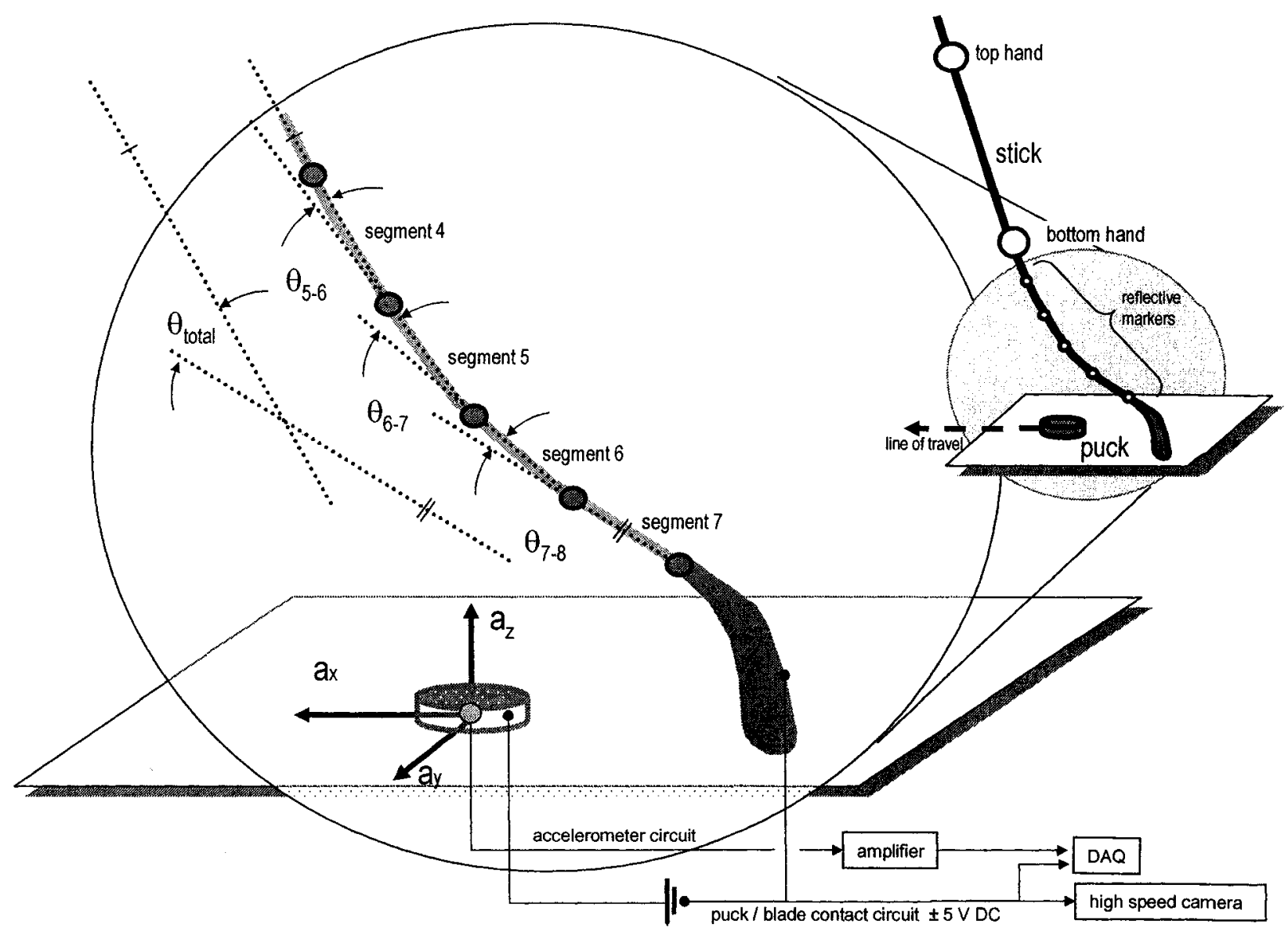

Figure 3.3.3 Set up of the experiment. Stick angle deflections $\left(\theta_{5-6}, \theta_{6-7}, \theta_{7-8}, \theta_{\text {total }}\right)$, accelerometer's axis and complete computer systems. 


\subsection{Testing Protocol}

The subjects wore ice hockey gloves and stood on a $3 \mathrm{~m}$ square piece of 0.004 $\mathrm{m}$ thick polyethylene (artificial ice) to execute the slap shots. Subjects performed a minimum of three practice trials. Each subject took from eight to ten slap shots. A minimum of $60 \mathrm{~s}$ occurred between each trial. A shot was considered a good trial if:

1) The puck went into the target area $(0.60 \mathrm{~m} \times 0.60 \mathrm{~m})$ approximately $3.3 \mathrm{~m}$ from shoot to goal,

2) The puck/blade contact circuit was working properly,

3) The puck acceleration was successfully captured, and

4) The subject was satisfied that the trial was a maximal effort.

\section{5 Data Analysis}

\subsubsection{Stick kinematics}

Once that the digitizing process with the Arial Performance Analysis System ${ }^{\mathrm{TM}}$ (Ariel Dynamics, San Diego CA) was complete (i.e. extraction of the $x, y$ coordinate positions of stick markers), the stick kinematic data were organized in Microsoft $®$ Excel 2002 spreadsheets in order to identify parameters from joint angles and joint angular velocities with respect to time. Basically, the event (i.e. slap shot) was divided into different sequences (i.e. $t_{1}, t_{2}, t_{3}, t_{4}, t_{5}$ and $t_{6}$ ) according with the time events defined (Figure 3.5.1). The base of such times 
(i.e. initial/final and total contact) were given by the puck/blade contact circuit recorded by the PC DAQ board (AT-MIO-16X, National Instruments).

The initial and final puck/blade contact times were defined as $t_{1}$ and $t_{6}$, respectively. As it is shown in Figure 3.5.1, the complete time interval (i.e. Time $\mathrm{A}=\mathrm{t}_{6}-\mathrm{t}_{1}$ ) and the total time puck contact (i.e. Time $\mathrm{B}=\sum \Delta t$, where puck acceleration $>10 \mathrm{~g}$ 's) were synchronized with the stick joint angles and stick joint angular velocities.

Two main phases were observed: stick bend and stick recoil. Times $t_{2}$ and $t_{3}$ were defined as the points in time where maximum stick bending (i.e. $\max \theta_{\mathrm{A}}$ ) and maximum stick angular velocity (i.e. $\max \omega_{\mathrm{A}}$ ) occurred inside the contact time window $(A)$ during the slap shot, respectively. On the other hand, times $t_{4}$ and $t_{5}$ were defined as the points in time where maximum stick recoil (i.e. $\min \theta_{\mathrm{A}}$ ) and minimum stick angular velocity (i.e. min $\omega_{\mathrm{A}}$ ) were taking place inside the contact time window $(A)$ during the event, respectively. 
a) Puck acceleration and contact time

b) Stick joint angles

c) Stick joint angular velocities

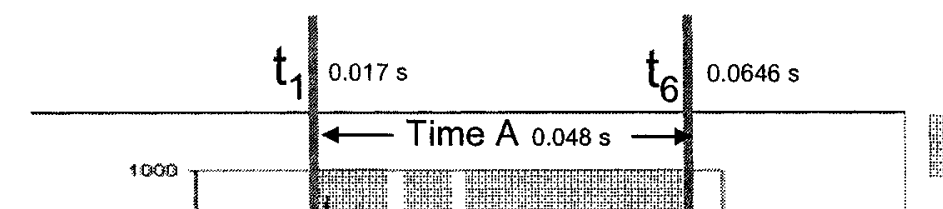
4148 mon 
The following Figures 3.5.2 - .4 show and example of the different phases of the slap shot based on the times $t_{1}$ through $t_{6}$ for the deflection angle between segments 6 and 7 (Figure 3.3.3) of one elite subject's trial. Such time events were calculated considering $\mathrm{t}_{1}$ as the temporal reference point, which was given by the contact circuit puck/blade for the initial contact. Also, the figures show on the top left corner of each image a black or white box, indicating that the contact circuit was "on" (puck contact) and "off" (no puck contact), respectively.
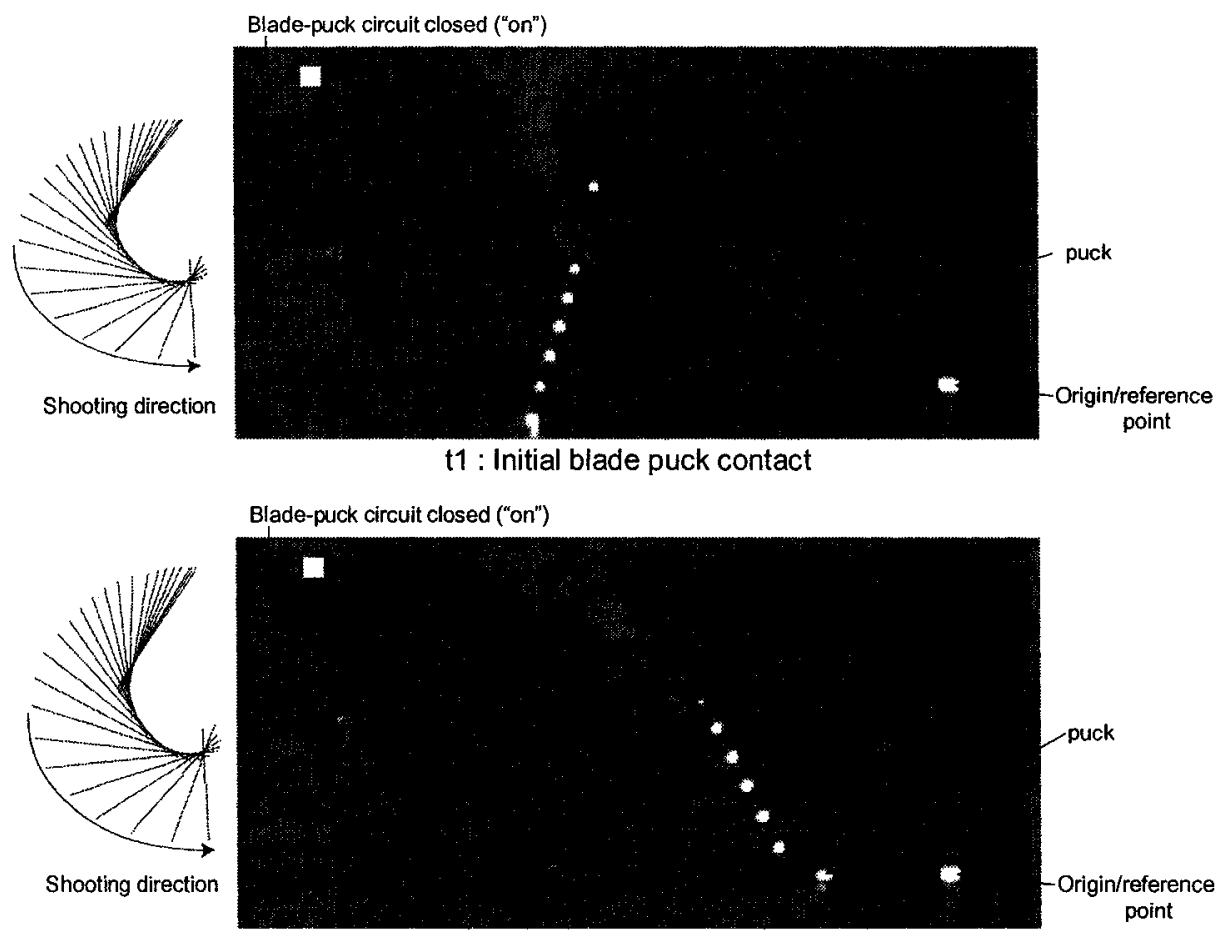

t6 : Final blade puck contact

Figure 3.5.2 Initial ( $\mathrm{t} 1$ ) and final (t6) puck contact of the slap shot. It is shown in the top left corner that the puck/blade circuit was "on". Images were collected at 1000 frames/second. 


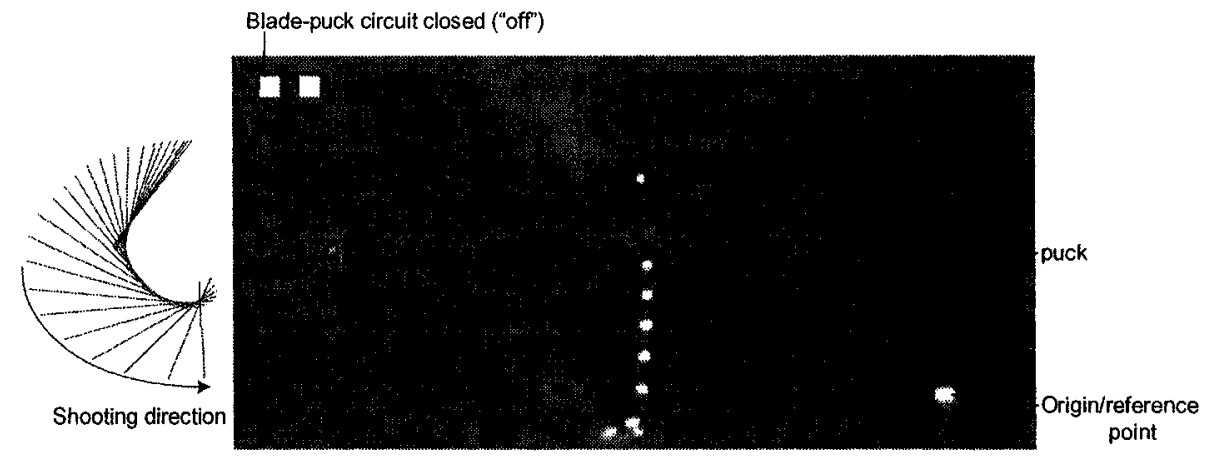

t2: Maximum stcik bending $\left(\max \theta_{A}\right)$

Blade-puck circuit closed ("off")
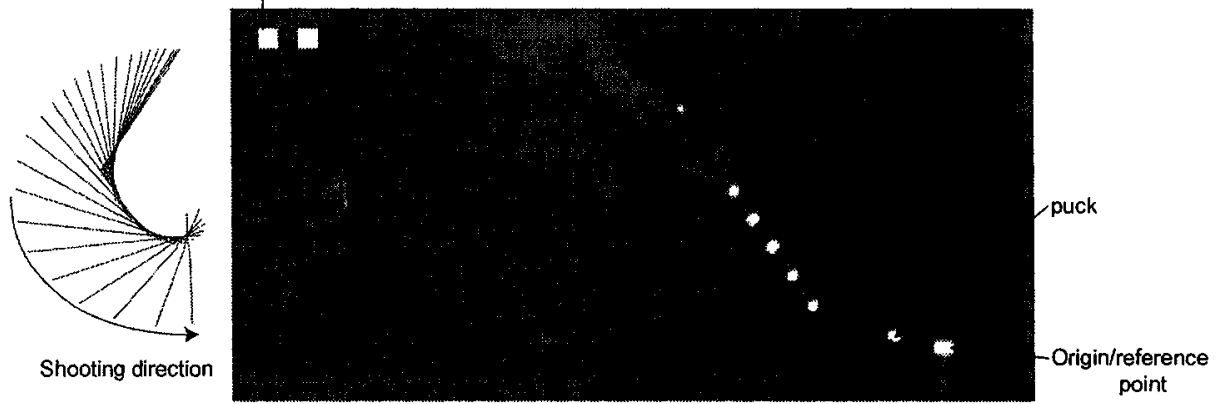

t4: Maximum stcik recoil $\left(\min \theta_{A}\right)$

Figure 3.5.3 Maximum bend (t2) and maximum recoil (t4) of the slap shot.

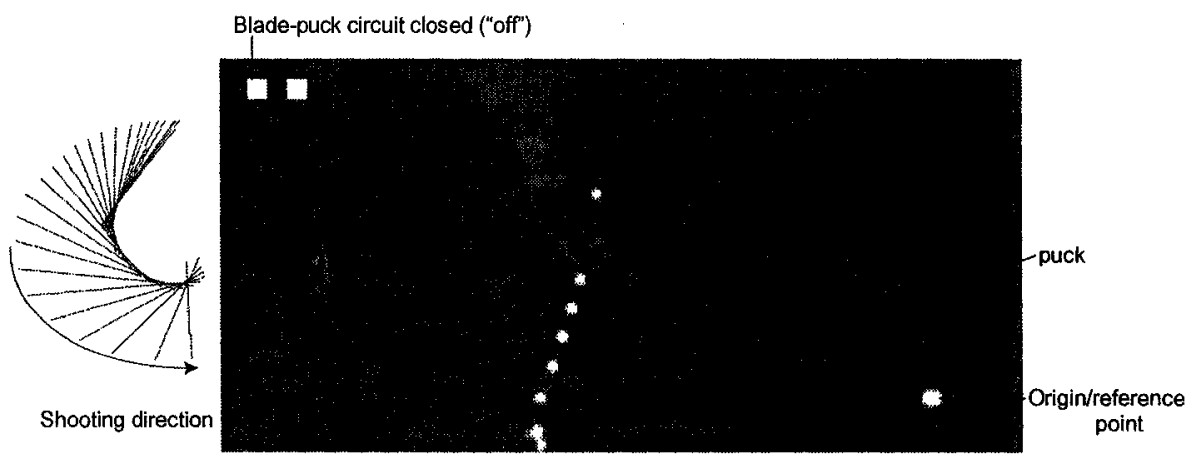

t3: Maximum Stick angular velocity $\left(\max \omega_{\mathrm{A}}\right)$

Blade-puck circuit closed ("off")

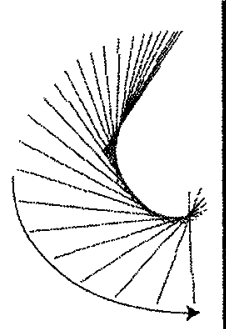

Shooting direction

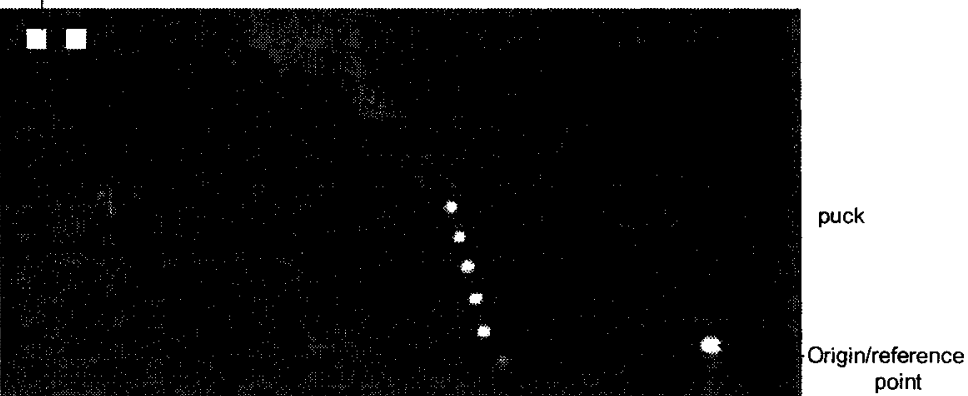

t5: Minimum Stick angular velocity ( $\left.\min \omega_{A}\right)$

Figure 3.5.4 Maximum $\omega(\mathrm{t} 3)$ and minimum $\omega(\mathrm{t} 5)$ of the slap shot. 


\subsubsection{Acceleration Data Processing}

The puck acceleration and the puck/blade time contact (Figure 3.5.1) were captured by the high speed DAQ board (10 Khz, AT-MIO-16X, National Instruments) in a binary format and then converted to a "txt" format by using a LabView 6.1 software module. A post analysis with Microsoft $®$ Excel software (2002) was done. This analysis included the integration in time of the acceleration data via the trapezoidal rule (Leithold,1981) in order to obtain the velocity-time history (Irvine, 2004) . A velocity-time pattern of the integration data of one elite subject's trial is shown in Figure 3.5.5. Peak puck velocity was identified as the maximum velocity achieved from this integrated data accelerometer.

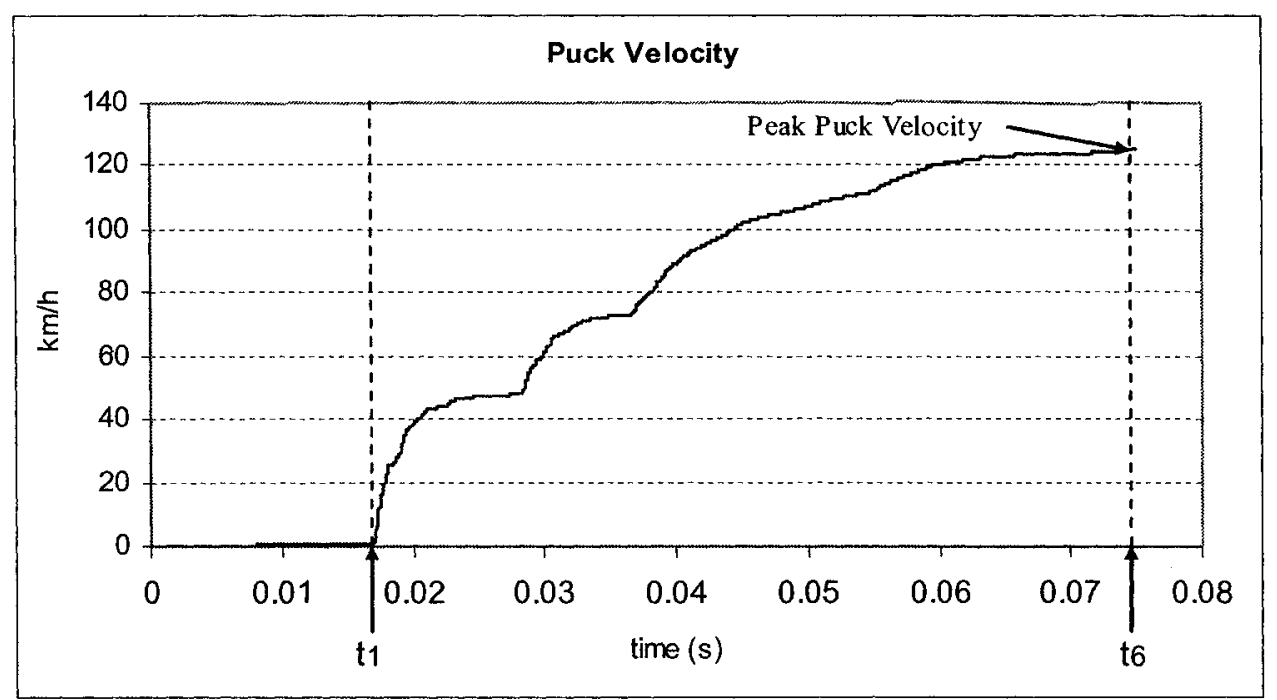

Figure 3.5.5 Graphic example of the acceleration data integration (i.e. puck velocity). 


\subsubsection{Stick and Puck Energies}

The maximum and average kinetic energy of the stick shaft during the swing of the slap shot were calculated. Given that the slap shot consists of both rotational and translational movements (Woo, 2004) as it is shown in figure 3.5.6, and considering the assumptions of classical Newtonian mechanics, an approximation of the stick swing energy was defined by

$$
E_{\text {stick-swing }}=E_{\text {stick-translational }}+E_{\text {stick-rotational }}
$$

where

$$
E_{\text {stick-translational }}=E_{s-t}=\frac{1}{2} m_{s} v_{t}^{2}
$$

was the energy due to translational movement, and

$$
E_{\text {stick-rotational }}=E_{s-r}=\frac{1}{2} I \omega_{s}^{2}
$$

was the energy due to rotational movement.

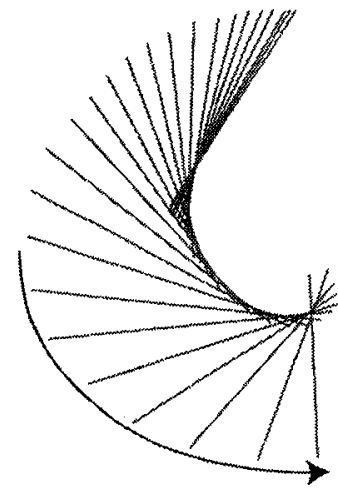

Estick-swing

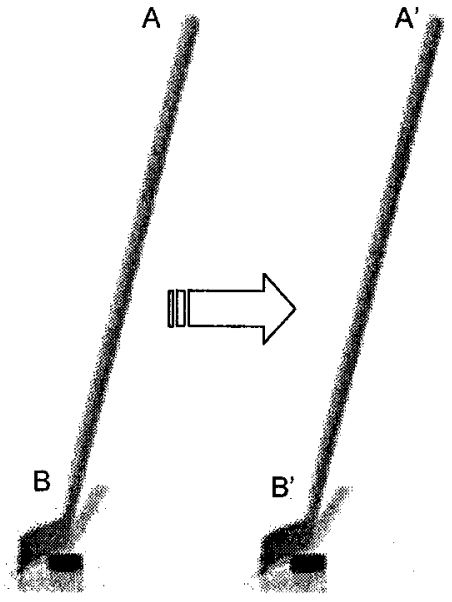

Estick-translationa $V_{t}$

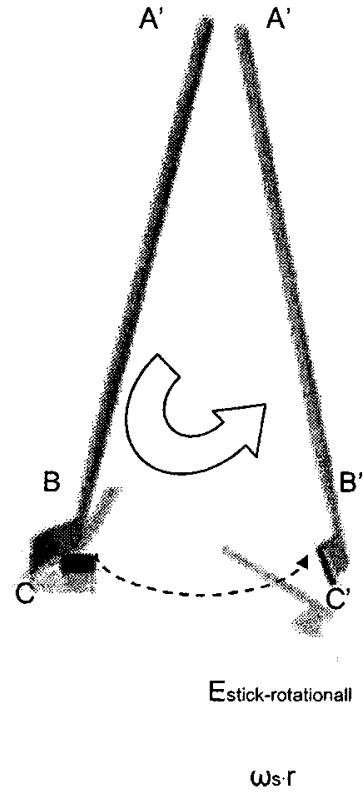

Ws.r

Figure 3.5.6 Deconstruction of the swing slap shot in terms of kinetic energy and velocities, i.e. translational velocity $\left(v_{t}\right)$, angular velocity $\left(\omega_{s}\right)$ and total length of the stick shaft $(r)$. 
Hence, stick swing energy was

$$
\begin{aligned}
& E_{\text {stick-swing }}=E_{s-s}=E_{s-t}+E_{s-r} \\
& \Rightarrow \quad E_{s-s}=\frac{1}{2} m_{s} v_{t}^{2}+\frac{1}{2} I \omega_{s}^{2} \quad \text { Eq. (3.5.3) }
\end{aligned}
$$

where $m_{s}=$ mass of the stick shaft (i.e. $0.600 \mathrm{~kg}$ ),

$v_{t}=$ translational velocity of the stick shaft,

$I=$ moment of inertia of the stick shaft, and

$\omega_{s}=$ angular velocity of the stick shaft (i.e. average angular velocity of segments $4,5,6$ and 7 )

Considering the rotational movement as predominant in the slap shot (Woo, 2004) and the translational movement contribution, the tangential resultant speed (i.e. linear velocity of distal segment 7 ) of the stick shaft was defined by

$$
V_{\text {stick-result. }}=\omega_{s} r+v_{t} \quad \text { Eq. (3.5.4) }
$$

where

$$
\begin{aligned}
& r=\text { total stick shaft length (i.e. } 1.35 \mathrm{~m} \text { ), and } \\
& v_{t}=\text { translational velocity of the stick shaft }
\end{aligned}
$$

solving for $v_{t}$

$$
\Rightarrow v_{t}=V_{\text {stick-result. }}-\omega_{s} r \quad \text { Eq. (3.5.5) }
$$

Then by substituting equation (3.5.5) in equation (3.5.1) the stick kinetic energy due to translational movement was obtained for the time history of each event. Furthermore, for obtaining the kinetic rotational energy given by equation (3.5.2), the mass of the stick shaft was considered to be distributed uniformly, with the 
axis of rotation perpendicular to the plane of view through the center of mass, in order to obtain the moment of inertia given by

$$
I_{c m}=\frac{1}{12} M\left(a^{2}+b^{2}\right) \quad \text { Eq. (3.5.6) }
$$

where

$M=$ mass of the stick shaft

$a=$ distance of the stick major axis

$b=$ total stick shaft length

The above equation approximates the shaft's shape as a uniform rectangular body.

However, considering that the axis of rotation was not necessarily situated at the center of mass but, instead, at the top hand (i.e. first marker on top of the shaft) as observed by Woo (2004), the parallel axis theorem was used for obtaining the moment of inertia of the stick shaft:

$$
I=I_{I I}=I_{c m}+M D^{2} \quad \text { Eq. (3.5.7) }
$$

where $D=$ distance between the two axis of rotation points at the center of mass $(\mathrm{cm})$ and the parallel center of rotation.

By substituting equation (3.5.6) into equation (3.5.7) the moment of inertia of the stick shaft was obtained. Therefore, knowing the angular velocity of the lower stick shaft (i.e. average angular velocity of segments $4,5,6$ and 7 ) given by the previous kinematic analysis, the elements required for the calculation of the stick swing energy were completed. The following Figure 3.5.6 shows the stick shaft's geometric parameters and mass considered for this analysis. 


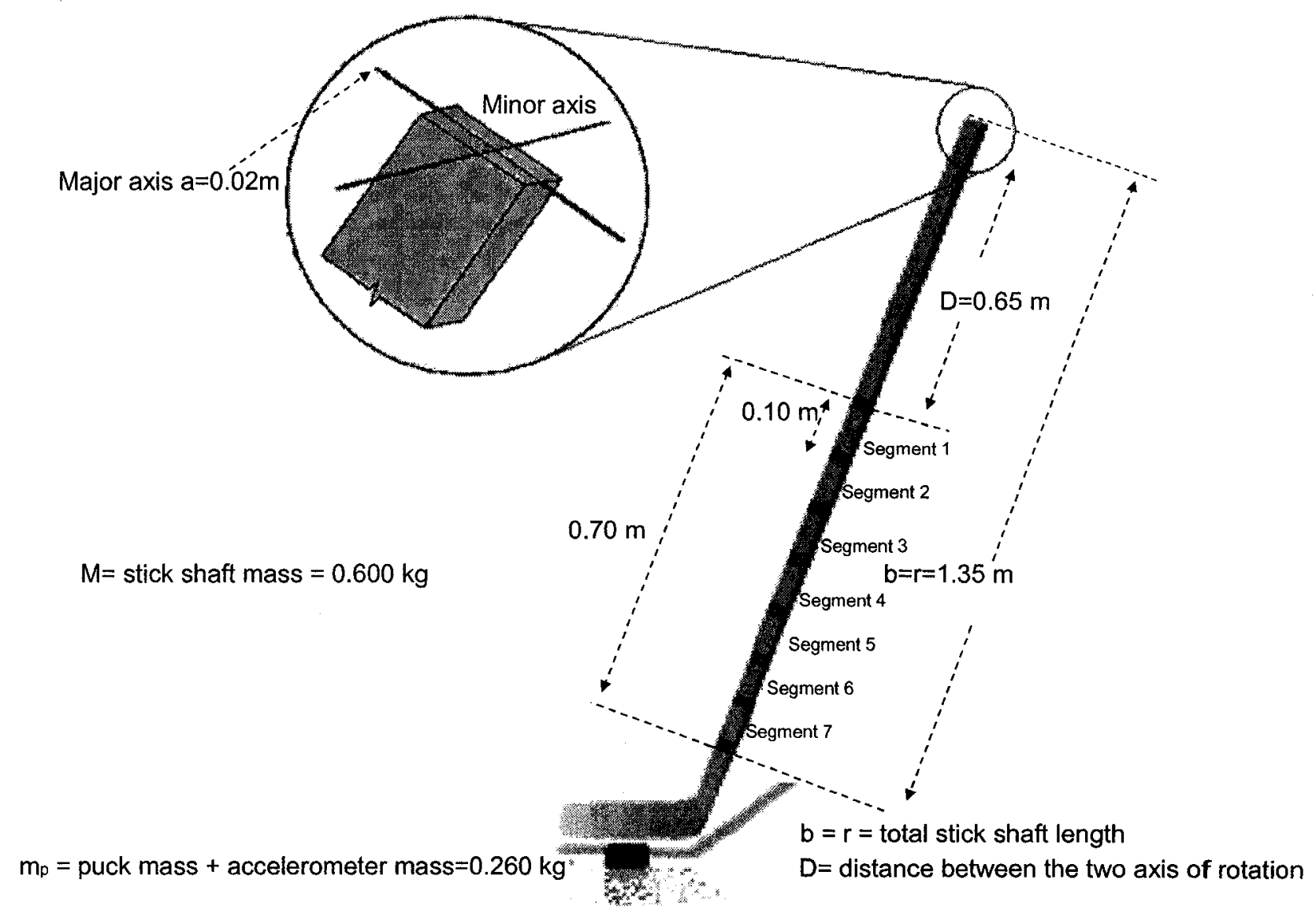

Figure 3.5.7 Stick shaft dimensions, showing major and minor axis (adapted from Pearsall et al, 1999).

Finally, the stick bend energy was estimated by assuming a linear elastic deformation behaviour defined as

$E_{\text {stick-bend }}=\frac{1}{2} K d^{2} \quad$ Eq. (3.5.8)

where $K=$ stick stiffness

$d=$ distance deflection of the stick shaft 
An average stick stiffness of $15,000 \mathrm{~N} / \mathrm{m}$ was assumed based on three point bend tests (Wu et al., 2003).

Taking into account a geometric deformation depicted by the stick during the slap shot, as Figure 3.5.7 shows, the linear distance deflection of the stick shaft was estimated.

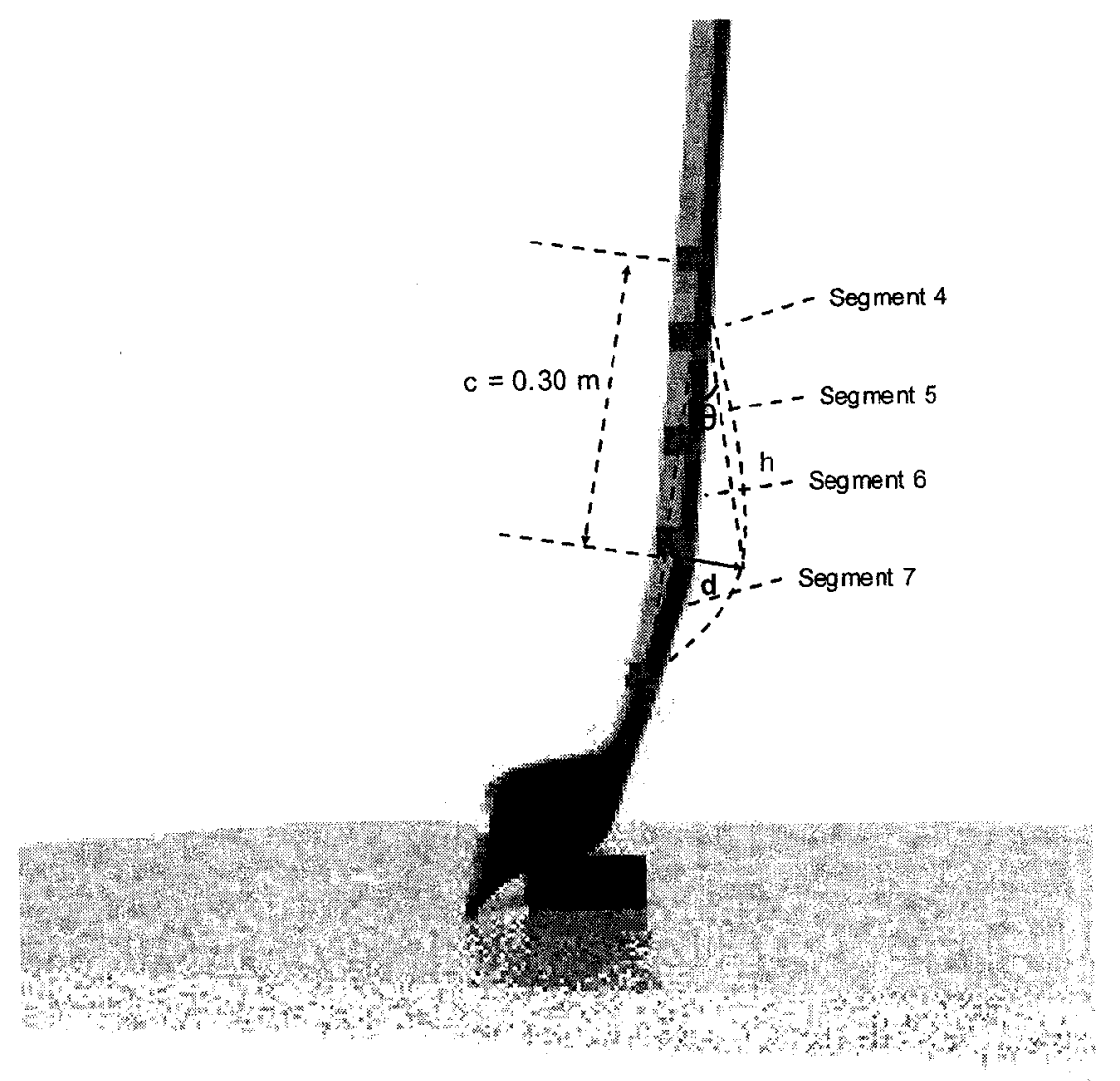

Figure 3.5.8 Deflection distance of stick shaft.

By considering the rectangle triangle described by the segments 4,5 and 6

(Figure 3.5.7) the relationships between angle and the sides were given by

$\operatorname{Sin} \theta=\frac{d}{h} \quad$ Eq. (3.5.9) and $\quad \operatorname{Cos} \theta=\frac{c}{h} \quad$ Eq. (3.5.10)

where 


$$
\begin{aligned}
& h=\text { hypotenuse } \\
& d=\text { deflection distance } \\
& c=\text { length (segment } 5+\text { segment } 6+\text { segment } 7 \text { ) } \\
& \theta=\text { maximum angle deflection (i.e. } \theta_{5-6}+\theta 6-7+\theta \text { 7-8) }
\end{aligned}
$$

Solving for $h$ for equations (3.5.9) and (3.5.10) we obtained

$$
h=\frac{c}{\operatorname{Cos} \theta} \quad \text { and } \quad h=\frac{d}{\operatorname{Sin} \theta}
$$

By equating $h$

$$
h=h \quad \Rightarrow \quad \frac{d}{\operatorname{Sin} \theta}=\frac{c}{\operatorname{Cos} \theta} \quad \Rightarrow \quad d=c \times \frac{\operatorname{Sin} \theta}{\operatorname{Cos} \theta}
$$

thus, $d=c \times \operatorname{Tan} 6 \quad$ Eq. (3.5.11)

where $\quad G=$ maximum angle deflection ( $\theta_{\text {total }}$ obtained by previous kinematic analysis (section 3.3.1)

Therefore, by substituting equation (3.5.11) on (3.5.8) and considering the $K=15,000 \mathrm{~N} / \mathrm{m}$, the stick bending energy during the slap shot was calculated.

Regarding the kinetic energy of the puck, it was given by

$$
E_{\text {puck }}=\frac{1}{2} m_{p} v_{p}^{2} \quad \text { Eq. (3.5.12) }
$$

where $v_{p}=$ velocity of the puck ( section 3.5 .2 )

$$
m_{p}=\text { mass of the puck (including mass of the accelerometer, section 3.1) }
$$




\subsubsection{Statistical Analysis}

The independent variable (factor) for this study was the skill level (i.e. elite and recreational) of ice hockey players.

The dependant variables related with the puck included: peak puck velocity, average puck acceleration, blade/puck contact time, puck energy

The dependant variables related with the stick included: stick distance deflection, angle deflection, angular velocity and times inside the blade/puck contact time window as well as in the total event. Stick energies were also included such as rotational, translational and bending energies.

Statistical Analysis performing one way ANOVA and Multiple Regression (Correlation Matrices and Linear Regression) was done by using Systat $₫ 8.0$ (SPSS Inc. 2000) statistical software.

A summary of the variables noted above is presented in the following table 3.5.1. 
Table 3.5.1 Summary of variables investigated

\begin{tabular}{|c|c|c|}
\hline Variable & Abbreviation & Description \\
\hline \multicolumn{3}{|l|}{ IV: } \\
\hline Skill (2 levels) & $\begin{array}{l}\text { Elite, } \\
\text { Rec }\end{array}$ & $\begin{array}{l}\text { Elite players, } \\
\text { Recreational players }\end{array}$ \\
\hline \multicolumn{3}{|l|}{ DV: } \\
\hline Time Window A & $\mathrm{T}_{\mathrm{A}}$ & Initial to final puck-blade contact. \\
\hline Total Contact Time & $\mathrm{T}_{\mathrm{B}}$ & Total puck-blade contact $\left(\mathrm{T}_{\mathrm{B}} \leq \mathrm{T}_{\mathrm{A}}\right)$ \\
\hline Percentage & $\mathrm{T}_{\mathrm{B} / \mathrm{T}_{\mathrm{A}}}$ & $\begin{array}{l}\text { Percentage contact time total in contact } \\
\text { time window A. }\end{array}$ \\
\hline Average Acceleration & Accel & Puck average acceleration \\
\hline Final Puck Velocity & $\begin{array}{l}\text { Vel_ms } \\
\text { (Vel_kmh) }\end{array}$ & $\begin{array}{l}\text { Peak puck velocity in } \mathrm{m} / \mathrm{s} \\
\text { (Peak puck velocity in } \mathrm{km} / \mathrm{h} \text { ) }\end{array}$ \\
\hline $\begin{array}{l}\text { Maximum segment joint angle } \\
\text { (within } T_{A} \text { ) }\end{array}$ & $\begin{array}{l}\max \theta_{56 \mathrm{~A}} \\
\max \theta_{67 \mathrm{~A}} \\
\max \theta_{78 \mathrm{~A}}\end{array}$ & $\begin{array}{l}\text { Stick Bend phase within } T_{A} \text { for } \\
\text { segments: } \\
4 \\
5 \\
6\end{array}$ \\
\hline $\begin{array}{l}\text { Minimum segment joint angle } \\
\text { (within } \mathrm{T}_{\mathrm{A}} \text { ) }\end{array}$ & $\begin{array}{l}\min \theta_{56 \mathrm{~A}} \\
\min \theta_{67 \mathrm{~A}} \\
\min \theta_{78 \mathrm{~A}}\end{array}$ & $\begin{array}{l}\text { Stick Recoil phase within } \mathrm{T}_{\mathrm{A}} \text { for } \\
\text { segments: } \\
4 \\
5 \\
6\end{array}$ \\
\hline $\begin{array}{l}\text { Maximum segment joint angle } \\
\text { (total event) }\end{array}$ & $\begin{array}{l}\max \theta_{56} \\
\max \theta_{67} \\
\max \theta_{78} \\
\max \theta\end{array}$ & $\begin{array}{l}\text { Stick Bend phase in total event for } \\
\text { segments: } \\
4 \\
5 \\
6 \\
\text { Maximum angle deflection observed in } \\
\text { segments } 4,5 \text { and } 6 \text { (i.e. } \max \theta_{56}+\max \\
\theta_{67+\max } \theta_{78} \text { ) }\end{array}$ \\
\hline $\begin{array}{l}\text { Minimum segment joint angle } \\
\text { (total event) }\end{array}$ & $\begin{array}{l}\min \theta_{56} \\
\min \theta_{67} \\
\min \theta_{78} \\
\min \theta\end{array}$ & $\begin{array}{l}\text { Minimum segment joint angle } \\
\text { in total event for segments: } \\
4 \\
5 \\
6 \\
\text { Minimum angle deflection observed in } \\
\text { segments } 4,5 \text { and } 6 \text { (i.e. min } \theta_{56}+ \\
\min \theta_{67}+\min \theta_{78} \text { ) }\end{array}$ \\
\hline
\end{tabular}

...continued 
Table 3.5.1 continued

\begin{tabular}{|c|c|c|}
\hline $\begin{array}{l}\text { Maximum segment joint angle } \\
\text { velocity } \\
\text { (within } \mathrm{T}_{\mathrm{A}} \text { ) }\end{array}$ & $\begin{array}{l}\max \omega_{56 \mathrm{~A}} \\
\max \omega_{67 \mathrm{~A}} \\
\max \omega_{78 \mathrm{~A}}\end{array}$ & $\begin{array}{l}\text { Stick joint angular velocity observed at } \\
\text { stick bend phase within } T_{A} \text {, in segments: } \\
4 \\
5 \\
6\end{array}$ \\
\hline $\begin{array}{l}\text { Minimum segment joint angle } \\
\text { velocity } \\
\text { (within } \mathrm{T}_{\mathrm{A}} \text { ) }\end{array}$ & $\begin{array}{l}\min \omega_{56 \mathrm{~A}} \\
\min \omega_{67 \mathrm{~A}} \\
\min \omega_{78 \mathrm{~A}}\end{array}$ & $\begin{array}{l}\text { Stick joint angular velocity observed at } \\
\text { stick recoil phase within } T_{A} \text {, in } \\
\text { segments: } \\
4 \\
5 \\
6\end{array}$ \\
\hline $\begin{array}{l}\text { Time to } \max \theta \\
\text { (within } T_{A} \text { ) }\end{array}$ & $\begin{array}{l}T_{\max } \theta 56 \mathrm{~A} \\
\mathrm{~T}_{\max } \theta 67 \mathrm{~A} \\
\mathrm{~T}_{\max } \theta 78 \mathrm{~A}\end{array}$ & $\begin{array}{l}\text { Time point for stick Bend phase within } \\
T_{A} \text { for segments: } \\
4 \\
5 \\
6\end{array}$ \\
\hline $\begin{array}{l}\text { Time to } \min \theta \\
\left(\text { within } T_{A} \text { ) }\right.\end{array}$ & $\begin{array}{l}T_{\min } \theta 56 \mathrm{~A} \\
\mathrm{~T}_{\min } \theta 67 \mathrm{~A} \\
\mathrm{~T}_{\min } \theta 78 \mathrm{~A} \\
\end{array}$ & $\begin{array}{l}\text { Time point for stick Recoil phase within } \\
T_{A} \text { for segments: } \\
4 \\
5 \\
6\end{array}$ \\
\hline $\begin{array}{l}\text { Time to } \max \theta \\
\text { (total event) }\end{array}$ & $\begin{array}{l}\mathrm{T}_{\max } \theta 56 \\
\mathrm{~T}_{\max } \theta 67 \\
\mathrm{~T}_{\max } \theta 78\end{array}$ & $\begin{array}{l}\text { Time point for stick Bend phase in total } \\
\text { event for segments: } \\
4 \\
5 \\
6\end{array}$ \\
\hline $\begin{array}{l}\text { Time to } \min \theta \\
\text { (total event) }\end{array}$ & $\begin{array}{l}\mathrm{T}_{\min } \theta 56 \\
\mathrm{~T}_{\min } \theta 67 \\
\mathrm{~T}_{\min } \theta 78\end{array}$ & $\begin{array}{l}\text { Time point for stick Recoil phase in } \\
\text { total event for segments: } \\
4 \\
5 \\
6\end{array}$ \\
\hline $\begin{array}{l}\text { Time to } \max \omega \\
\left(\text { within } T_{A} \text { ) }\right.\end{array}$ & $\begin{array}{l}\mathrm{T}_{\max \omega 56} \\
\mathrm{~T}_{\max \omega 67} \\
\mathrm{~T}_{\max \omega 78}\end{array}$ & $\begin{array}{l}\text { Time point for stick joint angular } \\
\text { velocity observed at stick bend phase } \\
\text { within } T_{A} \text {, in segments: } \\
4 \\
5 \\
6\end{array}$ \\
\hline
\end{tabular}

.continued 
Table 3.5.1 Continued

\begin{tabular}{|c|c|c|}
\hline $\begin{array}{l}\text { Time to } \min \omega \\
\left(\text { within } T_{A} \text { ) }\right.\end{array}$ & $\begin{array}{l}T_{\min \omega 56} \\
T_{\min \omega 67} \\
T_{\min \omega 78}\end{array}$ & $\begin{array}{l}\text { Time point for stick joint angular } \\
\text { velocity observed at stick recoil phase } \\
\text { within } T_{A} \text {, in segments: } \\
4 \\
5 \\
6\end{array}$ \\
\hline $\begin{array}{l}\text { Time to max total deflection } \theta \\
\text { (total event) }\end{array}$ & $\mathrm{T}_{\max } \theta$ & $\begin{array}{l}\text { Time point for maximum angle } \\
\text { deflection observed in segments } 4,5 \text { and } \\
6 \text { (i.e. } \max \theta_{56}+\max \theta_{67}+\max \theta_{78} \text { ) }\end{array}$ \\
\hline $\begin{array}{l}\text { Time to min total deflection } \theta \\
\text { (total event) }\end{array}$ & $\mathrm{T}_{\min \theta}$ & $\begin{array}{l}\text { Time point for minimum angle } \\
\text { deflection observed in segments } 4,5 \text { and } \\
6 \text { (i.e. } \min \theta_{56}+\min \theta_{67}+\min \theta_{78} \text { ) }\end{array}$ \\
\hline $\begin{array}{l}\text { Recoil Angle } \\
\text { (total event) }\end{array}$ & $\begin{array}{l}\operatorname{Reco} \theta_{56} \\
\operatorname{Reco} \theta_{67} \\
\operatorname{Reco} \theta_{78}\end{array}$ & $\begin{array}{l}\text { Difference between Stick Bend phase } \\
\text { and minimum segment joint angle } \\
\text { in total event for segments: } \\
4\left(\max \theta_{56}-\min \theta_{56}\right) \\
5\left(\max \theta_{67}-\min \theta_{67}\right) \\
6\left(\max \theta_{78}-\min \theta_{78}\right)\end{array}$ \\
\hline Maximum Deflection Distance & $\mathrm{d}$ & $\begin{array}{l}\text { Maximum stick distance deflection } \\
\text { based on maximum angle deflection } \\
\text { (i.e.max } \theta \text { ) }\end{array}$ \\
\hline $\begin{array}{l}\text { Average Stick Rotation } \\
\text { Energy } \\
\text { (total event) }\end{array}$ & $\mathrm{E}_{\text {av_rot }}$ & $\begin{array}{l}\text { Average of the stick rotational kinetic } \\
\text { energy }\end{array}$ \\
\hline $\begin{array}{l}\text { Average Stick Translation } \\
\text { Energy }\end{array}$ & $\mathrm{E}_{\text {av_tr }}$ & $\begin{array}{l}\text { Average of the stick translational kinetic } \\
\text { energy }\end{array}$ \\
\hline Average Total Stick Energy & $\mathrm{E}_{\text {av tot }}$ & Average of total stick kinetic energy \\
\hline $\begin{array}{l}\text { Maximum Stick Rotation } \\
\text { Energy }\end{array}$ & $E_{\text {max_rot }}$ & $\begin{array}{l}\text { Maximum stick rotational kinetic } \\
\text { energy }\end{array}$ \\
\hline $\begin{array}{l}\text { Maximum Stick Translation } \\
\text { Energy }\end{array}$ & $E_{\text {max_tr }}$ & $\begin{array}{l}\text { Minimum stick translational kinetic } \\
\text { energy }\end{array}$ \\
\hline Maximum Total Stick Energy & $\mathrm{E}_{\max \text { tot }}$ & Maximum total stick kinetic energy \\
\hline Maximum Bending Energy & $\mathrm{E}_{\mathrm{d}}$ & $\begin{array}{l}\text { Stick Elastic Potential Energy based on } \\
\text { maximum stick distance deflection (i.e. } \\
\text { d) }\end{array}$ \\
\hline Maximum Puck Energy & $E_{\text {puck }}$ & $\begin{array}{l}\text { Puck kinetic energy based on Final Puck } \\
\text { Velocity (i.e.Vel_ms) }\end{array}$ \\
\hline
\end{tabular}




\section{CHAPTER 4}

\section{RESULTS}

The results for the DV examined are presented. For the one way ANOVA and Multiple Regression (Correlation Matrices and Linear Regression) analysis, respectively.

\section{1 ANOVA of Accelerometer Measures}

\subsubsection{ANOVA of Puck Accelerations}

- Average Acceleration: Accel

No significant differences (NSD) between both groups $(p=0.86)$ were found on puck average accelerations (Table 4.1.1)

Table 4.1.1. Puck Average
accelerations (g's).
\begin{tabular}{|ccc|}
\hline \multicolumn{3}{|c}{ g's } \\
Elite & Mean & SD \\
Rec & 63.8 & 9.9 \\
\hline
\end{tabular}

\subsubsection{ANOVA of Puck Velocities}

- Final Puck Velocity $\mathrm{m} / \mathrm{s}(\mathrm{km} / \mathrm{h})$ : Vel

Significant differences in final puck velocity were observed $\left({ }^{*} \mathbf{p}<0.004\right)$. On average, the 'elite' group showed greater puck velocities than the 'rec' group, $120.8 \pm 18 \mathrm{~km} / \mathrm{h}$ and $80.3 \pm 11.6 \mathrm{~km} / \mathrm{h}$ respectively (Table 4.1.2). 
Table 4.1.2 Final puck velocities.

\begin{tabular}{|ccccc|}
\hline & $\mathrm{Km} / \mathrm{h}$ & \multicolumn{3}{c|}{$\mathrm{m} / \mathrm{s}$} \\
Elite & Mean & $\mathrm{SD}$ & Mean & $\mathrm{SD}$ \\
Rec & 120.8 & 18.0 & 33.5 & 5.0 \\
\hline
\end{tabular}

\subsubsection{ANOVA of Times}

- Initial to final Puck Contact: $\mathrm{T}_{\mathrm{A}}$

- Total Puck Contact: $T_{B}$

Puck-blade contact times were found with significant differences in the total puck contact time $\left(T_{B}\right)$ and with almost significant differences in the complete time window $\left(\mathrm{T}_{\mathrm{A}}\right)$, as Table 4.1.3 and Figure 4.1.1 show.

Table 4.1.3 Puck-blade contact times.

\begin{tabular}{|lcccc|}
\hline & $\mathrm{T}_{\mathrm{A}}{ }^{*}$ & & $\mathrm{~T}_{\mathrm{B}}{ }^{* \star}$ & \\
& Mean & $\mathrm{SD}$ & Mean & $\mathrm{SD}$ \\
Elite & 0.044 & 0.009 & 0.038 & 0.009 \\
Rec & 0.033 & 0.006 & 0.027 & 0.005 \\
\hline
\end{tabular}

$$
{ }^{*} \mathbf{p}<0.06 * * \mathbf{p}<0.04
$$

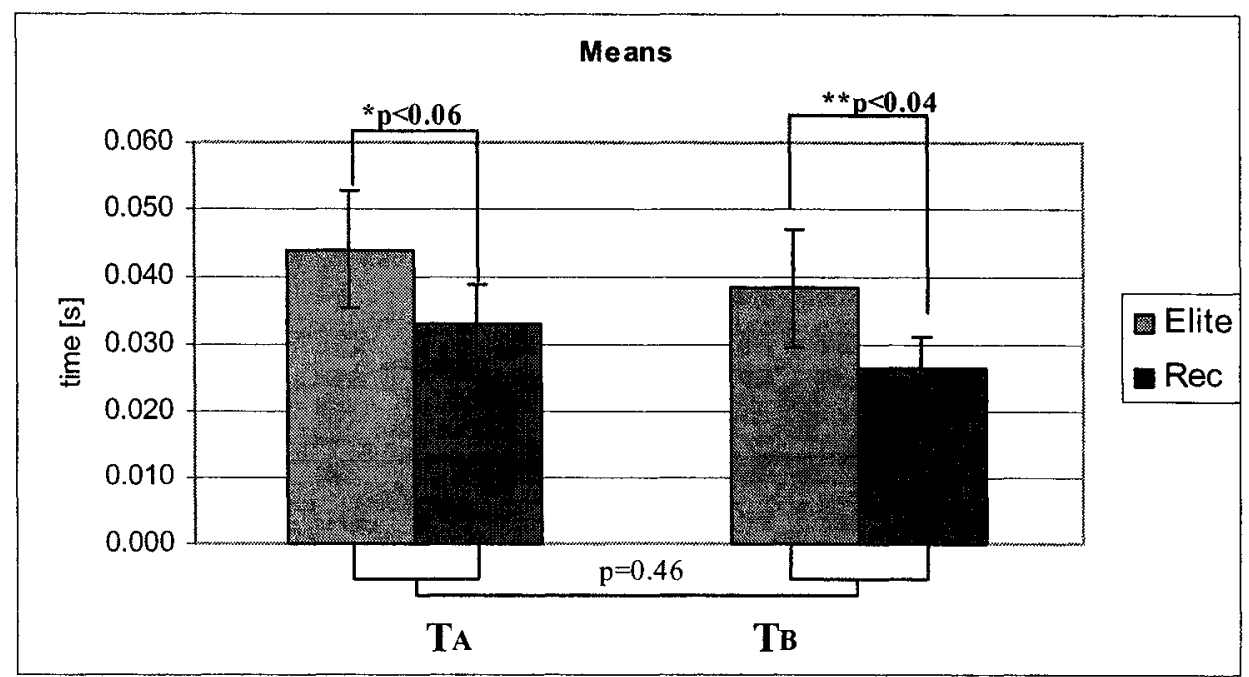

Figure 4.1.1 Puck-blade contact times $T_{A}$ and $T_{B}$. 
- Percentage total puck contact in contact time window $A: T_{B} / T_{A}$

NSD were found $(p=0.46)$ for the percentage of contact times $\left(T_{B} / T_{A}\right)$. Means of such percentage are shown in Table 4.1.4

Table 4.1.4 Percentage puckblade contact times.

\begin{tabular}{|ccc|}
\hline & $\mathrm{T}_{\mathrm{B}} / \mathrm{T}_{\mathrm{A}}$ & \\
& Mean & $\mathrm{SD}$ \\
Elite & 86.6 & 5.1 \\
Rec & 80.9 & 13.9 \\
\hline
\end{tabular}

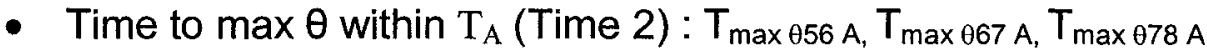

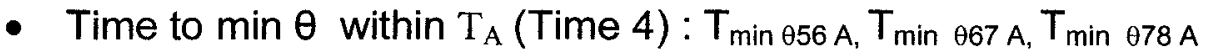

NSD were found in the time points for stick bend phase (Time 2) within $T_{A}$ for the segments analyzed, as it is shown in Table 4.1.5 and Figure 4.1.2. In contrast time points for stick recoil phase (Time 4) were found to be significantly different between groups (Table 4.1.6 and Figure 4.1.3).

Table 4.1.5 Time points for stick bend phase within $\mathrm{T}_{\mathrm{A}}$

\begin{tabular}{|c|c|c|c|c|c|c|}
\hline \multicolumn{7}{|c|}{$\begin{array}{l}\text { Summary Table of Means (tabstat5.sta) } \\
N=9 \text { (No missing data in dep. var. list) }\end{array}$} \\
\hline & $\begin{array}{c}T_{\max \theta 56 \mathrm{~A}} \\
\text { Mean }\end{array}$ & $\mathrm{T}_{\max \theta 56 \mathrm{~A}}$ & $\begin{array}{c}T_{\max \theta 67 A} \\
\text { Mean }\end{array}$ & $\begin{array}{c}T_{\max \theta 67 A} \\
S D\end{array}$ & $\begin{array}{r}T_{\max \theta 78 A} \\
\text { Mean }\end{array}$ & $\begin{array}{c}T_{\max \theta 78 \mathrm{~A}} \\
\mathrm{SD}\end{array}$ \\
\hline G_1:1 (Elite) & 0.011 & 0.014 & 0.011 & 0.007 & 0.016 & 0.011 \\
\hline $\mathrm{G} \_2: 2(\operatorname{Rec})$ & 0.021 & 0.011 & 0.022 & 0.010 & 0.021 & 0.011 \\
\hline & $p=0.278$ & & $p=0.084$ & & $p=0.566$ & \\
\hline
\end{tabular}

Table 4.1.6 Time points for stick recoil phase within $T_{A}$.

\begin{tabular}{|c|c|c|c|c|c|c|}
\hline \multicolumn{7}{|c|}{$\begin{array}{l}\text { Summary Table of Means (tabstat5.sta) } \\
\mathrm{N}=9 \text { (No missing data in dep. var. list) }\end{array}$} \\
\hline & $\begin{array}{c}\mathrm{T}_{\min } \theta 56 \mathrm{~A} \\
\text { Mean }\end{array}$ & $\begin{array}{c}T_{\min \theta 56 \mathrm{~A}} \\
\mathrm{SD}\end{array}$ & $\begin{array}{r}T_{\min } \theta 67 \mathrm{~A} \\
\text { Mean }\end{array}$ & $\begin{array}{c}\mathrm{T}_{\min } \theta 67 \mathrm{~A} \\
\mathrm{SD}\end{array}$ & $\begin{array}{r}\mathrm{T}_{\min } \theta 78 \mathrm{~A} \\
\text { Mean }\end{array}$ & $\begin{array}{c}T_{\min \theta 78 A} \\
S D\end{array}$ \\
\hline G_1:1 (Elite) & 0.046 & 0.013 & 0.036 & 0.010 & 0.035 & 0.013 \\
\hline G $2: 2(\operatorname{Rec})$ & 0.013 & 0.008 & 0.014 & 0.006 & 0.017 & 0.007 \\
\hline \multicolumn{3}{|c|}{$p=0.002$} & $p=0.006$ & & $p=0.032$ & \\
\hline
\end{tabular}




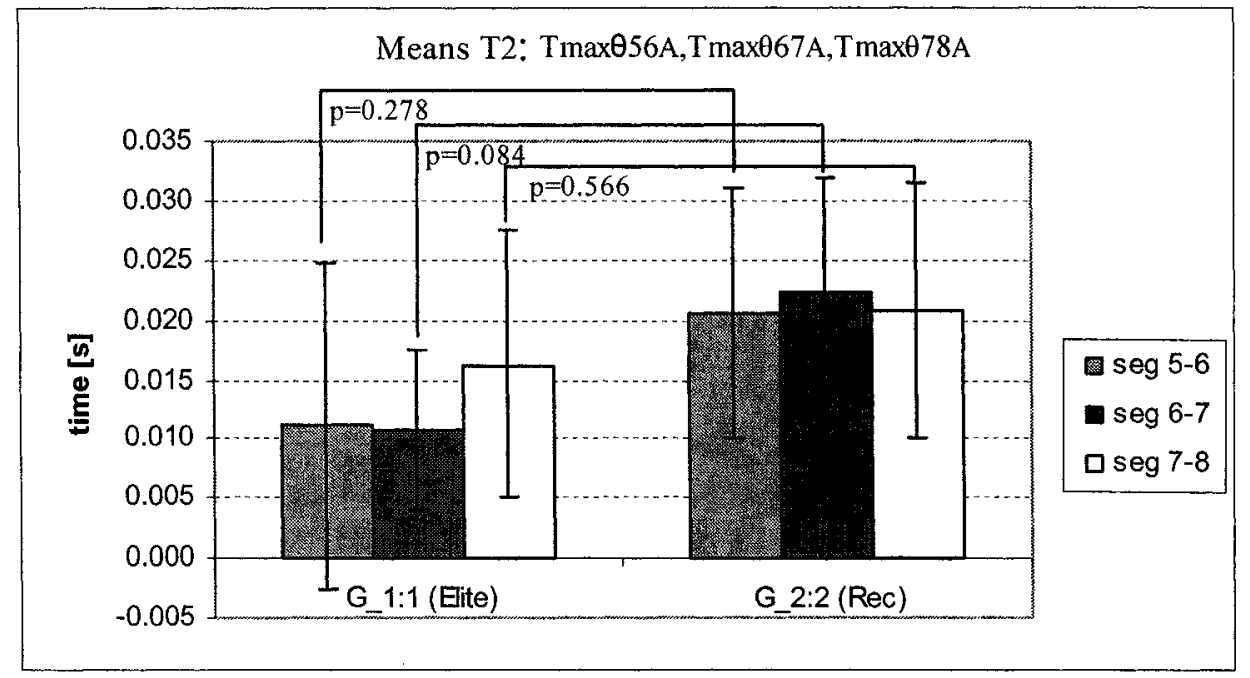

Figure 4.1.2 Time points for stick bend phase within $\mathrm{T}_{\mathrm{A}}$.

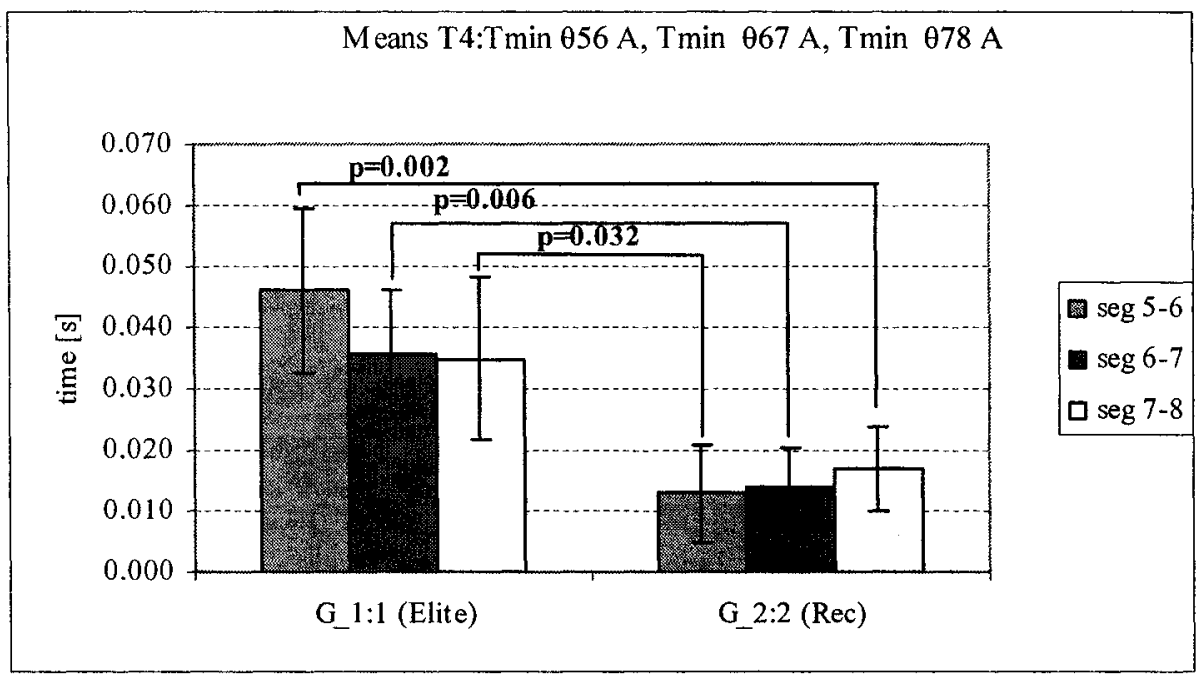

Figure 4.1.3 Time points for stick recoil phase within $\mathrm{T}_{\mathrm{A}}$.

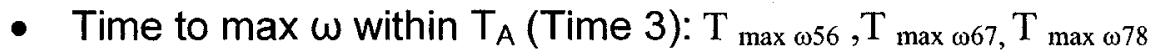

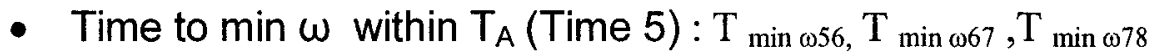

NSD were found in time points for stick joint angular velocity at stick bend phase within $\mathrm{T}_{\mathrm{A}}$ (Time 3), as it is shown in Table 4.1.7 and Figure 4.1.4. Time points for stick joint angular velocity in stick recoil phase within $T_{A}$ (Time 5) were found with NSD for segments 4 and 6 (i.e. $T_{\min \omega 56, T} \min \omega 78$ ), and for the 
segment $5\left(T_{\min \omega 67}\right)$ a significant difference $(p=0.010)$ was found (Table 4.1.8 and Figure 4.1.5).

Table 4.1.7 Stick joint angular velocity $(\omega)$ observed at stick bend phase within $T_{A}$.

\begin{tabular}{|c|c|c|c|c|c|c|}
\hline \multicolumn{7}{|c|}{$\begin{array}{l}\text { Summary Table of Means (tabstat5.sta) } \\
\mathrm{N}=9 \text { (No missing data in dep. var. list) }\end{array}$} \\
\hline & $\begin{array}{l}\mathrm{T}_{\max } \omega 56 \\
\text { Mean }\end{array}$ & $\begin{array}{r}\mathrm{T}_{\max \omega 56} \\
\mathrm{SD}\end{array}$ & $\begin{array}{l}T_{\max } \omega 67 \\
\text { Mean }\end{array}$ & $\begin{array}{r}T \max \omega 67 \\
S D\end{array}$ & $\begin{array}{l}T_{\max } \omega 78 \\
\text { Mean }\end{array}$ & $\begin{array}{r}\mathrm{T} \max \omega>78 \\
S D\end{array}$ \\
\hline G_1:1 (Elite) & 0.049 & 0.054 & 0.031 & 0.022 & 0.018 & 0.010 \\
\hline G_2:2(Rec) & 0.015 & 0.007 & 0.018 & 0.006 & 0.019 & 0.003 \\
\hline & $p=0.201$ & & $p=0.211$ & & $p=0.747$ & \\
\hline
\end{tabular}

Table 4.1.8 Stick joint angular velocity $(\omega)$ observed at stick recoil phase within $T_{A}$

\begin{tabular}{|c|c|c|c|c|c|c|}
\hline \multicolumn{7}{|c|}{$\begin{array}{l}\text { Summary Table of Means (tabstat5.sta) } \\
\mathrm{N}=9 \text { (No missing data in dep. var. list) }\end{array}$} \\
\hline & $\begin{array}{r}\min \omega 56 \\
\text { Mean }\end{array}$ & $\underset{S D}{T}$ & $\begin{array}{r}\mathrm{T} \min \omega 67 \\
\text { Mean }\end{array}$ & $\begin{array}{c}T_{\min \omega 67} \\
S D\end{array}$ & $\begin{array}{r}T_{\min \omega 78} \\
\text { Mean }\end{array}$ & $\begin{array}{c}\mathrm{T} \min \omega 78 \\
\mathrm{SD}\end{array}$ \\
\hline G_1:1 (Elite) & 0.032 & 0.019 & 0.028 & 0.004 & 0.024 & 0.009 \\
\hline \multirow[t]{2}{*}{ G 2:2 (Rec) } & 0.020 & 0.006 & 0.017 & 0.006 & 0.025 & 0.009 \\
\hline & $p=0.247$ & & $p=0.010$ & & $p=0.934$ & \\
\hline
\end{tabular}

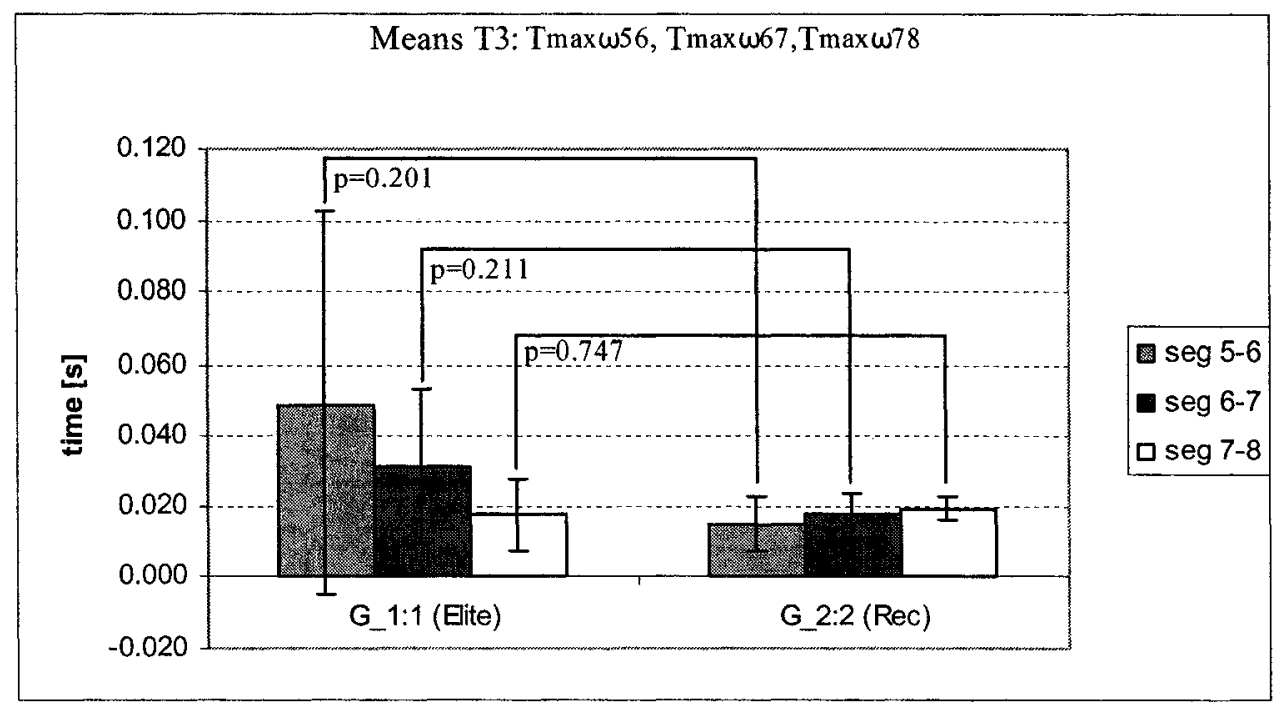

Figure 4.1.4 Stick joint angular velocity $(\omega)$ observed at stick bend phase within $T_{A}$. 


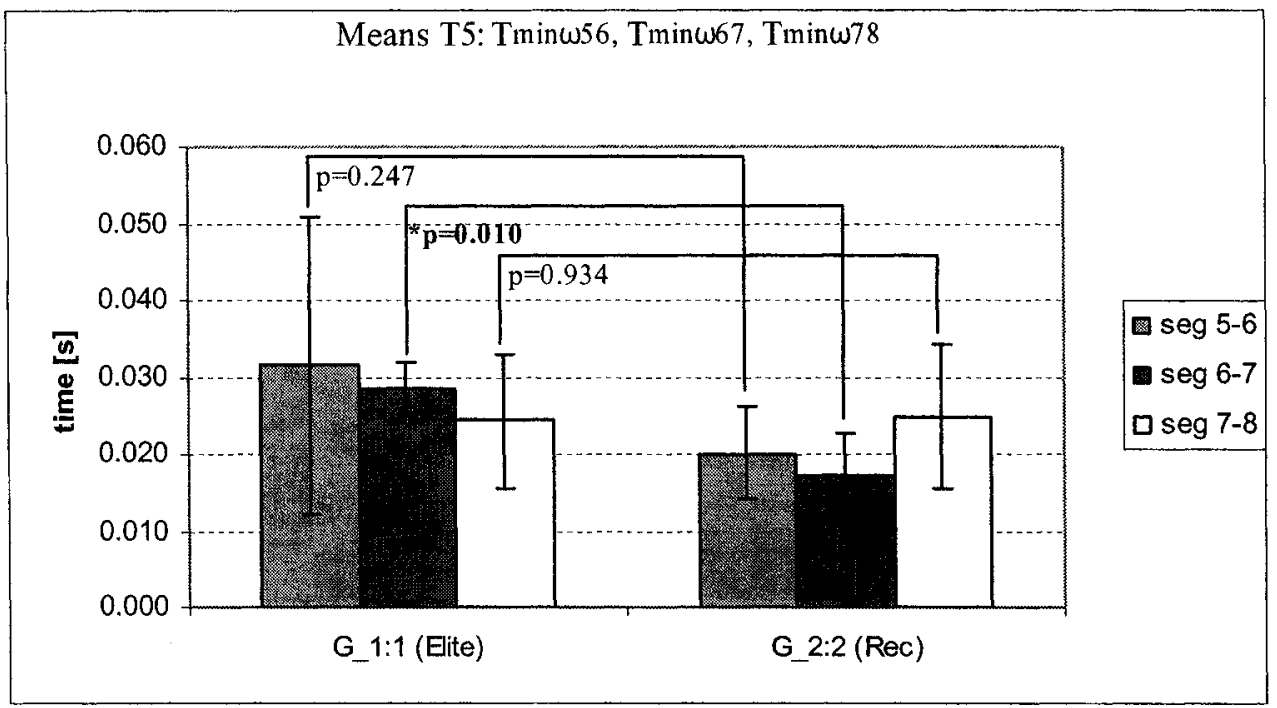

Figure 4.1.5 Stick joint angular velocity $(\omega)$ observed at stick recoil phase within $T_{A}$.

- Time to $\max$ total deflection $\theta\left(\max \theta_{56}+\max \theta_{67}+\max \theta_{78)}\right.$ in total event: $T \max \theta$

- Time to $\min$ total deflection $\theta\left(\min \theta_{56}+\min \theta_{67}+\min \theta_{78)}\right.$ in total event: $\mathrm{T} \min \theta$

NSD were found in maximum total deflection time points (Table 4.1.9 and Figure 4.1.6) for the total event. However, there were significant differences in minimum total deflection time points $\left({ }^{*} \mathrm{p}=0.012\right)$ in the total event as Table 4.1.9 and Figure 4.1.6 show.

Table 4.1.9 Time points for maximum $(\mathrm{T} \max \theta)$ and minimum $(\mathrm{T} \min \theta)$ total deflection $\theta$ in total event.

\begin{tabular}{|c|c|c|c|c|}
\hline \multicolumn{5}{|c|}{$\begin{array}{l}\text { Summary Table of Means (tabstat5.sta) } \\
N=9 \text { (No missing data in dep. var. list) }\end{array}$} \\
\hline & $\begin{array}{l}\mathrm{T} \max \theta \\
\text { Mean }\end{array}$ & $\mathrm{T}_{\max } \theta$ & $\begin{array}{l}T \min \theta \\
\text { Means }\end{array}$ & $\mathrm{T}_{\min } \theta$ \\
\hline G_1:1 (Elite) & 0.009 & 0.014 & 0.032 & 0.014 \\
\hline G_2:2(Rec) & 0.005 & 0.031 & 0.007 & 0.007 \\
\hline & $p=0.831$ & & ${ }^{*} p=0.012$ & \\
\hline
\end{tabular}




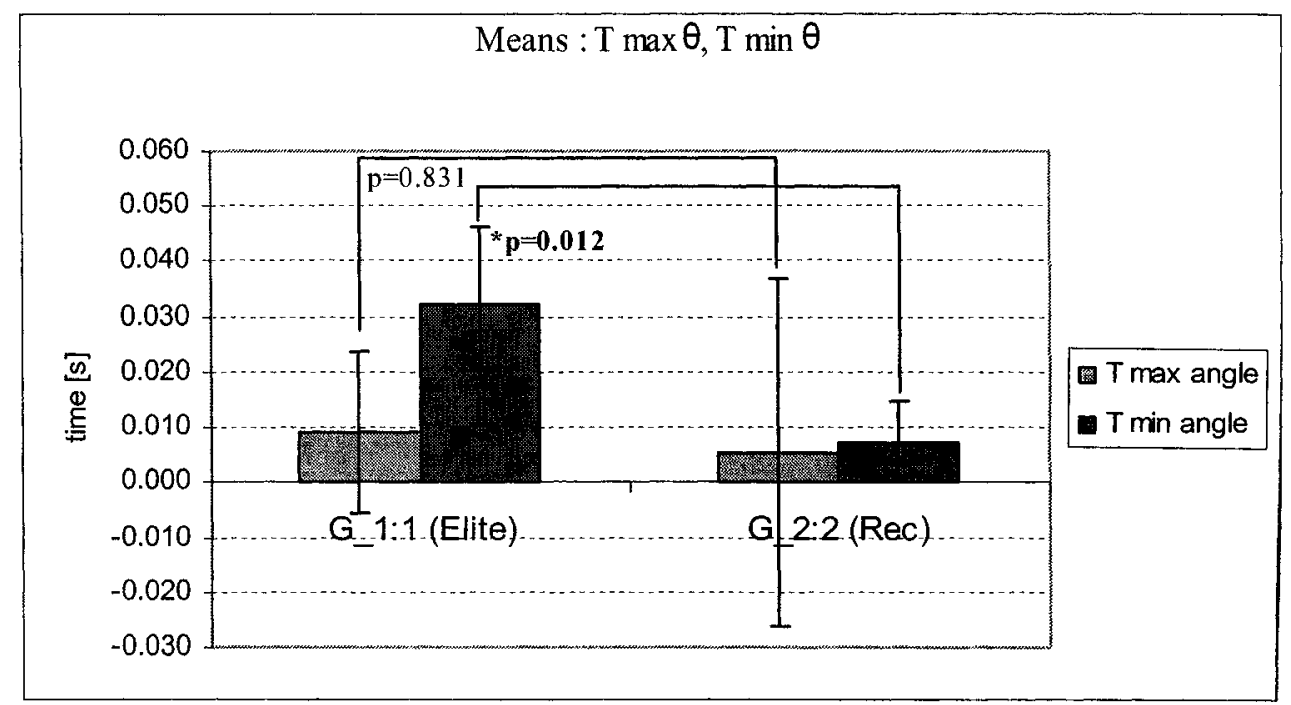

Figure 4.1.6 Time points for maximum $\left(\mathrm{T}_{\max \theta}\right)$ and minimum $\left(\mathrm{T}_{\min \theta}\right)$ total deflection $\theta$ in total event.

- Time to max $\theta$ in Total Event : $\mathrm{T}_{\max } \theta 656, \mathrm{~T}_{\max } \theta 67, \mathrm{~T}_{\max } \theta 78$

- Time to $\min \theta$ in Total Event : $\mathrm{T}_{\min } \theta 56, \mathrm{~T}_{\min } \theta 67, \mathrm{~T}_{\min } \theta 78$

NSD were found in time points for both bend $\left(\mathrm{T}_{\max }{ }_{956}, \mathrm{~T}_{\max }{ }_{067}, \mathrm{~T}_{\max } \theta_{788}\right)$ and recoil phases $\left(T_{\min }{ }_{056}, T_{\min }{ }_{667}, T_{\min }{ }_{978}\right)$ as it is shown in Tables: 4.1.10 - .11 and Figures $4.1 .7-.8$.

Table 4.1.10 Time points for stick bend phase in total event.

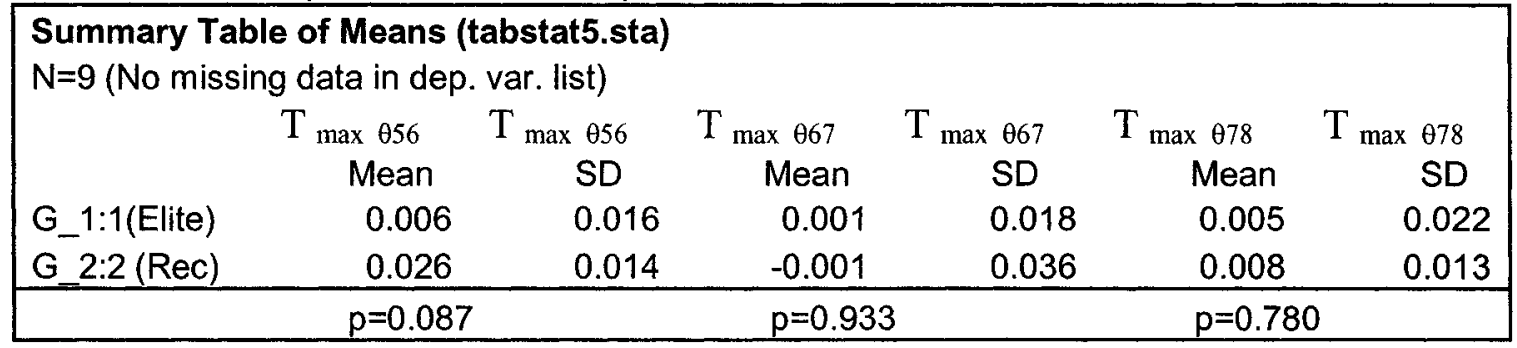

Table 4.1.11 Time points for stick recoil phase in total event.

\begin{tabular}{|c|c|c|c|c|c|c|}
\hline \multicolumn{7}{|c|}{$\begin{array}{l}\text { Summary Table of Means (tabstat5.sta) } \\
N=9 \text { (No missing data in dep. Var. list) }\end{array}$} \\
\hline & $\mathrm{T}_{\min } \theta 56$ & $T_{\operatorname{SD}} \theta 56$ & $\mathrm{~T}_{\min } \theta 67$ & $\begin{array}{l}T_{\min } \theta 67 \\
S D\end{array}$ & $\begin{array}{r}\mathrm{T} \min \theta 78 \\
\text { Mean }\end{array}$ & $\begin{array}{c}T_{\min } \theta 78 \\
\mathrm{SD}\end{array}$ \\
\hline G_1:1(Elite) & 0.058 & 0.082 & 0.031 & 0.021 & 0.016 & 0.023 \\
\hline \multirow[t]{2}{*}{ G_2:2(Rec) } & -0.012 & 0.009 & 0.011 & 0.020 & 0.032 & 0.015 \\
\hline & $p=0.093$ & & $p=0.202$ & & $p=0.231$ & \\
\hline
\end{tabular}




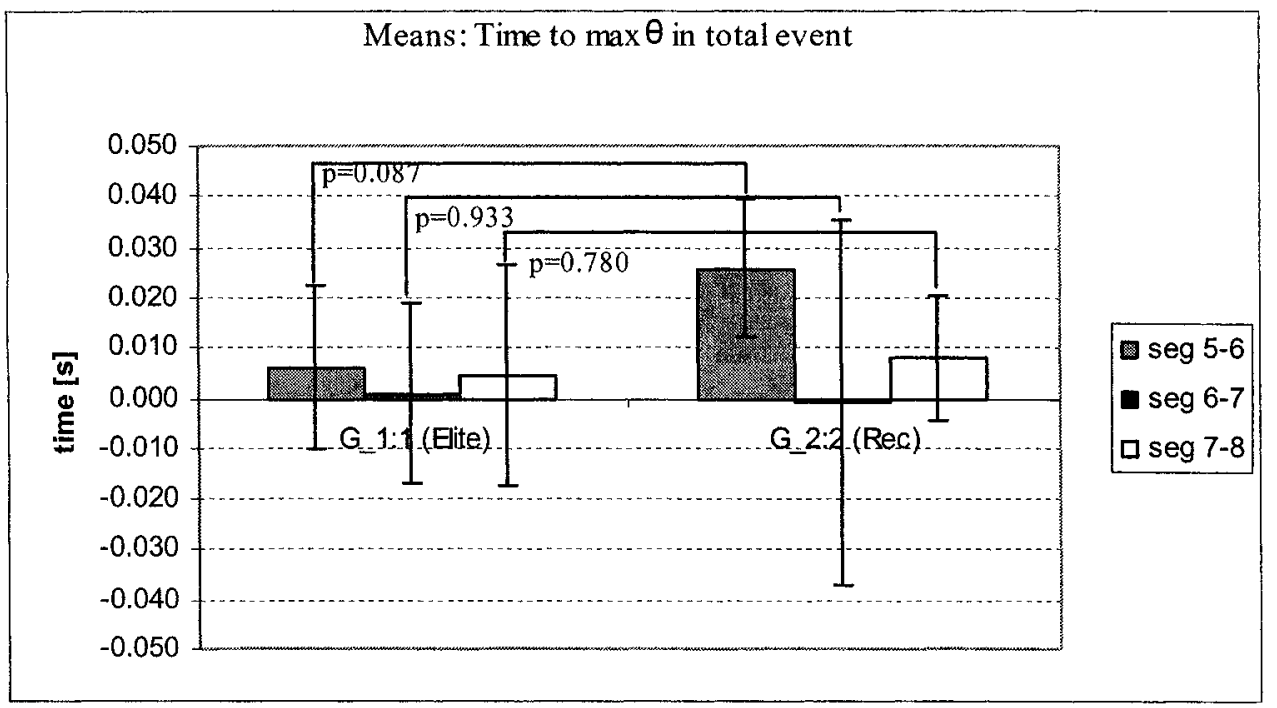

Figure 4.1.7 Time points for stick bend phase $\left(T_{\max } \theta 56, T_{\max } \theta 67, T_{\max } \theta 78\right)$ in total event.

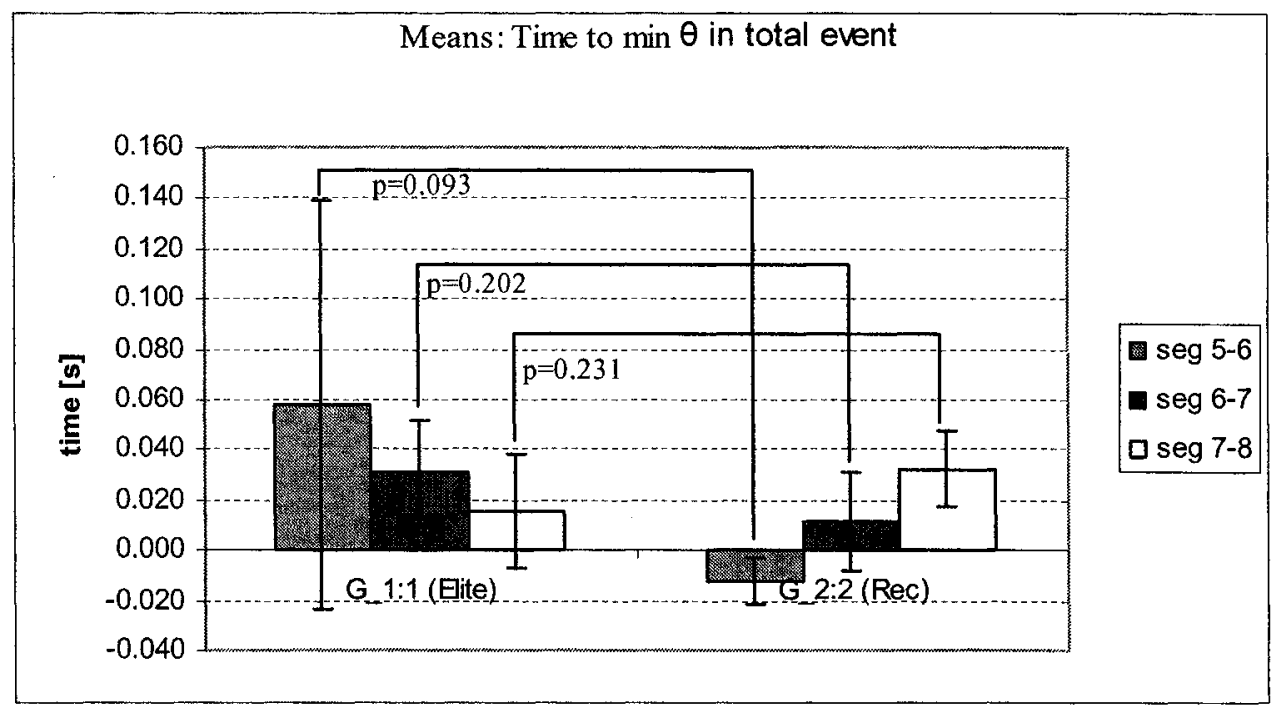

Figure 4.1.8 Time points for stick recoil phase $\left(\mathrm{T}_{\min }{ }_{956}, \mathrm{~T}_{\min }{ }_{067}, \mathrm{~T}_{\min } 078\right)$ in total event

\subsection{ANOVA of Stick Kinematics Measures. HSC.}

\subsubsection{ANOVA of Stick Joint Angle Displacements}

- Maximum segment joint angle within $T_{\mathrm{A}}: \max \theta_{56 \mathrm{~A}}, \max \theta_{67 \mathrm{~A}}, \max \theta_{78 \mathrm{~A}}$

- Minimum segment joint angle within $\mathrm{T}_{\mathrm{A}}$ : $\min \theta_{56 \mathrm{~A}}, \min \theta_{67 \mathrm{~A}}, \min \theta_{78 \mathrm{~A}}$ 
With regards to the stick bend phase within $T_{A}, N S D$ were found for maximum segment joint angles $\max \theta_{67 \mathrm{~A}}$ and $\max \theta_{78 \mathrm{~A}}$. However, for the most proximal segment examined (max $\theta_{56 \mathrm{~A}}$ ), a significant difference was found $(p=0.041$, Tables 4.2.1 -.2 and Figures 4.2.1 -.2$)$.

Table 4.2.1 Maximum stick segment joint angle displacements (bend phase)whithin $\mathrm{T}_{\mathrm{A}}$.

\begin{tabular}{|c|c|c|c|c|c|c|}
\hline \multicolumn{7}{|c|}{$\begin{array}{l}\text { Summary Table of Means (tabstat5.sta) } \\
N=9 \text { (No missing data in dep. var. list) }\end{array}$} \\
\hline & $\max \theta_{56 \mathrm{~A}}$ & $\max \theta_{56 \mathrm{~A}}$ & $\max \theta_{67 \mathrm{~A}}$ & $\max \theta_{67 \mathrm{~A}}$ & $\max \theta_{78 \mathrm{~A}}$ & $\max \theta_{78 \mathrm{~A}}$ \\
\hline & Mean & $S D$ & Mean & SD & Mean & $\mathrm{SD}$ \\
\hline G_1:1 (Elite) & 181.64 & 1.79 & 181.74 & 1.57 & 184.01 & 3.34 \\
\hline \multirow[t]{2}{*}{ G_2:2(Rec) } & 179.56 & 0.54 & 180.05 & 0.55 & 180.91 & 0.70 \\
\hline & $p=0.041$ & & $p=0.058$ & & $p=0.079$ & \\
\hline
\end{tabular}

Table 4.2.2 Minimum stick segment joint angle displacements (recoil phase)whithin $T_{A}$

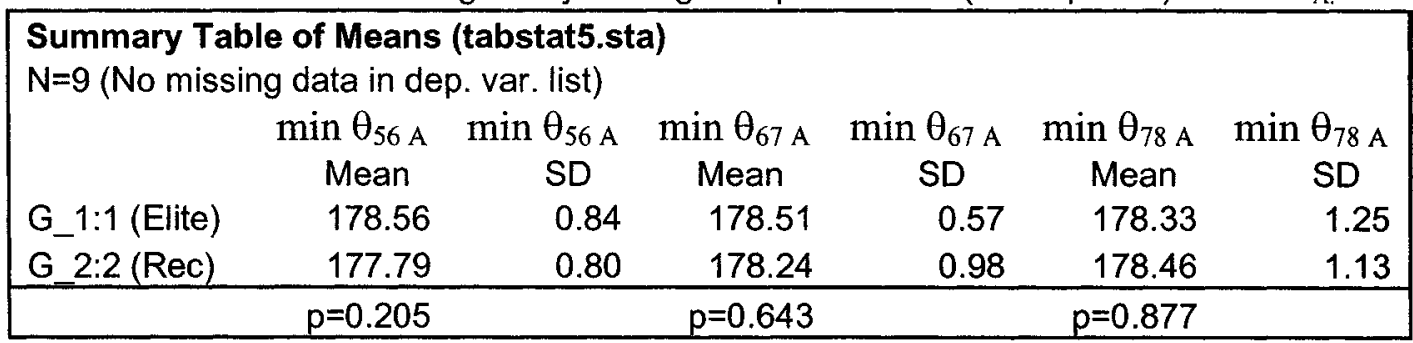

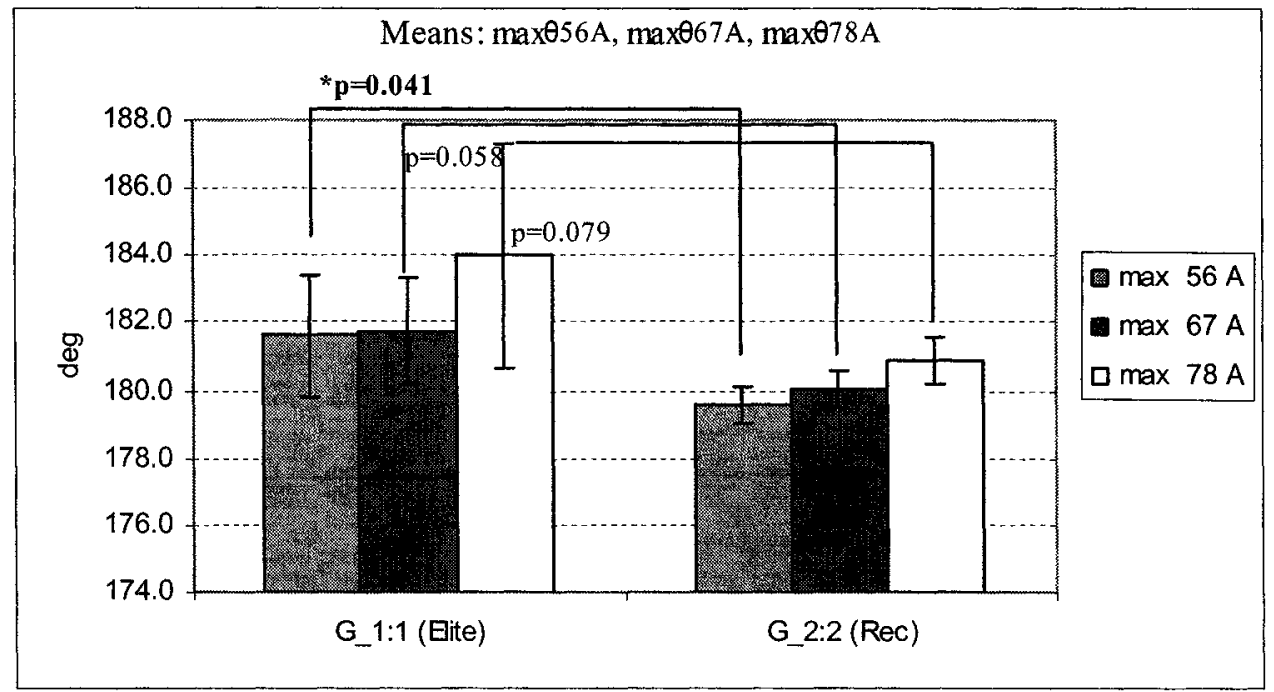

Figure 4.2.1 Maximum stick segment joint angle displacements (bend phase) whithin $\mathrm{T}_{\mathrm{A}}$. 


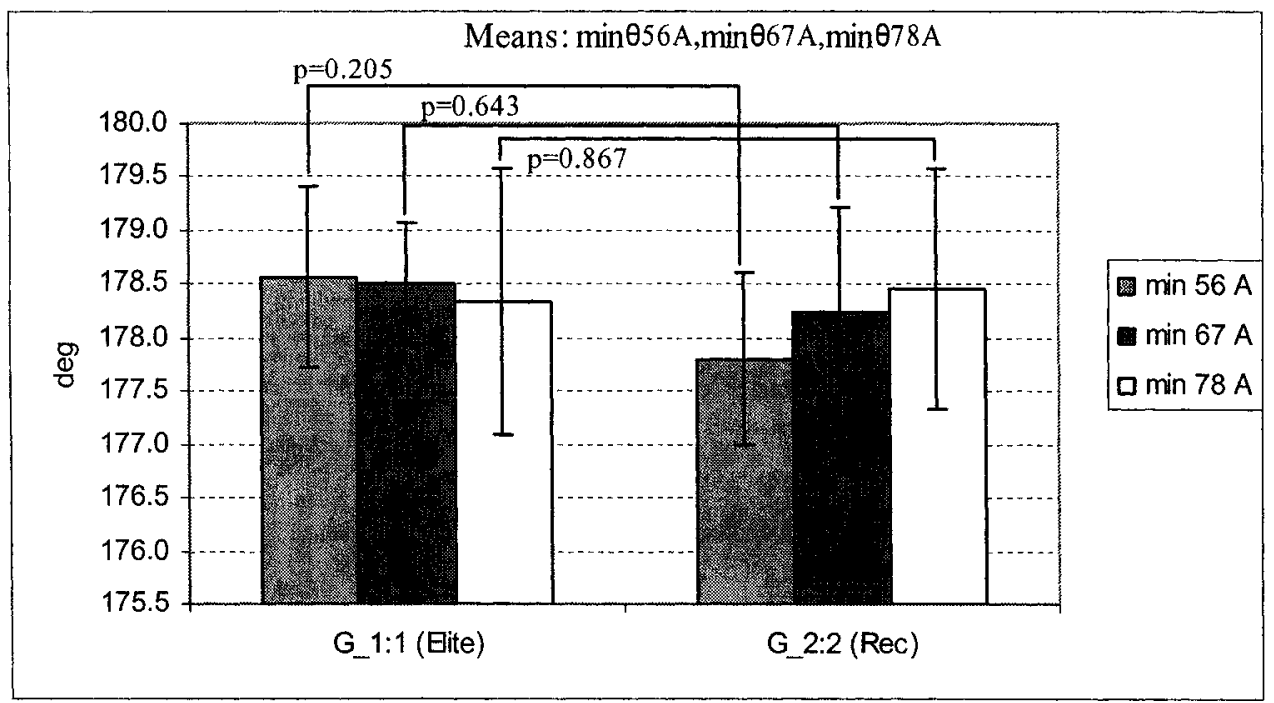

Figure 4.2.2 Minimum stick segment joint angle displacements (recoil phase) whithin $\mathrm{T}_{\mathrm{A}}$

- Maximum segment joint angle in total event: $\max \theta_{56}, \max \theta_{67}, \max \theta_{78}$

- Minimum segment joint angle in total event : $\min \theta_{56}, \min \theta_{67}, \min \theta_{78}$

NSD were found for maximum and minimum stick segment joint angles in the

total event, as it is shown in Tables $4.2 .3-.4$ and Figures $4.2 .3-.4$.

Table 4.2.3 Maximum stick segment joint angles in total event.

\begin{tabular}{|c|c|c|c|c|c|c|}
\hline \multicolumn{7}{|c|}{$\begin{array}{l}\text { Summary Table of Means (tabstat4.sta) } \\
\mathrm{N}=9 \text { (No missing data in dep. var. list) }\end{array}$} \\
\hline & $\max \theta_{56}$ & $\max \theta_{56}$ & $\max \theta_{67}$ & $\max \theta_{67}$ & $\max \theta_{78}$ & $\max \theta_{78}$ \\
\hline & Mean & SD & Mean & SD & Mean & $S D$ \\
\hline G_1:1 (Elite) & 182.128 & 1.700 & 182.390 & 1.170 & 184.661 & 2.873 \\
\hline G 2:2(Rec) & 181.207 & 0.579 & 181.366 & 0.768 & 182.899 & 1.743 \\
\hline & $p=0.289$ & & $p=0.156$ & & $p=0.290$ & \\
\hline
\end{tabular}

Table 4.2.4 Minimum stick segment joint angles in total event.

\begin{tabular}{|c|c|c|c|c|c|c|}
\hline \multicolumn{7}{|c|}{$\begin{array}{l}\text { Summary Table of Means (tabstat4.sta) } \\
N=9 \text { (No missing data in dep. var. list) }\end{array}$} \\
\hline & $\min \theta_{56}$ & $\min \theta_{56}$ & $\min \theta_{67}$ & $\min \theta_{67}$ & $\min \theta_{78}$ & $\min \theta_{78}$ \\
\hline & Mean & SD & Mean & SD & Mean & SD \\
\hline G_1:1 (Elite) & 175.881 & 3.503 & 176.266 & 3.209 & 175.655 & 3.626 \\
\hline $\mathrm{G}^{-} 2: 2(\operatorname{Rec})$ & 176.695 & 0.944 & 177.239 & 1.267 & 177.251 & 1.550 \\
\hline & $p=0.629$ & & $p=0.550$ & & $p=0.399$ & \\
\hline
\end{tabular}




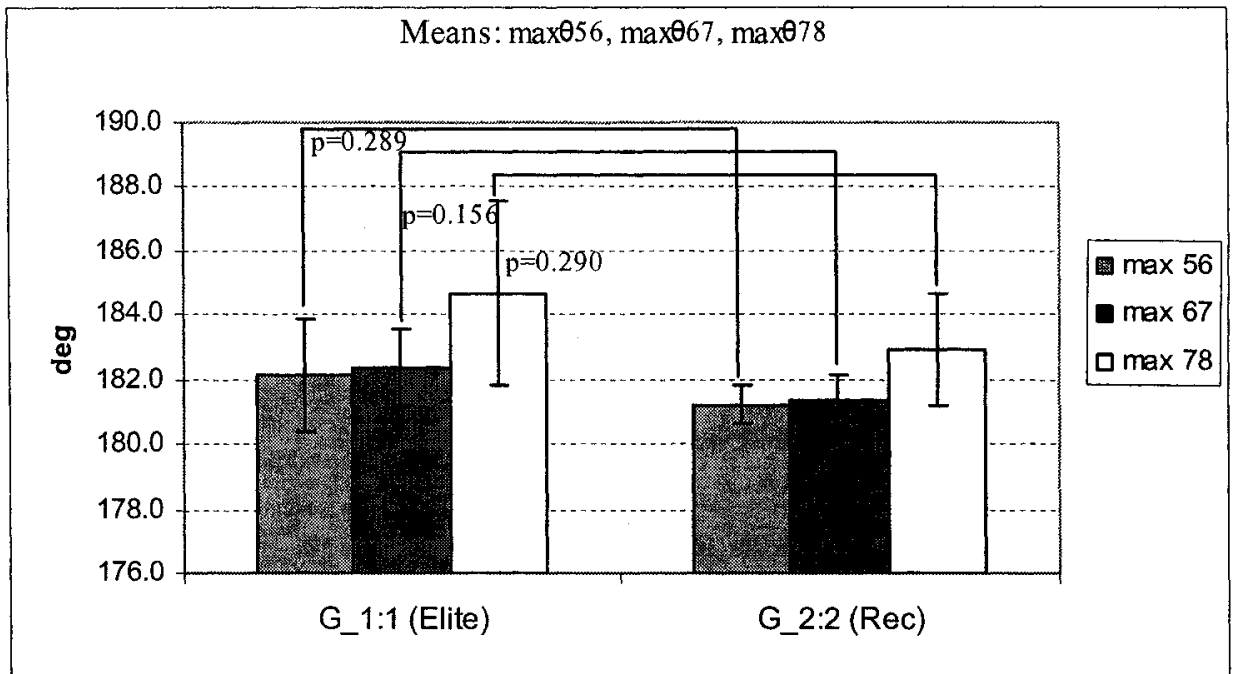

Figure 4.2.3 Maximum stick segment joint angles in total event

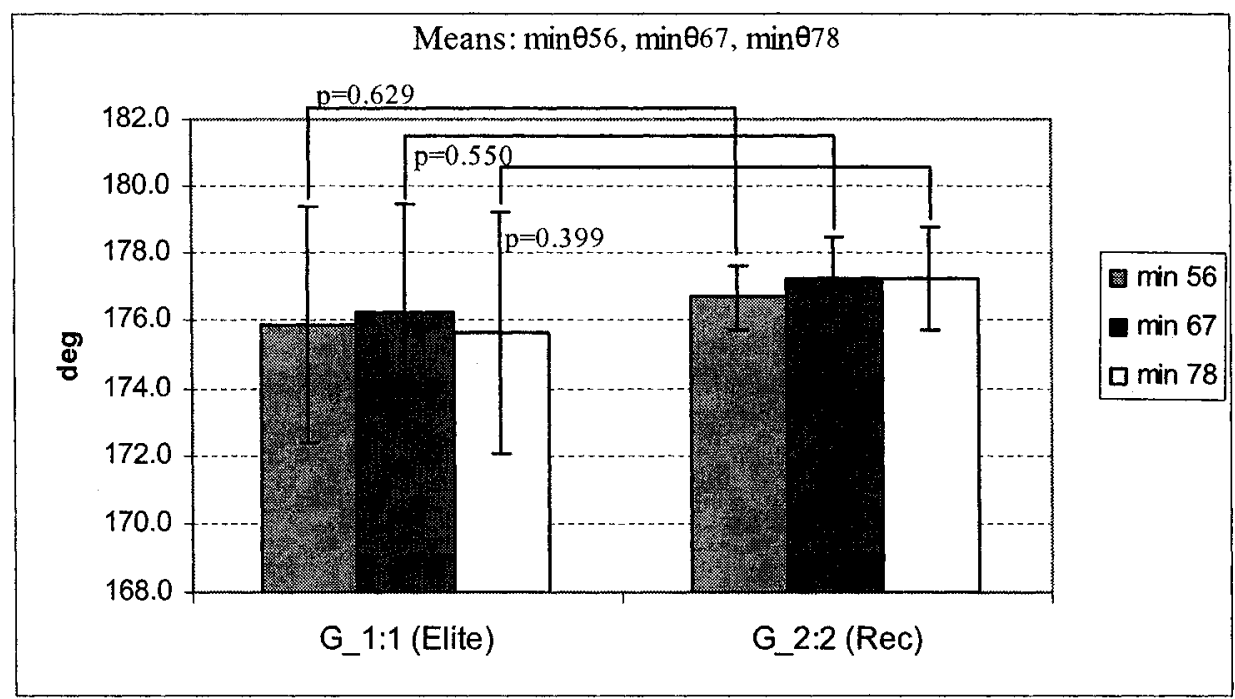

Figure 4.2.4 Minimum stick segment joint angles in total event

- Recoil angle in total event: $\operatorname{Reco} \theta_{56}\left(\max \theta_{56}-\min \theta_{56}\right), \operatorname{Reco} \theta_{67}\left(\max \theta_{67}-\min \right.$ $\theta_{67}, \operatorname{Reco} \theta_{78}\left(\max \theta_{78} \cdot \min \theta_{78}\right)$

NSD were found in recoil angle (difference between maximum and minimum segment joint angles) for the total event as Table 4.2 .5 and Figure 4.2 .5 are shown. However post hoc analysis identified inter-segment differences in stick shaft's bend within groups. 
Table 4.2.5 Recoil angle in total event.

\begin{tabular}{|c|c|c|c|c|c|c|}
\hline \multicolumn{7}{|c|}{$\begin{array}{l}\text { Summary Table of Means (tabstat5.sta) } \\
N=9 \text { (No missing data in dep. var. list) }\end{array}$} \\
\hline & $\operatorname{Reco} \theta_{56}$ & $\operatorname{Reco} \theta_{56}$ & $\operatorname{Reco} \theta_{67}$ & $\operatorname{Reco} \theta_{67}$ & $\operatorname{Reco} \theta_{78}$ & $\operatorname{Reco} \theta_{78}$ \\
\hline & Mean & $S D$ & Mean & SD & Mean & SD \\
\hline G_1:1 (Elite) & 6.25 & 3.38 & 6.12 & 4.05 & 9.01 & 5.96 \\
\hline G_2:2(Rec) & 4.51 & 1.48 & 4.13 & 1.96 & 5.65 & 2.68 \\
\hline \multicolumn{3}{|c|}{$p=0.330$} & $p=0.360$ & & $p=0.290$ & \\
\hline
\end{tabular}

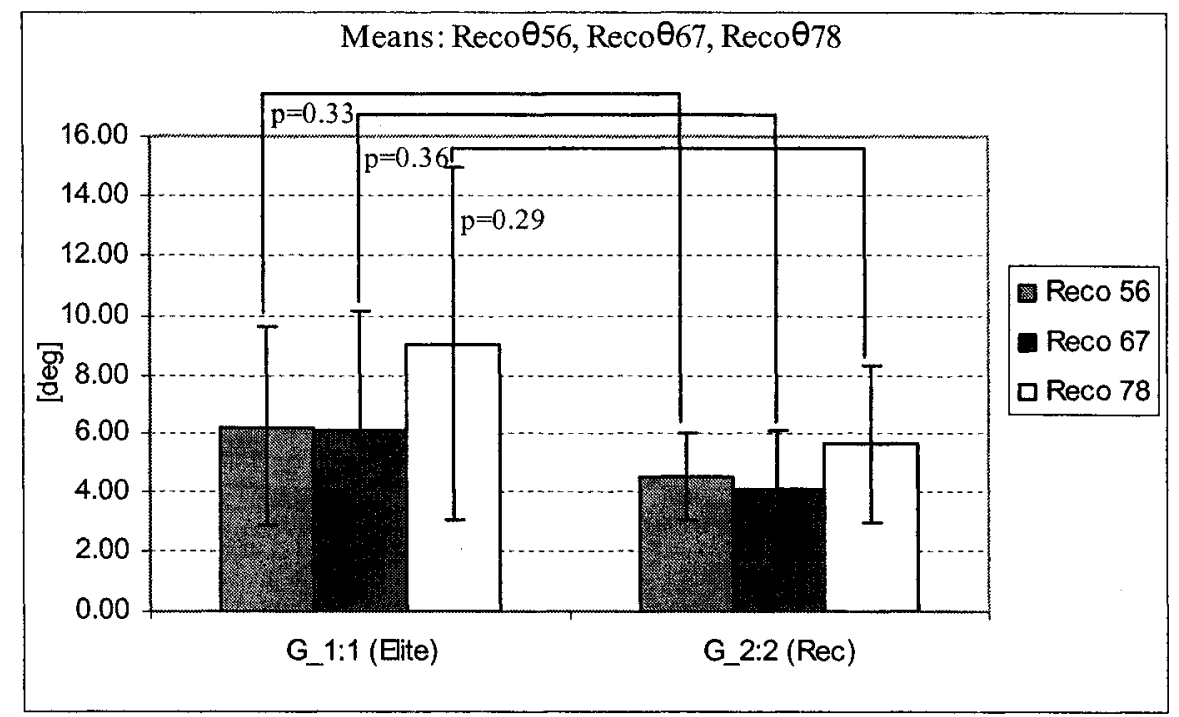

Figure 4.2.5 Recoil angle in total event.

- Difference between Segments: $\max \theta_{56}$ vs $\max \theta_{67} \quad p=0.60$ $\max \theta_{56}$ vs $\max \theta_{78} \quad \mathbf{p}=\mathbf{0 . 0 2}$

Post hoc analysis identified significant differences $(p=0.02)$ in maximum stick bending for the total event between segment $4\left(\max \theta_{56}\right)$ and segment $6\left(\max \theta_{78}\right)$ as Figure 4.2.6 shows. On the other hand, NSD were found between segment 4 (max $\left.\theta_{56}\right)$ and segment $5\left(\max \theta_{67}\right)$ as the same Figure 4.2 .6 shows. 


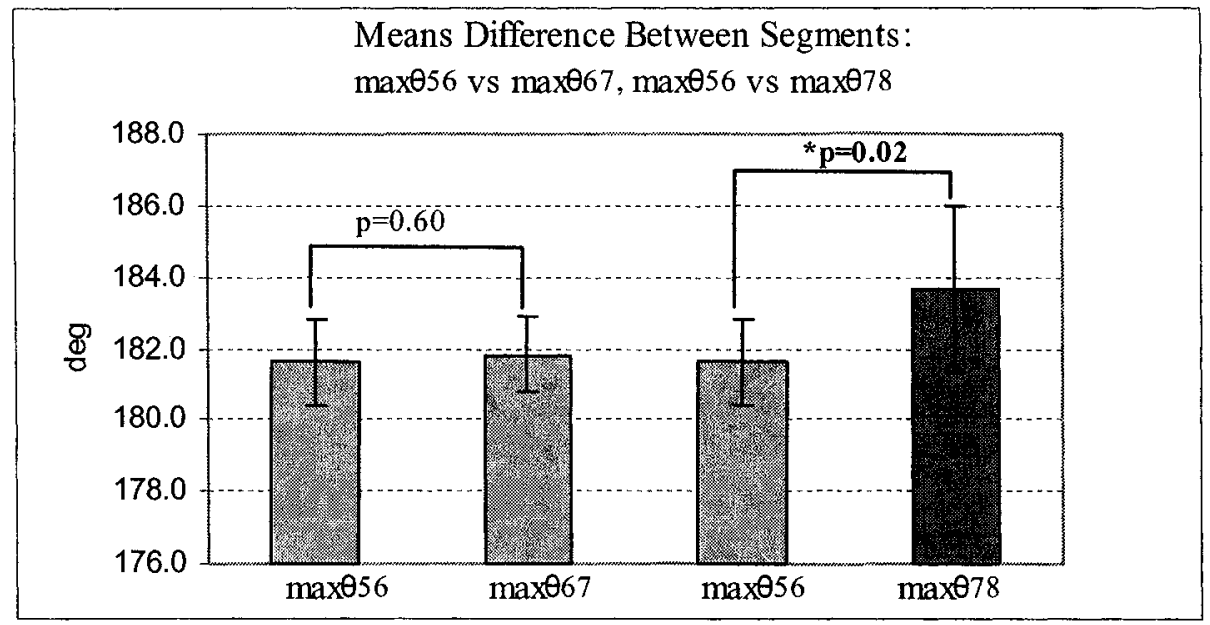

Figure 4.2.6 T-Test for differences in maximum stick bending between segment 4 $\left(\max \theta_{56}\right)$ vs segment5 $\left(\max \theta_{67}\right)$ and $6\left(\max \theta_{78}\right)$

- Difference between segments : $\max \theta_{67}$ vs $\max \theta_{56} \quad p=0.604$ $\max \theta_{67}$ vs $\max \theta_{78} \quad \mathbf{p}=\mathbf{0 . 0 0 3}$

Also, a post hoc analysis identified significant differences $(p=0.003)$ in maximum stick bending for the total event between segment $5\left(\max \theta_{67}\right)$ and segment 6 $\left(\max \theta_{78}\right)$ as Figure 4.2.7 shows. Conversely, NSD were found between segment $5\left(\max \theta_{67}\right)$ and segment $4\left(\max \theta_{56}\right)$ as the same Figure 4.2.7 shows.

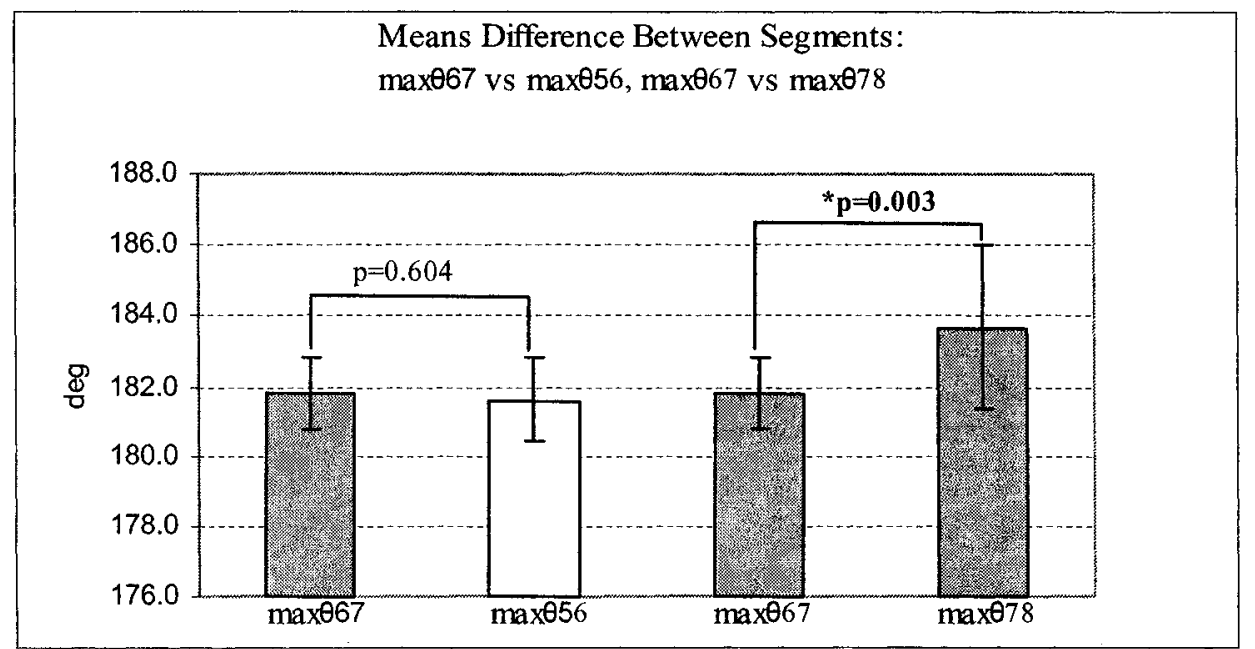

Figure 4.2.7 T-Test for differences in maximum stick bending between segment 5 $\left(\max \theta_{67}\right)$ vs segment $4\left(\max \theta_{56}\right)$ and $6\left(\max \theta_{78}\right)$ 
- Difference between segments : $\min \theta_{56}$ vs $\min \theta_{67} \quad p=0.27$ $\min \theta_{56}$ vs $\min \theta_{78} \quad \mathrm{p}=0.65$

NSD were found in the post hoc analysis in minimum segment joint angle deflection for the total event as Figures 4.2.8 and 4.2.9 show.

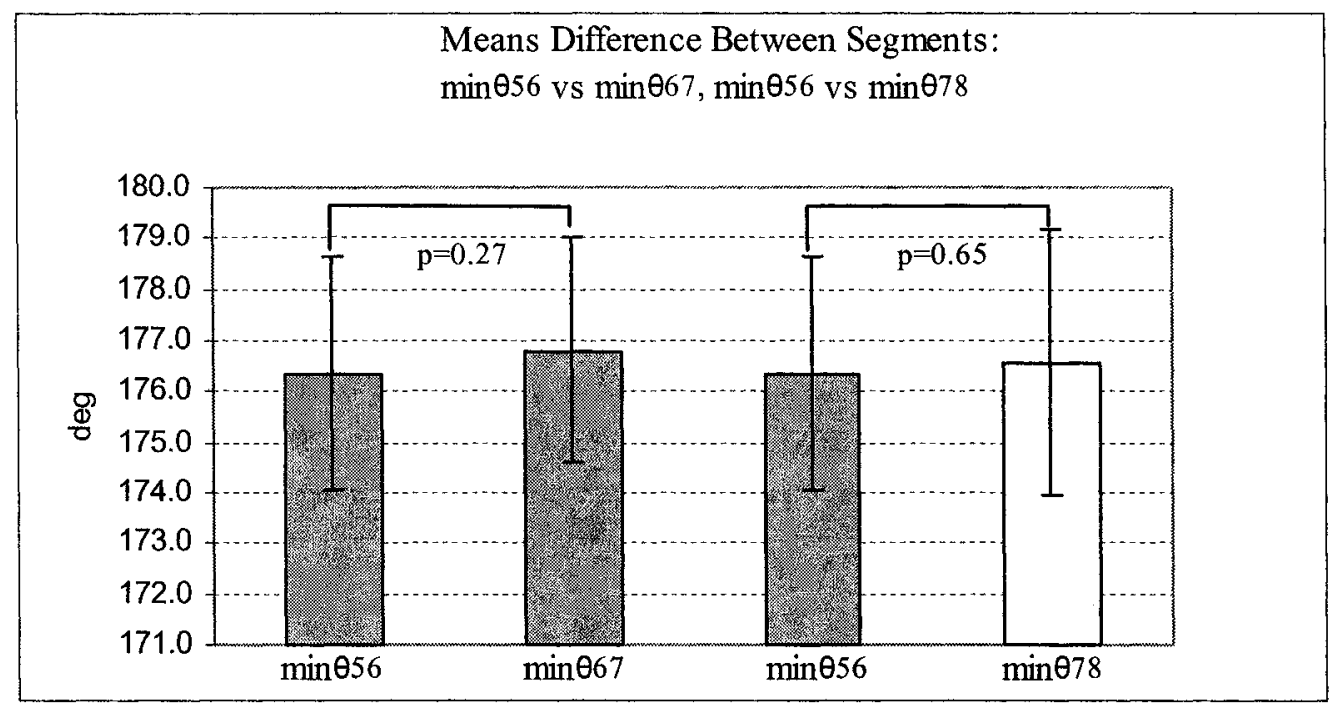

Figure 4.2.8 T-Test for differences in minimum stick deflection between segment 4 $\left(\max \theta_{56}\right)$ vs segment $5\left(\max \theta_{67}\right)$ and $6\left(\max \theta_{78}\right)$

- Difference between segments: $\min \theta_{67}$ vs $\min \theta_{56} \quad p=0.27$ $\min \theta_{67}$ vs $\min \theta_{78} \quad p=0.61$

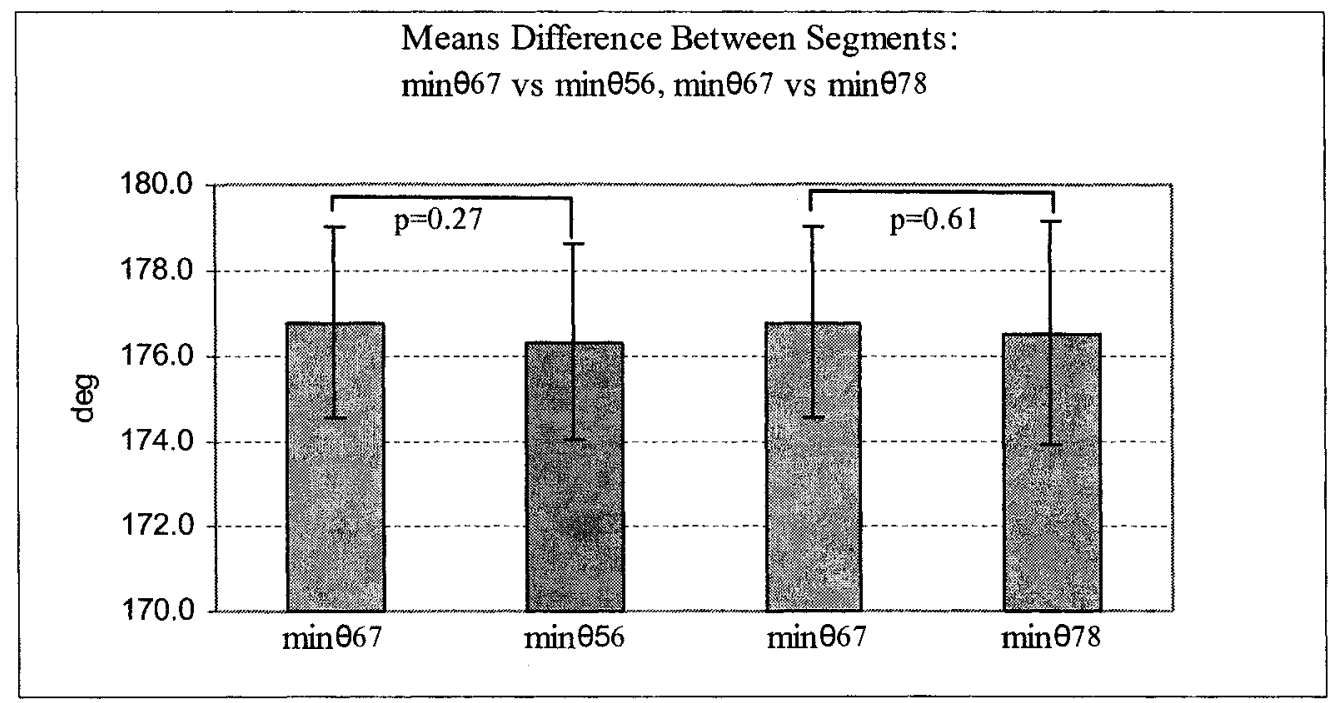

Figure 4.2.9-Test for differences in minimum stick deflection between segment 5 (max $\left.\theta_{67}\right)$ vs segment $4\left(\max \theta_{56}\right)$ and $6\left(\max \theta_{78}\right)$ 
- Maximum $\theta$ deflection $\left(\max \theta_{56}+\max \theta_{67}+\max \theta_{78}\right)$ in total event : $\max \theta$.

- Minimum $\theta$ deflection $\left(\min \theta_{56}+\min \theta_{67}+\min \theta_{78}\right)$ in total event: $\min \theta$

There were significant differences in maximum angle deflection $(\max \theta)$ between both groups $(p=0.03)$. In contrast, NSD were found in minimum stick angle deflection $(\min \theta)$.Table 4.2.6 and Figure 4.2.10 show such results.

Table 4.2.6 Maximum and Minimum $\theta$ deflection in total event.

\begin{tabular}{|c|c|c|c|c|}
\hline \multicolumn{5}{|c|}{$\begin{array}{l}\text { Summary Table of Means (tabstat5.sta) } \\
\mathrm{N}=9 \text { (No missing data in dep. var. list) }\end{array}$} \\
\hline & $\max \theta$ & $\max \theta$ & $\min \theta$ & $\min \theta$ \\
\hline & Mean & SD & Mean & $S D$ \\
\hline G_1:1 (Elite) & 7.6 & 4.0 & -3.7 & 3.3 \\
\hline $\mathrm{G}^{-} 2: 2(\operatorname{Rec})$ & 2.2 & 1.5 & -5.0 & 1.9 \\
\hline
\end{tabular}

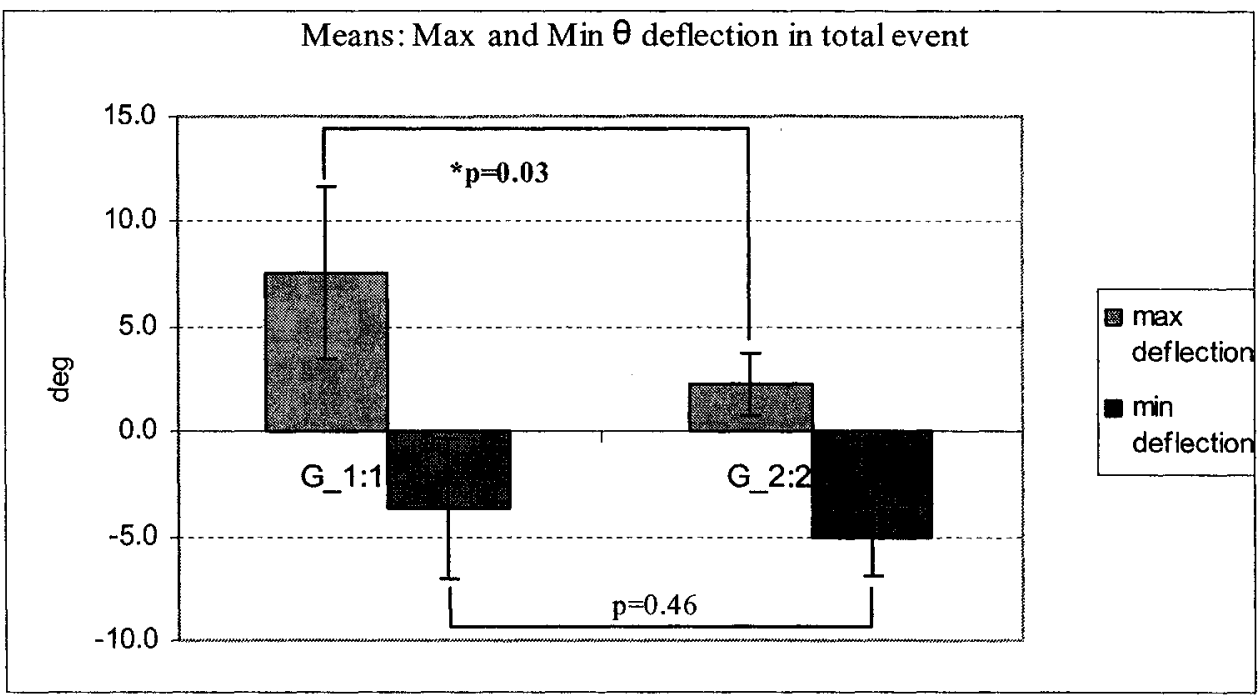

Figure 4.2.10 Maximum and Minimum $\theta$ deflection in total event. 


\subsubsection{ANOVA of Stick Joint Angular Velocity}

- Maximum segment joint angle velocity within $T_{\mathrm{A}}: \max \omega_{56 \mathrm{~A}}, \max \omega_{67} \mathrm{~A}$, $\max \omega_{78} \mathrm{~A}$

- Minimum segment joint angle velocity within $T_{A}: \min \omega_{56 \mathrm{~A}}, \min \omega_{67 \mathrm{~A}}$, $\min \omega_{78} \mathrm{~A}$

With regards to stick joint angular velocities, NSD were found for both bend $\left(\max \omega_{56 \mathrm{~A}}, \max \omega_{67 \mathrm{~A}}, \max \omega_{78 \mathrm{~A}}\right)$ and recoil $\left(\min \omega_{56 \mathrm{~A}}, \min \omega_{67 \mathrm{~A}}, \min \omega_{78 \mathrm{~A}}\right)$ phases, as Tables $4.2 .7-.8$ and Figures $4.2 .11-.12$ show.

Table 4.2.7 Stick joint angular velocities observed at stick bend phase within $T_{A}$.

\begin{tabular}{|c|c|c|c|c|c|c|}
\hline \multicolumn{7}{|c|}{$\begin{array}{l}\text { Summary Table of Means (tabstat5.sta) } \\
\mathrm{N}=9 \text { (No missing data in dep. var. list) }\end{array}$} \\
\hline & $\max \omega_{56 \mathrm{~A}}$ & $\max \omega_{56 \mathrm{~A}}$ & $\max \omega_{67 \mathrm{~A}}$ & $\max \omega_{67 \mathrm{~A}}$ & $\max \omega_{78 \mathrm{~A}}$ & $\max \omega_{78 \mathrm{~A}}$ \\
\hline & Mean & $S D$ & Mean & $\mathrm{SD}$ & Mean & SD \\
\hline & 130.95 & 163.23 & 168.77 & 63.18 & 422.27 & 311.43 \\
\hline \multirow{2}{*}{ G $2: 2(\operatorname{Rec})$} & 121.90 & 88.00 & 109.55 & 82.67 & 147.33 & 121.29 \\
\hline & $p=0.92$ & & $p=0.28$ & & $p=0.11$ & \\
\hline
\end{tabular}

Table 4.2.8 Stick joint angular velocities observed at stick recoil phase within $\mathrm{T}_{\mathrm{A}}$.

\begin{tabular}{|c|c|c|c|c|c|c|}
\hline \multicolumn{7}{|c|}{$\begin{array}{l}\text { Summary Table of Means (tabstat5.sta) } \\
N=9 \text { (No missing data in dep. var. list) }\end{array}$} \\
\hline & $\min \omega_{56 \mathrm{~A}}$ & $\min \omega_{56 \mathrm{~A}}$ & $\min \omega_{67 \mathrm{~A}}$ & $\min \omega_{67 \mathrm{~A}}$ & $\min \omega_{78 \mathrm{~A}}$ & $\min \omega_{78 \mathrm{~A}}$ \\
\hline & Mean & SD & Mean & SD & Mean & SD \\
\hline G_1:1 (Elite) & 2.77 & 177.41 & -97.24 & 151.76 & -242.65 & 387.11 \\
\hline G_2:2(Rec) & -58.59 & 81.13 & -37.34 & 43.88 & -129.09 & 143.81 \\
\hline & $p=0.51$ & & $p=0.42$ & & $p=0.56$ & \\
\hline
\end{tabular}




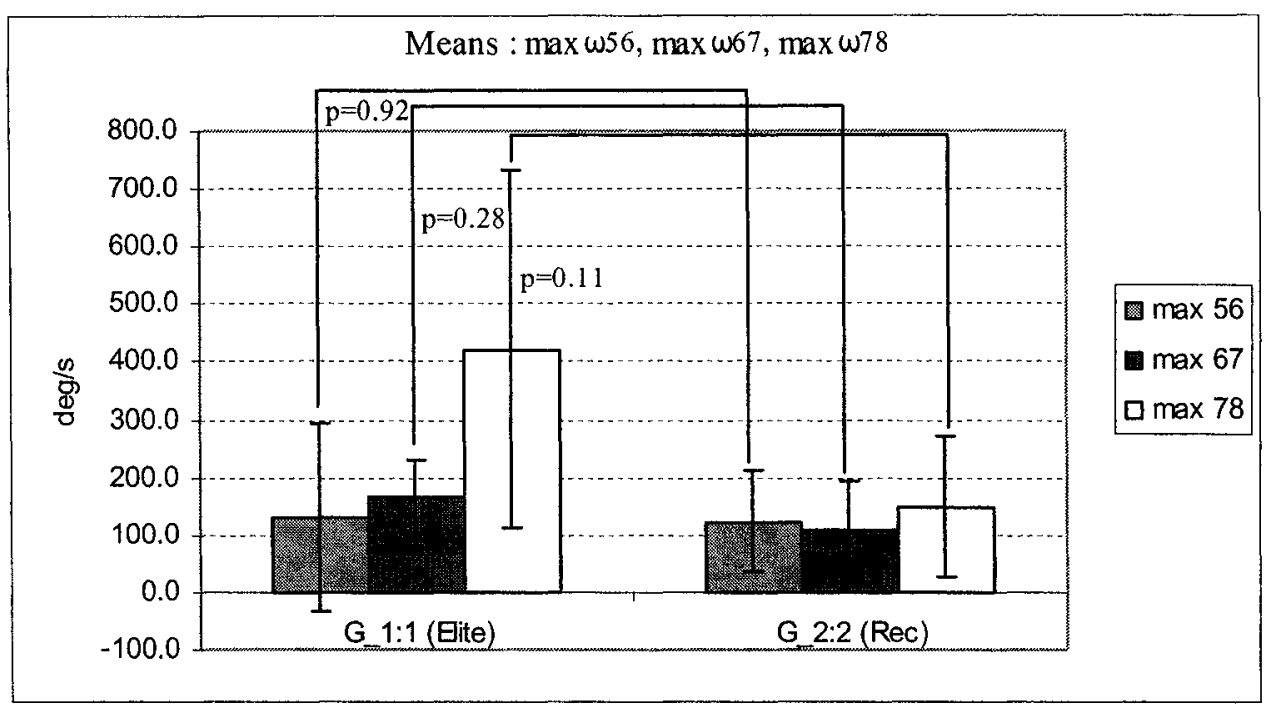

Figure 4.2.11 Stick joint angular velocities observed at stick bend phase within $T_{A}$.

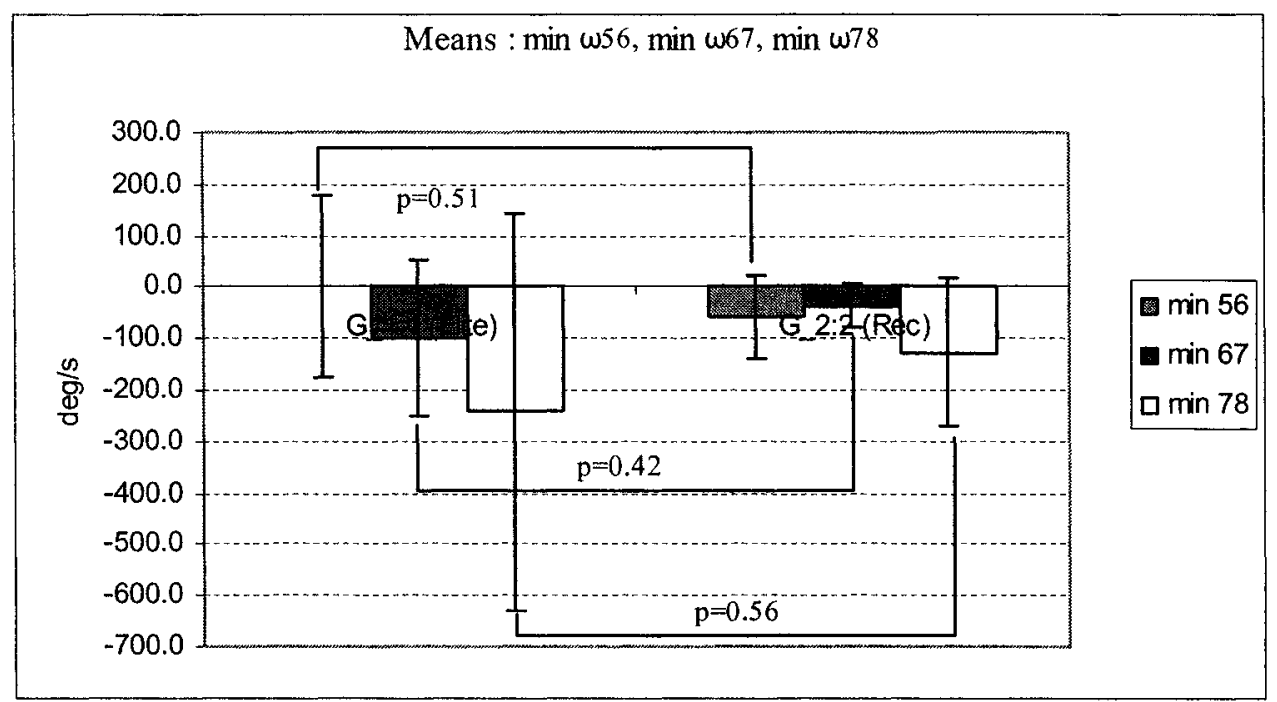

Figure 4.2.12 Stick joint angular velocities observed at stick recoil phase within $T_{A}$.

\subsubsection{ANOVA of Maximum deflection distance of the Stick: $\mathrm{d}$}

There were significant differences in maximum stick deflection distance (based on maximum angle deflection: $\max \theta)$ between both groups $(p=0.029)$ as Table 4.2.9 and Figure 4.2.13 show. 
Table 4.2.9 Maximum stick deflection.distance

\begin{tabular}{|c|c|c|}
\hline \multicolumn{3}{|c|}{$\begin{array}{l}\text { Summary Table of Means (tabstat5.sta) } \\
N=9 \text { (No missing data in dep. var. list) }\end{array}$} \\
\hline & $d$ & d \\
\hline & Mean & $\mathrm{SD}$ \\
\hline G_1:1 (Elite) & 0.040 & 0.022 \\
\hline $\mathrm{G}_{2} 2: 2(\operatorname{Rec})$ & 0.012 & 0.008 \\
\hline
\end{tabular}

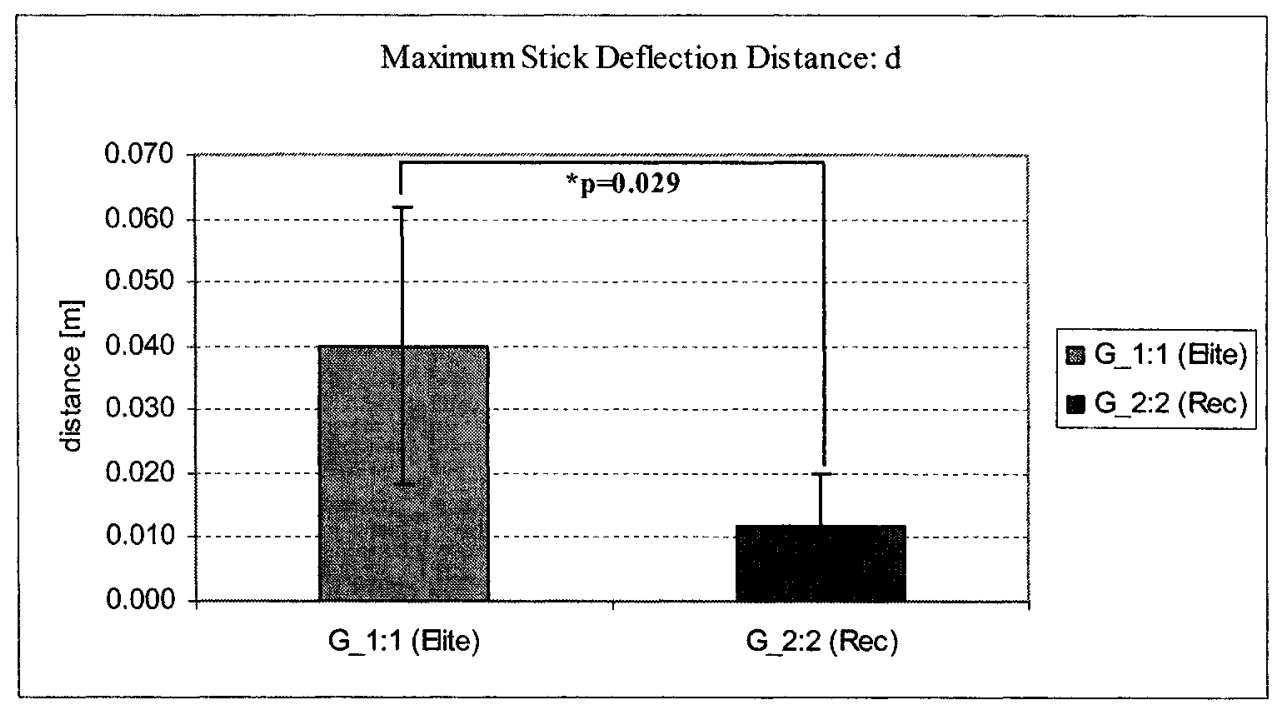

Figure 4.2.13 Maximum stick deflection distance.

\subsection{ANOVA of Stick and Puck Energy Measures.}

- Stick rotational energy: $E_{\text {av_rot }}$ (average), $E_{\text {max_rot }}$ (maximum)

- Stick translational energy : $\mathrm{E}_{\text {av_tr }_{-} \text {(average), } \mathrm{E}_{\text {max }} \text { tr }}$ (maximum)

- Total stick energy: $\mathrm{E}_{\text {av_tot }}$ (average), $\mathrm{E}_{\text {max_tot }}$ (maximum)

With regards to stick kinetic energy, NSD were found neither translational ( $E_{a_{-} \text {tr }}$

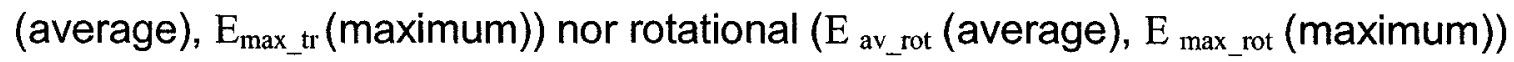
as Tables 4.3.1 - .2 and Figures 4.2.14 - .15 show. 
Table 4.3.1 Average stick kinetic energy (rotational, translational and total) in the slap shot swing.

\begin{tabular}{|c|c|c|c|c|c|c|}
\hline \multicolumn{7}{|c|}{$\begin{array}{l}\text { Summary Table of Means (tabstat5.sta) } \\
N=9 \text { (No missing data in dep. var. list) }\end{array}$} \\
\hline & $\begin{array}{l}\mathrm{E}_{\text {av rot }} \\
\text { Mean }\end{array}$ & $\mathrm{E}_{\mathrm{av} \text {,rot }}$ & $\begin{array}{l}E_{\text {av_tr }} \\
\text { Mean }\end{array}$ & $E_{\text {av_tr }}$ & $\begin{array}{l}E_{\text {av_tot }} \\
\text { Mean }\end{array}$ & $\begin{array}{c}E_{\text {av_tot }} \\
\text { SD }\end{array}$ \\
\hline G_1:1 (Elite) & 52.91 & 17.50 & 27.50 & 14.56 & 80.41 & 29.13 \\
\hline \multirow[t]{2}{*}{ G_2:2(Rec) } & 44.08 & 12.51 & 22.36 & 10.65 & 66.44 & 22.30 \\
\hline & $p=0.41$ & & $p=0.56$ & & $p=0.44$ & \\
\hline
\end{tabular}

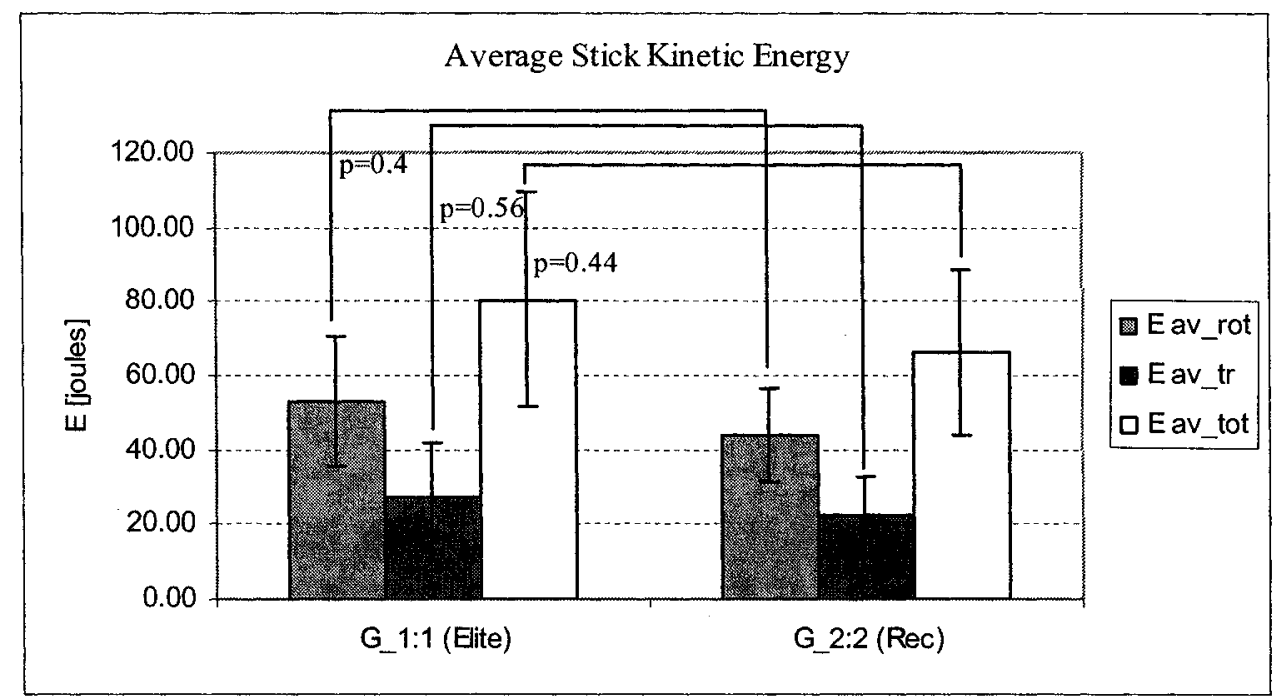

Figure 4.2.14 Average stick kinetic energy (rotational, translational and total) in the slap shot swing.

Table 4.3.2 Maximum stick kinetic energy (rotational, translational and total) in the slap shot swing.

\begin{tabular}{|c|c|c|c|c|c|c|}
\hline \multicolumn{7}{|c|}{$\begin{array}{l}\text { Summary Table of Means (tabstat5.sta) } \\
N=9 \text { (No missing data in dep. var. list) }\end{array}$} \\
\hline \multirow{3}{*}{$\begin{array}{l}\text { G_1:1 (Elite) } \\
\text { G_2:2(Rec) }\end{array}$} & $\begin{array}{c}E_{\text {max_rot }} \\
\text { Mean }\end{array}$ & $E_{\max _{-} \text {rot }}$ & $\begin{array}{r}\mathrm{E}_{\text {max_tr }} \\
\text { Mean }\end{array}$ & $\mathrm{E}_{\mathrm{SD}_{\mathrm{S}} \mathrm{tr}}$ & $\begin{array}{c}\mathrm{E}_{\text {max_tot }} \\
\text { Mean }\end{array}$ & $\mathrm{E}_{\mathrm{SD}_{\mathrm{Sax}} \text { tot }}$ \\
\hline & 103.55 & 21.87 & 75.72 & 57.37 & 179.27 & 77.46 \\
\hline & 75.35 & 23.49 & 48.09 & 20.52 & 123.44 & 42.86 \\
\hline & $p=0.11$ & & $p=0.34$ & & $p=0.21$ & \\
\hline
\end{tabular}




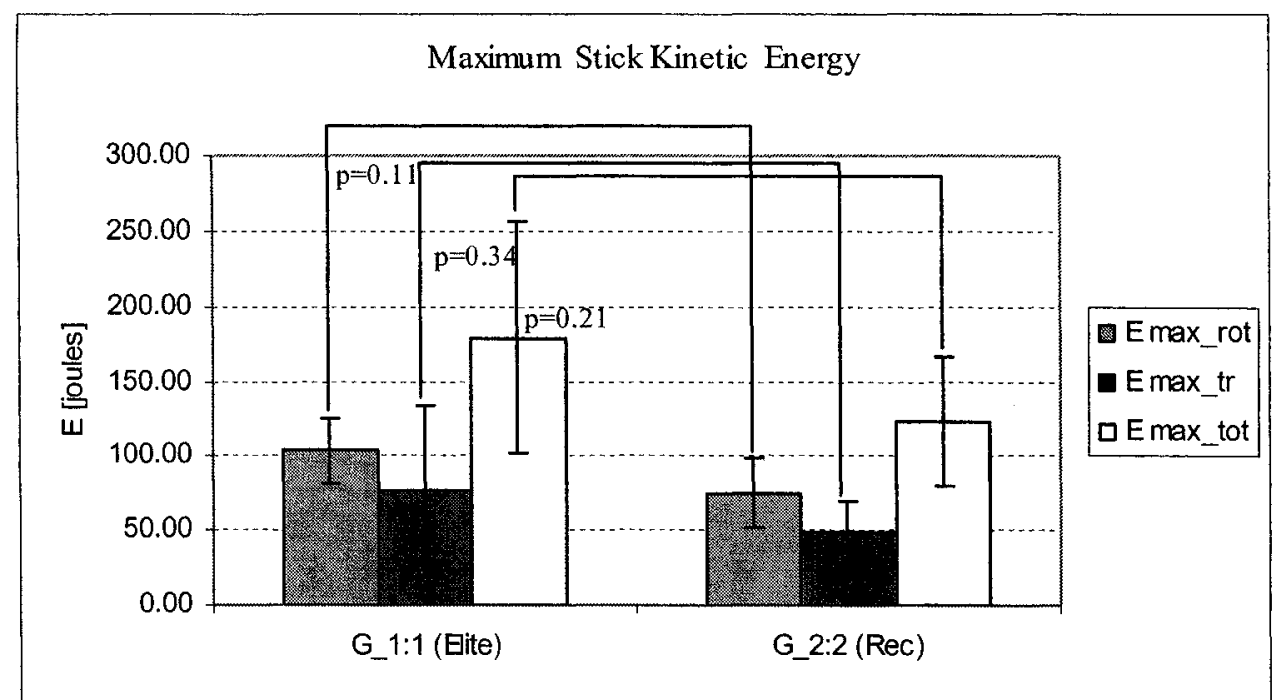

Figure 4.2.15 Maximum stick kinetic energy (rotational, translational and total) in the slap shot swing.

- Stick elastic potential (bend) energy: $E_{d}$

- Puck energy: $E_{\text {puck }}$

On the other hand, there were significant differences in stick elastic potential energy (based on maximum stick deflection distance: d) and puck energy, as Table 4.3.3. and Figures 4.2.16 - .17 show.

Table 4.3.3 Stick elastic potential and puck energies.

\begin{tabular}{|c|c|c|c|c|}
\hline \multirow{2}{*}{\multicolumn{5}{|c|}{$\begin{array}{l}\text { Summary Table of Means (tabstat5.sta) } \\
N=9 \text { (No missing data in dep. var. list) }\end{array}$}} \\
\hline & & & & \\
\hline \multirow{3}{*}{ G_1:1 (Elite) } & $\mathrm{E}_{\mathrm{d}}$ & $\mathrm{E}_{\mathrm{d}}$ & $E_{\text {puck }}$ & $\mathrm{E}_{\text {puck }}$ \\
\hline & Mean & SD & Mean & SD \\
\hline & 16.49 & 13.29 & 152.25 & 49.45 \\
\hline \multirow[t]{2}{*}{ G_ $2: 2(\operatorname{Rec})$} & 2.10 & 2.10 & 66.93 & 16.81 \\
\hline & $p=0.05$ & & $p=0.01$ & \\
\hline
\end{tabular}




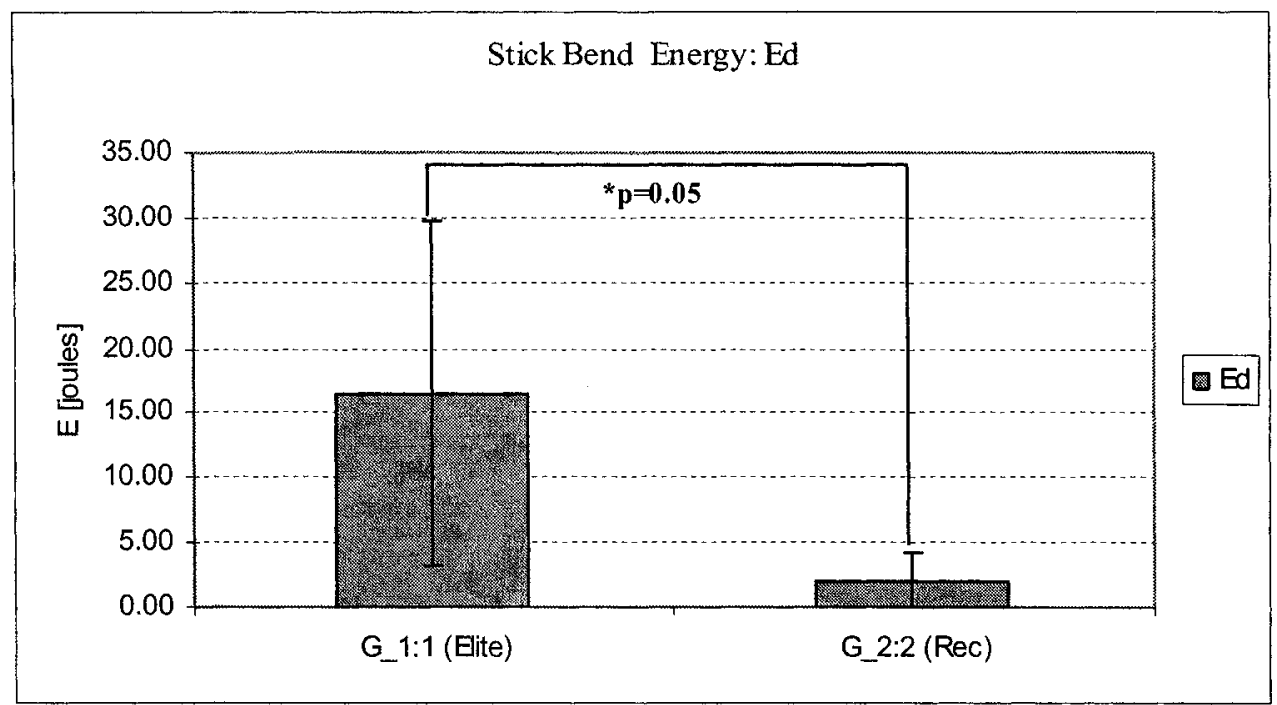

Figure 4.2.16 Means of stick elastic potential (bend) energy.

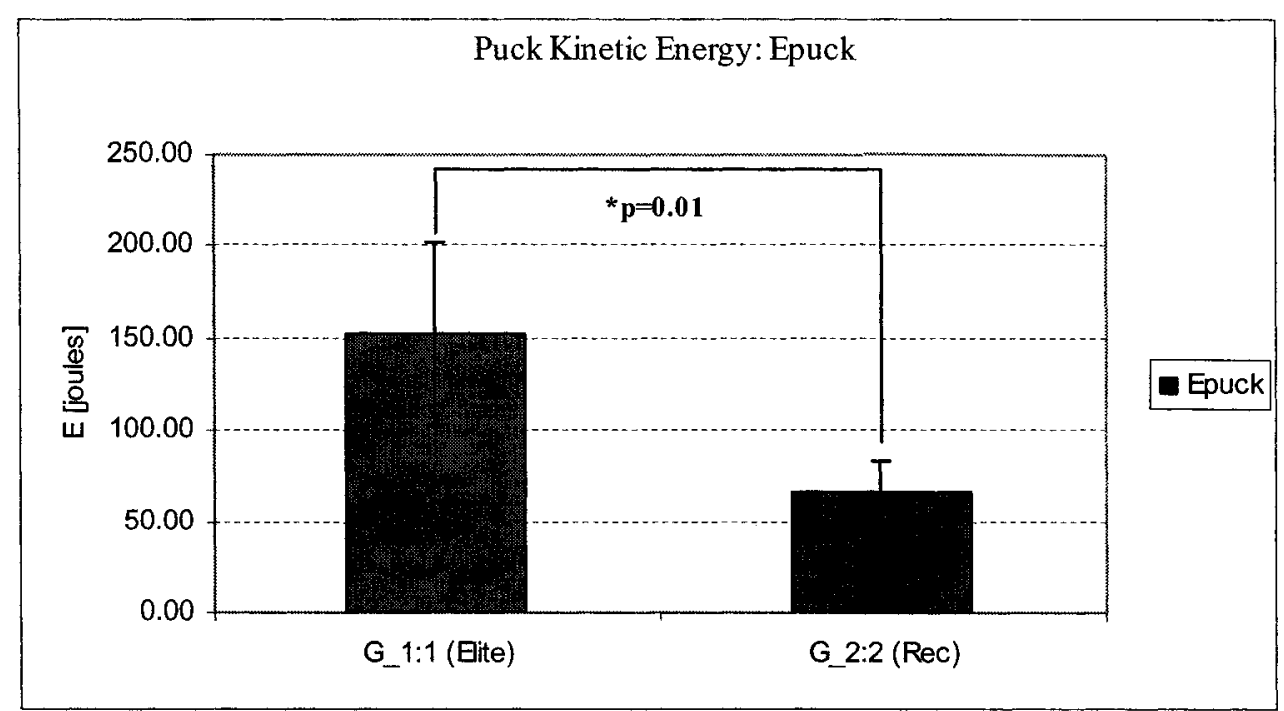

Figure 4.2.17 Means of puck kinetic energy. 


\subsection{Regressions and Correlation Statistics.}

Correlation matrices among the dependent variables (DV) are presented. Also, taking into account the final puck velocity (Vel_ms) as the predictable variable, linear regression equations and some examples of their graphical trends are presented. Overall results showed high linear relationships between the predictable variable (Vel_ms) and the dependent variables:

- Total Puck Contact: $\mathrm{T}_{B}$,

- Initial to final puck contact: $\mathrm{T}_{\mathrm{A}}$,

- Maximum segment joint angle within $\mathrm{T}_{\mathrm{A}}: \max \theta_{56 \mathrm{~A},}, \max \theta_{67 \mathrm{~A}}, \max \theta_{78 \mathrm{~A}}$,

- Maximum angle deflection in total event: $\max \theta$,

- Maximum distance deflection of the stick: $d$,

- Maximum stick kinetic energy: $\mathrm{E}_{\text {max _ot, }}, \mathrm{E}_{\text {max } \_ \text {tr }}, \mathrm{E}_{\text {max } \_ \text {tot, }}$

- Stick elastic potential (bend) energy: $E_{d}$, and

- Puck energy: $\mathrm{E}_{\text {puck }}$

\subsection{Regressions and Correlation Statistics of Puck Velocity versus average acceleration and contact times.}

The following Table 4.5.1 shows the correlation matrix between the final puck velocity (Vel_ms) and the blade-puck contact times $T_{A}$ and $T_{B}$; and the puck average acceleration (Accel), as well as with the percentage $T_{B} T_{A}$. Higher correlations (indicated in bold) between final puck velocity and contact times $T_{A}$ and $T_{B}$ were found. In the case of contact time $T_{A}$ a determinant coefficient of $r^{2}=$ 
0.54 was found (Equation 4.5.2), whereas for contact time $T_{B}$ a determinant coefficient of $r^{2}=0.82$ was found (Equation 4.5.1, Figure 4.5.1).

Table 4.5.1 Correlation matrix of DV: Puck velocity, puck aceleration and contact times.

\begin{tabular}{|c|c|c|c|c|c|}
\hline \multicolumn{6}{|c|}{$\begin{array}{l}\text { Correlations (tabstat5.sta) } \\
\text { Marked correlations are significant at } p<.05000 \\
N=9 \text { (Casewise deletion of missing data) }\end{array}$} \\
\hline & Vel_ms & Accel & $\mathrm{T}_{\mathrm{A}}$ & $\mathrm{T}_{\mathrm{B}}$ & $\mathrm{T}_{\mathrm{B}} / \mathrm{T}_{\mathrm{A}}$ \\
\hline Vel_ms & 1.00 & & & & \\
\hline Accel & 0.14 & 1.00 & & & \\
\hline $\mathrm{T}_{\mathrm{A}}$ & 0.74 & -0.49 & 1.00 & & \\
\hline $\mathrm{T}_{\mathrm{B}}$ & 0.91 & -0.19 & 0.91 & 1.00 & \\
\hline $\mathrm{T}_{\mathrm{B} / \mathrm{T}_{\mathrm{A}}}$ & 0.59 & 0.58 & 0.05 & 0.46 & 1.00 \\
\hline
\end{tabular}

- $V_{\text {puck }}=720.473 \mathrm{~T}_{\mathrm{B}}+\mathbf{4 . 4 2 2}$

$\left(\mathrm{R}=.91, \mathrm{R}^{2}=.82\right.$ Adjusted, $\left.\mathrm{R}^{2}=.79, \mathrm{p}<0.001, \mathrm{SEE}=3.20\right)$

Eq. (4.5.1)

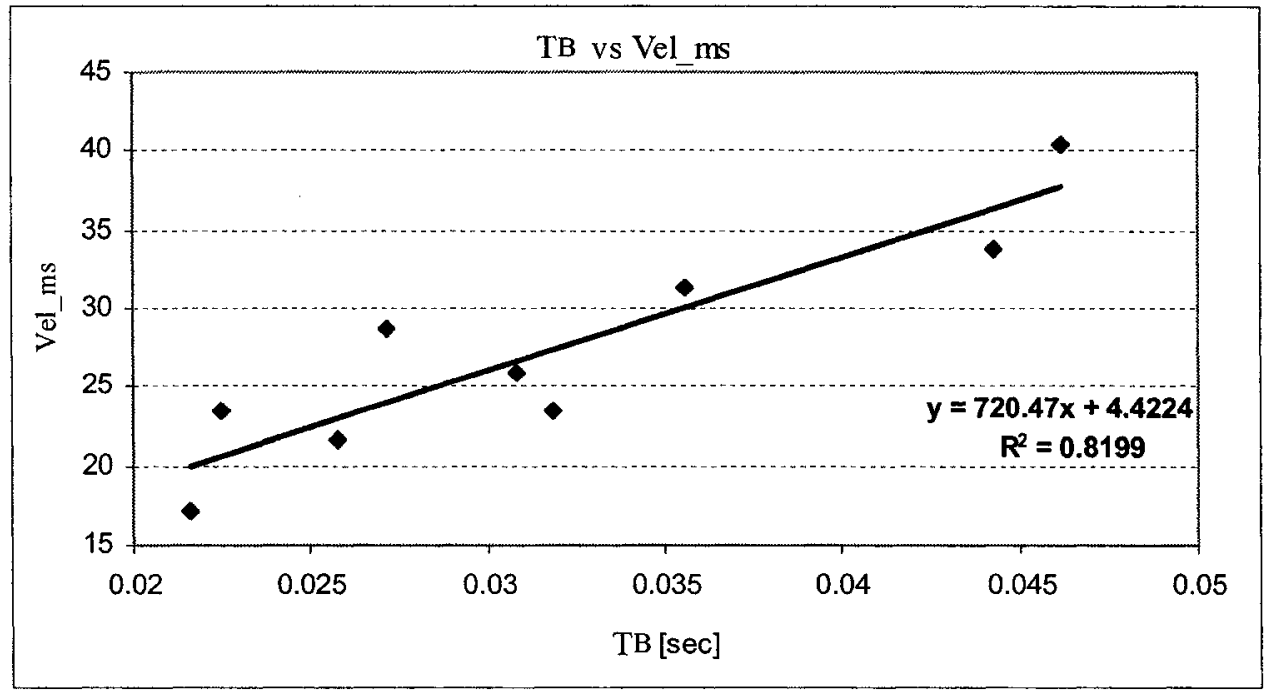

Figure 4.4.1 Linear regression for total puck contact $\left(\mathrm{T}_{\mathrm{B}}\right)$ vs final puck velocity $(\mathrm{Vel} \mathrm{ms})$

- $V_{\text {puck }}=596.21 \mathrm{~T}_{\mathrm{A}}+\mathbf{4 . 6 3}$

Eq. (4.5.2)

$\left(R=.74, R^{2}=.54\right.$ Adjusted, $R^{2}=.48, p<0.02$, SEE $\left.=5.10\right)$ 


\subsection{Regressions and Correlation Statistics of Puck Velocity versus maximum joint angle within $T_{A}$.}

The following Table 4.6.1 shows the correlation matrix between final puck velocity (Vel_ms) and the maximum segment joint angles within $T_{A}\left(\max \theta_{56} \mathrm{~A}\right.$, $\max \theta_{67 \mathrm{~A}}, \max \theta_{78 \mathrm{~A}}$ ). Also linear regressions are shown in Equations 4.6.1-.3, where higher determinant coefficient where found for joints ' $m a x \theta_{67} A_{1}$ ' and 'max $\theta_{78 \mathrm{~A}}$, that is, $r^{2}=0.65$ and $r^{2}=0.64$, respectively.

\begin{tabular}{|c|c|c|c|c|}
\hline \multicolumn{5}{|c|}{$\begin{array}{l}\text { Correlations (tabstat5.sta) } \\
\text { Marked correlations are significant at } p<.05000 \\
\mathrm{~N}=9 \text { (Casewise deletion of missing data) }\end{array}$} \\
\hline & Vel_ms & $\max \theta_{56 \mathrm{~A}}$ & $\max \theta_{67 \mathrm{~A}}$ & $\max \theta_{78 \mathrm{~A}}$ \\
\hline Vel_ms & 1.00 & & & \\
\hline $\max \theta_{56 \mathrm{~A}}$ & 0.66 & 1.00 & & \\
\hline $\max \theta_{67 \mathrm{~A}}$ & 0.81 & 0.64 & 1.00 & \\
\hline $\max \theta_{78 \mathrm{~A}}$ & 0.80 & 0.51 & 0.97 & 1.00 \\
\hline
\end{tabular}

- $\mathrm{V}_{\text {puck }}=4.16 \max \theta_{67 \mathrm{~A}}-\mathbf{7 2 4 . 1 9}$

$\left(R=.81, R^{2}=.65\right.$ Adjusted, $R^{2}=.60, p<0.01$, SEE $\left.=4.46\right)$

Eq. (4.6.1)

- $\mathrm{V}_{\text {puck }}=2.12 \max \theta_{78 \mathrm{~A}}-359.95$

Eq. (4.6.2)

$\left(\mathrm{R}=.80, \mathrm{R}^{2}=.64\right.$ Adjusted $\left., \mathrm{R}^{2}=.59, \mathrm{p}<0.01, \mathrm{SEE}=4.49\right)$

- $V_{\text {puck }}=2.43 \max \theta_{67 \mathrm{~A}}+0.91 \max \theta_{78 \mathrm{~A}}-\mathbf{5 7 8 . 9 4}$

Eq. (4.6.3)

$\left(R=.81, R^{2}=.66\right.$ Adjusted $, R^{2}=.54, p<0.04$, SEE $\left.=4.76\right)$

\subsection{Regressions and Correlation Statistics of Puck Velocity versus times of maximum and minimum joint angles within $\mathbf{T}_{\mathrm{A}}$.}

The following Table 4.7.1 shows the correlation matrix between final puck velocity (Vel_ms) and the times to maximum (Time 2: $\mathrm{T}_{\max } 856 \mathrm{~A}, \mathrm{~T}_{\max } \theta 67 \mathrm{~A}, \mathrm{~T} \max \theta 78$ 
A) and minimum (Time 4:T $\min \theta 56 \mathrm{~A}, \mathrm{~T} \min \theta 67 \mathrm{~A}, \mathrm{~T} \min \theta 78 \mathrm{~A}$ ) segment joint angles within $\mathrm{T}_{\mathrm{A}}$. Also linear regressions are shown in Equations 4.7.1-.4, where higher determinant coefficient where found for times to minimum segment joint angles.

Table 4.7.1 Correlation matrix of DV: Puck velocity, Times to $\max$ and $\min \theta$ within $\mathrm{T}_{\mathrm{A}}$.

\begin{tabular}{|c|c|c|c|c|c|c|c|}
\hline \multicolumn{8}{|c|}{$\begin{array}{l}\text { Correlations (tabstat5.sta) } \\
\text { Marked correlations are significant at } \mathrm{p}<\text {. } \\
\mathrm{N}=9 \text { (Casewise deletion of missing data) }\end{array}$} \\
\hline & Vel_ms & $\mathrm{T}_{\max \theta 56 \mathrm{~A}}$ & $\mathrm{~T}_{\max \theta 67 \mathrm{~A}}$ & $\mathrm{~T}_{\max \theta 78 \mathrm{~A}}$ & $\mathrm{~T}_{\min \theta 56 \mathrm{~A}}$ & $\mathrm{~T}_{\min \theta 67 \mathrm{~A}}$ & $\mathrm{~T}_{\min \theta 78 \mathrm{~A}}$ \\
\hline Vel_ms & 1.00 & & & & & & \\
\hline $\mathrm{T}_{\max \theta 56 \mathrm{~A}}$ & -0.36 & 1.00 & & & & & \\
\hline $\mathrm{T}_{\max \theta 67 \mathrm{~A}}$ & -0.42 & 0.38 & 1.00 & & & & \\
\hline $\mathrm{T}_{\max \theta 78 \mathrm{~A}}$ & -0.03 & 0.09 & 0.88 & 1.00 & & & \\
\hline $\mathrm{T}_{\min \theta 56 \mathrm{~A}}$ & 0.68 & -0.29 & -0.65 & -0.44 & 1.00 & & \\
\hline $\mathrm{T}_{\min \theta 67 \mathrm{~A}}$ & 0.72 & -0.59 & -0.65 & -0.37 & 0.91 & 1.00 & \\
\hline $\mathrm{T}_{\min } 678 \mathrm{~A}$ & 0.71 & -0.57 & -0.59 & -0.34 & 0.80 & 0.94 & 1.00 \\
\hline
\end{tabular}

- $\quad V_{\text {puck }}=237.09 \mathrm{~T}_{\min 056 \mathrm{~A}}+20.73$

Eq. (4.7.1)

$\left(R=.68, R^{2}=.46\right.$ Adjusted, $R^{2}=.38, p<0.04$, SEE $\left.=5.53\right)$

- $V_{\text {puck }}=365.63 T_{\min \theta 67 A^{+18.66}}$

Eq. (4.7.2)

$\left(R=.72, R^{2}=.52\right.$ Adjusted, $\left.R^{2}=.46, p<0.03, S E E=5.20\right)$

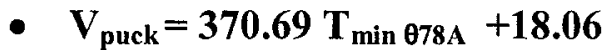

$\left(R=.71, R^{2}=.50\right.$ Adjusted, $\left.R^{2}=.43, p<0.03, S E E=5.32\right)$

Eq. (4.7.3)

- $\quad V_{\text {puck }}=90.88 T_{\min \theta 56 \mathrm{~A}}+59.99 \mathrm{~T}_{\min \theta 67 \mathrm{~A}}$

$+203.60 T_{\min \theta 78 \mathrm{~A}}+18.29$

$\left(\mathrm{R}=.73, \mathrm{R}^{2}=.54\right.$ Adjusted, $\left.\mathrm{R}^{2}=.26, p<0.24, \mathrm{SEE}=6.06\right)$

Eq. (4.7.4)

\subsection{Regressions and Correlation Statistics of Puck Velocity versus times of maximum and minimum joint angular velocities within $\mathbf{T}_{\mathbf{A}}$.}

The following Table 4.8.1 shows the correlation matrix between final puck

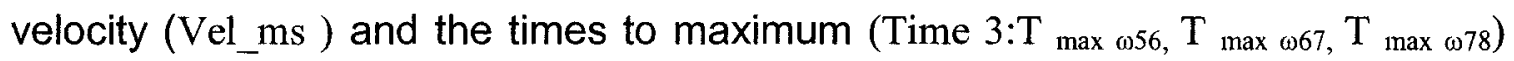




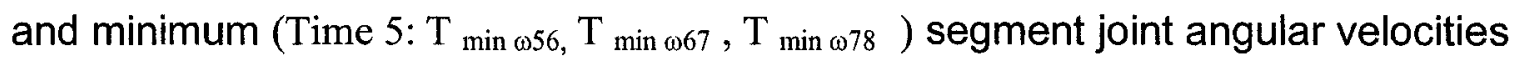
within $\mathrm{T}_{\mathrm{A}}$. Also linear regressions are shown in Equations 4.8.1-.4, where higher determinant coefficient where found for times $T_{\max \omega 56}$ and $T_{\max \omega 67}$, as well as for the time $T_{\min \omega 67}$ (Figure 4.8.1).

Table 4.8.1 Correlation matrix of DV: Puck velocity, Times to max and min $\omega$ within $\mathrm{T}_{\mathrm{A}}$.

\begin{tabular}{|c|c|c|c|c|c|c|c|}
\hline \multicolumn{8}{|c|}{$\begin{array}{l}\text { Correlations (tabstat5.sta) } \\
\text { Marked correlations are significant at } p<.05000 \\
N=9 \text { (Casewise deletion of missing data) }\end{array}$} \\
\hline & Vel_ms & $\mathrm{T}_{\max \omega 56}$ & $T_{\max } \omega 67$ & $\mathrm{~T}_{\max \omega 78}$ & $T_{\min \omega 56}$ & $\mathrm{~T}_{\min \omega 67}$ & $\mathrm{~T}_{\min \omega 78}$ \\
\hline Vel_ms & 1.00 & & & & & & \\
\hline $\mathrm{T}_{\max \omega 56}$ & 0.75 & 1.00 & & & & & \\
\hline $\mathrm{T}_{\max \omega 67}$ & 0.74 & 0.93 & 1.00 & & & & \\
\hline $\mathrm{T}_{\max \omega 78}$ & -0.12 & -0.11 & 0.06 & 1.00 & & & \\
\hline $\mathrm{T}_{\min \omega 56}$ & 0.33 & 0.09 & 0.08 & 0.62 & 1.00 & & \\
\hline $\mathrm{T}_{\min } \omega 67$ & 0.91 & 0.53 & 0.59 & -0.14 & 0.26 & 1.00 & \\
\hline $\mathrm{T}_{\min \omega} \omega 8$ & 0.01 & 0.29 & 0.24 & -0.51 & -0.57 & 0.14 & 1.00 \\
\hline
\end{tabular}

- $\quad V_{\text {puck }}=140.03 T_{\max \omega 56}+23.08$

Eq. (4.8.1)

$\left(\mathrm{R}=.75 \mathrm{R}^{2}=.56\right.$ Adjusted $\left.\mathrm{R}^{2}=.50, \mathrm{p}<0.02, \mathrm{SEE}=4.98\right)$

- $V_{\text {puck }}=864.73 T_{\min \omega 67}+8.06$

Eq. (4.8.2)

$\left(\mathrm{R}=.91 \mathrm{R}^{2}=.83\right.$ Adjusted $\left.\mathrm{R}^{2}=.81, \mathrm{p}<0.001, \mathrm{SEE}=3.12\right)$

- $\quad \mathrm{V}_{\text {puck }}=\mathbf{6 5 7 . 8 7} \mathrm{T} \min \omega 67+\mathbf{8 3 . 5 5} \mathrm{T}_{\max \omega 56-231.78 \mathrm{~T} \min \omega 78}$ $-128.99 \mathrm{~T}$ max $\omega 78+\mathbf{1 8 . 2 5}$

$\left(\mathrm{R}=.99 \mathrm{R}^{2}=.98\right.$ Adjusted $\left.\mathrm{R}^{2}=.96, \mathrm{p}<0.001, \mathrm{SEE}=1.42\right)$

Eq. (4.8.3)

- $\mathrm{V}_{\text {puck }}=331.27 \mathrm{~T}_{\max \omega 67}+19.46$

Eq. (4.8.4)

$\left(\mathrm{R}=.74, \mathrm{R}^{2}=.55\right.$ Adjusted, $\left.\mathrm{R}^{2}=.49, \mathrm{p}<0.02, \mathrm{SEE}=5.05\right)$ 


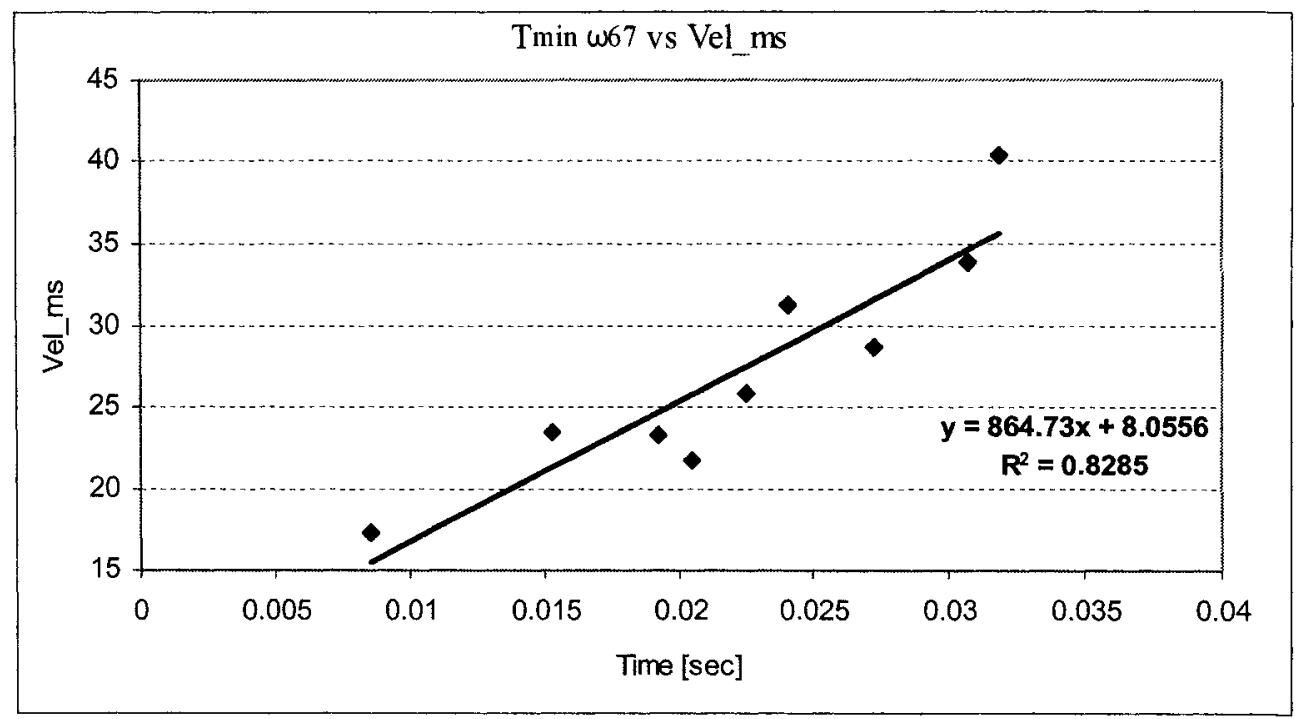

Figure 4.8.1 Linear regression for time to min $\omega$ within $T_{A}$ (Time 5): $T_{\min \omega 67}$ vs final puck velocity (Vel_ms).

\subsection{Regressions and Correlation Statistics of Puck Velocity versus maximum and minimum joint angular velocities within $\mathbf{T}_{\mathrm{A}}$.}

The following Table 4.9.1 shows the correlation matrix between final puck

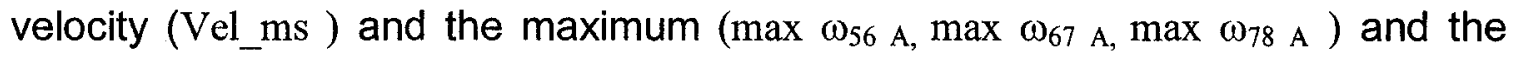
minimum (min $\omega_{56} \mathrm{~A}, \min \omega_{67 \mathrm{~A}}, \min \omega_{78 \mathrm{~A}}$ ) segment joint angular velocities within $\mathrm{T}_{\mathrm{A}}$ . Also linear regression is shown in Equation 4.9.1, where a relatively high determinant coefficient was found for $\max \omega_{78 \mathrm{~A}}$ and $\min \omega_{78 \mathrm{~A}}$ (i.e. $\mathrm{r}^{2}=0.53$ ). 
Table 4.9.1 Correlation matrix of DV: Puck velocity, maximum and minimum segment joint $\omega$ within $\mathrm{T}_{\mathrm{A}}$.

\begin{tabular}{|c|c|c|c|c|c|c|c|}
\hline \multicolumn{8}{|c|}{$\begin{array}{l}\text { Correlations (tabstat5.sta) } \\
\text { Marked correlations are significant at } p<.05000 \\
N=9 \text { (Casewise deletion of missing data) }\end{array}$} \\
\hline & Vel ms & $\max \omega_{56 \mathrm{~A}}$ & $\max \omega_{67 \mathrm{~A}}$ & $\max \omega_{78 \mathrm{~A}}$ & $\min \omega_{56 \mathrm{~A}}$ & $\min \omega_{67 \mathrm{~A}}$ & $\min \omega_{78}$ \\
\hline Vel_ms & $\overline{1} .00$ & & & & & & \\
\hline $\max \omega_{56 \mathrm{~A}}$ & -0.05 & 1.00 & & & & & \\
\hline $\max \omega_{67 \mathrm{~A}}$ & 0.42 & 0.39 & 1.00 & & & & \\
\hline $\max \omega_{78}$ & 0.61 & -0.22 & 0.65 & 1.00 & & & \\
\hline $\min \omega_{56 \mathrm{~A}}$ & 0.09 & 0.50 & -0.17 & -0.45 & 1.00 & & \\
\hline $\min \omega_{67 \mathrm{~A}}$ & -0.50 & 0.44 & -0.42 & -0.81 & 0.61 & 1.00 & \\
\hline $\min \omega_{78 \mathrm{~A}}$ & -0.49 & 0.25 & -0.34 & -0.78 & 0.47 & 0.89 & 1.00 \\
\hline
\end{tabular}

- $\mathrm{V}_{\text {puck }}=0.02 \max \omega_{78}+0.03 \min \omega_{56 \mathrm{~A}}+22.01$

Eq. (4.9.1)

$\left(\mathrm{R}=.73 \mathrm{R}^{2}=.53\right.$ Adjusted $\left.\mathrm{R}^{2}=.38, \mathrm{p}<0.1, \mathrm{SEE}=5.56\right)$

\subsection{Regressions and Correlation Statistics of Puck Velocity versus time to minimum segment joint angle within $\mathbf{T}_{\mathrm{A}}$.}

The following Table 4.10.1 shows the correlation matrix between final puck velocity (Vel_ms ) and the times to minimum segment joint angles within $T_{A}\left(T_{\min }\right.$ $\left.{ }_{056 \mathrm{~A}}, T_{\min }{ }_{667 \mathrm{~A}}, \mathrm{~T}_{\min } 078 \mathrm{~A}\right)$. Also linear regressions are shown in Equations 4.10.1.2, where low determinant coefficients where found (i.e. $r^{2}=0.47, r^{2}=0.43$ ).

Table 4.10.1 Correlation matrix of DV: Puck velocity and time to $\min \theta$ (Recoil) within $\mathrm{T}_{\mathrm{A}}$.

\begin{tabular}{|c|c|c|c|c|}
\hline \multicolumn{5}{|c|}{$\begin{array}{l}\text { Correlations (tabstat5.sta) } \\
\text { Marked correlations are significant at } p<.05000 \\
N=9 \text { (Casewise deletion of missing data) }\end{array}$} \\
\hline & Vel_ms & $\mathrm{T}_{\min \theta 56 \mathrm{~A}}$ & $\mathrm{~T}_{\min \theta 67 \mathrm{~A}}$ & $\mathrm{~T}_{\min \theta 78 \mathrm{~A}}$ \\
\hline Vel_ms & $\overrightarrow{1} .00$ & & & \\
\hline$T_{\min \theta 56 \mathrm{~A}}$ & 0.69 & 1.00 & & \\
\hline $\mathrm{T}_{\min } 067 \mathrm{~A}$ & 0.66 & 0.93 & 1.00 & \\
\hline$T_{\min } \theta 78 \mathrm{~A}$ & 0.51 & 0.80 & 0.94 & 1.00 \\
\hline
\end{tabular}


- $\mathrm{V}_{\text {puck }}=182.85 \mathrm{~T}_{\min 056 \mathrm{~A}}+25.23$

Eq. (4.10.1)

$\left(\mathrm{R}=.69, \mathrm{R}^{2}=.47\right.$ Adjusted, $\left.\mathrm{R}^{2}=.39, \mathrm{p}<0.04, \mathrm{SEE}=5.48\right)$

- $\mathrm{V}_{\text {puck }}=212.37 \mathrm{~T}_{\min } 667 \mathrm{~A}+25.93$

$\left(\mathrm{R}=.66, \mathrm{R}^{2}=.43\right.$ Adjusted, $\left.\mathrm{R}^{2}=.35, \mathrm{p}<0.05, \mathrm{SEE}=5.68\right)$

Eq. (4.10.2)

\subsection{Regressions and Correlation Statistics of Puck Velocity versus maximum and minimum segment joint angle in total event.}

The following Table 4.11.1 shows the correlation matrix between final puck velocity (Vel_ms) and the maximum ( $\left.\max \theta_{56,}, \max \theta_{67}, \max \theta_{78}\right)$ and the minimum (min $\theta_{56}, \min \theta_{67}, \min \theta_{78}$ ) segment joint angles in total event. Also linear regression is shown in Equation 4.11.1, where a relatively high determinant coefficient was found for joint ' $m a x \theta_{67}$ ', that is, $r^{2}=0.57$.

Table 4.11.1 Correlation matrix of DV: Puck velocity, maximum and minimum angle in total event.

\begin{tabular}{|c|c|c|c|c|c|c|c|}
\hline \multicolumn{8}{|c|}{$\begin{array}{l}\text { Correlations (tabstat5.sta) } \\
\text { Marked correlations are significant at } p<.05000 \\
\mathrm{~N}=9 \text { (Casewise deletion of missing data) }\end{array}$} \\
\hline & Vel_ms & $\max \theta_{56}$ & $\max \theta_{67}$ & $\max \theta_{78}$ & $\min \theta_{56}$ & $\min \theta_{67}$ & $\min \theta_{78}$ \\
\hline Vel_ms & $\overline{1} .00$ & & & & & & \\
\hline $\max \theta_{56}$ & 0.53 & 1.00 & & & & & \\
\hline $\max \theta_{67}$ & 0.75 & 0.50 & 1.00 & & & & \\
\hline $\max \theta_{78}$ & 0.64 & 0.38 & 0.97 & 1.00 & & & \\
\hline $\min \theta_{56}$ & -0.43 & 0.09 & -0.51 & -0.52 & 1.00 & & \\
\hline $\min \theta_{67}$ & -0.60 & -0.28 & -0.68 & -0.63 & 0.86 & 1.00 & \\
\hline $\min \theta_{78}$ & -0.65 & -0.24 & -0.63 & -0.63 & 0.86 & 0.82 & 1.00 \\
\hline
\end{tabular}

- $\mathrm{V}_{\text {puck }}=\mathbf{5 . 0 6} \max \boldsymbol{\theta}_{67} \mathbf{- 8 9 3 . 2 8}$

$\left(\mathrm{R}=.75, \mathrm{R}^{2}=.57\right.$ Adjusted, $\left.\mathrm{R}^{2}=.51, \mathrm{p}<0.02, \mathrm{SEE}=4.96\right)$

Eq. (4.11.1) 


\subsection{Regressions and Correlation Statistics of Puck Velocity versus time to minimum segment joint angle in total event.}

The following Table 4.12.1 shows the correlation matrix between final puck velocity (Vel_ms ) and the times to minimum segment joint angles in total event $\left(\mathrm{T}_{\min }{ }_{856}, \mathrm{~T}_{\min }{ }_{\theta 67}, \mathrm{~T}_{\min }{ }_{\theta 78}\right)$. Also linear regressions are shown in Equation 4.12.1 and Figure 4.12.1, where a high determinant coefficient was found for the time $' T_{\min } \theta 56^{\prime}\left(\right.$ i.e. $\left.\mathrm{r}^{2}=0.75\right)$.

Table 4.12.1 Correlation matrix of DV: Puck velocity and time to $\min \theta$ in total event.

\begin{tabular}{|c|c|c|c|c|}
\hline \multicolumn{5}{|c|}{$\begin{array}{l}\text { Correlations (tabstat5.sta) } \\
\text { Marked correlations are significant at } p< \\
.05000\end{array}$} \\
\hline \multicolumn{5}{|c|}{$\mathrm{N}=9$ (Casewise deletion of missing data) } \\
\hline & Vel_ms & $T_{\min } \theta 56$ & $T_{\min \theta 67}$ & $\mathrm{~T}_{\min } \theta 78$ \\
\hline Vel_ms & $\overline{1} .00$ & & & \\
\hline $\mathrm{T}_{\min } \theta 56$ & 0.87 & 1.00 & & \\
\hline$T_{\min } \theta 67$ & 0.60 & 0.71 & 1.00 & \\
\hline $\mathrm{T}_{\min } \theta 78$ & -0.44 & -0.08 & 0.00 & 1.00 \\
\hline
\end{tabular}

- $\mathrm{V}_{\text {puck }}=97.94 \mathrm{~T}_{\min } \mathbf{8 5 6}+\mathbf{2 5 . 4 2}$

Eq. (4.12.1) $\left(\mathrm{R}=.87, \mathrm{R}^{2}=.75\right.$ Adjusted $\left., \mathrm{R}^{2}=.72, \mathrm{p}<0.002, \mathrm{SEE}=3.74\right)$ 


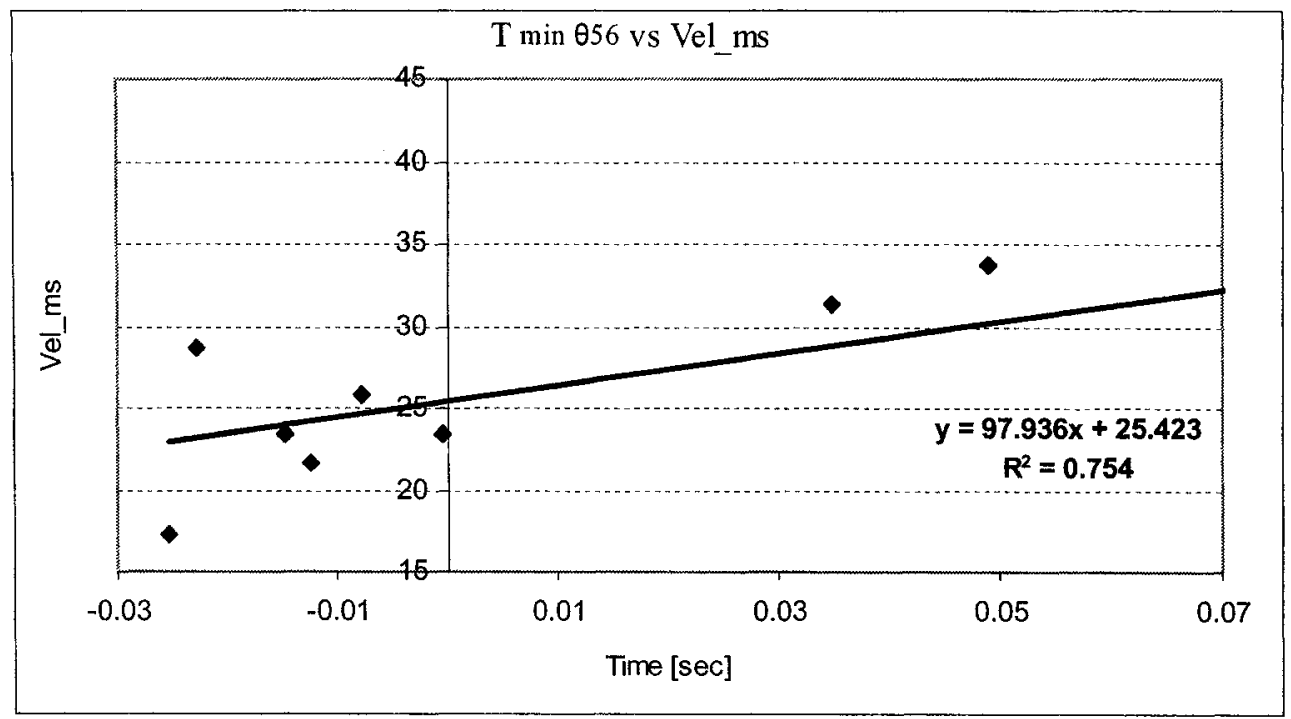

Figure 4.12.1 Linear regression for time to $\min \theta$ in total event: $T_{\min } \theta 56$, vs final puck velocity (Vel_ms).

\subsection{Regressions and Correlation Statistics of Puck Velocity versus recoil} angle and time to maximum total deflection in total event.

The following Table 4.13.1 shows the correlation matrix between final puck velocity (Vel_ms ) and the recoil angle $\left(\operatorname{Reco} \theta_{56}, \operatorname{Reco} \theta_{67}, \operatorname{Reco} \theta_{78}\right)$, as well as with the time to maximum total deflection in total event $(T \max \theta)$. Also linear regressions are shown in Equation 4.13.1-.2, where relatively high determinant coefficients were found for the recoil angles 'Reco $\theta_{67}$ ' and ' $R e c 0 \theta_{78}$ ', that is, $r^{2}=0.49$ and $r^{2}=0.50$, respectively. 
Table 4.13.1 Correlation matrix of DV: Puck velocity, recoil angle in total event and time to max total deflection $\theta$ in total event .

\begin{tabular}{|c|c|c|c|c|c|}
\hline \multicolumn{6}{|c|}{$\begin{array}{l}\text { Correlations (tabstat5.sta) } \\
\text { Marked correlations are significant at } p<.05000 \\
N=9 \text { (Casewise deletion of missing data) }\end{array}$} \\
\hline & Vel ms & $\operatorname{Reco} \theta_{56}$ & $\operatorname{Reco} \theta_{67}$ & $\operatorname{Reco} \theta_{78}$ & $\mathrm{~T}_{\max } \theta$ \\
\hline Vel_ms & $\overline{1.00}$ & & & & \\
\hline $\operatorname{Reco} \theta_{56}$ & 0.65 & 1.00 & & & \\
\hline $\operatorname{Reco} \theta_{67}$ & 0.70 & 0.92 & 1.00 & & \\
\hline $\operatorname{Reco} \theta_{78}$ & 0.71 & 0.88 & 0.90 & 1.00 & \\
\hline$T_{\max } \theta$ & 0.40 & 0.51 & 0.54 & 0.59 & 1.00 \\
\hline
\end{tabular}

- $V_{\text {puck }}=1.64 \operatorname{Reco} \theta_{67}+19.09$

Eq. $(4.13 .1)$

$\left(\mathrm{R}=.70, \mathrm{R}^{2}=.49\right.$ Adjusted, $\left.\mathrm{R}^{2}=.42, \mathrm{p}<0.03, \mathrm{SEE}=5.36\right)$

- $V_{\text {puck }}=1.12 \operatorname{Reco}_{78}+19.28$

$\left(\mathrm{R}=.71, \mathrm{R}^{2}=.50\right.$ Adjusted, $\left.\mathrm{R}^{2}=.44, \mathrm{p}<0.03, \mathrm{SEE}=5.28\right)$

Eq. (4.13.2)

\subsection{Regressions and Correlation Statistics of Puck Velocity versus maximum and minimum angle deflections in total event, and maximum deflection distance.}

The following Table 4.14.1 shows the correlation matrix between final puck velocity $\left(\mathrm{Vel} \_\mathrm{ms}\right)$ and the maximum $(\max \theta)$ and the minimum $(\min \theta)$ angle deflections in total event, as well as with the maximum deflection distance of the stick (d). Also linear regressions are shown in Equations 4.14.1-.2 and Figures 4.14.1-.2, where high determinant coefficients were found for maximum angle deflection $(\max \theta)$ and for maximum distance deflection of the stick (d), that is, $r^{2}=0.82$ for both variables. 
Table 4.14.1 Correlation matrix of DV: Puck velocity, maximum and minimum angle deflection in total event, and maximum stick deflection distance.

\begin{tabular}{|c|c|c|c|c|c|c|}
\hline \multicolumn{7}{|c|}{$\begin{array}{l}\text { Correlations (tabstat5.sta) } \\
\text { Marked correlations are significant at } p<.05000 \\
\mathrm{~N}=9 \text { (Casewise deletion of missing data) }\end{array}$} \\
\hline & Vel_ms & $\max \theta(\mathrm{deg})$ & $\max \theta(\mathrm{rad})$ & $\min \theta(\mathrm{deg})$ & $\min \theta(\mathrm{rad})$ & $\mathrm{d}$ \\
\hline Vel_ms & 1.00 & & & & & \\
\hline $\max \theta(\mathrm{deg})$ & 0.91 & 1.00 & & & & \\
\hline $\max \theta(\mathrm{rad})$ & 0.91 & 1.00 & 1.00 & & & \\
\hline $\min \theta(\mathrm{deg})$ & 0.04 & 0.15 & 0.15 & 1.00 & & \\
\hline $\min \theta(\mathrm{rad})$ & 0.04 & 0.15 & 0.15 & 1.00 & 1.00 & \\
\hline $\mathrm{d}$ & 0.91 & 1.00 & 1.00 & 0.15 & 0.15 & 1.00 \\
\hline
\end{tabular}

- $\mathrm{V}_{\text {puck }}=1.64 \max \theta+19.73$

$\left(\mathrm{R}=.91, \mathrm{R}^{2}=.82\right.$ Adjusted, $\left.\mathrm{R}^{2}=.80, \mathrm{p}<0.0008, \mathrm{SEE}=3.18\right)$

Eq. (4.14.1)

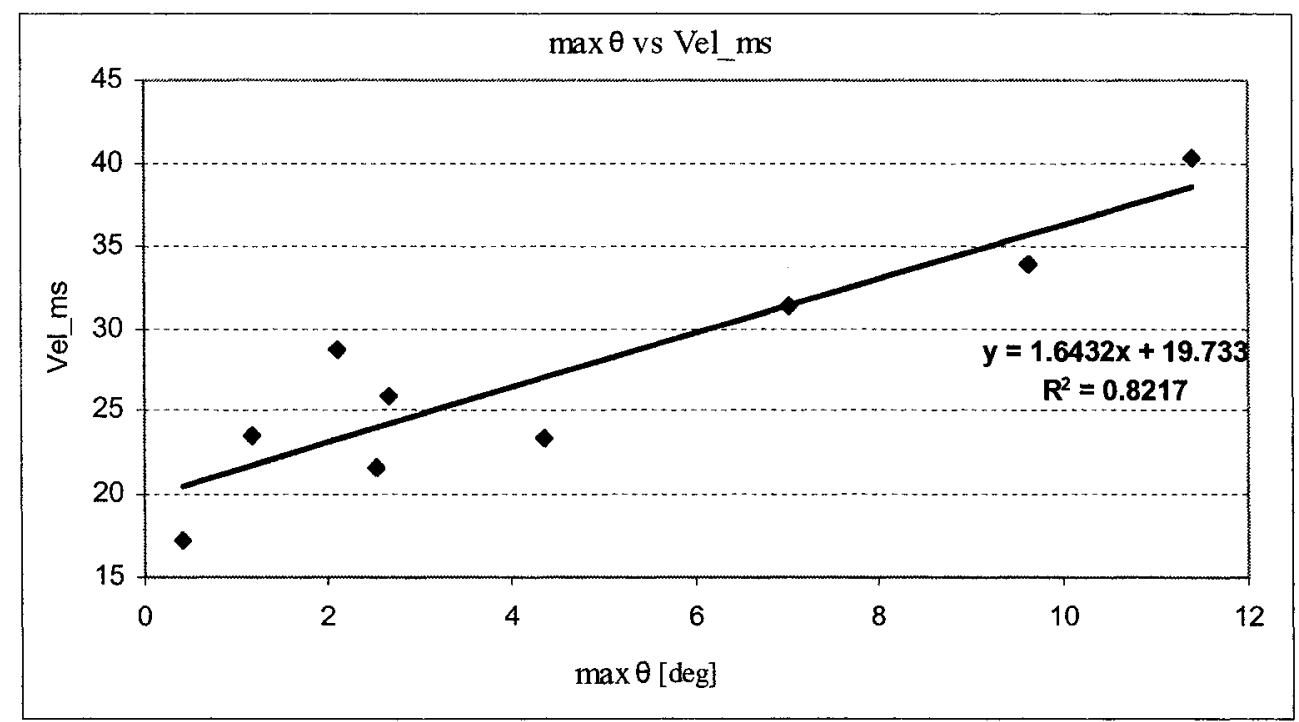

Figure 4.14.1 Linear regression for maximum angle deflection in total event: $\max \theta$ vs final puck velocity (Vel_ms).

- $\quad V_{\text {puck }}=308.51 \mathrm{~d}+19.78$

Eq. (4.14.2)

$\left(\mathrm{R}=.91, \mathrm{R}^{2}=.82\right.$ Adjusted, $\left.\mathrm{R}^{2}=.80, \mathrm{p}<0.0007, \mathrm{SEE}=3.16\right)$ 


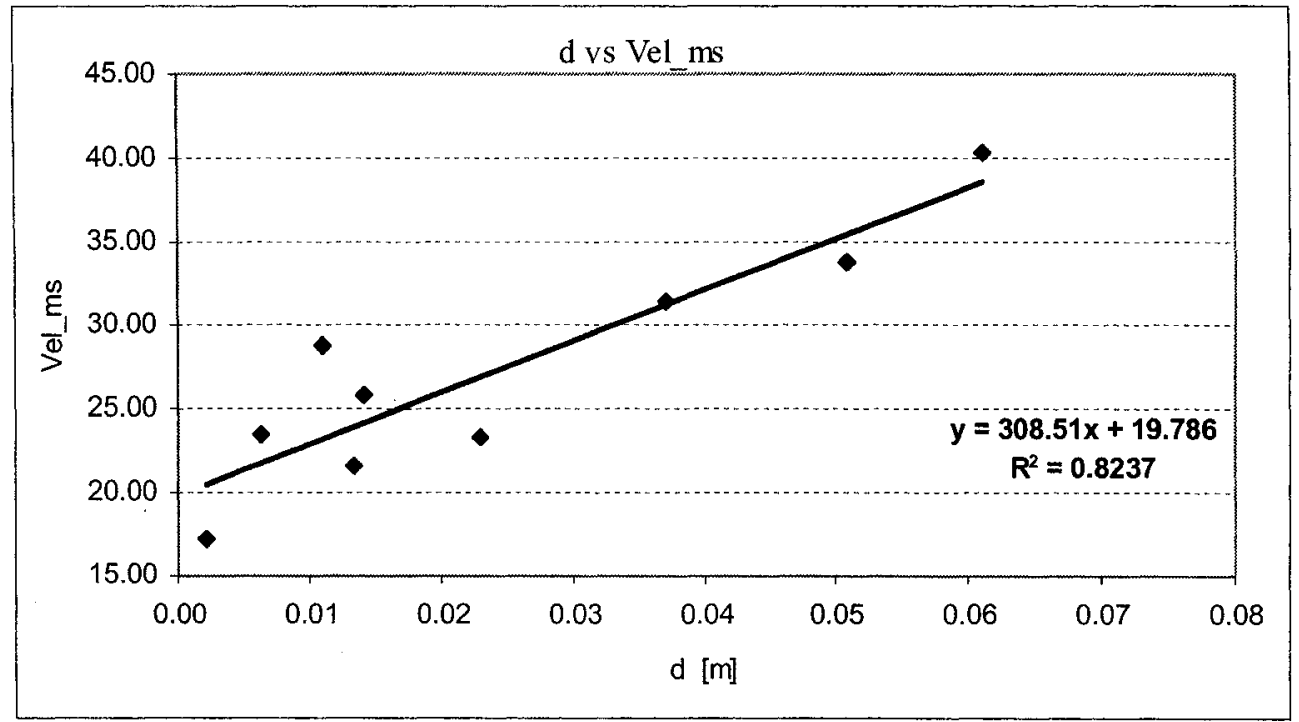

Figure 4.14.2 Linear regression for maximum deflection distance of the stick: $d$ vs final puck velocity (Vel_ms).

\subsection{Regressions and Correlation Statistics of Puck Velocity versus times to maximum and minimum total deflections in total event.}

The following Table 4.15.1 shows the correlation matrix between final puck velocity (Vel_ms ) and the times to maximum $\left(T_{\max \theta}\right)$ and to minimum ( $T$ min $\theta$ ) angle deflections in total event. Also linear regression is shown in Equation 4.15.1, where a relatively low determinant coefficient was found for $T \min \theta$, that is, $r^{2}=0.48$

Table 4.15.1 Correlation matrix of DV: Puck velocity, time to $\max$ and $\min$ total deflection $\theta$ in total event.

\begin{tabular}{|c|c|c|c|}
\hline \multicolumn{4}{|c|}{$\begin{array}{l}\text { Correlations (tabstat5.sta) } \\
\text { Marked correlations are significant at } p<.05000 \\
N=9 \text { (Casewise deletion of missing data) }\end{array}$} \\
\hline & Vel_ms & $\mathrm{T}_{\max \theta} \theta$ & $\mathrm{T}_{\min \theta}$ \\
\hline Vel_ms & -1 & & \\
\hline $\mathrm{T}_{\max \theta}$ & 0.40 & 1 & \\
\hline $\mathrm{T}_{\min \theta}$ & 0.70 & -0.03 & 1 \\
\hline
\end{tabular}

- $V_{\text {puck }}=296.57 T_{\min \theta}+21.85$

Eq. $(4.15 .1)$

$\left(\mathrm{R}=.70, \mathrm{R}^{2}=.48\right.$ Adjusted, $\left.\mathrm{R}^{2}=.41, \mathrm{p}<0.04, \mathrm{SEE}=5.41\right)$ 


\subsection{Regressions and Correlation Statistics of Puck Velocity versus stick and puck kinetic energies.}

The following Table 4.16.1 shows the correlation matrix between final puck velocity (Vel_ms ) and:

- Stick rotational energy: $\mathrm{E}_{\text {av_rot }}$ (average), $\mathrm{E}_{\text {max_rot }}$ (maximum)

- Stick translational energy : $\mathrm{E}_{\text {av_tr }}$ (average), $\mathrm{E}_{\text {max } \_ \text {tr }}$ (maximum)

- Total stick energy: $\mathrm{E}_{\text {av_tot }}$ (average), $\mathrm{E}_{\text {max _tot }}$ (maximum)

- Stick elastic potential (bend) energy: $E_{d}$

- Puck energy: $\mathrm{E}_{\text {puck }}$

High correlations (indicated in bold) were found for stick maximum energies (i.e. $E_{\text {max_rot }}, E_{\max \_t r}$ ), stick elastic potential (bend) energy (i.e. $E_{d}$ ) and puck energy (i.e. $\mathrm{E}_{\text {puck }}$ ). Linear regression analysis shows these high correlations in Equations 4.16.1-.5 and Figures 4.16.1-.5, where the higher determinant coefficients were observed for the stick elastic bend energy (i.e. $E_{d}$ ) and the puck kinetic energy (i.e. $E_{\text {puck }}$ ), that is, $r^{2}=0.81$ and $r^{2}=0.97$, respectively.

Table 4.16.1 Correlation matrix of DV: Puck velocity, stick kinetic energy (translational and rotational), total stick kinetic energy, stick elastic potential energy and puck kinetic energy.

\begin{tabular}{|c|c|c|c|c|c|c|c|c|c|}
\hline \multicolumn{10}{|c|}{$\begin{array}{l}\text { Correlations (tabstat5.sta) } \\
\text { Marked correlations are significant at } p<.05000 \\
N=9 \text { (Casewise deletion of missing data) }\end{array}$} \\
\hline $\mathrm{Vel} \mathrm{ms}$ & Vel_ms & $E_{\text {av rot }}$ & $\mathrm{E}_{\text {av } \operatorname{tr}}$ & $\mathrm{E}_{\text {av tot }}$ & $\mathrm{E}_{\max \text { rot }}$ & $E_{\max } \mathrm{tr}$ & $\mathrm{E}_{\max }$ tot & $\mathrm{E}_{\mathrm{d}}$ & $E_{\text {puck }}$ \\
\hline $\mathrm{E}_{\mathrm{av} \text { rot }}$ & 0.32 & 1.00 & & & & & & & \\
\hline $\mathrm{E}_{\mathrm{av} \operatorname{tr}}$ & 0.53 & 0.75 & 1.00 & & & & & & \\
\hline $\mathrm{E}_{\text {av tot }}$ & 0.45 & 0.95 & 0.92 & 1.00 & & & & & \\
\hline $\mathrm{E}_{\max \text { rot }}$ & 0.72 & 0.68 & 0.76 & 0.77 & 1.00 & & & & \\
\hline$E_{\max } \operatorname{tr}$ & 0.72 & 0.45 & 0.85 & 0.67 & 0.80 & 1.00 & & & \\
\hline $\mathrm{E}_{\text {max tot }}$ & 0.76 & 0.57 & 0.86 & 0.75 & 0.92 & 0.97 & 1.00 & & \\
\hline $\mathrm{E}_{\mathrm{d}}$ & 0.90 & 0.07 & 0.39 & 0.23 & 0.57 & 0.75 & 0.71 & 1.00 & \\
\hline$E_{\text {puck }}$ & 0.99 & 0.26 & 0.53 & 0.41 & 0.71 & 0.77 & 0.79 & 0.95 & 1.00 \\
\hline
\end{tabular}


- $V_{\text {puck }}=0.20 \mathrm{E}_{\text {max rot }}+10.07$

$\left(\mathrm{R}=.72, \mathrm{R}^{2}=.52\right.$ Adjusted $\left., \mathrm{R}^{2}=.45, \mathrm{p}<0.03, \mathrm{SEE}=5.21\right)$

Eq. (4.16.1)

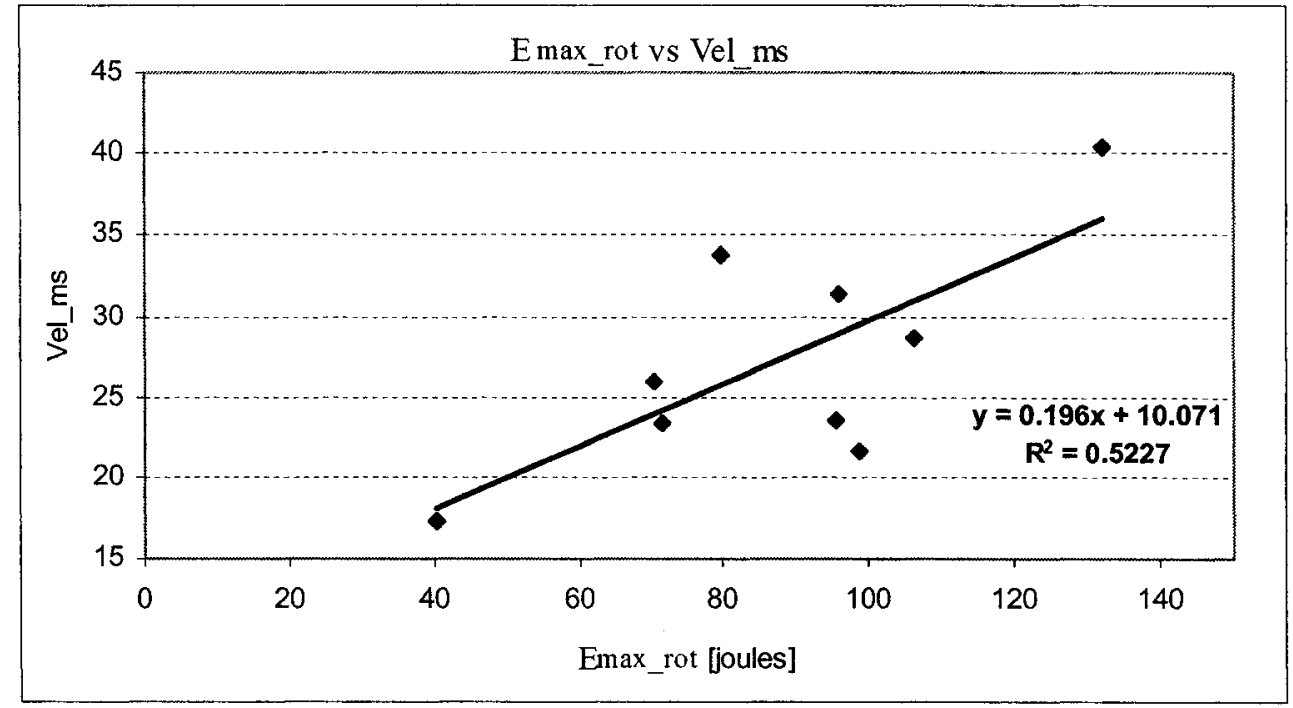

Figure 4.16.1 Linear regression for stick rotational (maximum)energy: $E_{\text {max_rot }}$ vs final puck velocity (Vel_ms).

- $V_{\text {puck }}=0.13 E_{\text {max } t r}+19.76$

$\left(\mathrm{R}=.72, \mathrm{R}^{2}=.52\right.$ Adjusted, $\left.\mathrm{R}^{2}=.45, \mathrm{p}<0.03, \mathrm{SEE}=5.21\right)$

Eq. (4.16.2)

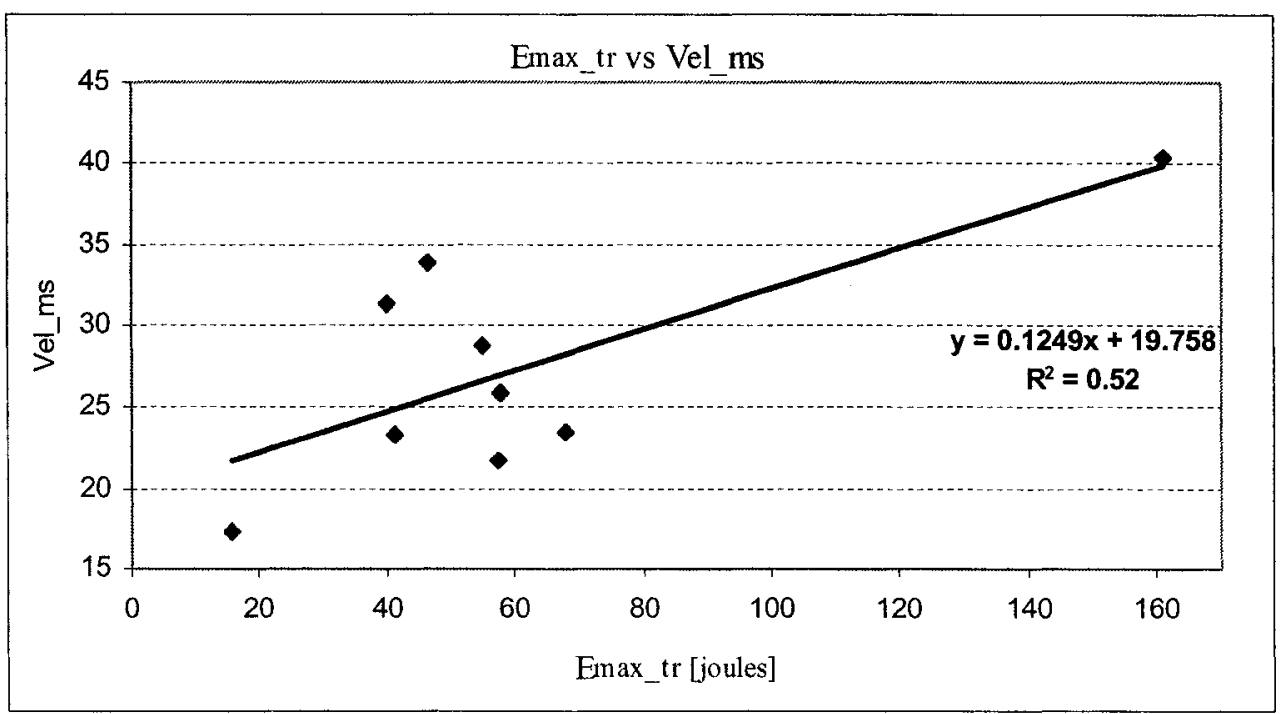

Figure 4.16.2 Linear regression for stick translational (maximum) energy: $E_{\text {max } \_r}$ vs final puck velocity (Vel_ms). 


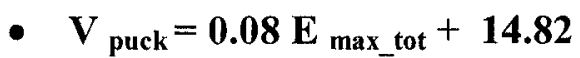

Eq. (4.16.3)

$\left(\mathrm{R}=.75, \mathrm{R}^{2}=.57\right.$ Adjusted, $\left.\mathrm{R}^{2}=.51, \mathrm{p}<0.02, \mathrm{SEE}=4.91\right)$

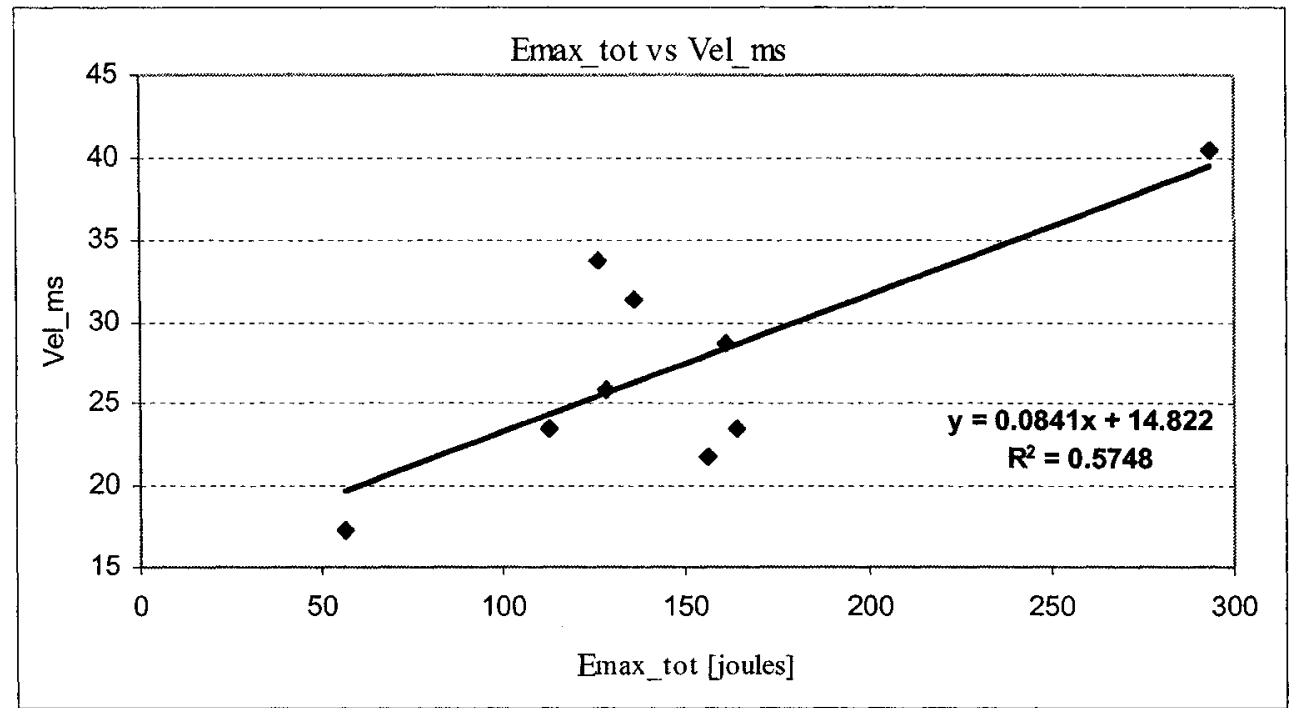

Figure 4.16.3 Linear regression for stick total (maximum) energy: $E_{\max \_ \text {tot }}$ vs final puck velocity (Vel_ms).

- $V_{\text {puck }}=0.56 \mathrm{E}_{\mathrm{d}}+\mathbf{2 2 . 5 0}$

$\left(\mathrm{R}=.90, \mathrm{R}^{2}=.81\right.$ Adjusted, $\left.\mathrm{R}^{2}=.78, \mathrm{p}<0.001, \mathrm{SEE}=3.30\right)$

Eq. (4.16.4)

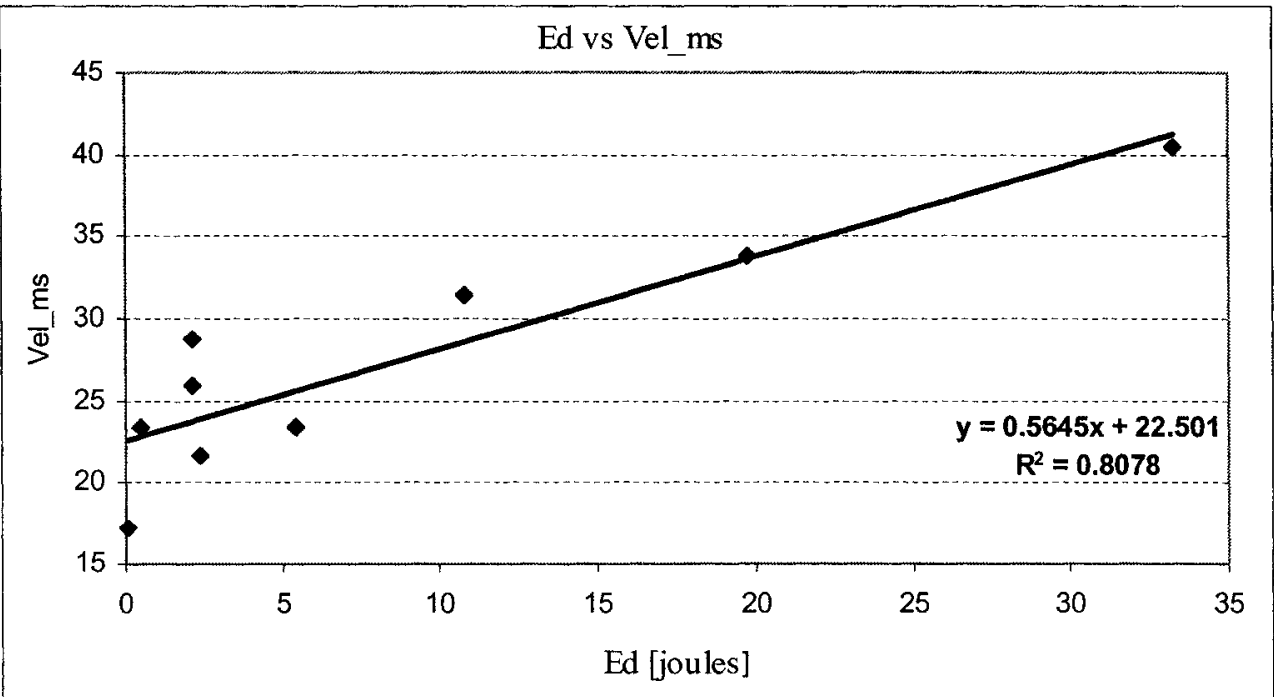

Figure 4.16.4 Linear regression for stick elastic potential (bend) energy: $E_{d}$ vs final puck velocity (Vel_ms). 
- $V_{\text {puck }}=0.13 E_{\text {puck }}+14.16$

Eq. (4.16.5)

$\left(\mathrm{R}=.99, \mathrm{R}^{2}=.97\right.$ Adjusted $\left.\mathrm{R}^{2}=.97, \mathrm{p}<0.0001, \mathrm{SEE}=1.23\right)$

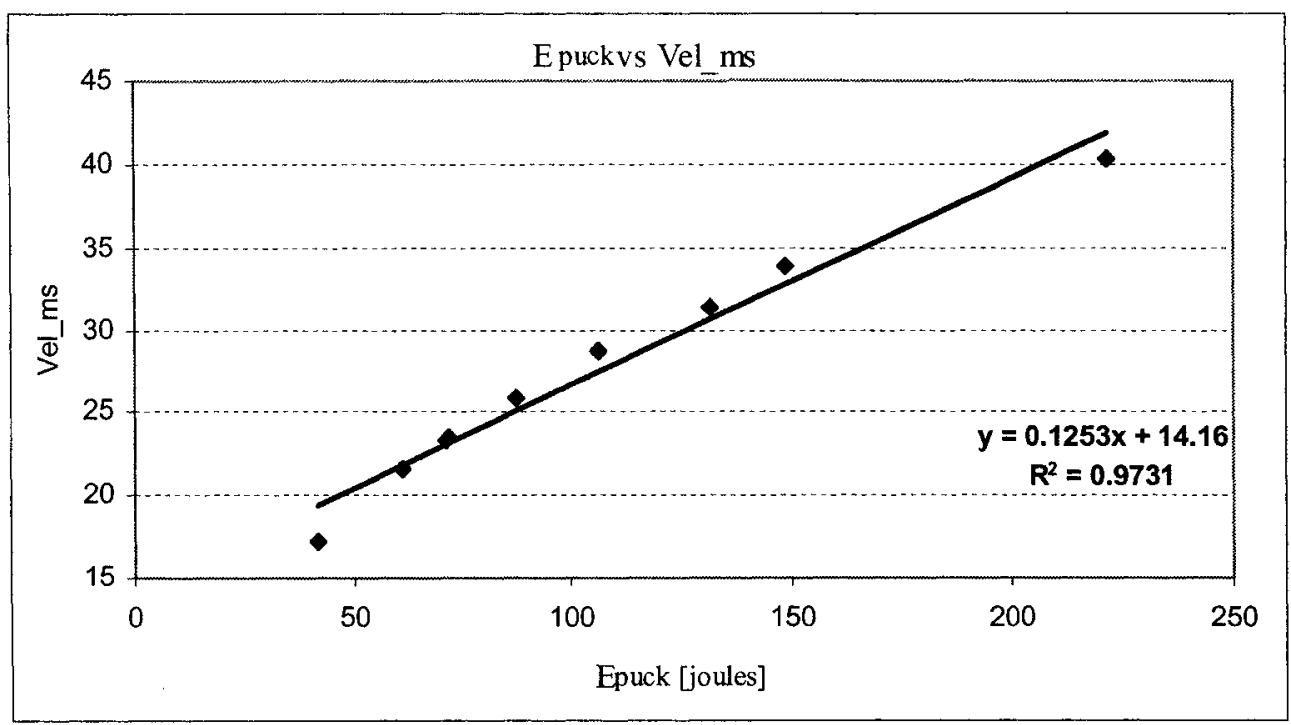

Figure 4.16.5 Linear regression for puck energy: $E_{\text {puck }}$ vs final puck velocity (Vel_ms). 


\section{CHAPTER 5}

\section{DISCUSSION}

\subsection{General- Hypotheses}

The purpose of this study was to identify the recoil effect of the ice hockey stick shaft during a stationary slap shot as observed for elite and novice players. This discussion will begin by addressing the original hypotheses.

Firstly, it was hypothesized that there would be significant differences between elite and recreational players in puck velocities and stick bending energy. This was found to be true, as the results indicated significant differences in final puck velocity $(p=0.004)$. On average, the 'elite' group achieved higher puck velocities than the 'rec' group within a range of $120.8 \pm 18 \mathrm{~km} / \mathrm{h}$ and $80.3 \pm 11.6 \mathrm{~km} / \mathrm{h}$, respectively (Table 4.1.2). Moreover, significant differences were observed in the

stick elastic (bend) energy $(p<0.05)$, whereby the 'elite' and 'rec' groups showed $16.49 \pm 13.29$ joules versus $2.10 \pm 2.10$ joules, respectively (Table 4.3.3, Figure 4.2.16).

Secondly, it was hypothesized that a high correlation between puck velocity and stick bending energy would be found. This was also shown to be true, given the high determination coefficient $\left(r^{2}=0.81\right)$ (Equation 4.15.4, Figure 4.15.4).

Thirdly, it was also hypothesized that a high correlation between blade-puck contact (acceleration and time) and puck velocity would be found. This was found to be partly true, since high correlations with puck contact times were found, that is, determination coefficients of $r^{2}=0.82$ and $r^{2}=0.54$ were found for 'total puck 
contact' $\left(T_{B}\right)$ and for 'initial to final puck contact' $\left(T_{A}\right)$, respectively (Table 4.4.1, Figure 4.4.1, Equations 4.4.1-.2). However, a low correlation with puck acceleration (Accel) was found $(r=0.14)$ as can be seen in Table 4.4.1. In addition no significant differences were found between both groups $(p=0.086)$ on puck average acceleration (Accel), which was within the range of $63.8 \pm 9.9 \mathrm{~g}$ 's and $61.8 \pm 19.5$ g's for the 'elite' and "rec" groups, respectively (Table 4.1.1).

\subsection{Puck Velocity}

As was expected, the results indicated significant differences in final puck velocity (Vel). The findings were within the range of previous studies (Alexander et al.,1963; Chau et al.,1973; Doré \& Roy,1976; Sim \& Chau, 1978; Marino, 1991; Pearsall et al., 1999 \& 2001; Wu et al., 2003). For instance Wu et al. (2003) findings for the skill group were $30.0 \pm 2.6 \mathrm{~m} / \mathrm{s}$, while peak puck velocities for the current study were $33.5 \pm 5 \mathrm{~m} / \mathrm{s}$. For the unskilled group (recreational), velocities of $23.3 \pm 3.9 \mathrm{~m} / \mathrm{s}$ were reported, whereas in this research project the recreational group performed slap shots at $22.3 \pm 3.2 \mathrm{~m} / \mathrm{s}$. However, there are small discrepancies in reported speed with other studies (Alexander et al.,1963; Cotton, 1966; Roy,1976), in which lower values for standing slap shots were reported. This might be related to the various measuring techniques used (i.e. ballistic, stop watch, cine) for recording puck velocities, among other factors (e.g. mechanical properties of the stick and the environment, subject sample size). In the present study, by integrating the data results from the accelerometer (embedded inside the puck), the puck velocity was estimated. Accelerometers 
are widely used in biomechanics research (Morris,1973; Nigg,1973; Unold,1974; Saha,1977; Denoth,1980; Bishop, 1993) as they provide direct kinetic measures (e.g. bone to bone impact forces in the ankle, Denoth,1980), fact that gives confidence to the puck velocity data obtained.

In addition, variation in player's skill (i.e. shooting technique) as well as body mass and strength may be related to the discrepancies in puck velocity reported by previous studies (Wu et al. , 2003).

\subsection{Temporal events within $\mathbf{T}_{A}$}

With regards to the temporal events of the slap shot (i.e. $T_{A}, T_{B}, t_{1}-t_{6}$ ) during puck-blade contact, a difference in both magnitude and sequence of the two main phases (i.e. stick shaft bend and recoil) between the two groups (i.e. 'elite' and 'rec') was observed. From the average times for the three stick shaft segments examined (normalized by time percentage of the blade-puck contact time, $T_{A}$ ), a consistent bend-recoil sequence for the 'elite' group was observed, in contrast to the 'rec' group, where a 'recoil' phase was relatively non existent. As shown in Figure 5.1, for the 'elite' group, the bending occurred at the instant of first contact $\left(\mathrm{t}_{1}\right)$ until $28.8 \%$ of blade-puck contact time window $\mathrm{T}_{\mathrm{A}}$, followed by the recoil phase, which lasted until $59.8 \%$ after bend phase or $88.6 \%$ after ' $t$ ' '.

On the other hand the "rec" group showed a different sequence, in which the bend phase began only half of the way through the contact time window $\mathrm{T}_{\mathrm{A}}$ (i.e. $44.4 \%$ ), covering $18.2 \%$ of $\mathrm{T}_{\mathrm{A}}$, then followed by the recoil-phase. 
The recoil-phase in the 'rec' group was presumed to account for $35.4 \%$ of the time interval, as can be seen in Figure 5.1.

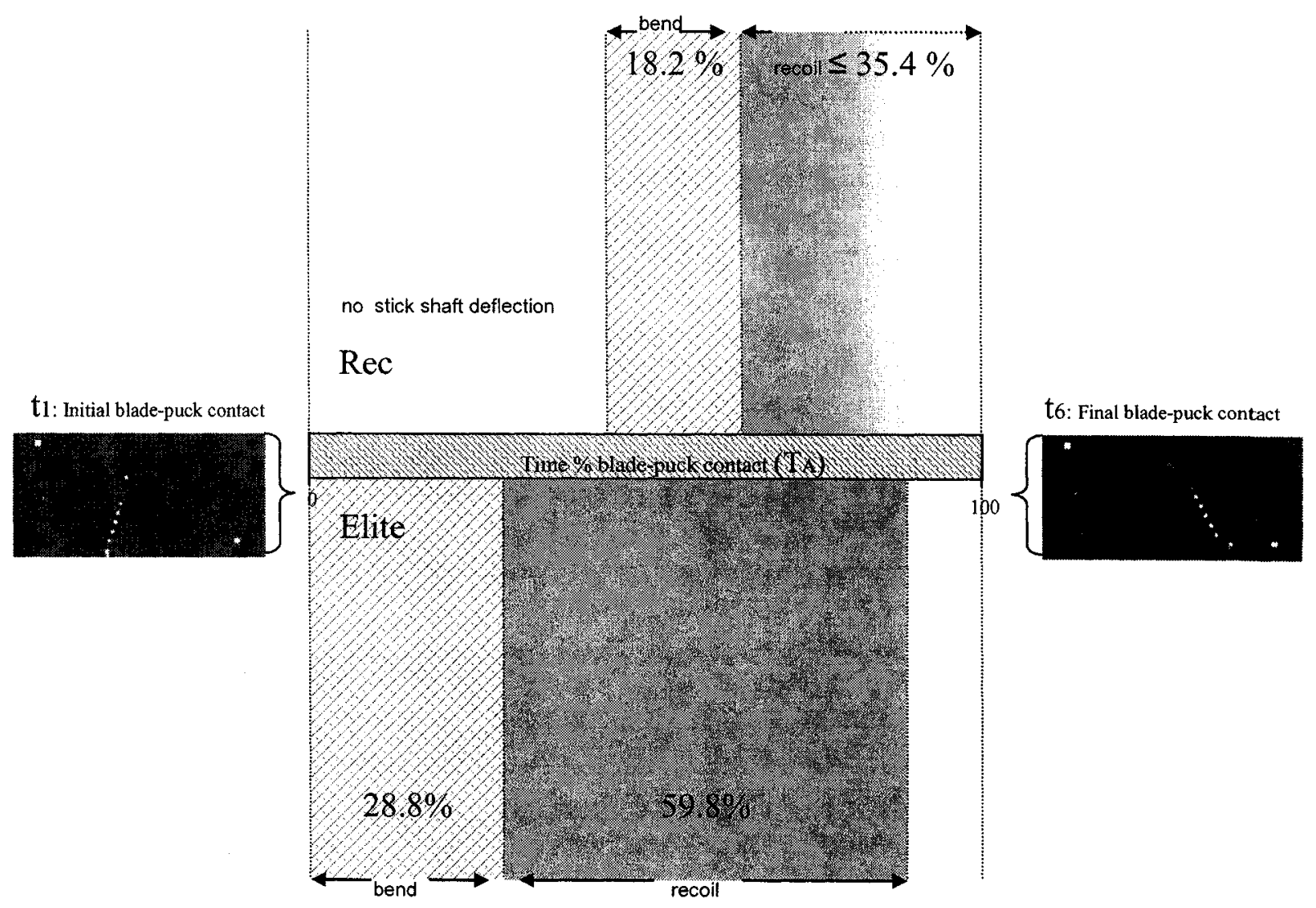

Figure 5.1 Percentage bend-recoil during puck-blade contact time in the slap shot.

The results also showed differences between 'elite' and 'rec' players based on when the maximum and minimum stick shaft angular velocities $(\omega)$ occurred; that is, the recoil-phase versus the bend-phase, respectively. Furthermore, a direct relationship between the recoil-phase and the stick angular velocity timing were suggested, since times to maximum and minimum angular velocities $(\omega)$ were found to be strongly related with the final puck velocity, as Table 4.7.1 and Equations 4.7.1-.3 indicate (e.g. $r^{2}=0.98$, Equation 4.7.3). 
The results also suggest that blade-puck contact time had a major effect on final puck velocity (Vel), and consequently on the impulse given to the puck ( i.e $\vec{J}=\int_{t 1}^{t 2} F(t) d t$ ) than puck acceleration. The regression analysis supports this fact (as shown in Table 4.4.1, Equation 4.4.1 and Figure 4.4.1), where a strong linear relationship $\left(r^{2}=0.82\right)$ between total puck contact $\left(T_{B}\right)$ and final puck velocity (Vel) was indicated. Stated simply, the longer the blade was in contact with the puck during the slap shot the greater the final puck velocity.

The significant differences found between groups in blade-puck contact time were consistent with the previous study by Woo (2004), where in the 'elite' players performed the typical shot motion with greater horizontal translation towards the target than the 'recreational' group.Thus 'elite' players have the opportunity for a longer blade-puck contact time during the slap shot.

Findings related to puck-blade impact duration have not been mentioned before in the ice hockey research literature; however, Roberts et al. (2001) reported impact duration for other sports, such as golf, football and tennis, measured with different techniques (i.e. force plate, high-speed imaging, electrical circuits). By using the electrical circuit technique the authors found the average impact duration of the golf swing of $0.000404 \mathrm{~s}$ or $0.404 \mathrm{~ms}$; that is, an excellent resolution considering nature of the event. Moreover, the electrical circuit technique was reported as the most accurate in comparison with the others, for instance, in the high speed imaging technique, the start and end points of contact are difficult to determine and the resolution of the measurement is limited by the frame rate of the camera. These facts, support the impact duration estimates 
stated in this study; which was defined by the 'initial to final puck contact' variable $\left(T_{A}\right)$ and the 'total puck contact' variable $\left(T_{B}\right)$. As Table 4.1.3 and Figure 4.1.1 shown earlier, a significant difference was found between groups in $T_{B}(p<0.04)$, within a time range of $0.038 \pm 0.009 \mathrm{~s}$ and $0.027 \pm 0.005 \mathrm{~s}$, for the 'elite' and 'rec' groups, respectively. Also, it is noticeable that $T_{B}<T_{A}$, that is, from initial ( $\left.t_{1}\right)$ to final ( $\left.t_{6}\right)$ blade-puck contact there was no continuity on the electrical circuit activation, as can be seen in Figures 3.5.3 - .4; this fact could be explained by a number of factors, including blade vibration that might have affected the properties of the electrical circuit.

\subsection{Temporal events outside $T_{A}$}

Alternatively, if we consider events beyond the boundaries of the blade-puck contact interval, in some instances the beginning of shaft bending and the completion of shaft recoil may precede or follow, respectively, blade-puck contact. For instance, typically with the 'elite' subjects, shaft bending precede blade-puck contact; however, the time at which this occurred was not determined. Similarly, both 'elite' and 'rec' subjects typically achieved ultimate shaft recoil after blade-puck contact, an event not precisely estimated. Future studies should address these points in order to determine their relevance in the performance of the slap shot.

From the above it is clear that the skill level of the players, had a major influence on the observed timing of the stick shaft bending behaviours as well as on puck impulse. 
This is supported by the significant differences found in:

- Times to minimum $\theta$ within the contact window $T_{A}$ :

$T_{\min 056 \mathrm{~A}} \quad(p=0.002)$

$T_{\min \theta 67 A} \quad(p=0.006)$,

$T_{\min \theta 78 \mathrm{~A}} \quad(p=0.032)$,

- Initial to final puck contact: $T_{A}(p<0.06)$,

- Total puck contact : $T_{B}(p<0.04)$, and

- Time to minimum $\theta$ deflection for the total event: $T \min \theta(p=0.012)$.

Thus, these findings strongly suggest that the blade-puck contact time and the interrelated bend-recoil sequence may be determinant factors in the performance of the slap shot. This notion is particularly compelling since the average acceleration magnitude was similar for both skill groups (Table 4.1.1).

\subsection{Stick angle displacements and Stick Deflection Distance}

With regards to the maximum and minimum stick joint angle displacements (i.e. bend and recoil-phases, respectively) within contact time window $\mathrm{T}_{\mathrm{A}}$ (Figure 5.2), no significant differences were found between groups except for the most proximal joint segment examined (i.e. joint 5-6).

However, as Figure 5.2 also shows, in the bend-phase, for both 'elite' and 'rec' groups, there was a trend observed of increasing shaft deflection towards the distal joint segment (i.e. 7-8) examined (Figures 4.2.1.-.2). Further, a combination of increasing and decreasing trends was observed for the recoil-phase for both groups. 


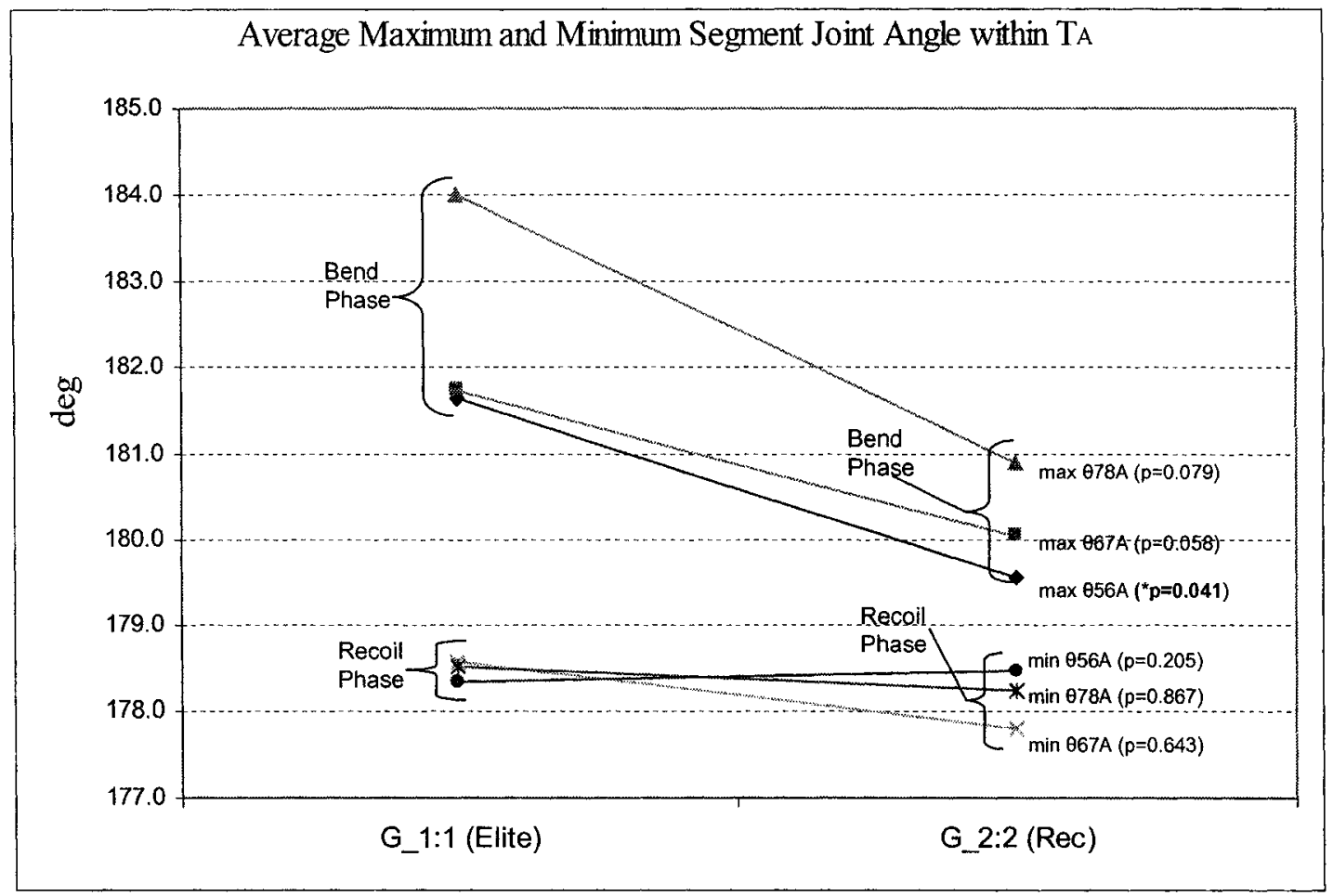

Figure 5.2 Average maximum and minimum joint angle displacements within $\mathrm{TA}$.

Also, it is observed in Figure 5.2 a greater joint angle difference between the last joint (i.e. $7-8$ ) and the others (i.e. 5-6, 6-7) in the case of the 'elite' group. This fact may contribute to the significant differences found in maximum angle deflection in the total event, and consequently to the maximum stick distance deflection, average difference between segments and stick elastic (bend) potential energy.

In general, the joint angle displacements found inside the time contact window ' $\mathrm{T}_{\mathrm{A}}$ ' were similar to trends observed in the total event (Figures 4.2.3.4). These differences in stick shaft deflections between both groups, might be related to the different load distribution applied to the stick shaft between the top and bottom hands. In other words, the shooting technique is 
determining different angular displacements within the stick shaft during a slap shot.

Findings in post hoc analysis for average joint angle displacements within groups indicate significant differences between the proximal joints $5-6,6-7$ (i.e. closer to the bottom hand), and the joint 7-8 (Figures 4.2.6 -.7). This fact lends support to the previous discussion about growing trends towards the distal joint segment 7-8 in maximum joint angle displacements, in which the 'elite' group may have proportioned the major contribution. Also, the tapering in the lower part of the shaft, which has less resistance, evidently is a contributing factor to the major angle displacements observed in the distal joint (i.e. 7-8).

In addition, regression analysis showed a strong linear relationship between maximum joint angle displacements within contact time window $T_{A}$ and final puck velocity. As can be seen in Equations 4.5.1 -.3, an average determination coefficient $\mathrm{r}^{2}=0.65$ was observed.

Hence, the group differences in maximum joint angle displacements may be interpreted to explain in large part the differences in group puck velocities. Moreover, regression analysis showed a strong relationship between the total maximum angle deflection (i.e. $\max \theta$ ) and final puck velocity (i.e. Vel), where a determination coefficient $r^{2}=0.82$ was obtained (Equation 4.13.1, Figure $4.13 .1)$.

Given the previous discussion and as it was expected, significant differences in maximum stick distance deflection were found between groups (i.e. 
$p=0.029$, Table 4.2.9, Figure 4.2.13). Furthermore, a strong relationship between maximum deflection distance and the final puck velocity was found (i.e. $r^{2}=0.82$, Equation 4.13.2, Figure 4.13.2). Together these results suggest that stick bending behaviours were strongly related to final puck velocity, corroborating the observation of Pearsall et al. (1999) and Wu et al. (2003).

\subsection{Mechanical energy and Impulse}

In general, the findings regarding kinetic energy of the system (i.e. stick-puck) may be considered consistent with the 'catapult' behaviour expected; that is, during the 'preloading' phase (i.e. blade surface contact) the stick swing energy ( $\left.E_{\text {max_tot }}\right)$ is converted in part into elastic potential energy $\left(E_{d}\right)$ within the stick's shaft and continues during the 'loading' phase (i.e. blade-puck contact) as the stick deforms by bending about its minor axis (note: this bending is distributed along the lower shaft's length and to a greater extend at its most distal end). Then, as the stick shaft unbends (i.e. recoil), the elastic potential energy of the stick is converted back into kinetic energy, which is transmitted in part or in whole to the puck (i.e. $E_{\text {puck }}$ ) and this gives additional impulse to propel the puck during 'release' and 'follow-through' phases.

No significant differences were found for the stick kinetic energy (rotational and translational) as it is observed in Tables 4.3.1-.2 and Figures 4.2.14-.15. However, significant differences between groups were found in the elastic (bend) potential energy (i.e. $E_{d}$ ) and in puck kinetic energy (i.e. $E_{\text {puck }}$ ) (Table 4.3.3 and Figures 4.2.16-.17). 
Considering the impact between puck-blade (stick) only in terms of pre-post energies, these findings were consistent with the principle of conservation of total mechanical energy of the system; in other words, the total kinetic energy is either preserved (i.e. elastic impact) or in part dissipates (i.e. non elastic impact) but does not increase. Figure 5.3 summarize these findings, in which the loss of kinetic energy of the system (i.e. stick-puck) during the impact was given by

$\Delta K E=\left(\frac{m_{s} V_{s}^{2}}{2}+\frac{m_{p} V_{p}^{2}}{2}\right)-\left(\frac{m_{s} v_{s}^{2}}{2}+\frac{m_{p} v_{p}^{2}}{2}\right)$

where

$$
\begin{aligned}
m_{s} & =\text { mass of the stick } \\
m_{p} & =\text { mass of the (puck + accelerometer) } \\
V_{s} & =\text { velocity of the stick before impact } \\
v_{s} & =\text { velocity of the stick after impact } \\
V_{p} & =\text { velocity of the puck before impact } \\
v_{p} & =\text { velocity of the puck after impact }
\end{aligned}
$$

Before impact $V_{p}=0$, then Equation (5.1) is reduced to

$$
\begin{aligned}
& \Delta K E=\left(\frac{m_{s} V_{s}^{2}}{2}\right)-\left(\frac{m_{s} v_{s}^{2}}{2}+\frac{m_{p} v_{p}^{2}}{2}\right) \\
& \text { Or } \\
& \Delta K E=E_{\text {swing }}-\left(E_{\text {bend }}+E_{\text {puck }}\right) \\
\Rightarrow & \Delta K E=E_{\text {swing }}-\left(E_{d}+E_{\text {puck }}\right)
\end{aligned}
$$


Figure 5.3 also shows the resultant 'impulse' imparted to the puck, which was given by

$\vec{J}=\int_{i 1}^{t 2} F(t) d t$

and evaluating integrals, we obtain

$$
\vec{J}=\int_{t 1}^{t 2} m \cdot \vec{a}(t) d t \quad \Rightarrow \quad \vec{J}=m\left(v_{f}-v_{i}\right)
$$

Where the linear momentum is given by

$$
p=m \cdot \vec{v}
$$

That is, the impulse imparted to the puck is equal to the change in the linear momentum of puck.

$\vec{J}=p_{f}-p_{i} \quad \Rightarrow \quad \vec{J}=\Delta p$

where the initial momentum of the puck was zero, given its resting initial condition (i.e. $v_{i}=0$ ) .

As Figure 5.3 shows, a greater loss of kinetic energy (i.e. $\Delta K E=10.53 \pm 14.72$ joules) and a greater impulse (i.e. $\vec{J}=8.71 \pm 1.3 \mathrm{~kg} \cdot \mathrm{m} / \mathrm{s}$ ) imparted to the puck was obtained for the 'elite' group, this fact is expected due to the significant differences found in stick elastic (bend) energy (i.e. $E_{d}$ ) and in the puck kinetic energy (i.e. $E_{\text {puck }}$ ).

Thus, it would appear that part of the kinetic energy of movement in the system (i.e. stick-blade) was converted into potential energy of deformation and recoiled 
back into kinetic energy of movement, this is consistent with the concept of a 'catapult' behaviour in which the kinetic energy and momentum of the bodies (i.e. system stick-puck) before blade-puck impact are determinant factors for imparting momentum and kinetic energy to the puck, in other words the amount of stick elastic (bend) energy (i.e. $E_{d}$ ) was strongly related with the final puck velocity. This fact was supported by the regression analysis, where a determination coefficient $r^{2}=0.81$ was found (Equation 4.15.4, Figure 4.15.4).

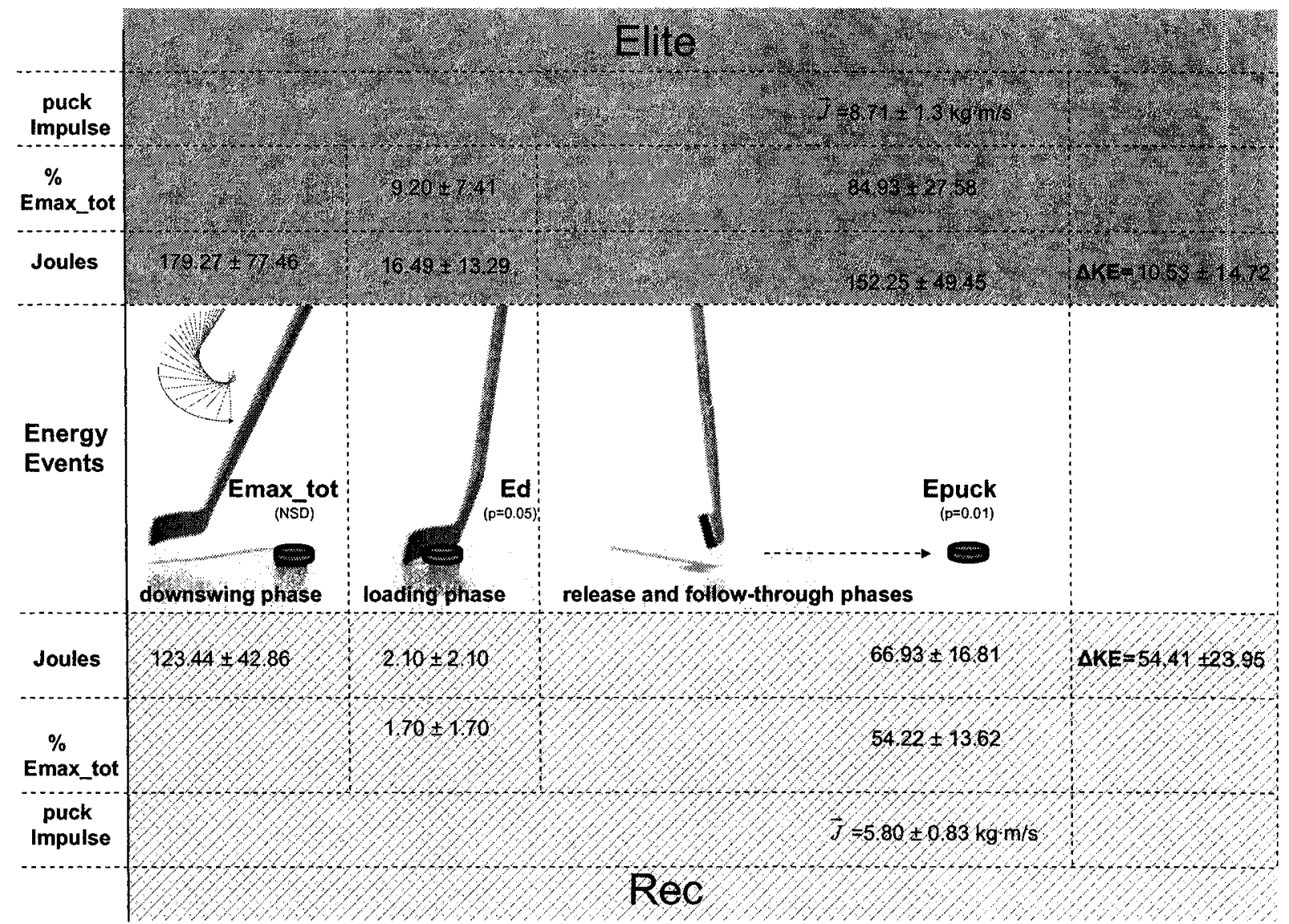

Figure 5.3 Summary of energy events for the stick-puck system during the slap shot, where swing kinetic energy $\left(E_{\text {max }}\right.$ tot $)$, stick elastic (bend) energy $\left(E_{d}\right)$ and puck kinetic energy $\left(E_{\text {puck }}\right)$ are shown. Also, loss of kinetic energy of the system $(\Delta K E)$ and the 'impulse' $(\vec{J})$ imparted to the puck are indicated.

Of course the impact scenario for this event is more complex, since the impact event was not instantaneous but instead occurred over 30 to $40 \mathrm{~ms}$, and, 
furthermore, energy gains and losses could have occurred at other stick-ground interfaces.

Muscle work performed during blade-puck contact is another factor for imparting momentum and kinetic energy to the puck, however, this was not measured given the previously established limitations of the study. Also, during blade-puck interaction the blade should be deformed during collision, however, the contribution of blade potential energy of elastic deformation was neglected in this study.

In addition to work done on the puck, there is loss of energy due to other factors such as hysteresis losses, surface-blade friction, puck surface friction, blade vibration, which finally dissipates as heat. All these factors were considered small compared to the energy transferred to the puck. Future studies should address these points in order to determine their influence on the performance of the slap shot.

\subsection{Future Directions and Relevance}

At first glance, the mechanics of the ice hockey stick may seen simplistic, however, as section 2.6 (i.e. structural dynamics) shows, the analysis of the stick mechanics in a slap shot could be achieved through a "beam" model, where the denominated "cantilever" beam configuration could mimic the stick. Such a configuration has a free point as Figure 5.7.1 shows. 


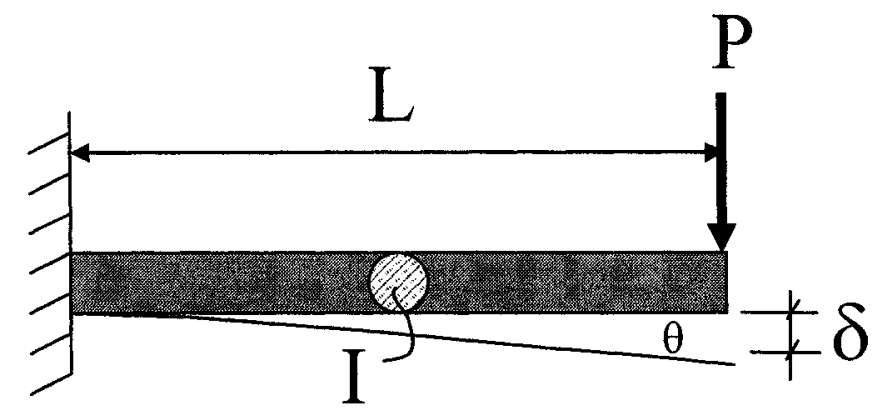

Figure 5.7.1 Cantilever beam configuration (adapted from www.vibrationdata.com)

For this configuration, the static deflection is given by

$$
\delta=\frac{P L^{3}}{3 E I}
$$

and the angle in the free point

$$
\theta=\frac{P L^{2}}{2 E I}
$$

(Rodriguez et al., 1996; Irvine,1999; Paz,1991; Chopra, 1995)

The next study of the slap shot, should attempt to solve the stick shaft's bending behaviour as a cantilever beam configuration with specific boundary conditions, as well as include interaction of stick-puck (i.e. loads-displacements). Computational modelling with a finite element analysis may also be desirable. For instance the ABAQUS $\odot$ ( RI, USA) software is capable of simulating a variety of physical phenomena such as the fatigue properties for material devices, collapse characteristics during a collision, and shock responses structures (http:// www.abaqus.com).

Lessard et al. (1994) considered this approach (i.e. beam element and finite element analysis) for analysing linear and torsional deformation responses in 
wooden and carbon fibre hockey sticks; however, the impact event puck-blade (stick) has not yet been addressed in biomechanics literature.

This approach has been considered for analyzing the 'catapult' behaviour in other sports. For instance in pole-vaulting, Ekevad and Lundberg $(1995,1997)$ modelled the pole with 20 beam elements and the vaulter with other seven beam elements linked together by pin joints. By modelling with ABAQUS (version $4.8,1989)$ they obtained some interesting results such as when using the optimum pole length, the maximum increase in the potential energy of the vaulter was 1.27 times the initial kinetic energy of the vaulter and the pole.

Thus, a better description of the complex event of the impact blade-puck in a slap shot, which involves the 'catapult' effect under different loading conditions, friction forces, and material properties among other factors (Figure 5.7.2), could be achieved in future studies.

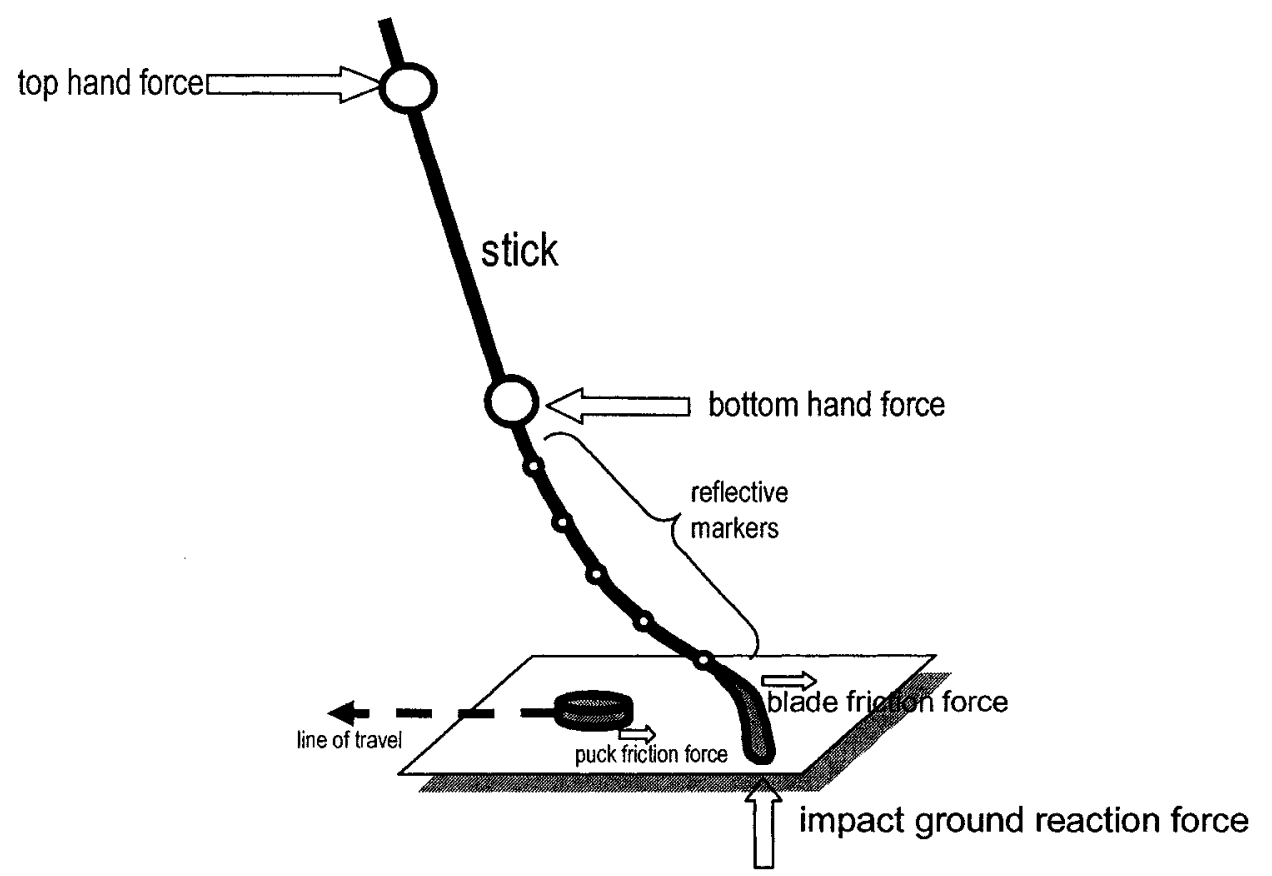

Figure 5.7.2 Main external contact forces involved in a slap shot that must be considered for future full stick dynamics studies. 
This study provides unique estimates of the dynamic response of the stick shaft; specifically the relative contribution of the kinetic energy of the system (i.e. stick shaft-puck) into the mechanical energy of the puck. This is relevant from several points of view. Firstly, given that ice hockey as a discipline is extremely tool dependant (i.e. ice hockey stick) and even though there has been no evidence that the performance of the slap shot is affected by using either composite or wooden sticks (Pearsall et al. 1999, Wu et al, 2003), by investigating the 'catapult' effect with different stick materials, some insights could be provided leading to product development such as optimization of design (e.g. blade geometry, recoil kick point), construction and materials. Thus, development of stronger, lighter and more flexible ice hockey sticks could have a great effect on puck velocities. Secondly, the precise knowledge of the biomechanics of the stick shaft loading and bending could provide relevant information to understand the injury mechanisms implicated in the execution of the slap shot (Lacroix, 2000). Thirdly, it could provide elements for a better understanding between science and coaching, which are not always in agreement. For example, in various sports (e.g. soccer-football) to attain the highest ball velocity, the coaches advise the athletes to "follow through" during a striking motion. In other words, the coaches want the athletes to move the whole body in the intended direction of the ball flight and to follow the ball after the initial contact. This recommendation is frequently given not only in soccer, but also in volleyball, tennis and even table tennis (Tsaousidis et al., 1996). In the case of ice hockey, coaches could take into account that the blade-puck contact time occurring during the 'release' and 
'follow through' phases is directly related with the increment of the mechanical work done on the puck and consequently the increment of the puck outcome velocity.

The present study showed several strengths in terms of instrumentation involved (e.g. high resolution in HSC and accelerometer) and consistency with the results obtained. However, some experimental limitations should be noted; such as, the fact that the polyethylene ice surface was not the same as real ice; the subjects performed stationary slap shots and the only equipment used were their gloves; the sample size consisted only of nine adult male subjects; and 2D analysis was performed.

Several improvements could be made in future studies, for instance with a larger sample size the variability of the sampling distribution could be decreased and consequently the statistical power and confidence of the study could be improved. By improving the electrical circuit consistency and by analyzing in more detail the events occurring before and after blade-puck contact, a more precise description could be performed. By using smaller reflective markers a better resolution in the digitizing process could be achieved. In addition, with a $3 D$ analysis by using alternative motion tracking systems such as the VICON ${ }^{T M}$ system, higher sample rates (i.e. $>1000 \mathrm{~Hz}$ ) could increase resolution allowing at the same time to observe torsion responses in the stick shaft during the slap shot. Moreover, by integrating the kinematics along with additional kinetic measurement techniques, such as hands grip dynamometers (i.e. top and bottom hand forces measures), force plate (i.e. stick ground reaction force), multiple 
accelerometers on the stick (i.e. one per reflective marker) and EMG, may provide further insights regarding this crucial skill (i.e. slap shot) for the performance of the ice hockey.

\section{CONCLUSION}

The present study was designed to examine the 'recoil' effect of the ice hockey stick shaft during a stationary slap shot. With regard to puck velocity, the present findings were in agreement with previous studies (Alexander et al.,1963; Chau et al. 1973, Doré \& Roy,1976; Sim \& Chau, 1978; Marino, 1991; Pearsall et al. 1999 \& 2001; Wu et al., 2003).

Stick elastic bend energy (i.e. Ed) and blade puck contact times (i.e. $T_{A}, T_{B}$ ) were identified as the two main factors highly related to final puck velocity (i.e. Vel ). From these results, a better understanding of the impact blade-puck event during a stationary slap shot was obtained. This provides more insight into mechanical parameters that influence the performance of ice hockey shooting. Further these findings provide guidance for future ice hockey stick development (e.g. construction materials, design). 
APPENDIX A

Ethics Approval 


\section{APPENDIX B}

\section{ANOVA Tables}

The following tables demonstrate statistical procedures and results for each variable examined in this study. ANOVA tables and $\mathrm{t}$-test tables are included.

\section{B.1 Accelerometer}

\section{B.1.1 Puck Accelerations}

- Average Acceleration: Accel

Table B.1.1 Analysis of variance of average puck acceleration.

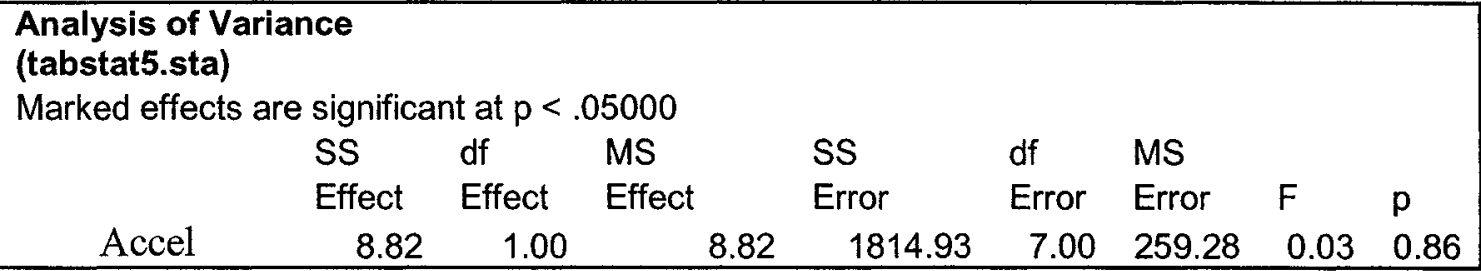

\section{B.1.2 Puck Velocities}

- Final Puck Velocity $\mathrm{m} / \mathrm{s}$ : Vel_ms

- Final Puck Velocity $\mathrm{Km} / \mathrm{h}$ : Vel_kmh

Table B.1.2 Analysis of variance of final puck velocity.

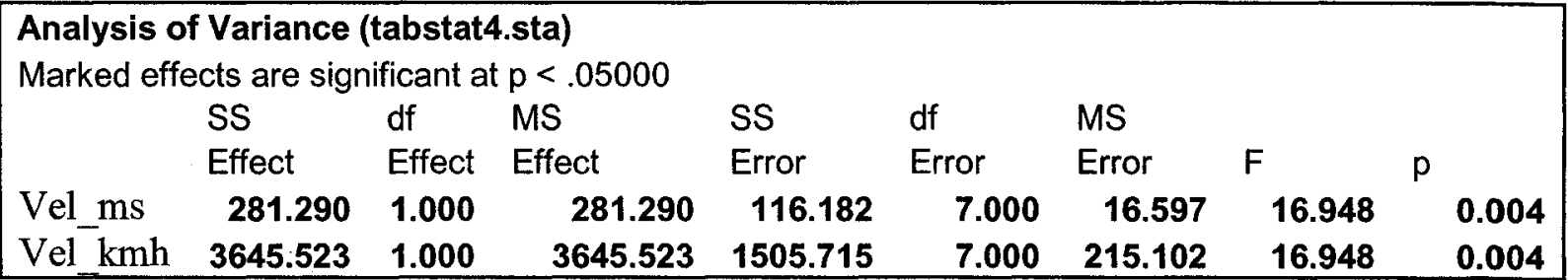

\section{B.1.3 Times}

- Initial to final Puck Contact: $T_{A}$

- Total Puck Contact: $T_{B}$

Table B.1.3 Analysis of variance of contact times $T_{A}$ and $T_{B}$

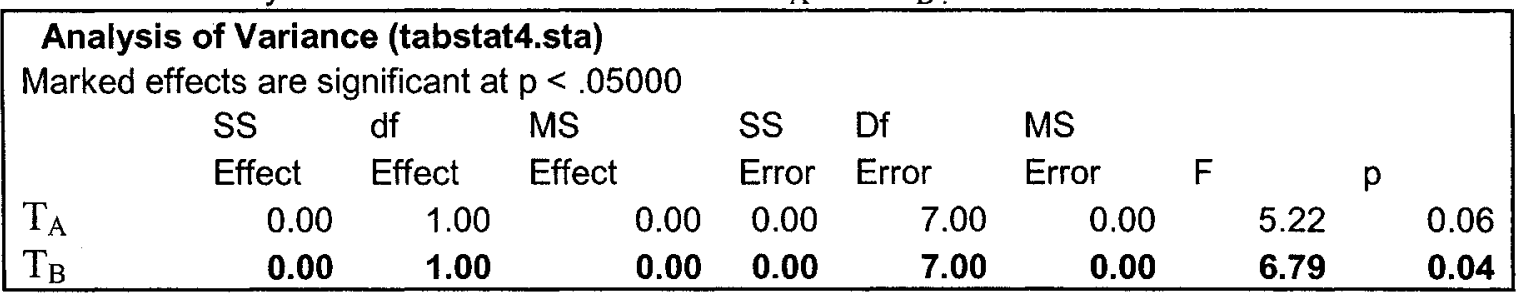


- Percentage total puck contact in contact time window $A: T_{B} / T_{A}$

Table B.1.4 Analysis of variance of percentage $T_{B}, T_{A}$.

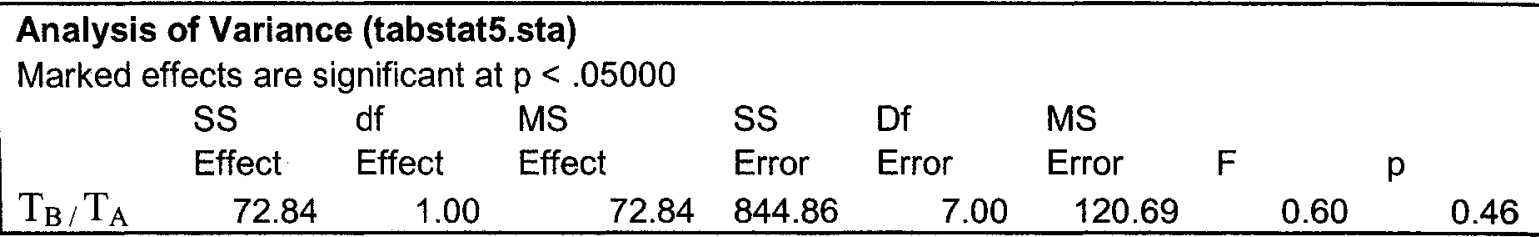

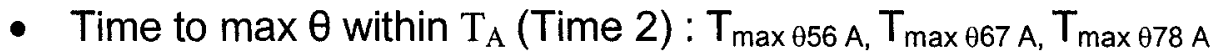

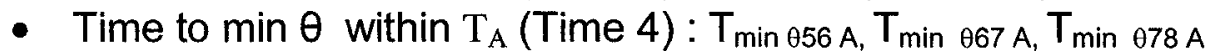

Table B.1.5 Analysis of variance of maximum and minimum angle deflection within $\mathrm{T}_{\mathrm{A}}$.

\begin{tabular}{|c|c|c|c|c|c|c|c|c|}
\hline \multicolumn{9}{|c|}{$\begin{array}{l}\text { Analysis of Variance (tabstat5.sta) } \\
\text { Marked effects are significant at } p<.05000\end{array}$} \\
\hline & SS & Df & MS & SS & df & MS & & \\
\hline & Effect & Effect & Effect & Error & Error & Error & $F$ & $p$ \\
\hline$T_{\max \theta 56 \mathrm{~A}}$ & 0.000 & 1.000 & 0.000 & 0.001 & 7.000 & 0.000 & 1.385 & 0.278 \\
\hline $\mathrm{T}_{\max \theta 67 \mathrm{~A}}$ & 0.000 & 1.000 & 0.000 & 0.001 & 7.000 & 0.000 & 4.061 & 0.084 \\
\hline$T_{\max \theta 78 \mathrm{~A}}$ & 0.000 & 1.000 & 0.000 & 0.001 & 7.000 & 0.000 & 0.363 & 0.566 \\
\hline$T_{\min \theta 56 \mathrm{~A}}$ & 0.002 & 1.000 & 0.002 & 0.001 & 7.000 & 0.000 & 21.667 & 0.002 \\
\hline $\mathbf{T}_{\min } 067 \mathrm{~A}$ & 0.001 & 1.000 & 0.001 & 0.000 & 7.000 & 0.000 & 15.057 & 0.006 \\
\hline$T_{\min } 078 \mathrm{~A}$ & 0.001 & 1.000 & 0.001 & 0.001 & 7.000 & 0.000 & 7.084 & 0.032 \\
\hline
\end{tabular}

- Time to $\max \omega$ within $\mathrm{T}_{\mathrm{A}}$ (Time 3 ): $\mathrm{T}_{\max \omega 56}, \mathrm{~T}_{\max \omega 67, \mathrm{~T}_{\max \omega 78}}$

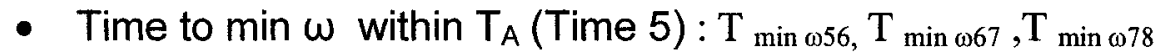

Table B.1.6 Analysis of variance of maximum and minimum stick angular velocities within $T_{A}$

\begin{tabular}{|c|c|c|c|c|c|c|c|c|}
\hline \multicolumn{9}{|c|}{ Analysis of Variance (tabstat5.sta) } \\
\hline \multicolumn{9}{|c|}{ Marked effects are significant at $p<.05000$} \\
\hline & SS & df & MS & SS & $\mathrm{df}$ & MS & & \\
\hline & Effect & Effect & Effect & Error & Error & Error & $F$ & $p$ \\
\hline $\mathrm{T}_{\max \omega 56}$ & 0.003 & 1.000 & 0.003 & 0.009 & 7.000 & 0.001 & 1.987 & 0.201 \\
\hline $\mathrm{T}_{\max \omega 67}$ & 0.000 & 1.000 & 0.000 & 0.002 & 7.000 & 0.000 & 1.891 & 0.211 \\
\hline $\mathrm{T}_{\max \omega 78}$ & 0.000 & 1.000 & 0.000 & 0.000 & 7.000 & 0.000 & 0.113 & 0.747 \\
\hline $\mathrm{T}_{\min \omega 56}$ & 0.000 & 1.000 & 0.000 & 0.001 & 7.000 & 0.000 & 1.593 & 0.247 \\
\hline$T_{\min } \omega 67$ & 0.000 & 1.000 & 0.000 & 0.000 & 7.000 & 0.000 & 12.298 & 0.010 \\
\hline$T_{\min } \theta 78 \mathrm{~A}$ & 0.000 & 1.000 & 0.000 & 0.001 & 7.000 & 0.000 & 0.007 & 0.934 \\
\hline
\end{tabular}


- Time to max total deflection $\theta\left(\max \theta_{56}+\max \theta_{67}+\max \theta_{78)}\right.$ in total event: $T_{\max \theta}$

- Time to min total deflection $\theta\left(\min \theta_{56}+\min \theta_{67}+\min \theta_{78)}\right.$ in total event: $\mathrm{T} \min \theta$

Table B.1.7 Analysis of variance of times to maximum and minimum total deflection in total event.

\begin{tabular}{|c|c|c|c|c|c|c|c|c|}
\hline $\begin{array}{l}\text { Analys } \\
\text { (tabsta } \\
\text { Marked }\end{array}$ & $\begin{array}{l}\text { Ince } \\
\text { e signific }\end{array}$ & int at $p$ & .05000 & & & & & \\
\hline & $\begin{array}{l}\text { SS } \\
\text { Effect }\end{array}$ & $\begin{array}{l}\text { df } \\
\text { Effect }\end{array}$ & $\begin{array}{l}\text { MS } \\
\text { Effect }\end{array}$ & $\begin{array}{l}\text { SS } \\
\text { Error }\end{array}$ & $\begin{array}{l}\text { df } \\
\text { Error }\end{array}$ & $\begin{array}{l}\text { MS } \\
\text { Error }\end{array}$ & $F$ & $p$ \\
\hline $\mathrm{T}_{\max } \theta$ & 0.000 & 1.000 & 0.000 & 0.005 & 7.000 & 0.001 & 0.049 & 0.831 \\
\hline $\mathbf{T}_{\min } \theta$ & 0.001 & 1.000 & 0.001 & 0.001 & 7.000 & 0.000 & 11.460 & 0.012 \\
\hline
\end{tabular}

- Time to $\max \theta$ in Total Event: $\mathrm{T}_{\max } \theta 56, \mathrm{~T}_{\max } \theta 67, \mathrm{~T}_{\max } \theta 78$

- Time to $\min \theta$ in Total Event : $\mathrm{T}_{\min } \theta_{56}, \mathrm{~T}_{\min } \theta 67, \mathrm{~T} \min \theta 78$

Table B.1.8 Analysis of variance of times to maximum and minimum deflection in total event.

\begin{tabular}{|c|c|c|c|c|c|c|c|c|c|}
\hline \multicolumn{10}{|c|}{$\begin{array}{l}\text { Analysis of Variance (tabstat5.sta) } \\
\text { Marked effects are significant at } p<.0\end{array}$} \\
\hline & SS & df & MS & SS & df & MS & & & \\
\hline & Effect & Effect & Effect & Error & Error & Error & & $\mathrm{F}$ & $p$ \\
\hline$T_{\max } \theta 56$ & 0.001 & 1.000 & 0.001 & 0.002 & 7.000 & & 0.000 & 3.968 & 0.087 \\
\hline$T_{\max } \theta 67$ & 0.000 & 1.000 & 0.000 & 0.006 & 7.000 & & 0.001 & 0.008 & 0.933 \\
\hline $\mathrm{T}_{\max } \theta 78$ & 0.000 & 1.000 & 0.000 & 0.002 & 7.000 & & 0.000 & 0.084 & 0.780 \\
\hline $\mathrm{T}_{\min } 956$ & 0.011 & 1.000 & 0.011 & 0.020 & 7.000 & & 0.003 & 3.781 & 0.093 \\
\hline$T_{\min } \theta 67$ & 0.001 & 1.000 & 0.001 & 0.003 & 7.000 & & 0.000 & 1.978 & 0.202 \\
\hline $\mathrm{T}_{\min } \theta 78$ & 0.001 & 1.000 & 0.001 & 0.002 & 7.000 & & 0.000 & 1.724 & 0.231 \\
\hline
\end{tabular}




\section{B.2 Stick Kinematics. HSC.}

\section{B.2.1 Stick Joint Angle Displacements}

- Maximum segment joint angle within $T_{\mathrm{A}}: \max \theta_{56 \mathrm{~A}}, \max \theta_{67 \mathrm{~A}}, \max \theta_{78 \mathrm{~A}}$

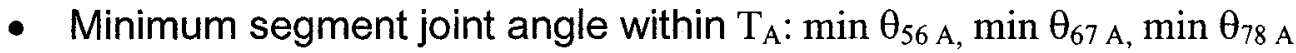

Table B.2.1 Analysis of variance of maximum and minimum segment joint angles within $T_{A}$

\begin{tabular}{|c|c|c|c|c|c|c|c|c|}
\hline \multirow{2}{*}{\multicolumn{9}{|c|}{$\begin{array}{l}\text { Analysis of Variance } \\
\text { (tabstat5.sta) } \\
\text { Marked effects are significant at } p<.05000\end{array}$}} \\
\hline & & & & & & & & \\
\hline & SS & $d f$ & MS & SS & $d f$ & MS & \multirow[b]{2}{*}{$F$} & \multirow[b]{2}{*}{$p$} \\
\hline & Effect & Effect & Effect & Error & Error & Error & & \\
\hline $\max \theta_{56 \mathrm{~A}}$ & 9.604 & 1.000 & 9.604 & 10.784 & 7.000 & 1.541 & 6.234 & 0.041 \\
\hline $\max \theta_{67 \mathrm{~A}}$ & 6.343 & 1.000 & 6.343 & 8.620 & 7.000 & 1.231 & 5.150 & 0.058 \\
\hline $\max \theta_{78 \mathrm{~A}}$ & 21.363 & 1.000 & 21.363 & 35.370 & 7.000 & 5.053 & 4.228 & 0.079 \\
\hline $\min \theta_{56 \mathrm{~A}}$ & 1.314 & 1.000 & 1.314 & 4.722 & 7.000 & 0.675 & 1.948 & 0.205 \\
\hline $\min \theta_{67 \mathrm{~A}}$ & 0.160 & 1.000 & 0.160 & 4.790 & 7.000 & 0.684 & 0.234 & 0.643 \\
\hline $\min \theta_{78 \mathrm{~A}}$ & 0.036 & 1.000 & 0.036 & 9.774 & 7.000 & 1.396 & 0.026 & 0.877 \\
\hline
\end{tabular}

- Maximum segment joint angle in total event: $\max \theta_{56}, \max \theta_{67}, \max \theta_{78}$

- Minimum segment joint angle in total event : $\min \theta_{56}, \min \theta_{67}, \min \theta_{78}$

Table B.2.2 Analysis of variance of maximum and minimum segment joint angles in total Event.

\begin{tabular}{|llllllllll|}
\hline \multicolumn{2}{|c|}{ Analysis of Variance (tabstat4.sta) } \\
\multicolumn{1}{|c|}{ Marked effects are significant at $p<.05000$} \\
& SS & Df & MS & SS & df & MS & & \\
$\max \theta_{56}$ & 1.885 & 1.000 & 1.885 & 10.016 & 7.000 & 1.431 & 1.318 & 0.289 \\
$\max \theta_{67}$ & 2.333 & 1.000 & 2.333 & 6.464 & 7.000 & 0.923 & 2.527 & 0.156 \\
$\max \theta_{78}$ & 6.899 & 1.000 & 6.899 & 36.924 & 7.000 & 5.275 & 1.308 & 0.290 \\
$\min \theta_{56}$ & 1.471 & 1.000 & 1.471 & 40.369 & 7.000 & 5.767 & 0.255 & 0.629 \\
$\min \theta_{67}$ & 2.106 & 1.000 & 2.106 & 37.315 & 7.000 & 5.331 & 0.395 & 0.550 \\
$\min \theta_{78}$ & 5.663 & 1.000 & 5.663 & 49.055 & 7.000 & 7.008 & 0.808 & 0.399 \\
\hline
\end{tabular}


- Recoil angle in total event: $\operatorname{Rec} \theta_{56}\left(\max \theta_{56}-\min \theta_{56}\right), \operatorname{Reco} \theta_{67}\left(\max \theta_{67}-\min \right.$ $\theta_{67}, \operatorname{Reco} \theta_{78}\left(\max \theta_{78}-\min \theta_{78}\right)$

Table B.2.3 Analysis of variance of recoil angle in total event.

\begin{tabular}{|c|c|c|c|c|c|c|c|c|}
\hline \multicolumn{9}{|c|}{$\begin{array}{l}\text { Analysis of Variance } \\
\text { (tabstat5.sta) }\end{array}$} \\
\hline & SS & $d f$ & MS & SS & $d f$ & MS & & \\
\hline & Effect & Effect & Effect & Error & Error & Error & $F$ & $p$ \\
\hline $\operatorname{Reco} \theta_{56}$ & 6.69 & 1.00 & 6.69 & 43.09 & 7.00 & 6.16 & 1.09 & 0.33 \\
\hline $\operatorname{Reco} \theta_{67}$ & 8.87 & 1.00 & 8.87 & 64.63 & 7.00 & 9.23 & 0.96 & 0.36 \\
\hline $\operatorname{Reco} \theta_{78}$ & 25.06 & 1.00 & 25.06 & 135.13 & 7.00 & 19.30 & 1.30 & 0.29 \\
\hline
\end{tabular}

- Difference between Segment joint angles: $\max \theta_{56}$ vs $\max \theta_{67} p=0.60$ $\max \theta_{56}$ vs $\max \theta_{78} \quad \mathbf{p}=\mathbf{0 . 0 2}$

Table B.2.4 Post hoc analysis between max. segment joint angles 5-6 vs 6-7,7-8.

\begin{tabular}{|c|c|c|c|c|c|c|c|c|}
\hline \multicolumn{9}{|c|}{$\begin{array}{l}\text { T-test for Dependent Samples (tabstat5.sta) } \\
\text { Marked differences are significant at } p<.05000\end{array}$} \\
\hline \multicolumn{9}{|c|}{$\begin{array}{lllllll}\text { Mean } & \text { Std.Dv. } \\
\text { Std.Dv. } \mathrm{N} & \text { Diff. } & \text { Diff. } & t & \text { df } & p\end{array}$} \\
\hline $\max \theta_{0}$ & 181.82 & 1.05 & 9.00 & -0.20 & 1.14 & 0.54 & 8.00 & 0.60 \\
\hline \multicolumn{9}{|l|}{$\max \theta_{56}$} \\
\hline $\max \theta_{78}$ & 183.68 & 2.34 & 9.00 & -2.07 & 2.19 & 2.83 & 8.00 & 0.02 \\
\hline
\end{tabular}

- Difference between segments : $\max \theta_{67}$ vs $\max \theta_{56} \quad p=0.604$ $\max \theta_{67}$ vs $\max \theta_{78} \quad \mathbf{p}=\mathbf{0 . 0 0 3}$

Table B.2.5 Post hoc analysis between max. segment joint angles 6-7vs 7-8, 5-6.

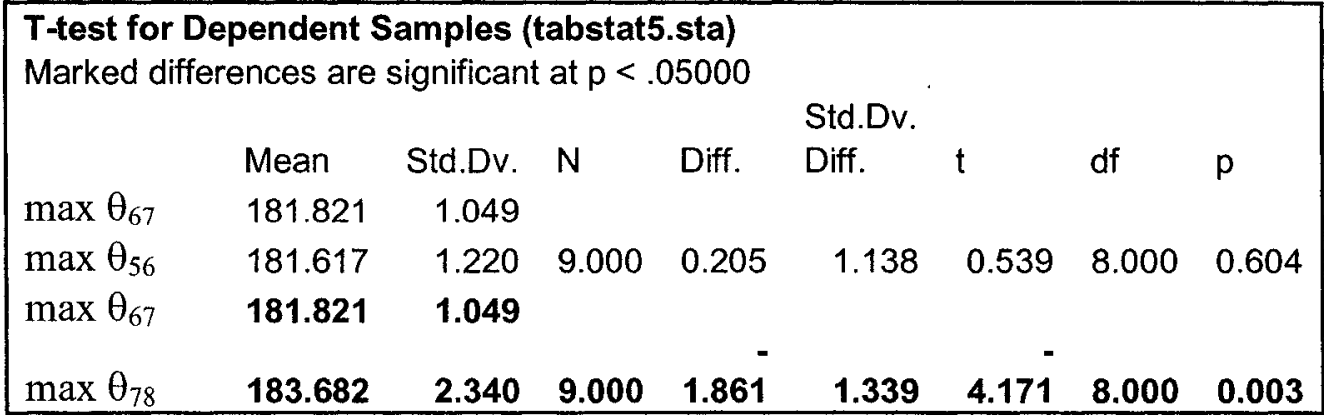


- Difference between segments : $\min \theta_{56}$ vs $\min \theta_{67} \quad p=0.27$ $\min \theta_{56}$ vs $\min \theta_{78} \quad \mathrm{p}=0.65$

Table B.2.6 Post hoc analysis between min. segment joint angles 5-6. vs 6-7, 7-8.

\begin{tabular}{|c|c|c|c|c|c|c|c|c|}
\hline \multicolumn{9}{|c|}{$\begin{array}{l}\text { T-test for Dependent Samples (tabstat5.sta) } \\
\text { Marked differences are significant at } p<.05000\end{array}$} \\
\hline & & & & & Std.Dv. & & & \\
\hline & Mean & Std.Dv. & $\mathrm{N}$ & Diff. & & $t$ & df & $p$ \\
\hline $\min \theta_{56}$ & 176.33 & 2.29 & & & & & & \\
\hline $\min \theta_{67}$ & 176.81 & 2.22 & 9.00 & -0.47 & 1.19 & -1.19 & 8.00 & 0.27 \\
\hline $\min \theta_{56}$ & 176.33 & 2.29 & & & & & & \\
\hline $\min \theta_{78}$ & 176.54 & 2.62 & 9.00 & -0.21 & 1.33 & -0.47 & 8.00 & 0.65 \\
\hline
\end{tabular}

- Difference between segments: $\min \theta_{67}$ vs $\min \theta_{56} \quad p=0.27$ $\min \theta_{67}$ vs $\min \theta_{78} p=0.61$

Table B.2.6 Post hoc analysis between min. segment joint angles 6-7. vs 5-6, 7-8.

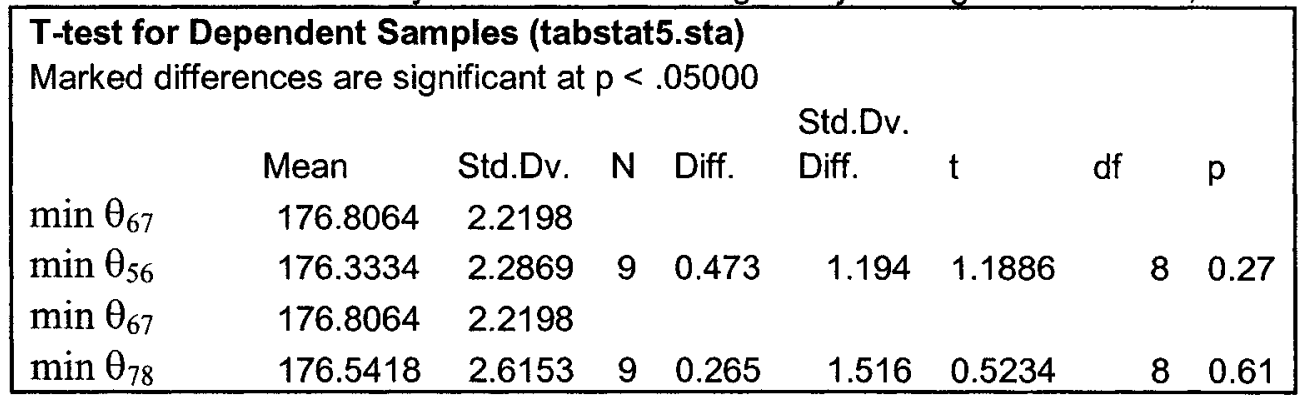

- Maximum $\theta$ deflection $\left(\max \theta_{56}+\max \theta_{67}+\max \theta_{78}\right)$ in total event : $\max \theta$

- Minimum $\theta$ deflection $\left(\min \theta_{56}+\min \theta_{67}+\min \theta_{78}\right)$ in total event: $\min \theta$

Table B.2.7 Analysis of variance of maximum and minimum angle deflection.

\begin{tabular}{|c|c|c|c|c|c|c|c|c|}
\hline \multicolumn{9}{|c|}{$\begin{array}{l}\text { Analysis of Variance (tabstat5.sta) } \\
\text { Marked effects are significant at } p<.05000\end{array}$} \\
\hline & SS & Df & MS & $\begin{array}{l}\text { SS } \\
\text { Frror }\end{array}$ & $\begin{array}{l}\text { df } \\
\text { Frror }\end{array}$ & $\begin{array}{l}\text { MS } \\
\text { Frror }\end{array}$ & & \\
\hline $\max \theta$ & $\begin{array}{l}\text { Eftect } \\
62.60\end{array}$ & $\begin{array}{r}\text { Effect } \\
1.00\end{array}$ & $\begin{array}{l}\text { Eftect } \\
62.60\end{array}$ & $\begin{array}{l}\text { Error } \\
58.36\end{array}$ & $\begin{array}{l}\text { Error } \\
7.00\end{array}$ & $\begin{array}{l}\text { Error } \\
\mathbf{8 . 3 4}\end{array}$ & $\begin{array}{l}F \\
7.51\end{array}$ & $\begin{array}{l}\mathrm{P} \\
0.03\end{array}$ \\
\hline $\min \theta$ & 4.04 & 1.00 & 4.04 & 46.15 & 7.00 & 6.59 & 0.61 & 0.46 \\
\hline
\end{tabular}


B.2.2 Maximum Deflection Distance on the Stick : d

Table B.2.8 Analysis of variance of maximum deflection distance.

\begin{tabular}{|c|c|c|c|c|c|c|c|c|}
\hline \multicolumn{9}{|c|}{ Analysis of Variance (tabstat5.sta) } \\
\hline & SS & Df & MS & SS & df & MS & & \\
\hline d & $\begin{array}{l}\text { Effect } \\
0.002\end{array}$ & $\begin{array}{l}\text { Effect } \\
1.000\end{array}$ & $\begin{array}{l}\text { Effect } \\
0.002\end{array}$ & $\begin{array}{l}\text { Error } \\
0.002\end{array}$ & $\begin{array}{l}\text { Error } \\
7.000\end{array}$ & $\begin{array}{l}\text { Error } \\
\quad \mathbf{0 . 0 0 0}\end{array}$ & $\begin{array}{l}F \\
7.472\end{array}$ & $\begin{array}{l}p \\
0.029\end{array}$ \\
\hline
\end{tabular}

\section{B.2.3 Stick Joint Angular Velocity}

- Maximum segment joint angle velocity within $T_{A}$ : $\max \omega_{56} \mathrm{~A}, \max \omega_{67} \mathrm{~A}$, $\max \omega_{78} \mathrm{~A}$

- Minimum segment joint angle velocity within $T_{A}: \min \omega_{56} \mathrm{~A}, \min \omega_{67} \mathrm{~A}$, $\min \omega_{78} \mathrm{~A}$

Table B.2.9 Analysis of variance of max. and min. segment joint angular velocities within $T_{A}$

\begin{tabular}{|c|c|c|c|c|c|c|c|c|}
\hline \multirow{2}{*}{\multicolumn{9}{|c|}{$\begin{array}{l}\text { Analysis of Variance (tabstat5.sta) } \\
\text { Marked effects are significant at } p<.05000\end{array}$}} \\
\hline & & & & & & & & \\
\hline & $\begin{array}{l}\text { SS } \\
\text { Effect }\end{array}$ & $\begin{array}{l}\text { df } \\
\text { Effect }\end{array}$ & $\begin{array}{l}\text { MS } \\
\text { Effect }\end{array}$ & $\begin{array}{l}\text { SS } \\
\text { Error }\end{array}$ & $\begin{array}{l}\text { df } \\
\text { Error }\end{array}$ & $\begin{array}{l}\text { MS } \\
\text { Error }\end{array}$ & $F$ & $\mathrm{p}$ \\
\hline $\max \omega_{56 \mathrm{~A}}$ & 182.11 & 1.00 & 182.11 & 110905.82 & 7.00 & 15843.69 & 0.01 & 0.92 \\
\hline $\max \omega_{67 \mathrm{~A}}$ & 7792.54 & 1.00 & 7792.54 & 39311.88 & 7.00 & 5615.98 & 1.39 & 0.28 \\
\hline $\max \omega_{786 \mathrm{~A}}$ & 167973.77 & 1.00 & 167973.77 & 349809.58 & 7.00 & 49972.80 & 3.36 & 0.11 \\
\hline $\min \omega_{56 \mathrm{~A}}$ & 8366.96 & 1.00 & 8366.96 & 120747.71 & 7.00 & 17249.67 & 0.49 & 0.51 \\
\hline $\min \omega_{67 \mathrm{~A}}$ & 7971.20 & 1.00 & 7971.20 & 76792.10 & 7.00 & 10970.30 & 0.73 & 0.42 \\
\hline $\min \omega_{78 \mathrm{~A}}$ & 28659.25 & 1.00 & 28659.25 & 532279.69 & 7.00 & 76039.96 & 0.38 & 0.56 \\
\hline
\end{tabular}




\section{B.2.4 Stick and Puck Energy}

- Stick rotational energy: $\mathrm{E}_{\text {av_rot }}$ (average), $\mathrm{E}_{\text {max _rot }}$ (maximum)

- Stick translational energy : $E_{\text {av_tr }}$ (average), $E_{\text {max } t r}$ (maximum)

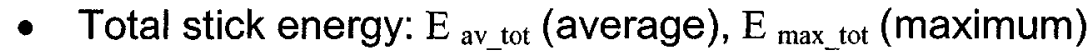

- Stick elastic potential (bend) energy: $E_{d}$

- Puck energy: $\mathrm{E}_{\text {puck }}$

Table B.2.10 Analysis of variance of stick and puck energies.

\begin{tabular}{|c|c|c|c|c|c|c|c|c|}
\hline \multicolumn{9}{|c|}{$\begin{array}{l}\text { Analysis of Variance } \\
\text { (tabstat5.sta) } \\
\text { Marked effects are significant at } p<.05000\end{array}$} \\
\hline \multicolumn{9}{|c|}{$\begin{array}{lll}\text { SS } & \text { df } & \text { MS }\end{array}$} \\
\hline & Effect & Effect & Effect & Error & Error & Error & $F$ & $p$ \\
\hline $\mathrm{E}_{\text {av_rot }}$ & 173.18 & 1.00 & 173.18 & 1544.52 & 7.00 & 220.65 & 0.78 & 0.41 \\
\hline $\mathrm{E}_{\text {av_tr }}^{-}$ & 58.71 & 1.00 & 58.71 & 1090.10 & 7.00 & 155.73 & 0.38 & 0.56 \\
\hline $\mathrm{E}_{\text {av_tot }}^{-}$ & 433.56 & 1.00 & 433.56 & 4535.03 & 7.00 & 647.86 & 0.67 & 0.44 \\
\hline$E_{\text {max_rot }}$ & 1766.96 & 1.00 & 1766.96 & 3642.19 & 7.00 & 520.31 & 3.40 & 0.11 \\
\hline$E_{\text {max_tr }}$ & 1697.39 & 1.00 & 1697.39 & 11560.49 & 7.00 & 1651.50 & 1.03 & 0.34 \\
\hline$E_{\text {max_tot }}$ & 6928.00 & 1.00 & 6928.00 & 25346.75 & 7.00 & 3620.96 & 1.91 & 0.21 \\
\hline $\mathbf{E}_{\mathbf{d}}$ & 459.93 & 1.00 & 459.93 & 547.81 & 7.00 & 78.26 & 5.88 & 0.05 \\
\hline $\mathbf{E}_{\text {puck }}$ & 16178.72 & 1.00 & 16178.72 & 8465.54 & 7.00 & 1209.36 & 13.38 & 0.01 \\
\hline
\end{tabular}




\section{REFERENCES}

Abdel-Aziz, Y.I., Karara, H.M. (1971) Direct Linear Transformation from Comparator Co-ordinates Into Object Space Co-ordinates. Proc. ASP/UI Symposium on Close-range Photogrammetry. American Society of Photogrammetry, Falls Church, VA. 1-18.

Alexander, J.F., Haddow, J.B. \& Schultz, G.A. (1963) Comparison of the ice hockey wrist and slap shots for speed and accuracy. Research Quarterly Exercise Sport 34: 259-266.

Alexander, J.F., Drake, C.J., Rechenbach, P.J., Haddow, J.B (1964) Effect of strength development on speed of shooting of varsity ice hockey players. Research Quarterly Exercise Sport 35: 101-106.

Andriacci, T.P., Alexander E.J. (2000) Studies of Human Locomotion: past, present and future. Journal of Biomechanics. 33:1217-1224

Bishop, P.J. (1993) Protective equipment: Biomechanical evaluation. Sports Injuries: Basic Principles of Prevention and Care. Renstreom, P.A.,Ed. Blackwell Scientific Publications, Boston, 28: 355-373

Brüel \&Kjær Co. (1982) Measuring Vibration, http://www.vibrationdata.com

Cotton, C. (1966) Comparison of ice hockey wrist, sweep and slap shots for speed. Master's thesis, University of Michigan, Ann Arbor.

Chao, E.Y.S. (1978) Experimental Methods for Biomechanical Measurements of Joint Kinematics. CRC Handbook of Engineering in Medicine and Biology. CTC Press, West Palm Beach, FL. 385-409.

Chau, E.G., Sim, F.H., Stauffer, R.N. , Johannson, K.G. (1973) Mechanics of ice hockey injuries. Mechanics and Sport, American Society of Mechanical Engineers. 143-154.

Chopra, A.K. (1995) Dynamics of structures: theory and applications to earthquake engineering. Englewood Cliffs, N.J. Prentice Hall ,4,16:144-147, 588609.

Denoth, J. (1980) Ein mechanisches Modell zur Bescheibung von passiven Belastungen. Sportplatzbeläge (eds. Nigg, B.M. and Denoth J.). Juris Verlag, Zürich. 45-67.

Dhanjoo, N.G. (1982) Human Body Dynamics : Impact, occupational and athletic aspects. Oxford Medical Engineering Series. Oxford Science Publications, 5: 181-189. 
Doré, R. \& Roy, B. (1976) Dynamometric analysis of different hockey shots. In:

Proceedings of the Fourth International Congress on Biomechanics,

Biomechanics, V-B, (ed. Komi P.V.), pp. 277-285.

Dowbiggin, B. (2001) The stick: A history, a celebration, an elegy. Macfarlane Walter \& Ross. Toronto.

Ekevad, M., Lundberg, B. (1995) Simulation of 'smart' pole vaulting. Journal of Biomechanics. 28:1079-1090.

Ekevad, M., Lundberg, B. (1997) Influence of pole length and stiffness on the energy conversion in pole-vaulting. Journal of Biomechanics. 30:259-264.

Elishakoff, I., Irretier H. (1987) Lecture Notes in Engineering. Refined Dynamical Theories of Beams, Plates and Shells and their applications. Edited by C.A. Brebbia \& S.A. Orzag. Proceedings of the Euromech-Colloquium 219: 163-170.

Emmert, W. (1984) The slap shot -strength and conditioning program for hockey at Boston college. National Strength Conditioning Association Journal. 6(2):4.

Fallon, L.P., Collier, R.D., Sherwood, J.A., Mustone, T.J. (2000) Determining baseball bat performance using a conservation equations model with field test validation. In A.J. Subic, S.J. Haake (Eds.) The Engineering of sport: Research, Development and Innovation. Oxford: Blackwell Science, 201-211.

Fekete, J.F. (1968) Severe brain injury and death following minor hockey accidents: The effectiveness of the safety helmets of amateur hockey players. Can. Med. Assoc. J. 99, 1234-9.

Furlong, W.B. (1968).How science is changing hockey: $80 \mathrm{mph}$ mayhem on ice. Popular Mechanics .February: 110-114.

Hamill, J.\& Knutzen, K.M. (2003) Biomechanical Basis of Human Movement. $2^{\text {nd }}$. Edition. Lippincott Williams \& Wilkins. 1: 3-31, 10:337-380.

Hayes, D. (1965) A mechanical analysis of the hockey slap shot. Journal Canadian Association for Health, Physical Education and Recreation. 31(2): 17.

Hockey Canada report (2003) (http://www.hockeycanada.ca/e/about/index.html).

Hoerner, E.F. (1989) The dynamic role played by the ice hockey stick. Safety in ice hockey. ASTM STP 1050, C.R. Castaldi and E.F. Hoerner Eds. American Society for Testing and Materials, Philidelphia, USA. 154-163.

Inman, V.T., Ralston, H.J., Todd, F. (1981) Human walking. Baltimore: Williams and Wilkins. 1-61. 
Irvine, T. (1999) Application of the Newton-Raphson Method to Vibration Problems. Vibrationdata Publications, 1999.

Irvine, T. (2004) http://www.vibrationdata.com.

Kistler Instrumentation Corporation, Catalogue \& Specifications. http://www.kistler.com.

Lacroix, V.J. (2000) A complete approach to groin pain. The Physician and Sport Medicine. 28 (1).

Leavangie, P.K.; Norkin, C.C. (2001) Joint Structure and Function -A comprehensive Analysis. 3thd Edition. 1: 1-49.

Leithold, L. (1981) The Calculus with analytic geometry. Harper \& Row . Fourth edition.

Lerner, L.S. (1996) Physics for Scientists and Engineers. James and Barlett Publishers, Inc. Chapters: 7,9,10 and 11.

Lessard, L.B \& Nemes, J. (1994) Analysis and testing of graphite hockey sticks. Mechanical Laboratory II course project (Rabee Abu Hujeir, Dotane Harel and Jim Marson). Department of Mechanical Engineering, McGill University, Montreal, Canada.

Light, L.H., McLellan, G.E., Klenerman, L. (1980) Skeletal Transients on Heel Strike in Normal Walking with Different Footwear. Journal of Biomechanics 13: 477-480.

Marino, G.W. (1998) Biomechanical investigations of performance characteristics of various types of ice hockey sticks. Proceedings 1 of the International Society of Biomechanics of Sport (eds H.J. Riehle \& M.M. Vieten), Konstanz, Germany, pp. 184-187.

McMahon, T.A., Greene, P.R. (1979) The influence of track compliance on running . Journal of Biomechanics, 12: 893-904.

Morris, J.R. (1973) Accelerometry: A Technique for the measurement of Human Body Movements. Journal of Biomechanics 6(6):729-736.

Murphy, S. PhD Thesis (2001) 3D Dynamic Analysis of the Ice Hockey Stick During the Stationary Slap Shot. University of Waterloo, Ontario, Canada.

Nigg, B.M., Neukomm, P.A. (1973) Ershütterungsmessungen beim Skifahren. Med. Welt. 24 (48):1883-1885. 
Nigg, B. M.; Herzog, W. (2002) Biomechanics of the Musculo-skeletal system. $2^{\text {nd }}$ Edition $3: 254-260,288-313$.

Novacheck, T.F., (1998) The Biomechanics of Running. Gait and Posture. 777795.

Ohanian, H.C., (1985) Physics. Penguin Books Canada Ltd. Vol. One Chapters: 7,8 and 11.

Paz, M. (1991) Structural Dynamics: Theory and Computation. Van Nostrand Reinhold. Third Edition. 14:306-334.

Pearsall, D.J., Montgomery, D.L., Rothsching, N. \& Turcotte, R.A. (1999). The influence of stick stiffness on the performance of ice hockey slap shots. Sports Engineering. 2, 3-11.

Pearsall, D.J., Turcotte, R.A., Murphy S.D. (2000) Biomechanics of Ice Hockey. Exercise \& Sport Science Ed. Garrett \& Kirkendall 43,675-692.

Pearsall, D.J., Wall, R.E., and Hoshizaki, B.T. (1998) Comparison of International Safety Standards for Ice Hockey Helmets. Safety in Ice Hockey, Third Volume, ASTM STP 1341, A.B Ashare, Ed. American Society for Testing and Materials.

Pourcelot P., Audigié F., Degueurce C., Geiger D., Denoix J.M. (2000) A method to synchronise cameras using the direct linear transformation technique. Journal of Biomechanics 33: 1751-1754.

Prokop, L. (1972) Die Auswirkungen von Kunststoffbahnen auf den Bewegungsapparat. Oesterr. J. für Sportmedizin . (Die Effects of plastic sheets on the movement apparatus. Oesterr. J. for sport medicine). 2:3-19.

Rodríguez G. G., Meli P. R., Sánchez R. R. (1996) Modelo Tridimensional de Elemento Finito Para el Análisis Estructural del Sagrario Metropolitano. Memorias del $X$ Congreso Nacional de Ingenieria Estructural. (Threedimensional finite element model for the structural analysis of the Sagrario Metropolitano, Memorials of the Xth National Congress of Structural Engineering), Mérida Yucatán, México. : 691-628.

Roberts, J. R., Jones, R., Rothberg, S. J. (2001) Measurement of contact time in short duration sports ball impacts: an experimental method and correlation with the perceptions of elite golfers. Sports Engineering. 4,191-203.

Rothshing, N. (1997) The effect of shafts stiffness on the performance of the ice hockey slap shot. Master thesis, Department of Physical Education, McGill University, Montreal, Canada. 
Roy, B., Doré, R. (1973) Kinematics of the slap shot in ice hockey as executed by players of different age classifications. Proceedings of the Fourth International Congress of Biomechanics. Biomechanics IV-B. 286-290.

Roy, B., Dore, R. (1974) Facteurs biomecaniques caracteristiques des different types de lacers au hockey sur glace. (Biomechanical factors of the different types of shots in ice hockey.) Mouvement. 9: 169-175.

Roy, B., Doré, R. (1975) Incidence des caracteristiques des batons de hockey sur l'efficacite gestuelle des lancers. (Influence of hockey stick characteristics on the efficiency of shots.) Ingeniéur 306:13-18.

Roy, B., Doré, R. (1976) Kinematics of the slap shot in ice hockey as executed by players of different age classifications. Proceedings of the Fifth International Congress on Biomechanics, Biomechanics V-B. 287-290.

Saha, S., Lakes, R.S. (1979) The Effect of Soft Tissue on Wave Propagation and Vibration Tests for determining the in-vivo Properties of Bone. Journal of Biomechanics. 10 (7): 393-401.

Simm, F.H., Chau E.V. (1978) Injury potential in modern ice hockey. American Journal of Sports Medicine. 6 (6): 378-384.

Tsaousidis, N., Zatsiorsky, V. (1996) Two types of ball-effector interaction and their relative contribution to soccer kicking. Human Movement Science 15: 861876.

Unold, E. (1974) Ershütterungsmessungen beim Gehen und Laufen auf verschiedenen Unterlagen mit vershiedenem Shuhwerk. Jugend und Sport. 8:289-292.

Wells, K.F. \& Luttgens, K. (1976) Kinesiology, scientific basis of human motion. Philadelphia: W.B. Saunders Company.

Woo TK (2004) Three dimensional kinematics of the ice hockey slap shot. Master Thesis, Department of Kinesiology \& Physical Education, McGill University, Montreal, Canada.

Wu, T-C., Pearsall, D., Hodges, A., Turcotte, R., Lefebvre, R. (2003) The performance of the ice hockey slap and wrist shots: the effect of stick construction and player skill. Sports Engineering. 6(1), 31-39. 